\title{
Functional Characterization of Neurexophilins in the Central Nervous System
}

\author{
Dissertation \\ zur Erlangung des Doktorgrades \\ der Mathematisch-Naturwissenschaftlichen Fakultäten \\ der Georg-August-Universität zu Göttingen
}

\author{
vorgelegt von \\ Vasileios Benglopoulos \\ aus Thessaloniki, Griechenland
}

Göttingen 2002 
Diese Arbeit wurde in der Arbeitsgruppe von Dr. Markus Missler, Abteilung Neuro- und Sinnesphysiologie

(Professor Dr. Diethelm W. Richter)

am Zentrum Physiologie und Pathophysiologie, Göttingen,

angefertigt.

D7

Referent:

Prof. Dr. F.-W. Schürmann

Korreferent:

Prof. Dr. A. Stumpner

Tag der mündlichen Prüfung:

20.06.2002 


\section{CONTENTS}

ABBREVIATIONS

1 INTRODUCTION 1

1.1 Communication between neurons 1

1.2 Neuropeptides as chemical messengers in the nervous system 2

1.3 Neurexins as organizers of synaptic function 3

$1.4 \quad$ Neurexophilins are neuropeptide-like glycoproteins 5

$\begin{array}{lll}1.5 & \text { Aims and objectives of the current study }\end{array}$

2 MATERIALS AND METHODS 9

$2.1 \quad$ Materials 9

$\begin{array}{llr}2.1 .1 & \text { Instruments } & 9\end{array}$

$\begin{array}{ll}\text { 2.1.2 General chemicals } & 10\end{array}$

$\begin{array}{lll}2.1 .3 & \text { Chemicals for cell culture } & 13\end{array}$

$\begin{array}{lll}2.1 .4 & \text { Kits } & 14\end{array}$

$\begin{array}{lll}2.1 .5 & \text { Consumables } & 14\end{array}$

$\begin{array}{ll}\text { 2.1.6 Media for bacterial culture } & 16\end{array}$

$\begin{array}{lll}2.1 .7 & \text { Bacterial strains } & 16\end{array}$

$\begin{array}{lll}2.1 .8 & \text { Eukaryotic cell lines } & 17\end{array}$

$\begin{array}{lll}2.1 .9 & \text { Genomic library } & 17\end{array}$

$\begin{array}{lll}2.1 .10 & \text { cDNA and genomic clones } & 17\end{array}$

$\begin{array}{lll}2.1 .11 & \text { Vectors and plasmids } & 18\end{array}$

$\begin{array}{lll}2.1 .12 & \text { Primary antibodies } & 18\end{array}$

$\begin{array}{ll}2.1 .13 & \text { Secondary antibodies and PAP complexes }\end{array}$

$\begin{array}{lll}2.1 .14 & \text { Synthetic oligonucleotides } & 19\end{array}$

2.2 Methods 22

2.2.1 Preparation of electro-competent bacteria 22

2.2.2 Electro-transformation (electroporation) of bacteria with plasmid DNA 22 
2.2.3 Plasmid DNA preparations 23

2.2.3.1 DNA miniprep 23

2.2.3.2 DNA maxiprep 23

2.2.4 Restriction enzyme analysis of DNA 23

2.2.5 Agarose gel electrophoresis 24

2.2.6 Purification of DNA from preparative digestions 24

2.2.7 De-phosphorylation of 5' DNA ends 25

$\begin{array}{lll}2.2 .8 \text { Ligation } & 25\end{array}$

2.2.9 Measurement of DNA concentration 25

2.2.10 Blunt-end cloning 26

2.2.11 Partial DNA digestion 26

$\begin{array}{lll}2.2 .12 & \text { DNA adaptor synthesis }\end{array}$

$\begin{array}{lll}2.2 .13 & \text { DNA sequencing } & 27\end{array}$

2.2.14 Polymerase chain reaction (PCR) cloning 27

$\begin{array}{lll}2.2 .15 & \text { Site-directed mutagenesis } & 28\end{array}$

2.2.16 PCR for genotyping 29

2.2.17 Cloning of the mouse neurexophilin 3 gene 30

$\begin{array}{lll}2.2 .17 .1 & \text { Library plating } & 30\end{array}$

2.2.17.2 Plaque lifting 30

2.2.17.3 Screening 31

2.2.17.4 Secondary screening 31

2.2.17.5 Elution of $\lambda$ bacteriophage plaques 32

2.2.17.6 Solutions 32

2.2.18 Southern blot $\quad 32$

2.2.18.1 DNA transfer from agarose gels 32

2.2.18.2 Transfer of bacterial DNA from LB agar plates 33

2.2.18.3 Radioactive labeling of DNA probes using random primers 33

2.2.18.4 Hybridization 33

2.2.18.5 Oligonucleotide hybridization 34

2.2.18.6 Solutions 35

2.2.19 Preparation of mouse tail DNA for PCR 35

2.2.20 Preparation of mouse tail DNA for Southern blot 35

2.2.21 SDS-polyacrylamide gel electrophoresis (SDS-PAGE) 36

2.2.22 Western blot 37

2.2.22.1 Transfer of proteins to a nitrocellulose membrane 37

2.2.22.2 Immunodetection 38 
2.2.23 Coomassie-blue staining of SDS-PAGE gels 39

2.2.24 Bacterial protein expression 39

2.2.24.1 Transformation 40

2.2.24.2 Expression $\quad 40$

2.2.24.3 Purification $\quad 40$

2.2.24.4 Concentration - Dialysis 41

2.2.25 COS7 cell culture, transfection and stainings 42

2.2.25.1 Cell culture $\quad 42$

2.2.25.2 Transfection $\quad 42$

2.2.25.3 Cell lysate preparation 43

2.2.25.4 $\beta$-Galactosidase staining 43

2.2.25.5 Immunocytochemical staining $\quad 44$

2.2.25.6 Double staining for $\beta$-galactosidase and antibody 44

2.2.26 Embryonic stem cell culture 45

2.2.26.1 Feeder layer preparation $\quad 46$

2.2.26.2 Preparation of cells as a single cell suspension (SCS) 46

$\begin{array}{ll}2.2 .26 .3 \text { Electroporation } & 47\end{array}$

2.2.26.4 Selection $\quad 47$

2.2.26.5 Analysis of positive clones 48

2.2.26.6 Preparation of embryonic stem cells for blastocyst injection 48

2.2.26.7 Culture equipment and solutions 48

2.2.27 Preparation of mouse brains for cryostat sectioning 49

$\begin{array}{ll}2.2 .28 \text { Cryostat sectioning } & 50\end{array}$

2.2.29 $\beta$-Galactosidase staining of mouse brain sections $\quad 50$

2.2.30 Immunohistochemistry 51

2.2.31 Double staining for $\beta$-galactosidase and antibody 52

2.2.32 Nissl staining 52

2.2.33 Preparation of total brain extract 52

2.2.34 $\alpha$-Latrotoxin binding assay of mouse brain extracts 53

$\begin{array}{ll}2.2 .35 & \text { Mouse husbandry }\end{array}$

2.2.36 DNA database search $\quad 54$

$3 \quad$ RESULTS

3.1 Cloning and characterization of the mouse neurexophilin 3 gene 56

3.1.1 Screening and restriction enzyme analysis of neurexophilin 3 genomic 56 
clones

3.1.2 Evolutionary conservation and structure comparison of neurexophilins 61

3.2 Generation of neurexophilin 3 knock-in mice 64

3.2.1 Cloning of targeting vectors $\quad 65$

3.2.1.1 Neurexophilin 3 targeting vector cloning strategy 68

3.2.1.2 Neurexophilin 1 targeting vector cloning strategy 69

$\begin{array}{lll}\text { 3.2.2 In vitro testing of targeting vector function } & 70\end{array}$

3.2.2.1 Transfection with neurexophilin 3 expression vectors 71

3.2.2.2 Transfection with neurexophilin 1 expression vector 75

3.2.3 Generation of recombinant embryonic stem cells 77

3.2.3.1 Neurexophilin 3 knock in embryonic stem cell culture 77

3.2.3.2 Neurexophilin 1 knock in embryonic stem cell culture 83

3.2.4 Establishment of mouse lines $\quad 85$

3.3 Analysis of neurexophilin 3 knock-in mice $\quad 88$

3.3.1 Expression of neurexophilin 3 in the brain $\quad 88$

3.3.1.1 Expression in adult mice $\quad 89$

3.3.1.2 Expression during ontogeny 92

3.3.2 Expression of neurexophilin 3-Flag fusion protein 98

3.3.3 Double histochemical staining of brain sections for $\beta$-galactosidase and 100 reelin/calretinin

3.4 Generation of neurexophilin knock-out mouse lines 103

3.4.1 Generation of neurexophilin 3 knock-out mice 103

3.4.1.1 Establishment of the mouse line 105

3.4.1.2 Nissl staining of neurexophilin 3 knock-out mouse brain sections 108

3.4.2 Generation of neurexophilin 1/neurexophilin 3 double knock-out mice 110

3.4.2.1 Establishment of the mouse line 110

$\begin{array}{lll}3.4 .2 .2 & \text { Western blot analysis } & 112\end{array}$

3.5 Expression of recombinant neurexophilins 114

$\begin{array}{lll}\text { 3.5.1 Cloning of expression constructs } & 114\end{array}$

3.5.2 Determination of optimal expression conditions 115

$\begin{array}{lll}\text { 3.5.3 Purification of expressed proteins } & 116\end{array}$

$\begin{array}{lll}\text { 3.5.4 Elution and concentration of expressed proteins } & 118\end{array}$

$\begin{array}{lll}4 & \text { DISCUSSION } & 120\end{array}$

4.1 Study of neurexophilin 3 with reference to the knock-in approach $\quad 121$ 
$\begin{array}{lll}4.2 & \text { Neurexophilins in evolution } & 123\end{array}$

$\begin{array}{lll}4.3 & \text { Expression of neurexophilin } 3 \text { in the brain } & 124\end{array}$

$\begin{array}{lll}4.4 & \text { Putative function of neurexophilins as signaling molecules } & 126\end{array}$

$\begin{array}{lll}4.5 & \text { Conclusion and outlook } & 127\end{array}$

5 SUMMARY 129

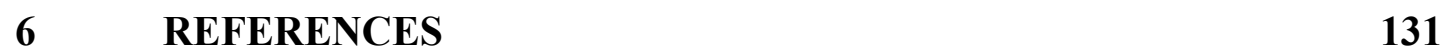

APPENDIX

Appendix 1 Mouse neurexophilin 3 genomic sequence (annotated)

Appendix 2 Rat neurexophilin 3 cDNA sequence (annotated) 


\section{ABBREVIATIONS}

Abbreviations that are cited in the International System of Standards are not included in the following list.

\begin{tabular}{|c|c|}
\hline ATP & adenosine triphosphate \\
\hline $\mathrm{bp}$ & base pair \\
\hline BSA & bovine serum albumin \\
\hline cDNA & complementary DNA \\
\hline C-terminal & at the $\mathrm{COOH}$-terminus of a protein \\
\hline C-terminus & $\mathrm{COOH}$-terminus of a protein \\
\hline DAB & 3,3' diaminobenzidine \\
\hline dATP & deoxyadenosine triphosphate \\
\hline $\mathrm{dCTP}$ & deoxycytidine triphosphate \\
\hline dGTP & deoxyguanosine triphosphate \\
\hline $\mathrm{dH}_{2} \mathrm{O}$ & distilled $\mathrm{H}_{2} \mathrm{O}$ \\
\hline DNA & deoxyribonucleic acid \\
\hline D-PBS & Dulbecco's PBS \\
\hline dNTPs & deoxynucleotide triphosphates \\
\hline dTTP & deoxythymidine triphosphate \\
\hline $\mathrm{E}$ & embryonic day (e.g. E16) \\
\hline E. coli & Escherichia coli \\
\hline EDTA & ethylenedinitrilo-tetraacetic acid \\
\hline et al. & et alteres \\
\hline ES cells & embryonic stem cells \\
\hline FCS & fetal calf serum \\
\hline$\beta$-gal & $\beta$-galactosidase \\
\hline GST & glutathione-S-transferase \\
\hline IRES & internal ribosomal entry site \\
\hline $\mathrm{kb}$ & kilobase pair \\
\hline $\mathrm{kDa}$ & kilodalton \\
\hline KI & knock-in \\
\hline $\mathrm{KO}$ & knock-out \\
\hline lacZ & lactose catabolism gene \\
\hline LB & Luria-Bretani bacterial growing me \\
\hline
\end{tabular}




\begin{tabular}{|c|c|}
\hline LB agar & Luria-Bretani bacterial growing agarose \\
\hline MEF cells & mouse embryonic fibroblast cells \\
\hline mRNA & messenger RNA \\
\hline MW & molecular weight \\
\hline$n e o^{R}$ & neomycin resistance gene \\
\hline NGS & normal goat serum \\
\hline Nph1, 2, 3, 4 & neurexophilin 1-4 isoforms \\
\hline N-terminal & at the $\mathrm{NH}_{2}$-terminus of a protein \\
\hline N-terminus & $\mathrm{NH}_{2}$-terminus of a protein \\
\hline OD & optical density \\
\hline $\mathrm{o} / \mathrm{n}$ & over night \\
\hline $\mathrm{P}$ & postnatal day (e.g. P14) \\
\hline PAGE & polyacrylamide gel electrophoresis \\
\hline PBS & phosphate buffer saline \\
\hline PCR & polymerase chain reaction \\
\hline RNA & ribonucleic acid \\
\hline RT & room temperature \\
\hline SDS & sodium dodecyl sulfate \\
\hline TK & thymidine kinase \\
\hline Tris & Tris-hydroxymethyl-aminomethane \\
\hline $\mathrm{U}$ & enzymatic unit \\
\hline UTR & untranslated region \\
\hline UV & ultraviolet \\
\hline WT & wild type \\
\hline Xgal & 5-bromo-4-chloro-3-indolyl- $\beta$-galactosidase \\
\hline $5^{\prime}$ & 5 prime \\
\hline $3^{\prime}$ & 3 prime \\
\hline
\end{tabular}




\subsection{Communication between neurons}

The human brain contains around $10^{11}$ neurons, each of them participating in an average of 10000 synaptic connections (Garner et al., 2002). Among all cell types in the body, neurons are unique in their ability to communicate with each other in a very rapid and specialized way. Neuronal communication can take place over long distances and is facilitated by the highly polarized shape of the neuron. The features of a prototypic neuron are the dendrites and the axon, a usually longer structure that enables contact between neurons that are not in close proximity to each other. During differentiation, neurons acquire specific functions and this is reflected in the properties of the sites of communication with other neurons, the synapses. Each neuron forms a high number of synapses, which can be functionally different and therefore provide the neuron with a very specialized role in the context of a neuronal network (Cowan et al., 2001).

There are two types of synapses in the nervous system: electrical and chemical. In electrical synapes, that are less common in the brain, the two cells are very close to each other and communication takes place by the flow of ionic current through gap junctions, which connect the cytoplasms of the two cells (Bennett et al., 1991). Chemical synapses is the major means of neuronal communication in the brain (Kandel et al., 2000). They are composed of three elements: the presynaptic terminal, the synaptic cleft and the postsynaptic terminal. The mediators of the communication event are molecules called neurotransmitters, that are synthesized in the presynaptic cell. They are usually stored in synaptic vesicles located in the presynaptic terminal. As a result of entry of $\mathrm{Ca}^{2+}$ into the presynaptic terminal, synaptic vesicles fuse to the plasma membrane at regions called active zones and release the neurotransmitter molecules into the synaptic cleft (Südhof, 1995). Neurotransmitters bind to specific receptors on the postsynaptic plasma membrane, which can cause a huge number of postsynaptic responses, a common form of which is to affect the probability of a certain type of ion channel to open (Hille, 2001). Both electrical and chemical synapses can be either excitatory, characterized by a depolarization of the postsynaptic membrane as a result of the communication event or inhibitory, where the effect of communication is a hyperpolarization of the postsynaptic membrane (Shepherd, 1998).

An important difference between electrical and chemical synapses is that in the former transmission is accomplished by the direct flow of ionic current, while in the latter a multistep process is involved. On the presynaptic terminal this process includes a docking step, where 
synaptic vesicles dock to the active zone, a priming step, where synaptic vesicles become competent for membrane fusion and a fusion/exocytosis step where neurotransmitter is released into the synaptic cleft (Südhof, 1995). On the postsynaptic terminal, it depends on the properties of the receptor that receives the neurotransmitter and it may involve binding of other proteins (e.g. GTP-binding protein) on its cytoplasmic domain (Kandel et al., 2000). This multistep nature of chemical synapses provides them with a high degree of complexity and enables them to be modulated in a very specialized way in any of the steps being involved.

\subsection{Neuropeptides as chemical messengers in the nervous system}

Probably the most important feature regarding the ability of a chemical synapse to be highly specialized and modulated is the existence of a high number of molecules that can act as neurotransmitters. There are two classes of neurotransmitters in the nervous system: small molecule neurotransmitters and neuropeptides. The first class accounts for a low number of small molecules, which are usually amino acids, of which some of the most important ones are glutamate, which acts on excitatory synapses and $\gamma$-aminobutyric acid (GABA) and glycine, which act on inhibitory synapses. The second class of chemical messengers, neuropeptides, consists of a plethora of short peptides. Their function is usually more specialized, compared to that of small molecule neurotransmitters, which can provide them with a modulatory effect on the synapse. Neuropeptides can be grouped in families (e.g. opioid), some of which (e.g. insulins) function also as hormones in other parts of the body (Kandel et al., 2000).

Neuropeptides are synthesized in the cell body, in contrast to small molecule neurotransmitters which are usually synthesized directly in presynaptic terminals by cytoplasmic enzymes. As a first step, a neuropeptide is synthesized as a prepropeptide on polysomes of the rough endoplasmatic reticulum. It typically contains a hydrophobic Nterminal signal peptide sequence, whose function is to provide the neuropeptide with the appropriate signal for transport to the plasma membrane. This is accomplished by binding of the translation complex to specialized structures of the ribosome. The signal peptide is usually cleaved while translation is still taking place, and translation continues giving rise to a propeptide. This precursor peptide is then cleaved at precise recognition sites by a proprotein convertase, resulting in the biologically active mature protein (Seidah and Chrétien, 1997). Cleavage of the proprotein and subsequent transport of the mature protein to the plasma membrane is performed in the trans-Golgi network and in secretory granules that are derived 
from it (Arvan and Castle, 1998). The most typical recognition site for cleavage of a proprotein is the dibasic amino acid motif, i.e. a 2-amino acid sequence of lysine or arginine in any combination. Cleavage in that case takes place on the first bond N-terminal to the dibasic sequence (Kandel et al., 2000).

Neuropeptides can be released into the synaptic cleft together with small molecule neurotransmitters as, for example, in the case of the opioid peptide dynorphin that is coreleased together with glutamate in the hippocampus, with dynorphin playing an inhibitory and glutamate an excitatory role (Weisskopf et al., 1993). This co-release property of chemical messengers extends the repertoire of synaptic function and provides it with an additional level of modulation.

\subsection{Neurexins as organizers of synaptic function}

Neurexins are synaptic membrane proteins, that were discovered when a member of the family was found to be a receptor for $\alpha$-latrotoxin (Ushkaryov et al., 1992). $\alpha$-Latrotoxin is a vertebrate-specific toxin of the black widow spider venom that causes massive neurotransmitter release (Frontali et al., 1976). A more detailed study of the composition of the $\alpha$-latrotoxin receptor revealed that neurexin was bound with high affinity to a $29 \mathrm{kDa}$ protein (Petrenko et al., 1993), later named neurexophilin due to its strong binding to neurexin (Petrenko et al., 1996).

Neurexins comprise a large protein family consisting of thousands of isoforms that are generated by alternative splicing of transcripts from three genes, each of which containing two individual promoters $(\alpha$-neurexin and $\beta$-neurexin promoters, Ushkaryov et al., 1992, Ushkaryov et al., 1994, Ullrich et al., 1995). Apart from neurexophilin and $\alpha$-latrotoxin, several other proteins have also been found to bind to neurexins: a) neuroligins, which are neuronal cell surface proteins, bind to $\beta$-neurexins in a splice-site specific manner (Ichtchenko et al., 1995), b) CASK, a PDZ domain protein, binds to the cytoplasmic domain of both $\alpha$ - and $\beta$-neurexins (Hata et al., 1996), c) Mint 1, a putative vesicular trafficking protein, is associated with both $\alpha$ - and $\beta$-neurexins via binding to CASK (Butz et al., 1998) and d) $\alpha$-dystroglycan, a cell adhesion protein, binds to the extracellular domain of both $\alpha$ and $\beta$-neurexins (Sugita et al., 2001).

The structure of neurexins, their splicing properties and their binding partners have suggested throughout all the above studies a role for them as potential regulators of synapse assembly and/or as receptors for signaling molecules. Trangenic mouse expression of epitope-tagged neurexins has revealed that they are localized on presynaptic terminals (Rohlmann et al., 
submitted for publication). Studies with knock-out mice, where all or some of the $\alpha$-neurexin genes have been deleted have shown that $\alpha$-neurexins are essential for postnatal development in mice, since triple knock-out mice die at birth (Missler et al., submitted for publication). In addition, the same study has revealed that $\alpha$-neurexins do not have a major function on synaptogenesis, but are essential for synaptic function, since $\alpha$-neurexin knock-out mice exhibit impaired synaptic transmission due to decreased $\mathrm{Ca}^{2+}$ currents. In particular, $\alpha$ neurexins have been found to control a new transsynaptic signaling pathway, involving both pre- and postsynaptic voltage-gated $\mathrm{Ca}^{2+}$ channels (Missler et al., submitted for publication). Figure 1 (modified from Rohlmann et al., submitted for publication) summarizes some of the main properties of neurexins at the synapse:

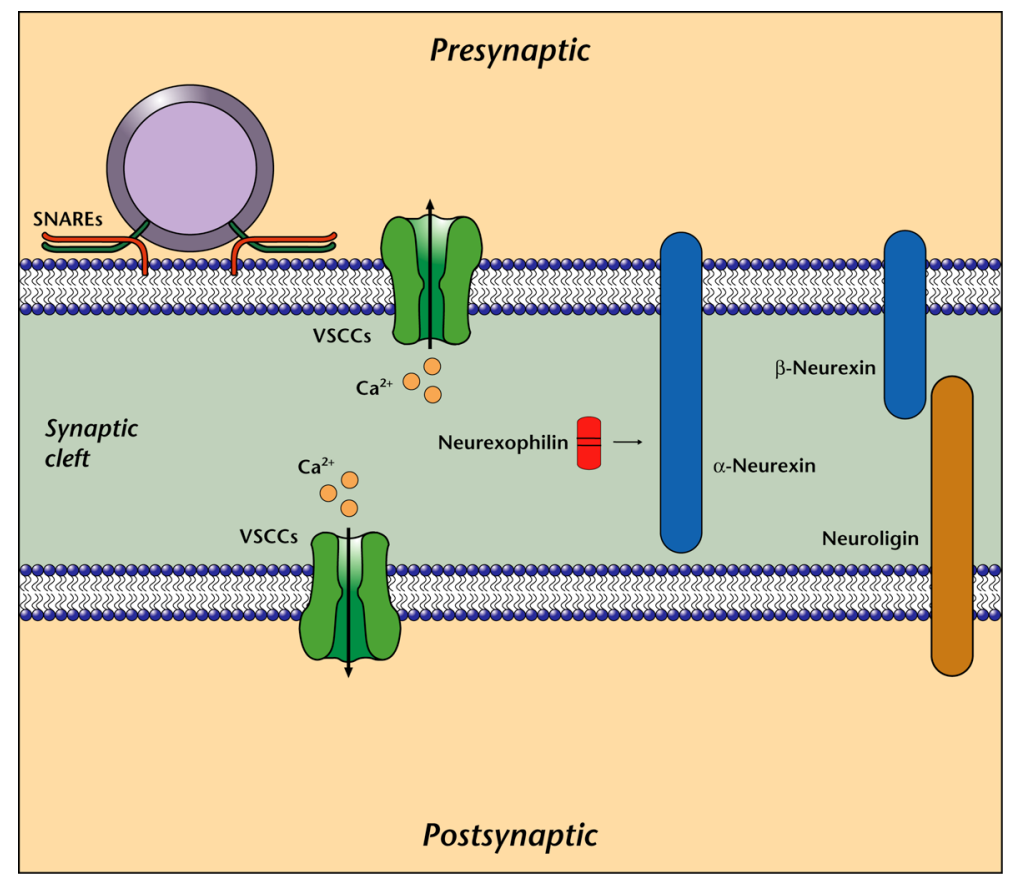

Figure 1. Properties of neurexins at the synapse (modified from Rohlmann et al., submitted for publication). $\alpha$-Neurexins control a signaling pathway, involving both pre- and postsynaptic voltage-gated $\mathrm{Ca}^{2+}$ channels (VSCCs). Entry of $\mathrm{Ca}^{2+}$ into the presynaptic terminal triggers fusion of synaptic vesicles to the plasma membrane (shown on the top left of the picture), which results in neurotransmitter release. The lines in the neurexophilin molecule represent the borders between its domains (see next section). 


\subsection{Neurexophilins are neuropeptide-like glycoproteins}

Neurexophilins form a family of four glycoproteins, three of which (apart from neurexophilin 4 (Nph4)) bind with strong affinity to the extracellular domain of $\alpha$-neurexins (Petrenko et al., 1996, Missler et al., 1998). Analysis of their DNA sequence showed that they are composed of five domains (Missler and Südhof, 1998): a) a non-conserved, hydrophobic signal peptide sequence at the $\mathrm{N}$-terminus, b) a non-conserved $\mathrm{N}$-terminal region, c) a highly conserved sequence that contains three $\mathrm{N}$-glycosylation sites, a non-conserved, "linker" sequence and e) a highly conserved C-terminal sequence, characterized by the presence of six cysteines. In situ hybridization results revealed that neurexophilin 1 (Nph1) is expressed in a highly localized pattern in subpopulations of neurons in various regions of the rat brain (Petrenko et al., 1996). On the other hand the three $\alpha$-neurexins together are expressed essentially in all regions of the brain (Ullrich et al., 1995). The structure of neurexophilins, containing a signal peptide followed by a non-conserved region, in addition to the absence of transmembrane segments raised the hypothesis that neurexophilins are secreted molecules, which was confirmed by binding recombinant Nph1 to the extracellular domain of neurexin $1 \alpha$ (Petrenko et al., 1996). Neurexophilins are expressed in a precursor form as prepropeptides, which in neuronal, but not in other cell types, is proteolytically processed, resulting in the mature form of the protein (Missler and Südhof, 1998). A knock-out mouse line has been generated for Nph1 and mice were viable with no obvious abnormality (Missler et al., 1998).

Together all the above studies have suggested that neurexophilins represent a family of putative signaling molecules that function in analogy to neuropeptides, by binding to $\alpha$ neurexins. Given the different expression pattern of neurexophilins and $\alpha$-neurexins, it has been hypothesized that this putative function has probably a spatially-related modulatory effect on the role of $\alpha$-neurexins at the synapse.

A scheme of the domain structure of neurexophilins is given in figure 2: 
Preproprotein

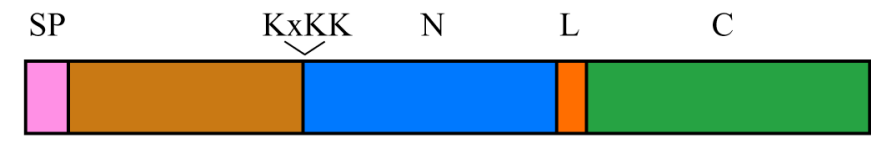

Processed and secreted

protein

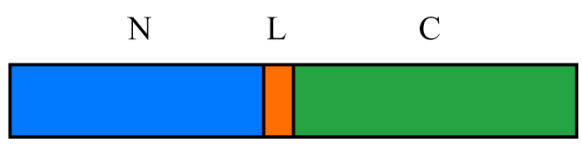

Figure 2 Domain structure of neurexophilins. Neurexophilins are expressed as prepropeptides that are later cleaved, resulting in the mature form of the protein. The prepropeptide consists of five domains: a) a hydrophobic signal peptide (SP, shown in pink), b) a non-conserved sequence (shown in brown), c) a possibly $\mathrm{N}$-glycosylated domain $(\mathrm{N}$, shown in blue), d) a variable linker sequence (L, shown in red) and e) a cysteine-rich domain ( $\mathrm{C}$, shown in green). The sequence KxKK (lysine - variable amino acid - lysine - lysine) represents a highly conserved dibasic motif between the second and the third domain, with the characteristics of a neuropeptide cleavage site (cleavage in the middle of the sequence, between $\mathrm{x}$ and $\mathrm{K}$ ).

\subsection{Aims and objectives of the current study}

The results of the previous studies on neurexophilins have provided important information about their structure and biochemical properties. Based on this information, as mentioned in the previous section, a neuropeptide-like signaling function of neurexophilins with a potential modulatory effect on the role of $\alpha$-neurexins has been proposed. Investigating this hypothesis raises various questions: a) in which organisms are neurexophilins expressed?, b) which is the area of action in the brain?, c) what is the effect of the potential signaling function of neurexophilins?, d) are there any differences between the function of different neurexophilin isoforms?, e) what is the effect of the absence of neurexophilins in the brain?

The current study attempts to address the above questions. Various approaches can be followed in conducting studies towards this direction. In order to investigate the role of neurexophilins in the central nervous system in vivo, a mouse neurogenetic approach was designed. Before the current study, out of four neurexophilin isoforms, the mouse genes for only Nph1 and neurexophilin 2 (Nph2) had been cloned (Petrenko et al., 1996). Since Nph4 does not bind to $\alpha$-neurexins and therefore probably performs a different function, a detailed study of it was not conducted. Nph2 is not expressed in the mouse brain (Missler and Südhof, 
1998) and for this reason it was also not studied. Neurexophilin 3 (Nph3) on the other hand was shown to meet all the requirements for the given study. In addition, it was found to bind to $\alpha$-neurexins in the brains of Nph1 knock-out (Nph1-KO) mice (Missler et al., 1998), suggesting that it is fully functional in vivo with respect to the above proposed hypothesis.

As the first step of the current study, the mouse Nph3 gene was cloned and characterized. The generation of two knock-in mouse lines for Nph1 and Nph3 (Nph1-KI, Nph3-KI respectively) was then designed in a way that the resulting knock-in allele would be transcribed into a bicistronic mRNA, also encoding for $\beta$-galactosidase by a reporter gene. The aim of this approach was to characterize with high sensitivity the neurexophilin-expressing cells in the brain by the use of a staining assay that is based on the enzymatic activity of $\beta$-galactosidase. Information about expression of a protein can also be retrieved by in situ hybridization. However, although this method is very useful in determining areas of expression, it has a limited sensitivity which usually renders it unable to characterize in detail small subpopulations of cells, especially when the studied protein is expressed in low levels. Since Nph1 is expressed in a nonuniform fashion in subpopulations of neurons in the rat brain, a similar pattern was suspected for the expression of $\mathrm{Nph} 3$ and therefore the knock-in approach was followed. In addition, the $\beta$-galactosidase assay is well compatible with immunohistochemical methods, which enables further characterization of positive cells by means of double staining.

Furthermore, neurexophilins were tagged with a bacterial epitope (HA for Nph1 and Flag for $\mathrm{Nph} 3$ ), fused to their C-terminus, in order to improve their ability to be detected immunohistochemically, since the available anti-neurexophilin antibodies are not able to provide this information due to poor antigenicity of neurexophilins (Dr. Markus Missler, personal communication). An additional goal was the establishment and analysis of a $\mathrm{Nph} 3$ knock-out (Nph3-KO) mouse line, as well as of a double Nph1/Nph3 knock-out (Nph1/Nph3$\mathrm{KO})$ mouse line. This was addressed by the use of the Cre-loxP system for removal of DNA sequences (Sternberg and Hamilton, 1981), by including two loxP sites in the recombinant knock-in DNA sequence (Cre recombinase, provided by transgenic mice, excises the sequence between two loxP sites, see section 3 . 2 . 1). Therefore Nph3-KO mice would be generated by breeding Nph3-KI mice with Cre-expressing transgenic mice. A double Nph1/Nph3-KO mouse line would then be generated by breeding Nph3-KO with Nph1-KO mice, already existing in the laboratory (Missler et al., 1998). In parallel to the in vivo approach, the establishment of a protein expression system was aimed towards the production of sufficient amounts of recombinant neurexophilins for use in in vitro experiments. These could include electrophysiological measurements of the extracellular effect of neurexophilins 
on hippocampal neurons as well as binding studies in order to study a potential interaction of neurexophilins with the other binding partners of $\alpha$-neurexins. 


\subsubsection{Instruments}

Autoclave
Balances
Cell culture hood
Centrifuges
Cryostat
DNA sequencer

Electrophoresis chambers (for DNA)

Electrophoresis chambers (for proteins)

Electrophoresis power supply

Electroporators

Film development machine

Freezers

Heat block

Incubators, for bacterial culture

Incubator, for COS, ES cell culture

Incubator, for Southern blot

Ligation chamber

Light microscopes

Magnetic stirring plates

Microwave oven

Multipipette

Oligonucleotide synthesizer
Fedegari, Pavia, Italy

Sartorius, Göttingen

Kendro, Asheville, North Carolina, USA

Eppendorf, Hamburg; Kendro, Asheville, North Carolina, USA

Leica, Nußloch

Applied Biosystems, Foster City, California, USA

Amersham Pharmacia Biotech (former: Hoefer), Little Chalfont, UK

BioRad, Hercules, California, USA

Biometra, Göttingen

Bio-Rad, Hercules, California, USA

Protec, Oberstenfeld

Sanyo, Gunma, Japan

Unitek, USA/Scientific Plastics (Europe), Milton

Keynes, UK

New Brunswick Scientific, Edison, USA; WTC

binder, Tuttlingen

Sanyo, Gunma, Japan

Biometra, Göttingen

Techne, Cambridge, UK

Carl Zeiss, Jena

Heidolph, Kelheim; H+P Labortechnik, Oberschleißheim/München

Bosch, Stuttgart

Brand, Wertheim/Main

Applied Biosystems, Foster City, California, USA 
PCR machine

pH meter

Pipettes

Pipetting device

Polytron

Radiocativity counter

Refrigerators

Rotators

Shakers

Sonicator

Spectrophotometer

Sterilization oven

UV documentation/crosslinker

Vortexer

Waterbaths
Biometra, Göttingen

WTW-inoLab, Weilheim

Brand, Wertheim/Main; Gilson, Villiers-le-Bel, France

Brand, Wertheim/Main

Kinematica, Littau/Luzern, Switzerland

Perkin-Elmer, Boston, Massachusetts, USA

Sanyo, Gunma, Japan, Liebherr, Biberach an der Riß

Snijders, Almere, The Netherlands

GFL, Burgwedel; Heidolph, Kelheim

Bandelin, Berlin

Eppendorf, Hamburg

Memmert, Schwabach

INTAS, Göttingen

IKA, Wilmington, North Carolina, USA

Julabo, Seelbach; Lauda, Lauda-Königshofen

\subsubsection{General chemicals}

Chemicals were of highest purity (for molecular biology or pro analysi). All chemicals that are not listed below were obtained from VWR International (former: Merck, Darmstadt).

Agarose

Alkaline phophatase

AMBA

Ampicillin, sodium salt

APS

ATP

Bromophenol blue

BSA
Invitrogen (former: Life Technologies),

Groningen, The Netherlands

Roche, Mannheim

Roche, Mannheim

Amersham Pharmacia Biotech (former: USB), Little Chalfont, UK

BioRad, Hercules, California, USA

Invitrogen (former: Life Technologies),

Groningen, The Netherlands

Amersham Pharmacia Biotech (former: USB), Little Chalfont, UK

Amersham Pharmacia Biotech, Little Chalfont, UK 
Cresyl violet acetate

Cryomatrix

DAB

dATP

$\left[\gamma_{-}{ }^{32} \mathrm{P}\right] \mathrm{ATP}$

$\mathrm{dCTP}$

$\left[\alpha-{ }^{32} \mathrm{P}\right] \mathrm{dCTP}$

Developer

dGTP

DMF

DMSO

DNA standard

dTTP

ECL system

EDTA $\cdot \mathrm{Na}_{2} \cdot 2 \mathrm{H}_{2} \mathrm{O}$

EGTA

Ethanol

Ethidium bromide

Faramount (aqueous mounting medium)

Fixative

Formamide

Gelatin

Glucose

Glutathione agarose beads

Glutathione, reduced form
Sigma, Taufkirchen

Thermo Shandon, Pittsburgh, Pennsylvania, USA

Sigma, Taufkirchen

Invitrogen (former: Life Technologies),

Groningen, The Netherlands

Amersham Pharmacia Biotech, Little Chalfont, UK

Invitrogen (former: Life Technologies),

Groningen, The Netherlands

Amersham Pharmacia Biotech, Little Chalfont, UK

Tetenal, Norderstedt

Invitrogen (former: Life Technologies),

Groningen, The Netherlands

Amersham Pharmacia Biotech (former: USB),

Little Chalfont, UK

Sigma, Taufkirchen

Invitrogen (former: Life Technologies),

Groningen, The Netherlands

Invitrogen (former: Life Technologies),

Groningen, The Netherlands

Amersham Pharmacia Biotech, Little Chalfont, UK

Amersham Pharmacia Biotech (former: USB),

Little Chalfont, UK

Roche, Mannheim

Calbiochem, San Diego, California, USA

Roche, Mannheim

DAKO, Hamburg

Tetenal, Norderstedt

Calbiochem, San Diego, California, USA

Sigma, Taufkirchen

Sigma, Taufkirchen

Novagen, Madison, Wisconsin, USA

Sigma, Taufkirchen 
Glycerol

HEPES, sodium salt

Hexanucleotide mix

Igepal CA-630

Imidazole

IPTG

Isopropanol

Kanamycin sulfate

Klenow enzyme

$\alpha$-Latrotoxin sepharose beads

LB broth base

LB agar

Lysozyme

Milk powder

NGS

PEG

Phenol

Phenol/Chloroform/Isoamyl alcool

Phosphorylation buffer

PMSF

Ponceau S

Poly-L-lysine

Polynucleotide kinase

Protease inhibitor cocktail

Proteinase K

Protein standards
Amersham Pharmacia Biotech (former: USB),

Little Chalfont, UK

Sigma, Taufkirchen

Roche, Mannheim

Sigma, Taufkirchen

Amersham Pharmacia Biotech (former: USB),

Little Chalfont, UK

Roche, Mannheim

ICN, Costa Mesa, California, USA

Amersham Pharmacia Biotech (former: USB),

Little Chalfont, UK

Roche, Mannheim

Kindly provided by Dr. Alexander G. Petrenko,

New York University Medical Center, New

York, USA (Petrenko et al., 1990)

Invitrogen (former: Life Technologies),

Groningen, The Netherlands

Invitrogen (former: Life Technologies),

Groningen, The Netherlands

Roche, Mannheim

Nestle Deutschland, Frankfurt/Main; BioRad, Hercules, California, USA

Invitrogen (former: Life Technologies),

Groningen, The Netherlands

Sigma, Taufkirchen

Amersham Pharmacia Biotech (former: USB),

Little Chalfont, UK

Amersham Pharmacia Biotech (former: USB),

Little Chalfont, UK

Roche, Mannheim

Roche, Mannheim

Sigma, Taufkirchen

Sigma, Taufkirchen

Roche, Mannheim

Roche, Mannheim

Roche, Mannheim

BioRad, Hercules, California, USA 
Red Tag DNA polymerase

Restriction endonucleases, buffers

Salmon sperm DNA

SDS

SOC medium

Sodium chloride

Sucrose

Taq DNA polymerase

T4 DNA ligase, buffer

TEMED

T-PBS

Tris

Tri-sodium citrate $\cdot 2 \mathrm{H}_{2} \mathrm{O}$

TritonX100

Xgal

Yeast tRNA

2.1.3

Chloroquine

DEAE dextran

$\mathrm{dH}_{2} \mathrm{O}$

DMEM medium

DMEM powder

D-PBS

FCS (for COS cell culture)

FCS (for ES cell culture)
Sigma, Taufkirchen

Roche, Mannheim

Roche, Mannheim

Amersham Pharmacia Biotech (former: USB),

Little Chalfont, UK

Invitrogen (former: Life Technologies),

Groningen, The Netherlands

Calbiochem, San Diego, California, USA

Sigma, Taufkirchen

Roche, Mannheim

Roche, Mannheim

BioRad, Hercules, California, USA

Sigma, Taufkirchen

Amersham Pharmacia Biotech (former: USB),

Little Chalfont, UK

Calbiochem, San Diego, California, USA

Eurobio, Paris, France

Roche, Mannheim

Roche, Mannheim

\section{Chemicals for cell culture}

Sigma, Taufkirchen

Amersham Pharmacia Biotech, Little Chalfont, UK

Invitrogen (former: Life Technologies),

Groningen, The Netherlands

Invitrogen (former: Life Technologies),

Groningen, The Netherlands

Invitrogen (former: Life Technologies),

Groningen, The Netherlands

Invitrogen (former: Life Technologies),

Groningen, The Netherlands

Invitrogen (former: Life Technologies),

Groningen, The Netherlands

Hyclone, Logan, Utah, USA 
Ganciclovir

G418 sulfate

LIF (ESGRO)

MEM-non essential amino acids

Mineral oil

Mitomycin C

N-Lauroylsarcosine

Penicillin/Streptomycin

Sodium bicarbonate

Trypsin/EDTA

\section{1 .4}

High Fidelity PCR

$\lambda$-Bacteriophage Mini Kit

Plasmid Maxi Kit

ProLong Antifade Kit

Qiaex II Agarose Gel Extraction Kit

QIAprep Spin Miniprep Kit

Site Directed Mutagenesis
Sigma, Taufkirchen

Invitrogen (former: Life Technologies),

Groningen, The Netherlands

Chemicon, Temecula, California, USA

Invitrogen (former: Life Technologies),

Groningen, The Netherlands

Sigma, Taufkirchen

Sigma, Taufkirchen

Sigma, Taufkirchen

Invitrogen (former: Life Technologies),

Groningen, The Netherlands

Invitrogen (former: Life Technologies),

Groningen, The Netherlands

Invitrogen (former: Life Technologies),

Groningen, The Netherlands

\section{Kits}

Roche, Mannheim

Qiagen, Hilden

Qiagen, Hilden

Molecular Probes, Eugene, Oregon, USA

Qiagen, Hilden

Qiagen, Hilden

Stratagene, La Jolla, California, USA

\section{1 .5}

Blotting paper

Cell culture plastic equipment

Cellophane sheets

Concentrators

Dialysis membranes

\section{Consumables}

Schleicher \& Schuell, Dassel; Whatman, Maidstone, UK

Corning, Acton, Massachusetts, USA

BioRad, Hercules, California, USA

Millipore, Bedford, Massachusetts, USA

Spectrum, Rancho Dominguez, California, USA 
ECL X-ray films

Electroporation cuvettes

Falcon tubes (14 ml)

Filters

Glass coverslips

Glass slides

G-50 sephadex columns

Hybond-N nylon membranes

Microcentrifuge tubes

Microtome blades (for cryostat sectioning)

Needles

Nitrocellulose membranes

Pasteur pipettes

Pipettes ( $1 \mathrm{ml}, 5 \mathrm{ml}, 10 \mathrm{ml}, 25 \mathrm{ml})$

Pipette tips

Pipette tips, aerosol resistant (for PCR)

Plastic tubes for bacterial centrifugations

(40 ml, $250 \mathrm{ml}$ )

Plastic tubes, sterile $(15 \mathrm{ml}, 50 \mathrm{ml})$

Plates, for bacterial culture

PCR tubes

Safe-lock microcentrifuge tubes

SDS-PAGE gel loading tips

Spectrophotometry cuvettes

Syringes

Ultracentrifuge tubes

X-ray films
Amersham Pharmacia Biotech, Little Chalfont, UK

BioRad, Hercules, California, USA

Becton Dickinson, Franklin Lakes, New Jersey, USA

Corning, Acton, Massachusetts, USA; Sartorius, Göttingen; Schleicher \& Schuell, Dassel

Menzel-Gläser, Braunschweig

Menzel-Gläser, Braunschweig

Roche, Mannheim

Amersham Pharmacia Biotech, Little Chalfont, UK

Corning, Acton, Massachusetts, USA

Leica, Nußloch

HSW, Tuttlingen

Whatman Biometra, Göttingen

Brand, Wertheim/Main; Rofa-Mavi, Beverwijk, The Netherlands

Corning, Acton, Massachusetts, USA

Brand, Wertheim/Main

Brand, Wertheim/Main

Kendro, Asheville, North Carolina, USA

Corning, Acton, Massachusetts, USA

Greiner, Nürtingen

Sarstedt, Nümbrecht

Eppendorf, Hamburg

Corning, Acton, Massachusetts, USA

Brand, Wertheim/Main

HSW, Tuttlingen

Kendro, Asheville, North Carolina, USA

Kodak, Rochester, New York, USA 


\subsubsection{Media for bacterial culture}

\section{$\underline{\text { LB agar }}$}

$32 \mathrm{~g}$ of LB agar powder were dissolved in $11 \mathrm{dH}_{2} \mathrm{O}$ and autoclaved. Dissolvement was complete only during autoclaving. The solution was cooled to $\sim 50^{\circ} \mathrm{C}$ and antibiotics were optionally added for antibiotic-resistance selection. The solution was poured onto $85 \mathrm{~mm}$ or $150 \mathrm{~mm}$ plates $(\sim 40 \mathrm{ml}$ or $\sim 100 \mathrm{ml}$ per plate respectively) and plates were shortly flamed with a Bunsen burner, to brake any air bubbles. Plates were let at RT o/n to allow LB agar to solidify and dry and kept inverted at $4^{\circ} \mathrm{C}$.

Composition: $1 \%$ SELECT peptone $140,0.5 \%$ SELECT yeast extract, $0.5 \% \mathrm{NaCl}, 1.2 \%$ SELECT agar

\section{$\underline{\text { LB medium }}$}

$20 \mathrm{~g}$ of LB broth base were dissolved in $11 \mathrm{dH}_{2} \mathrm{O}$, autoclaved and stored at RT. For antibioticresistance selection antibiotics were added before use.

Composition: $1 \%$ SELECT peptone $140,0.5 \%$ SELECT yeast extract, $0.5 \% \mathrm{NaCl}$

\section{$\underline{\text { SOC medium }}$}

High quality medium, used for special applications. Obtained ready to use.

Composition: $2 \%$ tryptone, $0.5 \%$ yeast extract, $10 \mathrm{mM} \mathrm{NaCl}, 2.5 \mathrm{mM} \mathrm{KCl}, 10 \mathrm{mM} \mathrm{MgCl}, 10$ $\mathrm{mM} \mathrm{MgSO}_{4}, 20 \mathrm{mM}$ glucose

\section{$\underline{\text { Antibiotic concentrations }}$}

Ampicillin $\quad 50 \mu \mathrm{g} / \mathrm{ml}$, stored as $1000 \mathrm{x}$ stock in $\mathrm{dH}_{2} \mathrm{O}$, at $-20^{\circ} \mathrm{C}$

Kanamycin $\quad 30 \mu \mathrm{g} / \mathrm{ml}$, stored as $1000 \mathrm{x}$ stock in $\mathrm{dH}_{2} \mathrm{O}$, at $-20^{\circ} \mathrm{C}$

\subsubsection{Bacterial strains}

Epicurian coli XL1-Blue

(Escherichia coli strain)

Escherichia coli BL21(DE3)

Escherichia coli Origami(DE3)

Escherichia coli XL1-Blue MRF'

Escherichia coli XL1-Blue MRA(P2)
Stratagene, La Jolla, California, USA

Novagen, Madison, Wisconsin, USA

Novagen, Madison, Wisconsin, USA

Stratagene, La Jolla, California, USA

Stratagene, La Jolla, California, USA 


\subsubsection{Eukaryotic cell lines}

COS7 Monkey kidney cells, used for transfections.

American Type Culture Collection, Manassas, Virginia, USA

E14.1 Mouse embryonic stem cells (ES cells), derived from male SV/129 mouse embryos. They were established by Professor Klaus Rajewski, University of Cologne.

MEF Mouse embryonic fibroblast (MEF) cells, used as feeder layer cells in ES cell culture.

Genome Systems, St. Louis, Missouri, USA

\subsubsection{Genomic library}

An aliquot of Sv129 $\lambda$ bacteriophage mouse genomic library (Stratagene) was kindly provided by Dr. Nils Brose, Max Planck Institute for Experimental Medicine, Göttingen.

\subsubsection{0 cDNA and genomic clones}

Neurexophilin 1 cDNA clone

Neurexophilin 3 cDNA clone

Neurexophilin 4 cDNA clone

Neurexophilin 1 genomic clone 4

Neurexophilin 1 genomic clone 5

Neurexophilin 1 genomic clone 10
Petrenko et al., 1996. Cloned in pCMV5 (construct name: pCMVD2).

Missler and Südhof, 1998. Cloned in pCMV5 (construct name: pCMVNph3).

Missler and Südhof, 1998. Cloned in pCMV5 (construct name: pCMVNph4).

Petrenko et al., 1996. Cloned in pBluescript II SK (construct name: pmNph1-4).

Petrenko et al., 1996. Cloned in pBluescript II SK (construct name: pmNph1-5).

Petrenko et al., 1996. Cloned in pBluescript II SK (construct name: pmNph1-10). 


\subsubsection{Vectors and plasmids}

\begin{tabular}{|c|c|}
\hline pBlueIRES & $\begin{array}{l}\text { Kindly provided by Dr. Nils Brose, Max Planck Institute } \\
\text { for Experimental Medicine, Göttingen }\end{array}$ \\
\hline pBluescript II SK & Stratagene, La Jolla, California, USA \\
\hline pCMV5 & $\begin{array}{l}\text { Kindly provided by Dr. David Russel, UTSW, Dallas, } \\
\text { Texas, USA }\end{array}$ \\
\hline pCMVß̃gal & Stratagene, La Jolla, California, USA \\
\hline pCMV5-HA-SytI & $\begin{array}{l}\text { Kindly provided by Professor Thomas C. Südhof, UTSW, } \\
\text { Dallas, Texas, USA }\end{array}$ \\
\hline pCAG-CATZ & $\begin{array}{l}\text { Kindly provided by Professor Joachim Herz, UTSW, } \\
\text { Dallas, Texas, USA }\end{array}$ \\
\hline $\mathrm{pFRT}_{2}$ neo.lacZ & $\begin{array}{l}\text { Kindly provided by Dr. Susan M. Dymecki, Harvard } \\
\text { Medical School, Boston, Massachusetts, USA (Dymecki, } \\
\text { 1996) }\end{array}$ \\
\hline pET-32b(+) & Novagen, Madison, Wisconsin, USA \\
\hline $\mathrm{pET}-42 \mathrm{~b}(+)$ & Novagen, Madison, Wisconsin, USA \\
\hline pGEX-KG & Amersham Pharmacia Biotech, Little Chalfont, UK \\
\hline pMal-c2 & New England Biolabs, Beverly, Massachusetts, USA \\
\hline pTKneo3a & $\begin{array}{l}\text { Kindly provided by Professor Thomas C. Südhof, UTSW, } \\
\text { Dallas, Texas, USA (Rosahl et al., 1993) }\end{array}$ \\
\hline
\end{tabular}

\subsubsection{Primary antibodies}

Calretinin, polyclonal (goat)

Flag M2, monoclonal (mouse)

Flag M2-HRP, monoclonal (mouse)

Flag monoclonal (mouse)

Flag polyclonal (chicken)

Flag polyclonal (rabbit)

HA, monoclonal (mouse)

Nph1/3, F508 (rabbit)

Nph4, U347 (rabbit)

Neurexin, A473 (rabbit)
Chemicon, Temecula, California, USA

Sigma, Taufkirchen

Sigma, Taufkirchen

Chemicon, Temecula, California, USA

Chemicon, Temecula, California, USA

Sigma, Taufkirchen

Roche, Mannheim

Petrenko et al., 1996

Missler et al., 1998

Ushkaryov et al., 1992 


\subsubsection{Secondary antibodies and PAP complexes}

Goat anti mouse, Alexa Fluor 488

Goat anti mouse, Alexa Fluor 568

Goat anti mouse (immunohistochemistry)

Goat anti mouse (western blot)

Goat anti rabbit, Alexa Fluor 546

Goat anti rabbit (immunohistochemistry)

Goat anti rabbit (western blot)

Mouse PAP

Rabbit anti chicken

Rabbit anti goat, Alexa Fluor 568

Rabbit PAP
Molecular Probes, Eugene, Oregon, USA

Molecular Probes, Eugene, Oregon, USA

Sternberger Monoclonals, Lutherville, Maryland, USA

BioRad, Hercules, California, USA

Molecular Probes, Eugene, Oregon, USA

Sternberger Monoclonals, Lutherville, Maryland, USA

BioRad, Hercules, California, USA

Sternberger Monoclonals, Lutherville, Maryland, USA

Chemicon, Temecula, California, USA

Molecular Probes, Eugene, Oregon, USA

Sternberger Monoclonals, Lutherville, Maryland, USA

\subsubsection{Synthetic oligonucleotides}

Synthetic oligonucleotides were used as PCR primers, as primers for sequencing or for DNA adaptor synthesis. They were synthesized by Fritz Benseler and Ivonne Thanhäuser at the Department of Molecular Neurobiology, Max Planck Institute for Experimental Medicine, Göttingen, using an ABI 394 DNA/RNA Synthesizer.
00-01 5' CTGCCGTGCACTGCAACAACGCTGC 3'
00-02 5' GAAATCTTGTGCACTCACAC 3'
00-04 5' CCTAGATGGGCGGCAGAGGCCGGTG 3'
00-05 5' GGATCCAGATGGGTAGTAGGGGGTATC 3’ 


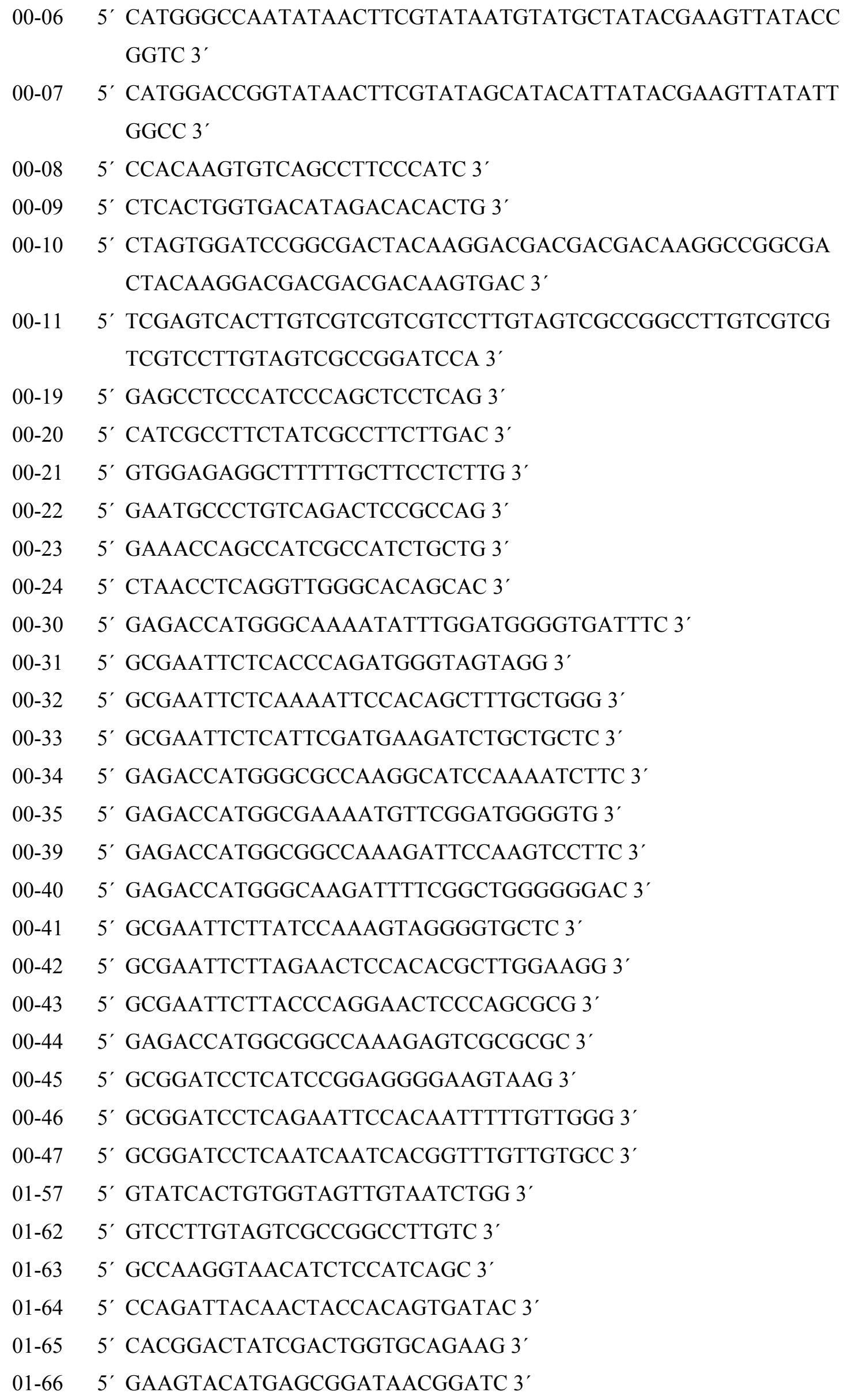




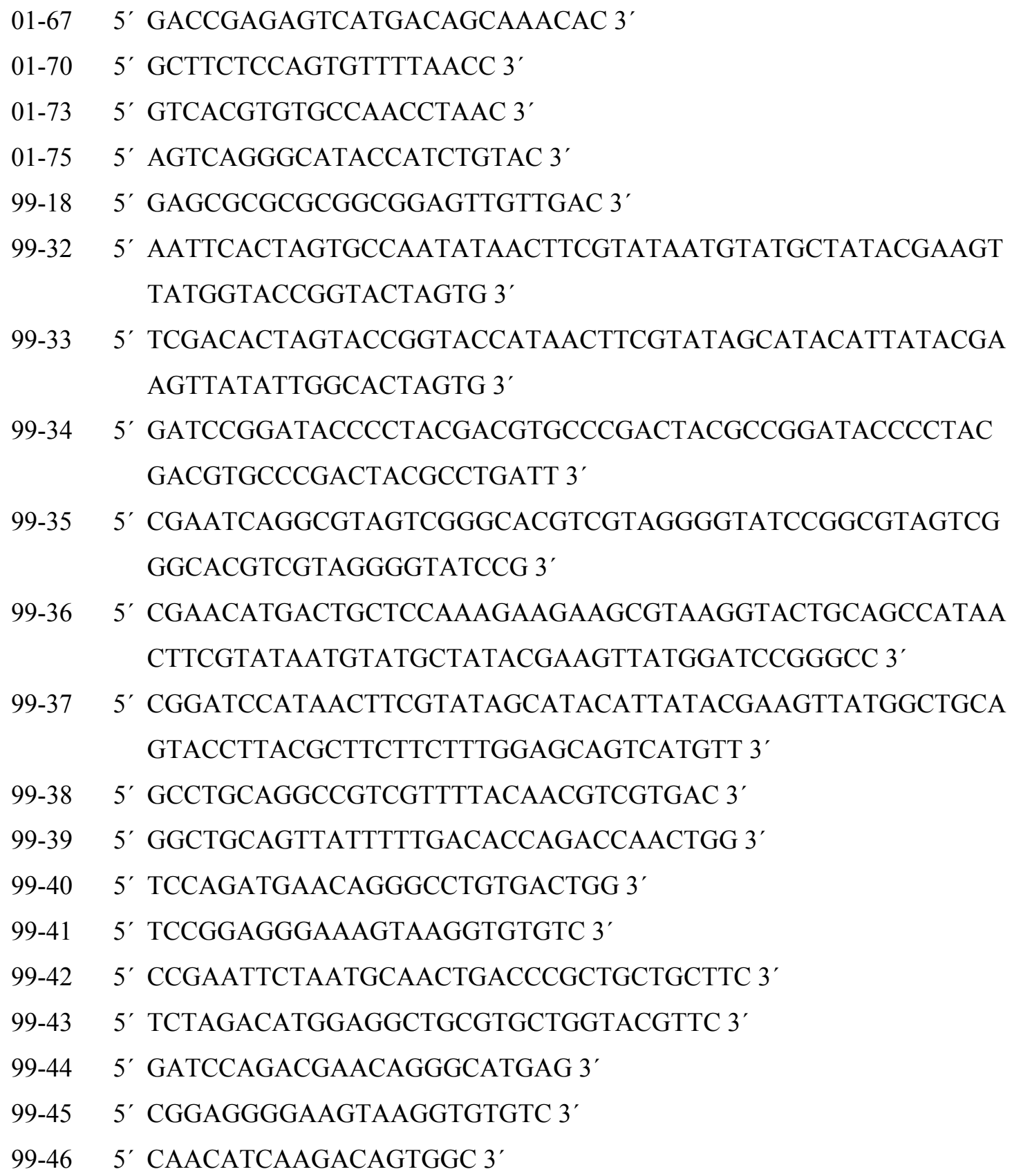




\subsubsection{Preparation of electro-competent bacteria}

Plasmid DNA, in order to be amplified, was inserted into E. coli (strain XL1-Blue MRF') by electroporation. $50 \mathrm{ml}$ of Luria-Bretani (LB) bacterial growing medium was inoculated with a single colony from an LB-tetracycline agar plate. Bacterial cells were grown at $37^{\circ} \mathrm{C}, \mathrm{o} / \mathrm{n}$, shaking at $250 \mathrm{rpm} .11 \mathrm{of} \mathrm{LB}$ medium was inoculated with $10 \mathrm{ml}$ of the above culture. Cells were grown at $37^{\circ} \mathrm{C}$ for $3-5 \mathrm{~h}$, till they reached an $\mathrm{OD}_{600}$ of $\sim 0.6-0.7$. Cells were centrifuged at $1500 \mathrm{~g}$, at $4^{\circ} \mathrm{C}$, for $15 \mathrm{~min}$ and resuspended in 11 of ice-cold $10 \%$ glycerol. Centrifugation and resuspension were repeated two times with $500 \mathrm{ml}$ and $250 \mathrm{ml}$ of $10 \%$ glycerol and cells were finally resuspended in $4 \mathrm{ml}$ of $10 \%$ glycerol. Cells were shock-frozen in liquid nitrogen in $40 \mu 1$ aliquots and stored at $-80^{\circ} \mathrm{C}$.

\subsubsection{Electro-transformation (electroporation) of bacteria with plasmid DNA}

$4 \mu 1$ of plasmid DNA (ligation mixture, diluted 1:4 with TE (see section 2.2.3.2) or plasmid preparation, diluted 1:300 with TE) were mixed with $40 \mu 1$ of electro-competent bacteria (thawed on ice) and kept on ice for 1-5 min. The mixture was transferred to an icecold electroporation cuvette and pulsed at $2.5 \mathrm{kV}$ in an E. coli pulser. In order to allow bacteria to recover, they were transferred to $1 \mathrm{ml} \mathrm{LB}$ and incubated at $37^{\circ} \mathrm{C}$ for $1 \mathrm{~h}$, shaking at $250 \mathrm{rpm}$.

For mini-prep DNA preparations, bacteria were plated on $85 \mathrm{~mm} \mathrm{LB}$ agar plates, containing the appropriate antibiotic, and grown at $37^{\circ} \mathrm{C} \mathrm{o} / \mathrm{n}$. Lac selection was optionally applied when a DNA fragment had been cloned into the $l a c Z$ sequence of a vector (e.g. polylinker sequence of pBluescript II SK). This method is based on the hydrolysis of Xgal, a lactose analogue, catalyzed by $\beta$-galactosidase (which is encoded by lac $Z$ ), in the presence of IPTG, which acts as inducer. One of the products of the hydrolysis has a deep blue colour. Therefore, in the presence of Xgal on the plate, non-recombinant colonies appear blue and recombinant ones appear white due to the disruption of the $l a c Z$ sequence. Selection was carried out by applying $40 \mu \mathrm{l}$ of Xgal solution ( $40 \mathrm{mg} / \mathrm{ml}$ in DMF) and $40 \mu \mathrm{l}$ of $100 \mathrm{mM}$ IPTG onto the plates, before plating the bacteria.

For maxi-prep DNA preparation, $4 \mathrm{ml}$ of LB medium, containing the appropriate antibiotic were added to the transformed bacteria and incubation was continued at $37^{\circ} \mathrm{C}$ for $4 \mathrm{~h} .1 \mathrm{ml}$ of 
the culture was used to inoculate $500 \mathrm{ml}$ of LB medium with the appropriate antibiotic and cells were grown at $37^{\circ} \mathrm{Co} / \mathrm{n}$.

\subsubsection{Plasmid DNA preparations}

\subsubsection{DNA miniprep}

$5 \mathrm{ml}$ (mini) cultures were inoculated with single colonies from LB agar plates and grown o/n. DNA was extracted and purified, using the QIAprep Spin Miniprep Kit, and stored in $10 \mathrm{mM}$ Tris-HCl, $\mathrm{pH} 8.5$ at $4^{\circ} \mathrm{C}$. Purification of plasmid DNA with this kit is based on an alkaline lysis procedure, followed by adsorption of plasmid DNA onto a silica-gel membrane. Purified DNA was analyzed with restriction analysis and, optionally, with DNA sequencing.

\subsubsection{DNA maxiprep}

For most cloned constructs, a higher and better purified amount of DNA was prepared by the maxiprep procedure after transformation of bacteria with miniprep DNA. DNA was extracted and purified, using the Qiagen Plasmid Maxi Kit, and stored in TE (see below) at $4^{\circ} \mathrm{C}$. Purification of plasmid DNA with this kit is based on a alkaline lysis procedure, followed by binding of plasmid DNA to an anion-exchange resin. The composition of purified DNA was confirmed with restriction analysis.

\begin{tabular}{c}
\hline$\underline{\text { TE buffer }}$ \\
$10 \mathrm{mM} \mathrm{Tris}$ \\
$1 \mathrm{mM} \mathrm{EDTA} \cdot \mathrm{Na}_{2} \cdot 2 \mathrm{H}_{2} \mathrm{O}$ \\
$\mathrm{pH} 8.0$
\end{tabular}

DNA is more stable in slightly alkaline conditions; EDTA stabilizes DNA by forming a complex with $\mathrm{Mg}^{++}$, which is required for DNA hydrolysis by DNases.

\subsubsection{Restriction enzyme analysis of DNA}

In order to check the composition of purified DNA, DNA was digested with restriction endonucleases. Digestions were carried out for $3 \mathrm{~h}$ to $\mathrm{o} / \mathrm{n}$, in $15 \mu \mathrm{l}$ reaction volume, in the optimal buffer for each endonuclease (suggested and provided as 10x concentrated by Roche). 
The digestion temperature was $37^{\circ} \mathrm{C}$ for most endonucleases, unless otherwise suggested by Roche. Double enzyme digestions were also carried out. The buffer used was determined by a compatibility table, provided by Roche. In cases where the optimal temperature of the two enzymes was different, the digestion was performed first at the lower temperature (usually $37^{\circ} \mathrm{C}$ ) and then at the higher.

\subsubsection{Agarose gel electrophoresis}

During agarose gel electrophoresis, DNA fragments are separated according to their size, i.e. the smaller a fragment is, the faster it migrates. The size of a fragment is estimated by comparison to the sizes of the bands of a DNA molecular weight marker. Agarose, in concentration $0.7-1.5 \%$, was dissolved in $1 \mathrm{x}$ TAE (see below) in a microwave oven. The solution was cooled to $\sim 60^{\circ} \mathrm{C}$ and ethidium bromide was added, at final concentration 1 $\mu \mathrm{g} / \mathrm{ml}$. The solution was poured into a gel chamber with a well separator and let to solidify at RT. The concentration of the gel reflects the area of DNA size where separation is required to be optimal, i.e. large fragments (>3 kb) separate better in low concentration gels and small fragments in high concentration gels. DNA samples were mixed with $1 / 10$ volume of $10 \mathrm{x}$ loading buffer (see below) and loaded into the wells of the gel. Gels were electrophoresed at 80-120 $\mathrm{V}$ for $30 \mathrm{~min}-4 \mathrm{~h}$ in $1 \mathrm{x}$ TAE. DNA bands, based on their binding to ethidium bromide, were visualized under UV light.

Buffers:

$$
\begin{array}{|c|}
\hline \underline{50 x \text { TAE }} \\
2 \mathrm{M} \text { Tris } \\
50 \mathrm{mM} \mathrm{EDTA} \cdot \mathrm{Na}_{2} \cdot 2 \mathrm{H}_{2} \mathrm{O} \\
4 \% \text { acetic acid } \\
\text { pH } 8.5 \\
\hline
\end{array}
$$

\begin{tabular}{|c|}
\hline $10 \mathrm{x}$ loading buffer \\
$57 \%$ glycerol \\
$100 \mathrm{mM}$ Tris $\mathrm{pH} 8.0$ \\
$10 \mathrm{mM}$ EDTA $\cdot \mathrm{Na}_{2} \cdot 2 \mathrm{H}_{2} \mathrm{O}$ \\
$\sim 0.001 \%$ bromophenol blue \\
\hline
\end{tabular}

\subsubsection{Purification of DNA from preparative digestions}

DNA digestions for cloning purposes (preparative digestions) were carried out $\mathrm{o} / \mathrm{n}$, in $60 \mu \mathrm{l}$ reaction volume. Digested DNA was either run on an agarose gel to separate different fragments or used directly (usually vector digestions).

DNA was purified from agarose gels either using the Qiaex II Gel Extraction Kit, according to manufacturer's protocol, or by phenol/chloroform extraction. When the second method was followed, the DNA band was collected from the gel, cut into small pieces with a pipette tip 
and incubated with an equal volume of phenol for $15 \mathrm{~min}$. The mixture was then shock-frozen in liquid nitrogen and centrifuged at $16000 \mathrm{~g}$ for $30 \mathrm{~min}$. Supernatant (aqueous phase) was recovered.

The supernatant or DNA that was not run on a gel was mixed with an equal volume of phenol/chloroform/isoamyl alcohol (25: $24: 1)$, in order to inactivate proteins, and centrifuged at $16000 \mathrm{~g}$ for $10 \mathrm{~min}$. The supernatant was recovered, mixed with 0.7 volume isopropanol and 0.1 volume sodium acetate and incubated on ice for $5 \mathrm{~min}$. The mixture was centrifuged at $16000 \mathrm{~g}$ for $15 \mathrm{~min}$. The pellet was air-dried and resuspended in TE or $\mathrm{dH}_{2} \mathrm{O}$.

\subsubsection{De-phosphorylation of 5' DNA ends}

In order to prevent vector re-ligation in a cloning procedure, 5' phosphate groups were eliminated by treating digested vector DNA with $1 \mu \mathrm{l}$ of alkaline phosphatase at $37^{\circ} \mathrm{C}$ for 30 $\min$.

\subsubsection{Ligation}

DNA ends of different or the same DNA fragment were ligated by incubation with T4 DNAligase at $12-15^{\circ} \mathrm{C} \mathrm{o} / \mathrm{n}$. Ligation is the formation of a covalent bond between a $5^{\prime}$ phosphate and a $3^{\prime}$ hydroxyl group. In the case of double-stranded DNA, it can take place when the $5^{\prime}$ phosphate group of at least one of the ligating ends is present. Ligation reaction mixture included 10-100 ng of vector DNA and 5-10 times more "insert" DNA, in molecular quantities. Reaction was carried out in $20 \mu \mathrm{l}$ volume, using $1 \mu \mathrm{l}$ of T4 DNA ligase, in 1x ligation buffer (it is provided with the ligase and includes the required ATP).

\subsubsection{Measurement of DNA concentration}

DNA concentration was estimated, using agarose gel electrophoresis, by comparing the intensity of a small amount of purified DNA with that of $10 \mu \mathrm{l}$ of $0.1 \mu \mathrm{g} / \mu \mathrm{l}$ DNA molecular weight marker. For a more accurate measurement, the $\mathrm{OD}_{260}$ of a specific dilution of purified DNA was measured. The concentration of DNA is calculated according to the following formula:

double-stranded DNA $\quad 1.0 \mathrm{OD}_{260}$ unit $=50 \mu \mathrm{g} / \mathrm{ml}=0.15 \mathrm{mM}$ (in nucleotides) 
single-stranded DNA

$1.0 \mathrm{OD}_{260}$ unit $=33 \mu \mathrm{g} / \mathrm{ml}=0.10 \mathrm{mM}$ (in nucleotides)

(oligonucleotides)

\section{2 .10 Blunt-end cloning}

By blunt-end cloning, two digested DNA ends with no overhangs are ligated. It is technically more difficult than sticky-end cloning, because adhesion of the two ends before ligation is not stable, since they do not hybridize with each other. The technique is applied for the ligation of two ends that have been digested either with blunt-end endonucleases or with sticky-end endonucleases and have been blunt-ended before ligation. It is usually used when no compatible restriction sites are present in the area of interest.

Fragment and vector DNA were purified by phenol/chloroform extraction. When blunt-end endonucleases were used, ligation took place, as described above. In the case of sticky-end endonucleases, purified fragments were dissolved in $21.5 \mu 1 \mathrm{dH}_{2} \mathrm{O}$ and the following reaction mixture was set up:

\begin{tabular}{|lr|}
\hline DNA & $21.5 \mu \mathrm{l}$ \\
buffer A & $2.5 \mu \mathrm{l}$ \\
$10 \mathrm{mM}$ dNTPs & $0.5 \mu \mathrm{l}$ \\
Klenow polymerase & $0.5 \mu \mathrm{l}$ \\
\hline
\end{tabular}

Buffer $\mathrm{A}$ is one of the buffers used for restriction digestions, provided with the endonucleases (Roche). The blunt-end reaction was carried out at $37^{\circ} \mathrm{C}$ for $30 \mathrm{~min}$. Blunt-end synthesis is the result of the elongation of the DNA strands at their $3^{\prime}$ end, by Klenow polymerase, eliminating the overhangs created by restriction digestions. This is not possible when the existing overhang has a shorter $5^{\prime}$ strand. Purification was repeated and DNA fragments were ligated.

\subsubsection{Partial DNA digestion}

Partial digestion was carried out when only one of the two ClaI restriction sites in the plasmids shown below was planned to be used. It was carried out by including $\mathrm{NaCl}$ in the reaction mixture, thus partially inhibiting the endonuclease. The method was followed in two cloning steps, shown below, together with the concentrations of $\mathrm{NaCl}$ used: 


\begin{tabular}{|c|c|}
\hline Construct cloned & $\underline{\mathrm{NaCl} \text { concentration }}$ \\
\hline $\begin{array}{l}\text { pTKNeo }{ }^{\mathrm{FRT}} \mathrm{Nph} 1 \text { tag }^{\operatorname{loxP}} \\
\text { pTKNeo }^{\mathrm{FRT}} \mathrm{Nph} 1 \text { tag }^{\operatorname{loxP}} 2\end{array}$ & $\begin{array}{c}400 \mathrm{mM} \\
900-1300 \mathrm{mM}\end{array}$ \\
\hline
\end{tabular}

\subsubsection{DNA adaptor synthesis}

DNA adaptors were synthesized by annealing two oligonucleotides in ligation buffer. Oligonucleotides were first heated at $95^{\circ} \mathrm{C}$ for $10 \mathrm{~min}$. The temperature of the mixture was then slowly dropped to $50^{\circ} \mathrm{C}$ by incubating for $1 \mathrm{~min}$ at $3{ }^{\circ} \mathrm{C}$-reduced temperatures. Oligonucleotides were let to anneal at $50^{\circ} \mathrm{C}$ for $10 \mathrm{~min}$. The temperature was then brought to $22^{\circ} \mathrm{C}$, with two intermediate $1 \mathrm{~min}$-incubations at $40^{\circ} \mathrm{C}, 30^{\circ} \mathrm{C}$. The annealed product was used directly for ligation.

\subsubsection{DNA sequencing}

In order to sequence DNA fragments, the latter were cloned into a plasmid vector, usually pbluescript, and sequenced using primers that anneal next to the polylinker sequence of the vector. In some cases, primers that anneal in the already known sequence of a cloned insert were used. Sequencing was performed using Cycle-Sequencing with fluorescent-marked dideoxy-terminators in an AB 373 DNA sequencer (modified from Sanger et al., 1977). The sequencing procedure was carried out by Fritz Benseler and Ivonne Thanhäuser at the Department of Molecular Neurobiology, Max Planck Institute for Experimental Medicine, Göttingen. Sequences were analyzed on a Macintosh computer, using Lasergene software (DNASTAR, Madison, Wisconsin, USA).

\subsubsection{Polymerase chain reaction (PCR) cloning}

By polymerase chain reaction (PCR, Saiki et al., 1988) a specific DNA sequence can be amplified, using as primers two oligonucleotides that hybridize at the two ends of the sequence. The Expand High Fidelity PCR System was used, according to manufacturer's protocol, for cloning of $l a c Z$ and protein expression sequences. This system is based on the use of the following two enzymes:

a) Taq DNA polymerase that amplifies DNA and 
b) Pwo DNA polymerase that corrects any introduced mutations, by its $3^{\prime} \rightarrow 5^{\prime}$ exonuclease proofreading activity.

PCR programmes applied:

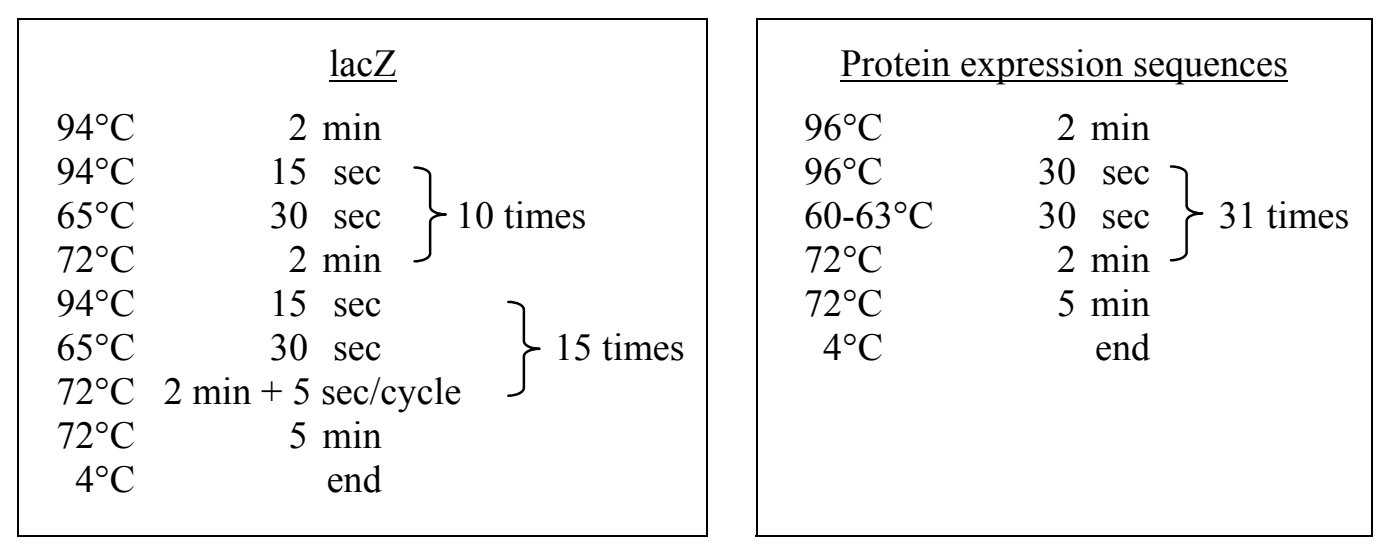

The PCR products were run on an agarose gel and DNA was purified.

\subsubsection{Site-directed mutagenesis}

Site-directed mutagenesis was performed in order to mutate the stop codons of Nph1, Nph3 genomic DNA and Nph1 cDNA into BamHI sites. Oligonucleotides were phosphorylated at $37^{\circ} \mathrm{C}$ for 30 min using the following reaction mixture:

\begin{tabular}{|c|c|}
\hline $\mathrm{H}_{2} \mathrm{O}$ & $14.8 \mu 1$ \\
\hline 10x phosphorylation buffer & \\
\hline oligonucleotide $(50 \mathrm{pmol} / \mu \mathrm{l})$ & $1.2 \mu 1$ \\
\hline $10 \mathrm{mM}$ ATP & \\
\hline polynucleotide kinase $(10 \mathrm{U} / 1)$ & \\
\hline
\end{tabular}

The polynucleotide kinase was inactivated by incubating the mixture at $70^{\circ} \mathrm{C}$ for $10 \mathrm{~min}$.

The ExSite PCR-Based Site-Directed Mutagenesis Kit was then used, according to manufacturer's protocol. Briefly, plasmid DNA, containing the stop codon, was used as template for a PCR reaction. Oligonucleotides, designed in a way to contain the desired mutation, were used as primers, after being phosphorylated as described above. The PCR products were treated with an enzyme mixture (DpnI/PfuI DNA polymerase) in order to eliminate parental DNA, based on its methylation, as well as to remove extended bases at the ends of the PCR products. PCR-amplified linear DNA was then intramolecularly ligated and used to heat shock-transform E. coli cells (strain Epicurian coli XL1-Blue).

PCR programme applied: 


\begin{tabular}{|rr|}
$94^{\circ} \mathrm{C}$ & $4 \mathrm{~min}$ \\
$50^{\circ} \mathrm{C}$ & $2 \mathrm{~min}$ \\
$72^{\circ} \mathrm{C}$ & $2 \mathrm{~min}$ \\
$94^{\circ} \mathrm{C}$ & $1 \mathrm{~min}$ \\
$56-60^{\circ} \mathrm{C}$ & $2 \mathrm{~min}$ \\
$72^{\circ} \mathrm{C}$ & $1-2 \mathrm{~min}$ \\
$72^{\circ} \mathrm{C}$ & 5 min \\
$4^{\circ} \mathrm{C}$ & end \\
\hline
\end{tabular}

\subsubsection{PCR for genotyping}

In order to genotype recombinant Nph3-KI embryonic stem cells (ES cells) as well as Nph3KI and Nph3-KO mice, DNA derived from ES cells or from mouse tail biopsies, was subjected to PCR analysis. In the case of ES cells, genotyping was always carried out also by Southern blot. For Nph3-KI mouse genotyping, both PCR and Southern blot were carried out in the beginning and after PCR genotyping was established, it was the only method that was further used. Nph3-KO mice were genotyped only by PCR. A reaction mixture, that is suitable for genomic PCR, characterized by high sensitivity was applied. Its composition, as well as the programme applied are given below:

\begin{tabular}{|lc|}
\hline \multicolumn{2}{|c|}{ Reaction mixture $(\mu \mathrm{l})$} \\
$\mathrm{dH}_{2} \mathrm{O}$ & 13.35 \\
$25 \mathrm{mM}$ dNTPs & 1 \\
$\mathrm{DMSO}$ & 2.5 \\
$\mathrm{BSA}(10 \mathrm{mg} / \mathrm{ml})$ & 0.2 \\
primer A (5 OD & \\
primer B (5 Onits) & 0.1 \\
5x buffer (see below) & 0.1 \\
Red Taq DNA polymerase & 0.75 \\
DNA & 2 \\
\hline
\end{tabular}

$\begin{array}{|rr|} & \text { Programme } \\ 93^{\circ} \mathrm{C} & 10 \mathrm{~min} \\ 93^{\circ} \mathrm{C} & 30 \mathrm{sec} \\ 60^{\circ} \mathrm{C} & 45 \mathrm{sec} \\ 65^{\circ} \mathrm{C} & 2 \mathrm{~min} \\ 65^{\circ} \mathrm{C} & 10 \mathrm{~min} \\ 4^{\circ} \mathrm{C} & \text { end } \\ & \\ & \end{array}$

5x buffer: $83 \mathrm{mM}\left(\mathrm{NH}_{4}\right)_{2} \mathrm{SO}_{4}, 335 \mathrm{mM}$ Tris $\mathrm{pH} 8.8,33.5 \mathrm{mM} \mathrm{MgCl} 2 \cdot 6 \mathrm{H}_{2} \mathrm{O}, 25 \mathrm{mM} \beta$ mercaptoethanol, $33.5 \mu \mathrm{M}$ EDTA $\cdot \mathrm{Na}_{2} \cdot 2 \mathrm{H}_{2} \mathrm{O}$ 
2 2 . 17 Cloning of the mouse neurexophilin 3 gene (based on Südhof, 1990)

\subsubsection{Library plating}

An Sv129 $\lambda$ bacteriophage genomic library was used. Bacteriophages were propagated in the host E. coli strain XL1-Blue MRA(P2). The optimal concentration of bacteriophage was titrated in a serial dilution experiment, judging by the density of the bacteriophage plaques:

A $100 \mathrm{~mm}$ LB agar plate with no antibiotics was streaked with host bacteria and incubated at $37^{\circ} \mathrm{C} \mathrm{o} / \mathrm{n} .50 \mathrm{ml}$ of bacterial growing medium were inoculated with a colony from the plate and incubated at $37^{\circ} \mathrm{Co} / \mathrm{n} .45 \mathrm{ml}$ of the culture were centrifuged at $2600 \mathrm{~g}$ at $4^{\circ} \mathrm{C}$ for $10 \mathrm{~min}$ and resuspended in $20 \mathrm{ml}$ of autoclaved $\lambda$ buffer. The suspension was diluted with $\lambda$ buffer to $\mathrm{OD}_{600} 1.0$. 1:50 to 1:10000 dilutions of the bacteriophage library were made. $300 \mu 1$ of each dilution were mixed with an equal volume of host bacteria, prepared as described above. The mixtures were incubated at $37^{\circ} \mathrm{C}$ for $20 \mathrm{~min}$, added to microwave-melted, autovlaved soft agarose $(0.7 \%$ agarose in LB) and poured onto $150 \mathrm{~mm} \mathrm{LB}$ agar plates with no antibiotics (each mixture onto one plate). The plates were incubated at $37^{\circ} \mathrm{C}$ for $6-9$ h. 1:500 dilution resulted in a gauze-like web appearance of plaques and was considered to be optimal.

The procedure described above was repeated using 20 mixtures of 1:500 diluted bacteriophage with host bacteria, plated onto 20 labelled plates. After the plaques on the plates reached their optimal density, plates were stored at $4^{\circ} \mathrm{C}$.

Composition of solutions is given in section 2.2.17.6.

\subsubsection{Plaque lifting}

Two sets of 20 Hybond-N nylon membranes were labelled. Each pair of membranes corresponded to a plate of the $\lambda$ bacteriophage library; one set was taken as the "master" set and the other as the "replica". The rationale behind the preparation of two identical sets of membranes relies on the fact that, during screening, a lot of plaques usually provide unspecific, false positive signals. The specific positive signals are therefore recognized by their identical position in the membranes of both the "master" and the "replica" set. Membranes were wet in $\mathrm{dH}_{2} \mathrm{O}$ and in $5 \mathrm{x}$ SSC and blotted on blotting paper. Membranes of the "master" set were placed onto their corresponding plates for $\sim 2 \mathrm{~min}$. At this point, a small number of asymmetric holes was made with a needle on the membrane and the plate for future alignment. Membranes were transferred temporarily to blotting paper and the 
corresponding "replica" membranes were placed onto the plates for $\sim 2 \mathrm{~min}$. The same holes were made on the "replica" membranes.

All membranes were transferred to blotting paper, that was wet with denaturing buffer, and incubated for $5 \mathrm{~min}$. Membranes were transferred to another piece of blotting paper, that was wet with neutralization buffer, and incubated for $8 \mathrm{~min}$. They were then shaked in 20x SSPE buffer for $10 \mathrm{~min}$ and air-dried. Membranes were heated at $80^{\circ} \mathrm{C}$ for $2 \mathrm{~h}$, to strengthen DNA binding, and washed in $2 \mathrm{x}$ SSC, $0.5 \%$ sodium dodecyl sulfate (SDS) at $55^{\circ} \mathrm{C}$ for $2 \mathrm{~h}$, to remove any residual cellular debris. When not used immediately, membranes were air-dried and kept at room temperature (RT).

Buffer compositions are given in section 2.2.17.6.

\subsubsection{Screening}

Membranes, prepared as described above, were screened by Southern blot (see section 2 . 2 . 18), using a 570 bp NheI-SfiI fragment from Nph3 rat cDNA. Dried membranes were wet in $2 \mathrm{x}$ SSPE, before use. Positive signals were confirmed by their identical position on both sets of membranes. The corresponding points on the plates, including a few $\mathrm{mm}$ of the surrounding area were collected, using a glass pipette. Plaques were eluted in $500 \mu 1$ of $\lambda$ buffer in microcentrifuge tubes for $2 \mathrm{~h}$, vortexing occasionally and, optionally, o/n at $4{ }^{\circ} \mathrm{C}$. The tubes were centrifuged briefly at $16000 \mathrm{~g}$, to remove LB agar, and supernatants, containing eluted plaques, were recovered. One drop of chloroform was added to each tube to prevent bacterial growth.

\subsubsection{Secondary screening}

The plating-lifting-screening procedure was repeated, since each area of plate collected contained a high number of different plaques, including the positive one. The eluted plaques were used as the bacteriophage source. This time the density of the plaques was planned to be lower than in primary screening, in order to clearly separate individual plaques. Positive, single plaques were collected and plated again. This time $100 \mathrm{~mm}$ plates were used and $2 \mathrm{mM}$ $\mathrm{MgSO}_{4}$ were included in the $\mathrm{LB}$ agar $\left(\mathrm{MgSO}_{4}\right.$ promotes bacteriophage growth). The plaque density applied was similar to that of primary screening. 


\section{2 .17 .5 Elution of $\lambda$ bacteriophage plaques}

$5 \mathrm{ml}$ of $\lambda$ buffer were added to each plate and plates were slowly shaked at $4^{\circ} \mathrm{Co} / \mathrm{n}$. $\lambda$ Buffer containing eluted plaques was collected. Remaining plaques were further eluted in $1 \mathrm{ml}$ of $\lambda$ buffer at RT for $10 \mathrm{~min}$ and $\lambda$ buffer was collected in the same tubes. $50 \mu \mathrm{l}$ of chloroform were added to each tube. The tubes were vortexed and centrifuged at $2600 \mathrm{~g}$ at $4{ }^{\circ} \mathrm{C}$ for $10 \mathrm{~min}$ to remove debris and becteria. Supernatants were recovered and one drop of chloroform was added to each tube.

The Qiagen $\lambda$ Mini Kit was used to purify bacteriophage DNA. This method is based on a polyethylene glycol precipitation step and binding of $\lambda$ DNA to an anion-exchange resin. DNA was stored in TE.

\subsubsection{Solutions}

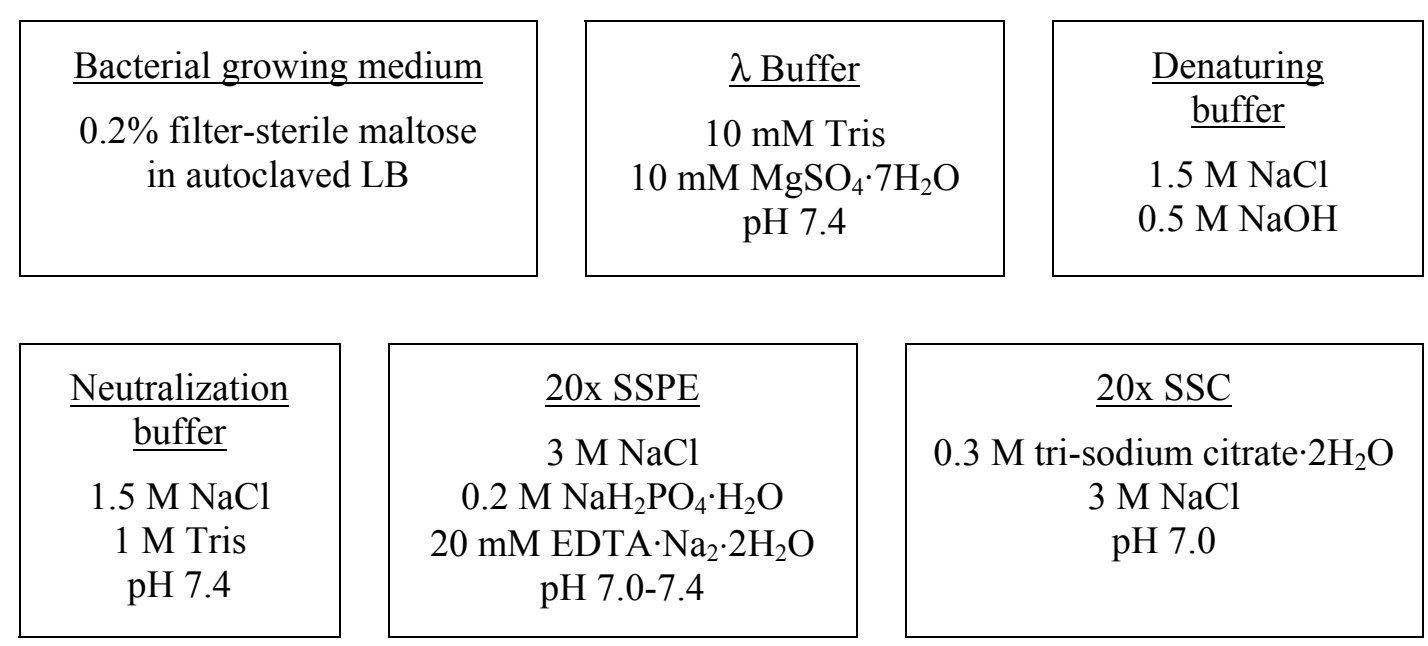

\subsubsection{Southern blot (Southern, 1975)}

\subsubsection{DNA transfer from agarose gels}

Tranfer of separated DNA fragments from agarose gels to nylon membranes facilitates analysis of them, using a radioactively labelled probe. Digested genomic or plasmid DNA was run on a $0.8 \%$ agarose gel. Genomic DNA was always run at $30 \mathrm{~V} \mathrm{o} / \mathrm{n}$. The gel was incubated in denaturing buffer for 30-60 min and in neutralization buffer for 30-60 min. Gel was blotted onto Hybond-N nylon membranes with 20x SSC o/n. The membrane was washed 
in $2 \mathrm{x}$ SSC for $2 \mathrm{~min}$, UV-crosslinked at $0.12 \mathrm{~J} / \mathrm{cm}^{2}$ and washed in $2 \mathrm{x}$ SSC, $1.5 \%$ SDS for 30 $\min$.

\section{2 . 2 18.2 Transfer of bacterial DNA from LB agar plates}

Transfer of DNA can also take place from bacterial colonies of an LB agar plate, in order to identify positive colonies in a cloning procedure. Colonies from LB agar plates were lifted on Hybond-N nylon membranes and a number of assymetric holes was made. Bacterial colonies on membranes were lysed with $10 \%$ SDS for $5 \mathrm{~min}$, denatured for $5 \mathrm{~min}$ and neutralized for 5 min by placing the membrane on blotting paper, wet with the respective solutions. The membranes were then incubated in 2x SSPE for 10 min, UV-crosslinked and washed with $2 x$ $\mathrm{SSC}, 1 \% \mathrm{SDS}$ for $30 \mathrm{~min}$.

\subsubsection{Radioactive labeling of DNA probes using random primers, Feinberg and Vogelstein, 1983)}

Radioactively labelled probe was synthesized using $\left[\alpha-{ }^{32} \mathrm{P}\right] \mathrm{dCTP}$, according to the following reaction mixture:

$$
\begin{aligned}
& 9 \mu 1 \text { DNA }\left(\sim 25 \mathrm{ng} \text {, denatured at } 100^{\circ} \mathrm{C} \text { for } 7-10 \mathrm{~min}\right) \\
& 2 \mu 1 \text { hexanucleotide mix }\left(62.5 \mathrm{OD}_{260} \text { units } / \mu \mathrm{l}\right) \\
& 3 \mu \mathrm{dATP} \text {, dGTP, dTTP }(1 \mu 1 \text { each, } 0.5 \mathrm{mM}) \\
& 1 \mu 1 \text { Klenow polymerase }(2 \mathrm{U} / \mu \mathrm{l}) \\
& 5 \mu 1\left[\alpha_{-}{ }^{32} \mathrm{P}\right] \mathrm{dCTP}(0.37 \mathrm{MBq} / \mu \mathrm{l}, 3.3 \mu \mathrm{M})
\end{aligned}
$$

The reaction was carried out at $37^{\circ} \mathrm{C}$ for $40 \mathrm{~min}$. Approximately $1 \mathrm{MBq}$ is usually incorporated into a probe. The probe was purified from nucleotides using G-50 sephadex columns and denatured at $100^{\circ} \mathrm{C}$ for $10 \mathrm{~min}$ before use.

\subsubsection{Hybridization}

Membranes were pre-hybridized in 50\% Hybe buffer (see section 2.2.18 .6) with denatured salmon sperm DNA (see below) at $42^{\circ} \mathrm{C}$ o/n. They were then incubated with denatured, radiolabelled probe in $50 \%$ Hybe buffer at $42^{\circ} \mathrm{C}$ o/n. Membranes were washed with an SSC, SDS solution for $10 \mathrm{~min}$ at RT and for $30 \mathrm{~min}$ at $65^{\circ} \mathrm{C}$. Concentrations of SSC, SDS varied 
according to the desirable stringency, i.e. for strong washing low concentration of SSC and high concentration of SDS were applied. For most applications, $0.1 \mathrm{xSSC}, 0.1 \%$ SDS were applied for genomic DNA and $0.1 \mathrm{x}$ SSC, $0.5 \%$ SDS for plasmid DNA. X-ray films were autoradiographically exposed by the membranes. For genomic DNA, films were exposed for 1-5 days at $-80^{\circ} \mathrm{C}$ and for plasmid DNA for $45 \mathrm{~min}-2 \mathrm{~h}$ at RT. Exposure at $-80^{\circ} \mathrm{C}$ activates the enhancer screen of the film cassette and is not necessary for short exposures.

\section{$\underline{\text { Salmon sperm DNA preparation }}$}

Salmon sperm DNA was dissolved in $\mathrm{dH}_{2} \mathrm{O}$ at $1 \%$ concentration. DNA was sonicated $3 \mathrm{x} 40$ sec at power 50 , cycle $50 \%$ to be sheared into fragments. Before use, DNA was denatured at $100^{\circ} \mathrm{C}$ for $7-10 \mathrm{~min}$.

\subsubsection{Oligonucleotide hybridization}

When a very short area of DNA is required to be probed, it is usually more convenient to use an oligonucleotide, rather than a DNA fragment as probe. In this case, radiolabeling is more efficient by phosphorylating the oligonucleotide with $\left[\gamma^{32} \mathrm{P}\right] \mathrm{ATP}$. A similar protocol to the one described above was followed for radiolabeling and hybridization:

Membranes prepared from agarose gel transfer of plasmid DNA were pre-hybridized in oligohybe buffer (see next section) at $42^{\circ} \mathrm{C}$ for $30-60 \mathrm{~min}$. Radiolabelled probe was prepared using the following reaction mixture:

\begin{tabular}{|ll|}
\hline $\mathrm{dH}_{2} \mathrm{O}$ & $6 \mu \mathrm{l}$ \\
10x phosphorylation buffer & $1 \mu \mathrm{l}$ \\
oligonucleotide $\left(5 \mathrm{OD}_{260}\right.$ units $)$ & $1 \mu \mathrm{l}$ \\
polynucleotide kinase $(10 \mathrm{U} / \mu \mathrm{l})$ & $1 \mu \mathrm{l}$ \\
{$\left[\gamma-{ }^{32} \mathrm{P}\right] \mathrm{ATP}(0.37 \mathrm{MBq} / \mu \mathrm{l}, 2 \mu \mathrm{M})$} & $1 \mu \mathrm{l}$ \\
\hline
\end{tabular}

The reaction was carried out at $37^{\circ} \mathrm{C}$ for $30 \mathrm{~min}$ and $490 \mu \mathrm{l}$ of TE were added. Membranes were hybridized with $50 \mu \mathrm{l}$ of the probe in oligohybe buffer at $42^{\circ} \mathrm{C}$ o/n. Membranes were washed twice with $6 \mathrm{x} \mathrm{SSC}, 0.1 \% \mathrm{SDS}$ at $50^{\circ} \mathrm{C}$ for $30 \mathrm{~min}$. X-ray films were exposed for $2 \mathrm{~h}$ as well as $\mathrm{o} / \mathrm{n}$. 


\subsubsection{Solutions}

\begin{tabular}{|lr|}
\hline \multicolumn{2}{|c|}{ 50\% Hybe buffer } \\
$\mathrm{dH}_{2} \mathrm{O}$ & $90 \mathrm{ml}$ \\
100x Denhardt's & $10 \mathrm{ml}$ \\
formamide & $500 \mathrm{ml}$ \\
20x SSPE & $250 \mathrm{ml}$ \\
$10 \%$ SDS & $150 \mathrm{ml}$ \\
pH 7.0-7.4 & \\
\hline
\end{tabular}
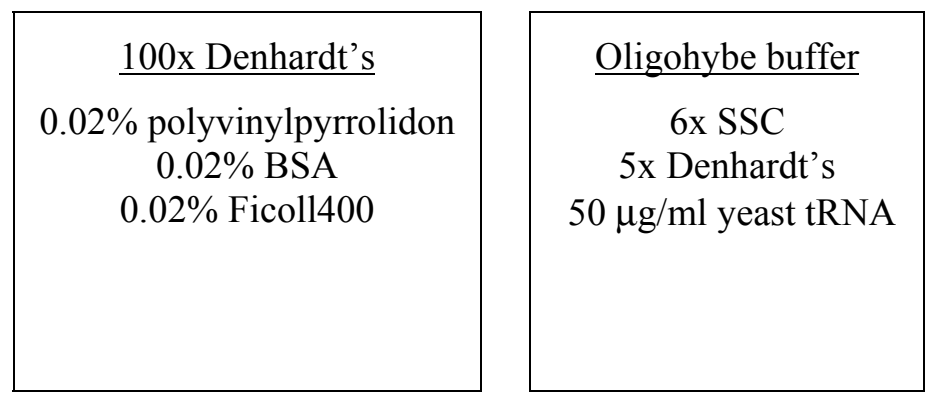

\section{2 .19 Preparation of mouse tail DNA for PCR}

Tail biopsies were used as source of mouse DNA. They were digested with $0.25 \mathrm{mg} / \mathrm{ml}$ proteinase $\mathrm{K}$ in $3 \mathrm{ml}$ SNET buffer (see below), shaking at $55^{\circ} \mathrm{Co} / \mathrm{n} .500 \mu 1$ of tail lysate was transferred to a microcentrifuge tube, mixed with $500 \mu 1$ phenol/chloroform/isoamyl alcohol (25:24:1) and centrifuged at $16000 \mathrm{~g}$ for $10 \mathrm{~min}$. The upper (aqueous) phase was recovered and DNA was precipitated with $300 \mu \mathrm{l}$ iso-propanol. Tubes were incubated on ice for $5 \mathrm{~min}$ and centrifuged at $16000 \mathrm{~g}$ at RT for $10 \mathrm{~min}$. DNA pellet was air-dried, resuspended in $500 \mu \mathrm{l}$ TE and kept at $4^{\circ} \mathrm{C}$.

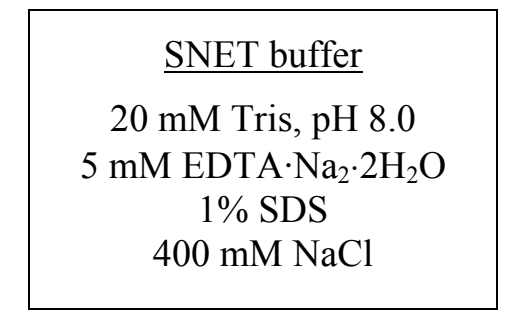

\subsubsection{Preparation of mouse tail DNA for Southern blot}

Tail biopsies were digested with proteinase $\mathrm{K}$ as described above. The tail lysate was mixed with $3 \mathrm{ml} \mathrm{phenol/chloroform/isoamyl} \mathrm{alcohol}(25: 24: 1)$ and centrifuged at $1800 \mathrm{~g}$ for 20 min. The upper (aqueous) phase was recovered and DNA was precipitated with $2 \mathrm{ml}$ isopropanol. Tubes were centrifuged at $3200 \mathrm{~g}$ at $4^{\circ} \mathrm{C}$ for $15 \mathrm{~min}$. DNA pellet was washed with $1 \mathrm{ml}$ of $70 \%$ ice-cold ethanol, to remove residual salt and centrifuged again at $3200 \mathrm{~g}$ at $4^{\circ} \mathrm{C}$ for $10 \mathrm{~min}$. The pellet was air-dried, resuspended in $400 \mu \mathrm{TE}$ and kept at $4^{\circ} \mathrm{C}$. When DNA from this preparation was used for PCR, it was diluted 1:50 and $1 \mu 1$ was used per reaction. 


\subsubsection{SDS-polyacrylamide gel electrophoresis (SDS-PAGE, Laemmli, 1970)}

By SDS-polyacrylamide gel electrophoresis (SDS-PAGE), proteins are separated according to their molecular weight. All solutions used are Tris-based buffers, containing SDS. The function of SDS is to unfold the proteins by binding to their hydrophobic groups and to provide them with a negative charge, irrespective of their isoelectric point. Proteins before subjected to electrophoresis, are mixed with a buffer which also contains $\beta$-mercaptoethanol (apart from SDS), a reducing agent that breaks disulfide bonds and thus separates multisubunit proteins to their monomers. The effect of SDS and $\beta$-mercaptoethanol is assisted by heating the sample at $100^{\circ} \mathrm{C}$. The electrophoresis gel consists of two parts: a) the stacking gel, a low concentration gel of $\mathrm{pH} 6.8$ which functions by focusing the different proteins of the loaded samples and b) the separation gel, a higher concentration gel of $\mathrm{pH} 8.8$ in which proteins are separated.

The separation gel was first prepared (see below). The concentration of the gel varied, according to the area of protein size where separation was required to be optimal, i.e. low molecular weight proteins separate better in high concentration gels and high molecular weight proteins in low concentration gels. The mixture was loaded into the running cassette and overlayed with $\mathrm{H}_{2} \mathrm{O}$-saturated n-butanol till it polymerized. n-Butanol was then removed and the gel surface was washed with $\mathrm{dH}_{2} \mathrm{O}$. The stacking gel was prepared (see below), loaded on top of the separation gel and a well separator was inserted. After polymerization, the running cassette was placed into a chamber, which was filled with running buffer (see below). The well separator was removed and wells were washed with running buffer. Protein samples were mixed with an equal volume of $2 \mathrm{x}$ sample buffer (see below), heated at $100^{\circ} \mathrm{C}$ for 3-5 min and loaded into the wells of the gel. A molecular weight standard was also loaded, enabling estimation of the molecular weight of the proteins analyzed. Pre-stained or unstained standard was used for western blot or Coomassie-blue staining application respectively (see sections 2.2. 22, 2.2 23). Electrophoresis was carried out at $80 \mathrm{~V}$ for $5-10 \mathrm{~min}$ to facilitate protein focusing and then at 100-150 V for 1-2 $\mathrm{h}$. Gels were used either for Western blot or for Coomassie-blue staining.

The composition of the gel mixtures, as well as of the other solutions used is shown below: 


\begin{tabular}{|c|c|c|c|c|}
\cline { 2 - 4 } \multicolumn{1}{c|}{} & \multicolumn{3}{c|}{ Separation gel } & Stacking gel \\
\hline & $\underline{7.5 \%}$ & $\underline{10 \%}$ & $\underline{12 \%}$ & $\underline{3.75 \%}$ \\
$\mathrm{dH}_{2} \mathrm{O}$ & $2.5 \mathrm{ml}$ & $2.5 \mathrm{ml}$ & $1.75 \mathrm{ml}$ & $1.25 \mathrm{ml}$ \\
Tris buffer & $1.25 \mathrm{ml}$ & $1.5 \mathrm{ml}$ & $1.25 \mathrm{ml}$ & $0.5 \mathrm{ml}$ \\
AMBA & $1.25 \mathrm{ml}$ & $2.0 \mathrm{ml}$ & $2.0 \mathrm{ml}$ & $0.25 \mathrm{ml}$ \\
$10 \%$ APS & $15 \mu \mathrm{l}$ & $17 \mu \mathrm{l}$ & $15 \mu \mathrm{l}$ & $12 \mu \mathrm{l}$ \\
TEMED & $7 \mu \mathrm{l}$ & $8 \mu \mathrm{l}$ & $7 \mu \mathrm{l}$ & $5 \mu \mathrm{l}$ \\
\hline
\end{tabular}

Lower Tris buffer was used for the separation gel and Upper Tris buffer for the stacking gel. AMBA: $30 \%$ acrylamide, $0.8 \%$ bis-acrylamide

\begin{tabular}{|l|}
\hline Lower Tris \\
$1.5 \mathrm{M}$ Tris \\
$0.4 \%$ SDS \\
$\mathrm{pH} 8.8$ \\
\end{tabular}

\begin{tabular}{|c|}
\hline Upper Tris \\
$0.5 \mathrm{M}$ Tris \\
$0.4 \%$ SDS \\
pH 6.8 \\
\\
\end{tabular}

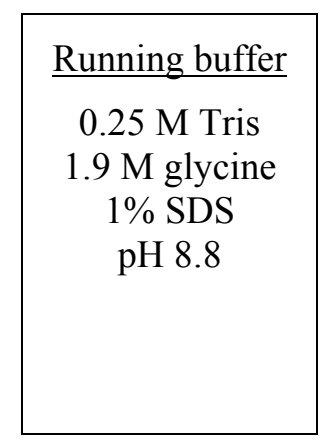

\begin{tabular}{|c|}
\hline 2x Sample buffer \\
0.125 M Tris \\
$4.6 \%$ SDS \\
$20 \%$ Glycerol \\
$5 \% \beta$-mercaptoethanol \\
small amount of \\
bromophenol blue \\
pH 6.8 \\
\hline
\end{tabular}

\subsubsection{Western blot (Towbin et al., 1979)}

Western blot analysis enables high sensitivity detection of a specific protein in a protein mixture, when an antibody against an epitope of the particular protein is available. The various proteins of the mixture are separated in an SDS-PAGE gel and transferred electrophoretically to a nitrocellulose membrane. The membrane is then subjected to immunodetection.

\subsubsection{Transfer of proteins to a nitrocellulose membrane}

After SDS-PAGE, the stacking gel was removed and the separation gel was assembled together with the membrane under transfer buffer (see below). Two sheets of blotting paper were placed on both sides of the assembly and two pieces of sponge on top of them. The whole assembly was "locked" with a transfer cassette and the cassette was placed in a chamber, filled with ice-cold transfer buffer. Proteins were transferred electrophoretically at $250 \mathrm{~mA}$ for $2 \mathrm{~h}$. An ice block, serving as cooling device, was included in the chamber. The membrane was stained with Ponceau-S (see below) for 15-30 sec, a reversible stain, to verify protein transfer. Protein bands were visualized after destaining with $\mathrm{H}_{2} \mathrm{O}$. The membrane was 
further destained with T-PBS (phosphate buffer saline (PBS) with $0.05 \%$ Tween 20, for composition of PBS see section 2 .2 . 24 . 3) for 1-2 min.

Solutions used:
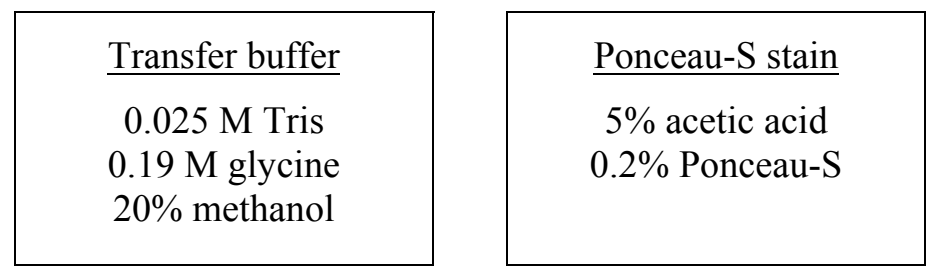

\subsubsection{Immunodetection}

For immunodetection of the protein of interest on a nitrocellulose membrane, the membrane is first incubated with blocking buffer (see below), the proteins of which bind weakly und unspecifically to all proteins of the membrane. The membrane is then incubated with an antibody against an epitope of the protein of interest (primary antibody) in blocking buffer. The antibody binds to the particular protein in a competitive fashion with the proteins of the blocking buffer. This results in high specificity of binding and elimination of background. The membrane is then incubated with a secondary antibody, also in blocking buffer, which binds to the primary antibody. The secondary antibody is conjugated with horseradish peroxidase (HRP), which enables its detection by the enhanced chemilluminesence (ECL) system (Whitehead et al., 1979). According to this system, HRP catalyzes oxidation of luminol in the presence of $\mathrm{H}_{2} \mathrm{O}_{2}$. Oxidized luminol is in an excited state which returns to its ground state by emitting light. In the presence of enhancers, this light is amplified and can be autoradiographically detected with high sensitivity on exposed films.

Procedure followed:

- Incubation of the membrane with blocking buffer for 30-60 min at RT

- Incubation with the primary antibody in blocking buffer at $4^{\circ} \mathrm{C}$ o/n or at RT for $60 \mathrm{~min}$ (see results section for concentrations used)

- Washing 3x 5 min with T-PBS

- Incubation with the secondary antibody (1:5000, unless otherwise stated) in blocking buffer at RT for $60 \mathrm{~min}$

- Washing 3x 15 min with T-PBS

- Enhanced chemilluminesense (ECL) detection:

$\circ$ Reagents 1 and 2 were mixed 1:1

- Membrane was incubated with the mixture for $60 \mathrm{sec}$

- Mixture was discarded and ECL X-ray films were exposed 


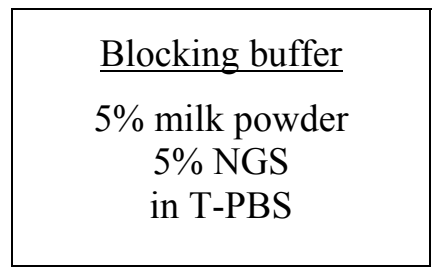

\subsubsection{Coomassie-blue staining of SDS-PAGE gels}

Coomassie-blue (Coomassie Brilliant blue R 250) is an irreversible, unspecific protein stain, suitable for staining of SDS-PAGE gels for the detection of differences between a particular protein sample and a control sample, when relatively high amounts of protein are present. Gels were incubated with the following staining solution for $15 \mathrm{~min}$, destained with $10 \%$ acetic acid for $2 \mathrm{~h}$ and washed with $\mathrm{H}_{2} \mathrm{O}$ :

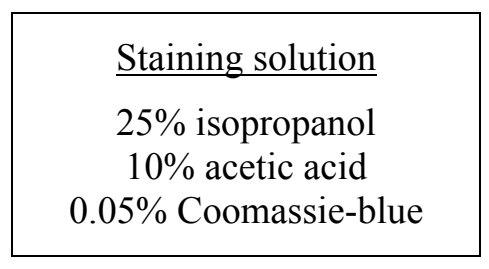

For long term storage, gels were incubated in $10 \%$ glycerol for $15 \mathrm{~min}$, covered with two sheets of cellophane, wet with $10 \%$ glycerol, and air-dried.

\subsubsection{Bacterial protein expression}

The pET system for protein expression (Novagen) was used. This system makes use of the strong bacteriophage $\mathrm{T} 7$ promoter. The $\mathrm{pET}-42 \mathrm{~b}(+)$ vector was used in combination with the E. coli strain BL21(DE3). An advantage of the system is that the expressing sequences remain transcriptionally silent in the uninduced state. The expression host contains a chromosomal copy of the T7 RNA polymerase gene under lacUV5 control and expression is induced by the addition of IPTG to the culture. pET-42b(+) vector was chosen for its multiple tag content (GST, 6·His, S tags) and for its cloning-convenient restriction sites. Fragments from rat cDNA were amplified by PCR and cloned into pET-42b(+). BL21(DE3) bacteria were grown on LB medium (or LB agar), containing $30 \mu \mathrm{g} / \mathrm{ml}$ kanamycin. Protein expression was analyzed by SDS-PAGE, followed by Coomassie-blue staining. The concentration of purified proteins was estimated by comparison to bovine serum albumin (BSA) samples of standard concentration, included in the SDS-PAGE gel. For some applications the pET-32b $(+)$ vector, in combination with the $E$. coli strain Origami(DE3) were tested, but were not further used. 


\subsubsection{Transformation}

$1 \mu 1$ of miniprep DNA was mixed with $20 \mu 1$ of competent BL21(DE3) bacteria on ice. The mixture was heat-shocked at $42^{\circ} \mathrm{C}$ for $30 \mathrm{sec}$ and placed back on ice for $2 \mathrm{~min} .80 \mu \mathrm{l}$ of SOC medium were added and the mixture was incubated at $37^{\circ} \mathrm{C}$ for $1 \mathrm{~h}$, shaking at $250 \mathrm{rpm}$. The mixture was plated on two $(3 \mu 1,98 \mu 1) 37^{\circ} \mathrm{C}$-warm LB agar plates and the plates were incubated at $37^{\circ} \mathrm{C}$ for $15-18 \mathrm{~h}$. $50 \mathrm{ml}$ of LB medium were inoculated with a single colony from the above plates and cultured at $37^{\circ} \mathrm{C}$ to $\mathrm{OD}_{600}$ 0.6-0.8. $900 \mu \mathrm{l}$ of the culture were mixed with $100 \mu \mathrm{l}$ of $80 \%$ glycerol and stored at $-80^{\circ} \mathrm{C}$.

\subsubsection{Expression}

$50 \mathrm{ml}$ of LB medium were inoculated with a small amount of frozen culture and cultured at $37^{\circ} \mathrm{C} \mathrm{o} / \mathrm{n}$. $6 \times 50 \mathrm{ml}$ of LB medium were inoculated with $2 \mathrm{ml}$ each from the above culture and cultured at $37^{\circ} \mathrm{C}$ to $\mathrm{OD}_{600} \sim 0.6$. Protein expression was induced by the addition of $0.1 \mathrm{mM}$ IPTG. The temperature and duration of induction were optimized for each recombinant protein (see results section).

\subsubsection{Purification}

Recombinant proteins were purified from the soluble fraction of lysed bacteria, using glutathione agarose beads. This method is based on the binding of glutathione-S-transferase (GST), which is part of the fusion recombinant proteins, to glutathione. The fusion protein is then eluted from the beads by incubation in a high glutathione buffer.

The cultures were centrifuged at $6000 \mathrm{~g}$, at $4^{\circ} \mathrm{C}$ for $10 \mathrm{~min}$ and bacterial pellets were resuspended in $18 \mathrm{ml}$ ice-cold lysis buffer (see below). Resuspended cultures were distributed into microcentrifuge tubes ( $1 \mathrm{ml}$ into each tube) and sonicated $2 \times 30 \mathrm{sec}$ at power 45 , cycle $50 \%$. Sonicated cultures were incubated with $1 \%$ TritonX 100 at $4{ }^{\circ} \mathrm{C}$ for $10 \mathrm{~min}$ and then centrifuged at $20000 \mathrm{~g}$ at $4^{\circ} \mathrm{C}$ for $15 \mathrm{~min}$. The soluble fractions were collected and pooled together.

$600 \mu 1$ of $50 \%$ slurry ( $300 \mu 1$ bed volume) of glutathione agarose beads were pre-washed $3 \times 5$ min with $1 \mathrm{ml}$ wash buffer (see below). The beads were collected by centrifuging at $1000 \mathrm{~g}$ for 1 min after each wash and resuspended in $500 \mu \mathrm{l}$ wash buffer after the last wash. The soluble fraction was incubated with the washed beads at RT for $20 \mathrm{~min}$. The beads were 
collected by centrifuging at $1000 \mathrm{~g}$ for $1 \mathrm{~min}$ and washed $3 \mathrm{x} 5 \mathrm{~min}$ with $14 \mathrm{ml}$ wash buffer. They were resuspended in $500 \mu \mathrm{l}$ wash buffer, transferred into 2 microcentrifuge tubes and centrifuged at $1000 \mathrm{~g}$ for $1 \mathrm{~min}$. The beads were then resuspended in $2.8 \mathrm{ml}$ (total volume) ice-cold elution buffer (see below) and incubated at $4{ }^{\circ} \mathrm{C} \mathrm{o} / \mathrm{n}$. The tubes were centrifuged at $16000 \mathrm{~g}$ for $30 \mathrm{sec}$ and the eluate was collected.

Buffers used:

\begin{tabular}{|ll|}
\hline$\underline{\text { Buffer }}$ & $\underline{\text { Composition }}$ \\
$0.2 \mathrm{M} \mathrm{PB}$ & $0.2 \mathrm{M} \mathrm{NaH}_{2} \mathrm{PO}_{4} / \mathrm{Na}_{2} \mathrm{HPO}_{4}, \mathrm{pH} 7.4$ \\
PBS & $0.01 \mathrm{M} \mathrm{PB}, 0.9 \% \mathrm{NaCl}$ \\
Lysis buffer & $\mathrm{PBS}, 100 \mu \mathrm{g} / \mathrm{ml} \mathrm{PMSF}$ \\
Wash buffer & $\mathrm{PBS}, 0.1 \%$ Triton \\
Elution buffer & $150 \mathrm{mM}$ Tris $\mathrm{pH} 8.0,1.5 \mathrm{mg} / \mathrm{ml}$ glutathione (reduced form)
\end{tabular}

\subsubsection{Concentration-Dialysis}

In order to use recombinant full length $\mathrm{Nph} 1$ and Nph3 for electrophysiological measurements of their extracellular effect on hippocampal neurons, they were concentrated and then dialyzed against a physiological buffer. Purified GST (from pET-42b(+) transformation) was also subjected to the same procedure to be used as control.

The eluate was concentrated using centriprep30 concentration columns by centrifuging 3 times at $5000 \mathrm{~g}$ at $4^{\circ} \mathrm{C}$ for $20 \mathrm{~min}$ using a fixed-angle rotor. Typical concentrate volume: 150 $200 \mu 1$. Proteins were then dialyzed against the following Na-HEPES buffer:

\begin{tabular}{|c|c|}
\hline $\mathrm{NaCl}$ & $125 \mathrm{mM}$ \\
\hline $\mathrm{KCl}$ & $2.5 \mathrm{mM}$ \\
\hline $\mathrm{NaH}_{2} \mathrm{PO}_{4} \cdot \mathrm{H}_{2} \mathrm{O}$ & $1.25 \mathrm{mM}$ \\
\hline Na-HEPES & $26 \mathrm{mM}$ \\
\hline Glucose & $25 \mathrm{mM}$ \\
\hline $\mathrm{CaCl}_{2} \cdot 2 \mathrm{H}_{2} \mathrm{O}$ & $2 \mathrm{mM}$ \\
\hline $\mathrm{MgCl}_{2} \cdot 6 \mathrm{H}_{2} \mathrm{O}$ & $1 \mathrm{mM}$ \\
\hline \multicolumn{2}{|c|}{ Osmolarity: 335 mosmo, pH 7.4 at $30^{\circ} \mathrm{C}$} \\
\hline
\end{tabular}

Since the molecular weight of all three recombinant proteins is at least $35 \mathrm{kDa}$, dialysis membranes with molecular weight cut off size (MWCO) of 12-14 kDa were used. A maximum MWCO of around half of that of the proteins to be dialyzed is suggested by the manufacturer for optimal retention of proteins. A higher MWCO would result in decreased yield and a lower MWCO in less efficient dialysis. The volume/length ratio of the membranes used was $0.32 \mathrm{ml} / \mathrm{cm}$, the least possible of the particular membranes, to facilitate better handling of the low amounts dialyzed. Dialysis was carried out at $4^{\circ} \mathrm{C} \mathrm{o} / \mathrm{n}$, using $200 \mathrm{ml}$ of 
buffer and replacing it with fresh buffer two times (final dialysis factor: $\sim 10^{9}$ ). Dialyzed proteins were recovered and kept as aliquots at $-80^{\circ} \mathrm{C}$.

\subsubsection{COS7 cell culture, transfection and stainings}

\subsubsection{Cell culture}

COS7 cells is a monkey kidney cell line, suitable for transfections with eukaryotic expression vectors. All procedures were carried out under sterile conditions. Handling of cultured cells took place in a cell culture hood and sterile tubes, culture dishes and solutions were used. Cells were cultured attached on the bottom of plastic dishes, in an incubator, at $37^{\circ} \mathrm{C}, 5 \%$ $\mathrm{CO}_{2}$, in a humidified atmosphere. Dulbecco's modified Eagle medium (DMEM) was used, containing $10 \%$ fetal calf serum (FCS) and penicillin (100 units $/ \mathrm{ml}) /$ streptomycin (100 $\mu \mathrm{g} / \mathrm{ml})$.

Cells were stored in liquid nitrogen and thawed in a $37^{\circ} \mathrm{C}$ waterbath. They were transferred to a $15 \mathrm{ml}$ tube with $9 \mathrm{ml}$ of medium and centrifuged at $800 \mathrm{~g}$, at RT for $3 \mathrm{~min}$. The cell pellet was resuspended in $10 \mathrm{ml}$ of medium and plated on a $100 \mathrm{~mm}$ dish. The medium was changed the following day to remove dead cells and cells were cultured to confluency (for $\sim 2$ days), without changing the medium, in order to enrich for secreted factors from the cells. Confluent cells were split: After a short washing with $10 \mathrm{ml}$ PBS, cells were dettached by a 2-5 min incubation with $2 \mathrm{ml}$ of $0.25 \%$ trypsin $/ 1 \mathrm{mM}$ EDTA $\cdot \mathrm{Na}_{2} \cdot 2 \mathrm{H}_{2} \mathrm{O}$ at $37^{\circ} \mathrm{C}$, followed by gentle tapping of the flask. Dettachment of cells was checked under the microscope. $8 \mathrm{ml}$ of medium were added and cells were pipetted against the bottom of the flask a few times, in order to break cell clumps. Cells were distributed to five $100 \mathrm{~mm}$ dishes, already containing $8 \mathrm{ml}$ of medium, and further cultured. For immunocytochemical and $\beta$-galactosidase stainings, 16 $\mathrm{mm}$ glass coverslips were included in the dishes and cells were also cultured on them. Before use, coverslips had been incubated with $1 \mathrm{M} \mathrm{HCl}$ for 30 min, washed 4 times with $\mathrm{dH}_{2} \mathrm{O}$, incubated with ethanol for $30 \mathrm{~min}$, air-dried and sterilized at $180^{\circ} \mathrm{C}$ for $4 \mathrm{~h}$.

\subsubsection{Transfection}

Transfection of cells was performed chemically, based on the cationic ether polymer DEAE dextran. Following DEAE dextran incubation, cells were treated with chloroquine, which increases the efficiency of transfection. 
Subconfluent cells ( 60-70\% confluency, around one day after splitting) were used for tranfection. Cells of each dish were washed twice with $6 \mathrm{ml}$ of 1x TBS (see below) and incubated with $3.3 \mathrm{ml}$ of DNA/DEAE dextran solution (see below) for $30 \mathrm{~min}$ in the incubator. The solution was replaced with $10 \mathrm{ml}$ of $100 \mu \mathrm{M}$ chloroquine in medium and incubation was continued for $3 \mathrm{~h}$. Cells were cultured in $10 \mathrm{ml}$ of medium for 2-4 days to allow protein expression.

Solutions used:

\begin{tabular}{|lr|}
\hline \multicolumn{2}{|c|}{$\underline{\text { 2x TBS }}$} \\
$5 \mathrm{M} \mathrm{NaCl}$ & $28 \mathrm{ml}$ \\
$1 \mathrm{M} \mathrm{KCl}$ & $3 \mathrm{ml}$ \\
$1 \mathrm{M} \mathrm{CaCl} \cdot 2 \mathrm{H}_{2} \mathrm{O}$ & $1 \mathrm{ml}$ \\
$1 \mathrm{M} \mathrm{MgCl} \mathrm{H}_{2} \mathrm{O}$ & $0.5 \mathrm{ml}$ \\
$0.2 \mathrm{M} \mathrm{Na} \mathrm{HPO}_{4}, \mathrm{pH} 7.4$ & $4.5 \mathrm{ml}$ \\
$1 \mathrm{M} \mathrm{Tris}, \mathrm{pH} 7.9$ & $20 \mathrm{ml}$ \\
sterile filtered & \\
\hline
\end{tabular}

\begin{tabular}{|lr|}
\hline \multicolumn{2}{|c|}{ DNA/DEAE dextran solution } \\
$\mathrm{H}_{2} \mathrm{O}$ & $1.25 \mathrm{ml}$ \\
$2 \mathrm{x}$ TBS & $1.65 \mathrm{ml}$ \\
$0.1 \mu \mathrm{g} / \mu \mathrm{l}$ plasmid DNA & $66 \mu \mathrm{l}$ \\
$5 \mathrm{mg} / \mathrm{ml}$ DEAE dextran & $330 \mu \mathrm{l}$ \\
$(\mathrm{MW}: \sim 500,000)$ & \\
& \\
& \\
\hline
\end{tabular}

\subsubsection{Cell lysate preparation}

For western blot analysis of the expressed protein, cells were lysed and the soluble fraction was collected. Cells of each dish were scraped in $2 \mathrm{ml}$ PBS and centrifuged at $16000 \mathrm{~g}$, at RT for $5 \mathrm{~min}$. The pellet was resuspended in $300 \mu \mathrm{l}$ of ice-cold lysis buffer (see below) and incubated on ice for $5 \mathrm{~min}$. The lysate was centrifuged at $20000 \mathrm{~g}$, at $4^{\circ} \mathrm{C}$ for $10 \mathrm{~min}$ and the supernatant was recovered and kept at $-20^{\circ} \mathrm{C}$.

\begin{tabular}{|c|}
\hline$\underline{\text { Lysis buffer }}$ \\
$50 \mathrm{mM}$ Tris, $\mathrm{pH} 8.0$ \\
$1 \%$ TritonX100 \\
$2 \mathrm{mM} \mathrm{CaCl}_{2} \cdot 2 \mathrm{H}_{2} \mathrm{O}$ \\
$80 \mathrm{mM} \mathrm{NaCl}$ \\
1 tablet protease inhibitors \\
\hline
\end{tabular}

\section{$2.2 .25 .4 \quad \beta$-Galactosidase staining}

Cells, transfected with constructs containing the tagging casetttes of the Nph1 and Nph3 targeting vectors or with $l a c Z$ control constructs were assayed for $\beta$-galactosidase activity. The principle of the assay is based, as in the case of lac selection (section 2 .2 .2), on the $\beta$ galactosidase-catalyzed hydrolysis of Xgal, resulting in a deep blue coloured product. 
Coverslips with transfected cells were treated in wells of 12-well plates and solutions were removed, using a vacuum device. Cells were washed with PBS, fixed with 4\% paraformaldehyde in $0.1 \mathrm{M} \mathrm{PB}$ on ice for $5 \mathrm{~min}$ and washed again with PBS. Cells were stained with the Xgal staining solution (see below) at $37^{\circ} \mathrm{C}$ for $1-4 \mathrm{~h}$, washed with PBS and embedded with aqueous mounting medium.

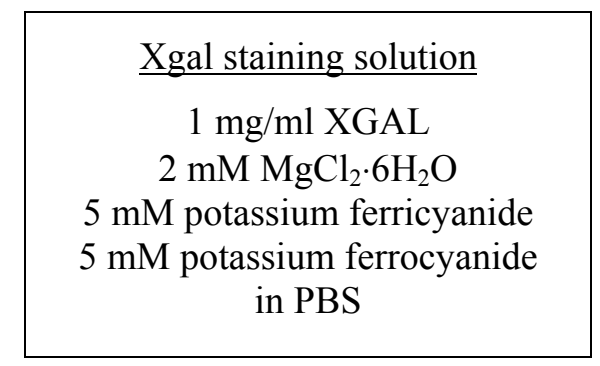

\subsubsection{Immunocytochemical staining}

The existence of the expressed protein in the transfected cells, as well as the function of specific epitopes in expressed fusion proteins were tested immunocytochemically. The principle of immunocytochemical staining applied is similar to that of western blot immunodetection, described in section 2.2.22.2, with some differences with respect to the amplification/detection system. Here, the final parameter that enables detection of the epitope of interest is the fluorescence emission of the secondary antibody.

Transfected cells, grown on glass coverslips, were washed with PBS, fixed with 4\% paraformaldehyde in $0.1 \mathrm{M} \mathrm{PB}$ at RT for $15 \mathrm{~min}$, washed again with PBS and incubated with $0.3 \%$ TritonX100 in PBS for 5 min. Cells were washed with PBS, blocked with 2\% normal goat serum (NGS) at RT for $1 \mathrm{~h}$ and incubated with the primary antibody in blocking solution at $4{ }^{\circ} \mathrm{C} \mathrm{o} / \mathrm{n}$ (see results section for antibody concentration). Cells were washed with PBS and incubated with a fluorescent secondary antibody (1:400) at RT for $1 \mathrm{~h}$. Since fluorescent antibodies are light sensitive, incubation with them, as well as all the subsequent steps, were carried out in the dark, which, in the case of incubations, was performed by covering the 12well plate with aluminium foil. Cells were washed with PBS extensively and embedded with aqueous mounting medium.

\subsubsection{Double staining for $\beta$-galactosidase and antibody}

In order to test a double staining application of the tagging cassettes of the Nph1 and Nph3 targeting vectors, a combination of the protocols of the above two sections was applied. 
Instead of immunofluorescence, a 3,3'-diamino-benzidine (DAB) detection protocol was followed. According to this method, after the primary antibody (either of mouse or of rabbit origin), cells are incubated with a secondary antibody, which is an anti-mouse or an antirabbit IgG respectively. Cells are then incubated with a third antibody (mouse or rabbit PAP), which is a complex of horseradish peroxidase and mouse or rabbit anti-peroxidase, and is able to detect primary antibodies of mouse or rabbit origin respectively, in the presence of the secondary antibody, which acts as a "bridge". DAB is finally added and its oxidation is catalyzed by horseradish peroxidase, in the presence of $\mathrm{H}_{2} \mathrm{O}_{2}$. The reaction is enhanced by $\mathrm{Ni}^{2+}$ ions, that are present in the solution. The oxidized form of DAB has a strong brown colour, which is detected by bright-field microscopy.

Between all incubation steps, cells were washed with PBS. Cells, grown on glass coverslips, were fixed with $4 \%$ paraformaldehyde in $0.1 \mathrm{M} \mathrm{PB}$ at RT for $15 \mathrm{~min}$, stained with the Xgal staining solution, as described above, and incubated with $0.3 \%$ TritonX100 in PBS for 5 min. They were blocked with $2 \%$ NGS at RT for $1 \mathrm{~h}$ and incubated with the primary antibody at $4^{\circ} \mathrm{C} \mathrm{o} / \mathrm{n}$. Cells were incubated with the secondary antibody $(1: 100)$ at $37^{\circ} \mathrm{C}$ for $30 \mathrm{~min}$, with the third antibody $(1: 400)$ at $37^{\circ} \mathrm{C}$ for $1 \mathrm{~h}$ and stained with the DAB staining solution (see below) at RT for 5-8 min. Cells were washed with PBS and embedded with aqueous mounting medium.

\begin{tabular}{|c|}
\hline DAB staining solution \\
$20 \mathrm{ml}$ PBS \\
$0.01 \mathrm{~g} \mathrm{DAB}$ \\
$0.03 \mathrm{~g} \mathrm{NiCl}{ }_{2} \cdot 6 \mathrm{H}_{2} \mathrm{O}$ \\
$3.5 \mu \mathrm{lof} 30 \% \mathrm{H}_{2} \mathrm{O}_{2}$ \\
filtered before use \\
\hline
\end{tabular}

\subsubsection{Embryonic stem cell culture}

ES cell culture was carried out in order to generate Nph3-KI recombinant ES cells and inject them into mouse blastocysts, leading to the generation of Nph3-KI mice. It was also carried out aiming at the generation of Nph1 recombinant ES cells, but no positive clone was identified. The protocol followed is based on the protocol by Willnow and Herz, 1994. ES cell culture was carried out as a series of the following procedures: ES cells were cultured on a layer of feeder cells and transfected with the target DNA by electropotation. They were then cultured on selective medium to eliminate non-recombinant clones. Recombinant clones were picked up and expanded. Part of each clone was frozen and part of it was used for DNA preparation and analysis. Nph3-KI positive recombinant clones were thawed and expanded. 
Part of each clone was again used for DNA analysis and the rest was frozen as aliquots. After DNA analysis, clones were thawed, shortly expanded and prepared for blastocyst injection. Both types of cells were cultured attached on the bottom of plastic equipment, in an incubator at $37^{\circ} \mathrm{C}, 5 \% \mathrm{CO}_{2}$, in a humidified atmosphere. The same medium (complete DMEM) was used for both cell types and contained leukemia inhibitory factor (LIF) to prevent differentiation of ES cells. Culture equipment and composition of medium and other solutions used are given in section 2.2.26.7.

\subsubsection{Feeder layer preparation}

Mouse embryonic fibroblast (MEF) cells were used as feeder cells. The role of feeder cells is to secrete factors that are required for the optimal growth of ES cells. In addition, they reduce the possibility of ES cell differentiation during culture.

The original MEF cell stocks were obtained frozen at passage 2. One vial was thawed, cultured to confluency and split 1:10 (see following section). Cells were cultured again to confluency, prepared as a single cell suspension (SCS, see following section) and frozen as two vials from one $75 \mathrm{~cm}^{2}$ flask, after being mixed with $2 \mathrm{x}$ freezing medium. Freezing took place at $-20^{\circ} \mathrm{C}$ for $1 \mathrm{~h}$, then at $-80^{\circ} \mathrm{C} \mathrm{o} / \mathrm{n}$ and finally in liquid nitrogen for long term storage. For each new experiment, one of the above vials (passage 3) was thawed, cultured, split and cultured again. Cells were then mitotically inactivated by incubating with $10 \mu \mathrm{g} / \mathrm{ml}$ mitomycin $\mathrm{C}$ in medium for $2 \mathrm{~h}$ in the incubator. Cells were washed with Dulbecco's PBS (DPBS), prepared as a SCS and distributed into flasks or dishes, depending on the application (see following sections). These were always gelatin-coated by incubating with $0.1 \%$ gelatin in D-PBS for 30-60 min.

\subsection{2 Preparation of cells as a single cell suspension (SCS)}

MEF and ES cells were always prepared as a SCS, in order to be split, to be frozen, before electroporation and before blastocyst injection. The medium was removed, cells were washed with D-PBS and $0.25 \%$ trypsin/ $1 \mathrm{mM}$ EDTA $\cdot \mathrm{Na}_{2} \cdot 2 \mathrm{H}_{2} \mathrm{O}$ was added in an amount just enough to cover the bottom of the flask or dish. After a short incubation at $37^{\circ} \mathrm{C}$ to help dettaching of cells, medium (at least $2 \mathrm{x}$ as much as trypsin/EDTA) was added in order to inactivate trypsin. Cells were then pipetted against the bottom of the flask or the dish several times to break cell 
clumbs and used as a SCS. Optionally, cells were transferred to a $15 \mathrm{ml}$ tube, centrifuged at $200 \mathrm{~g}$ for $5 \mathrm{~min}$ at RT and resuspended in medium or D-PBS, depending on the application.

\subsubsection{Electroporation}

ES cells were thawed at passage 10 and cultured on $25 \mathrm{~cm}^{2}$ flasks with inactivated MEF cells to subconfluency. They were split 1:4 and cultured again to subconfluency. Cells were prepared as a SCS in D-PBS and used for electroporation (cells from one flask for each electroporation). 60-100 $\mu \mathrm{g}$ of targeting vector DNA were linearized with NotI, extracted $2 \mathrm{x}$ with phenol/chloroform, $2 \mathrm{x}$ with chloroform and precipitated with sodium acetate and ethanol. DNA was washed $2 \mathrm{x}$ with $70 \%$ ethanol, to remove salts and to be "sterilized", and resuspended in D-PBS. ES cells and DNA were mixed in an electroporation cuvette. The mixture was charged at $500 \mu \mathrm{F}$ capacitance, $230 \mathrm{~V}$ voltage, transferred directly to $29 \mathrm{ml}$ of medium and distributed into 2x $100 \mathrm{~mm}$ dishes with inactivated MEF cells.

\subsubsection{Selection}

Cells were cultured for 11 days, changing the medium once or twice a day. From day 1 (the day following that of electroporation) to day 9, positive selection was applied by including geneticin (G418 sulfate) in the medium at a final concentration of the active compound 190 $\mu \mathrm{g} / \mathrm{ml}$. Geneticin is an analogue of neomycin; therefore, under its selection, only cells with a $n e o^{R}$ gene intergrated in their genome survive. By this means, all recombinant clones are selected. However, also non-homologous recombinant clones are included. In order to enhance selection for homologous recombinant ones, negative selection was also carried out from day 3 to day 5, incuding ganciclovir in the medium at final concentration $0.25 \mu \mathrm{M}$. Ganciclovir acts as a substrate of thymidine kinase (TK), resulting in a toxic product. A $2 \mathrm{x}$ TK sequence had been cloned in the targeting vectors, right next to the targeting sequence. Therofore, non-homologous recombinant clones would contain the $2 \mathrm{x}$ TK sequence, leading them to die in the presence of ganciclovir. However, negative selection is not very efficient and a lot of the surviving clones are usually non-homologous recombinant. 


\subsubsection{Analysis of positive clones}

Positive clones were picked up under the microscope, using pipette tips, prepared as a SCS and plated on 2x 96-well dishes with inactivated MEF cells. Cells were cultured to subconfluency. Cells from one of the 96-well dishes (masterplate) were prepared as a SCS, mixed with $2 \mathrm{x}$ freezing medium, overlayed with mineral oil and frozen at $-80^{\circ} \mathrm{C}$. Freezing took place in a styrofoam box, thereby allowing a slow decrease in temperature. The other 96well dish was used for DNA preparation. Cells were split 1:2, plated on gelatin-coated 96well dishes and cultured to subconfluency. MEF cells were not included in the dishes, since these cells would be used only for preparation of DNA and their optimal survival and undifferentiated status were not very important. Cells were lysed with lysis buffer at $60^{\circ} \mathrm{C} \mathrm{o} / \mathrm{n}$ and DNA was precipitated with ethanol and $\mathrm{NaCl}$. DNA was digested with the appropriate enzymes at $37^{\circ} \mathrm{C} \mathrm{o} / \mathrm{n}$ and analyzed by Southern blot. Handling of all solutions in 96-well dishes was carried out with the help of a multi-pipette, accomodating 8 tips.

\subsubsection{Preparation of embryonic stem cells for blastocyst injection}

After Nph3-KI recombinant clones were identified, the cells of their corresponding wells of the masterplate were thawed on 24-well plates with inactivated MEF cells (cells from one 96well into one 24-well). Cells were cultured, split and cultured again. Part of the cells were used for DNA preparation and analysis, in order to confirm the initial results. The rest of the cells were frozen as one vial from one well of a 24-well plate. After DNA analysis, cells from one vial were thawed, plated on one well of a 24-well plate with inactivated MEF cells, cultured briefly to subconfluency, prepared as a SCS and used for blastocyst injections in one day. Injections were carried out for two days for each of the Nph3-KI clones (\#59, \#73).

\subsubsection{Culture equipment and solutions}

\section{$\underline{\text { Culture equipment }}$}

MEF cells

ES cells before electroporation

Selection

Expansion of positive clones

Expansion of Nph3-KI recombinant clones

Preparation of clones for injection
$75 \mathrm{~cm}^{2}$ flasks

$25 \mathrm{~cm}^{2}$ flasks

$100 \mathrm{~mm}$ dishes

96-well plates

24-well plates

24-well plates 
DMEM was prepared by dissolving $13.38 \mathrm{~g}$ DMEM powder (amount for 11 ) and $2.3 \mathrm{~g}$ sodium bicarbonate in 1.081 of $\mathrm{dH}_{2} \mathrm{O}$. The preparation of medium in total volume of 1.081 and not in 11 , is essential for the adjustment of its osmolarity to 290 mosmo, which is optimal for the culture of ES cells. The medium was sterile filtered into 2x $500 \mathrm{ml}$ filter units and stored at $4^{\circ} \mathrm{C}$.

\begin{tabular}{|lr|}
\hline \multicolumn{2}{|c|}{ Complete DMEM preparation } \\
DMEM & $500 \mathrm{ml}$ \\
FCS & $95 \mathrm{ml}$ \\
MEM-non essential amino acids & $6 \mathrm{ml}$ \\
$\beta$-mercaptoethanol solution & $6 \mathrm{ml}$ \\
$(7 \mu 1 \beta$-mercaptoethanol in $10 \mathrm{ml}$ PBS $)$ & \\
penicillin $(10000$ units $/ \mathrm{ml}) /$ streptomycin $(10000 \mu \mathrm{g} / \mathrm{ml})$ & $3.3 \mathrm{ml}$ \\
LIF $\left(10^{7}\right.$ units $\left./ \mathrm{ml}\right)$ & $63 \mu \mathrm{l}$ \\
\hline
\end{tabular}

Complete DMEM was stored at $4{ }^{\circ} \mathrm{C}$ for up to one week and warmed up to RT before use. Its $\mathrm{pH}$ was not taken into account, since it would be adjusted to 7.4 under culture conditions.

$\underline{2 \mathrm{x} \text { freezing medium }}$
$60 \%$ complete DMEM
$20 \%$ FCS
$20 \%$ DMSO

\begin{tabular}{|c|}
\hline Lysis buffer \\
$10 \mathrm{mM} \mathrm{Tris,} \mathrm{pH} 7.5$ \\
$10 \mathrm{mM} \mathrm{EDTA} \cdot \mathrm{Na}_{2} \cdot 2 \mathrm{H}_{2} \mathrm{O}$ \\
$10 \mathrm{mM} \mathrm{NaCl}$ \\
$0.5 \% \mathrm{~N}-$ lauroylsarcosine, sodium salt \\
$0.1 \%$ proteinase $\mathrm{K}$ \\
\hline
\end{tabular}

\subsubsection{Preparation of mouse brains for cryostat sectioning}

For morphological applications on mouse brains, the brain was fixed and cryoprotected. Preparation methods varied, according to the age of the mouse and the desired fixation.

Mice at age day 3 (P3) or older were anaesthetized with chloroform and perfused. By perfusion, the blood of the animal is removed and the whole mouse body is fixed. PBS was used to remove the blood. For the majority of applications, 4\% paraformaldehyde in $0.1 \mathrm{M} \mathrm{PB}$ was used for fixation. As an alternative, acid fiaxtion was applied by using $4 \%$ formaldehyde, $0.9 \% \mathrm{NaCl}, 0.5 \% \mathrm{ZnCl}_{2}$ in $\mathrm{dH}_{2} \mathrm{O} .1-4 \mathrm{ml}$ of each of PBS and fixative were used, according to the age of the mouse, i.e. for older mice higher amounts were used. After perfusion, the brain was collected, kept in fixative at RT for $2 \mathrm{~h}$ and then in $25 \%$ sucrose at RT o/n. The sucrose incubation (cryoprotection) protects the brain from the low temperatures used in cryostat sectioning, by increasing its osmolarity.

New-born mice (P1) and mouse embryos were not perfused, due to the small size of the animal. The head of P1 mice was dissected, the skin was removed and the rest of the head was 
fixed by incubation in 2\% paraformaldehyde in $0.1 \mathrm{M}$ PB at RT for $2 \mathrm{~h}$. The head was cryoprotected with $25 \%$ sucrose at RT o/n. For preparation of mouse embryos, the mother was sacrificed by cervical dislocation and embryos were collected. Whole embryos were fixed in 2\% paraformaldehyde in $0.1 \mathrm{M} \mathrm{PB}$ at RT for $2 \mathrm{~h}$ and cryoprotected with $25 \%$ sucrose at RT o/n. In embryos and P1 mice, outer tissues are quite soft and, given the small size of the animal, fixative can easily penetrate them and reach the brain.

When not used immediately after cryoprotection, brains, P1 heads or embryos were kept in $25 \%$ sucrose at $4{ }^{\circ} \mathrm{C}$.

\subsubsection{Cryostat sectioning}

Brains were covered with embedding resin (cryomatrix) and frozen at $-40^{\circ} \mathrm{C}--50^{\circ} \mathrm{C}$. After freezing, they were equilibrated at $-13^{\circ} \mathrm{C}$. Sectioning was carried out with chamber temperature $-15^{\circ} \mathrm{C}$ and object temperature $-13^{\circ} \mathrm{C}$. Sagittal or coronal sections were cut. For most immunohistochemical applications, as well as for Nissl staining and for double ( $\beta$ galactosidase/antibody) staining, $30 \mu \mathrm{m}$ sections were cut. $60 \mu \mathrm{m}$ sections were cut for $\beta$ galactosidase staining. Sections from P3 or older mice were collected in PBS and further assayed in free-floating form, unless otherwise stated. Sections from P1 mice and embryos, due to the softness of tissue, were mounted directly on $0.01 \%$ poly-L-lysine coated glass slides and assayed on them. Sections used for Nissl staining were collected in PBS, mounted on $0.01 \%$ poly-L-lysine coated glass slides with $0.5 \%$ gelatin and further assayed. For poly-Llysine treatment, slides were incubated with $1 \mathrm{M} \mathrm{HCl}$, washed 4 times with $\mathrm{dH}_{2} \mathrm{O}$, incubated with ethanol for $30 \mathrm{~min}$ and air-dried. They were then dippped in $0.01 \%$ poly-L-lysine, airdried o/n and stored at $4^{\circ} \mathrm{C}$. Poly-L-lysine coating strengthens attachment of sections on the slide.

\subsection{9 $\beta$-Galactosidase staining of mouse brain sections}

$\beta$-Galactosidase staining was performed on brain sections from Nph3-KI mice to reveal the expression pattern of Nph3 in the brain. Sections were washed twice with PBS and incubated with the Xgal staining solution (see section 2 . 2 . 25 . 4) at $37^{\circ} \mathrm{C}$ for 2 days. Sections were washed with PBS and free-floating sections were mounted on glass slides with $0.5 \%$ gelatin. Mounted sections were dehydrated with 1 min incubations in 50\%,70\%,90\%, 100\% ethanol and 2-5 min in xylene and embedded with xylene-based mounting medium (Entellan). 


\subsubsection{Immunohistochemistry}

Immunohistochemical staining was carried out on Nph3-KI mouse brain sections in order to localize the Nph3-Flag fusion protein. The protocol followed was based on DAB immunodetection (see section 2 . 2 . 25.6). The general protocol is given below. However, this protocol was quite often modified in one or more of its parameters, or slightly different protocols were applied in parallel, in an attempt to optimize staining. These modifications are described below.

General protocol

- PBS washing

- Quenching: $10 \%$ methanol, $3 \% \mathrm{H}_{2} \mathrm{O}_{2}$, in PBS at RT for 15 min. Quenching eliminates erythrocyte peroxidase activity.

- PBS washing

- $0.5 \%$ TritonX100 in PBS at RT for $15 \mathrm{~min}$

- PBS washing

- Blocking: $20 \%$ NGS in PBS at RT for 2-4 h

- Primary antibody: $0.1 \%$ TritonX100, in block at $4{ }^{\circ} \mathrm{C} \mathrm{o} / \mathrm{n}$ (see results section for concentrations used)

- PBS washing

- Secondary antibody: $1: 100,0.1 \%$ TritonX100, in block at $37^{\circ} \mathrm{C}$ for $30 \mathrm{~min}$

- PBS washing

- Third antibody: $1: 400,0.1 \%$ TritonX100, in block at $37^{\circ} \mathrm{C}$ for $1 \mathrm{~h}$

- PBS washing

- DAB staining

- PBS washing

Free-floating sections were mounted on glass slides with $0.5 \%$ gelatin. Mounted sections were dehydrated and embedded, as described in the previous section.

\section{Modifications}

- No quenching.

- $1 \%$ or no TritonX100, instead of $0.5 \%$.

- $50 \%$ NGS for blocking, instead of $20 \%$. Also in antibody incubations.

- 10\% BSA for blocking, when goat primary antibodies were used. Also in antibody incubations.

- Blocking at $4^{\circ} \mathrm{Co} / \mathrm{n}$.

- Primary antibody incubation at $37^{\circ} \mathrm{C}$ for $4 \mathrm{~h}$.

- No Triton in antibody incubations. 


\subsubsection{Double staining for $\beta$-galactosidase and antibody}

In order to characterize further the Nph3-expressing cells in the neocortex and the hippocampus of Nph3-KI mice, double staining of Nph3-KI mouse brain sections was carried out for $\beta$-galactosidase and reelin or calretinin. Staining was carried out using fluorescent secondary antibodies, instead of $\mathrm{DAB}$ immunodetection. The procedure followed is a combination of the protocols described in the two previous sections. Cryostat sections were mounted directly on $0.01 \%$ poly-L-lysine coated glass slides, washed with PBS, incubated with the Xgal staining solution at $37^{\circ} \mathrm{C}$ for $4 \mathrm{~h}$, washed again with PBS and incubated with $0.5 \%$ TritonX100 for $10 \mathrm{~min}$. Sections were washed with PBS, blocked with $10 \%$ BSA for 2 $\mathrm{h}$ at RT and incubated with the first antibody at $4^{\circ} \mathrm{C} \mathrm{o} / \mathrm{n}$. Sections were washed with PBS, incubated with the secondary antibody (1:300) at RT for $45 \mathrm{~min}$, in the dark, and washed with PBS extensively, in the dark. Sections were embedded with a mounting system, optimal for fluorescence staining (ProLong Antifade Kit).

\subsubsection{Nissl staining}

Nissl staining was performed on Nph3-KO mouse brain sections, as well as on wild type (WT) sections, as control, in order to visualize the gross morphology of the Nph3-KO brain, as the first step for the analysis of the line. By this method, the rough endoplasmatic reticulum of the cell bodies of neurons is stained. Sections were mounted as described in section 2. 2 . 28 and dried at $37^{\circ} \mathrm{C}$ for $1-2$ days. Sections were incubated in $11 \%$ diethyl ether, $11 \%$ ethanol, $78 \%$ chloroform for 7-10 min. They were then hydrated by dipping twice in an reducing ethanol solution series $(100 \%, 70 \%, 50 \%)$ and finally in $\mathrm{dH}_{2} \mathrm{O}$. Sections were incubated in $0.1 \%$ cresyl violet acetate, $1 \%$ acetic acid for $4-7 \mathrm{~min}$ and then dehydrated by dipping once in the above ethanol $/ \mathrm{dH}_{2} \mathrm{O}$ series, backwards. Sections were further dehydrated in xylene for 5 min and embedded with xylene-based mounting medium. Respective Nph3-KO and WT sections (e.g. far lateral) were stained together.

\subsubsection{Preparation of total brain extract}

Protein extracts were prepared from brains of Nph3-KI and WT mice and were analyzed by western blot, using anti-Flag antibodies. Mice were sacrificed by cervical dislocation and the brain was collected and homogenized in $2 \mathrm{ml}$ of homogenization buffer (see below) with a 
polytron for $1 \mathrm{~min}$. Cells were lysed by the addition of a similar, detergent-containing buffer (see below) and incubation at $4^{\circ} \mathrm{C}$ for $1 \mathrm{~h}$. Cellular debris were removed by centrifugation in an ultracentrifuge at $170000 \mathrm{~g}$ at $4^{\circ} \mathrm{C}$ for $30 \mathrm{~min}$. The supernatant (total brain extract) was recovered and aliquots were shock-frozen in liquid nitrogen and kept at $-80^{\circ} \mathrm{C}$. Samples were loaded on SDS-PAGE gels.

Buffers used:

Homogenization buffer
10 mM HEPES, pH 7.4
1 mM EGTA
protease inhibitors

\begin{tabular}{|c|}
\hline$\underline{\text { Lysis buffer }}$ \\
10 mM HEPES, pH 7.4 \\
1 mM EGTA \\
protease inhibitors \\
$0.2 \mathrm{M} \mathrm{NaCl}$ \\
$2 \%$ Igepal CA-630 \\
\hline
\end{tabular}

\section{2 . $2.34 \alpha$-Latrotoxin binding assay of mouse brain extracts}

In order to confirm the absence of Nph1 and Nph3 in the brain of double Nph1/Nph3-KO mice, brain extracts from the above lines were assayed by an $\alpha$-latrotoxin binding assay, together with extracts from WT and Nph3-KO mouse brains as controls. This assay (modified from Missler et al., 1998) is based on the binding of Nph1 and Nph3 to $\alpha$-neurexins, which in turn bind to $\alpha$-latrotoxin.

Mice were sacrificed by cervical dislocation and the brain was collected and homogenized in $7 \mathrm{ml}$ of a Tris-homogenization buffer (see below) with a polytron for $1 \mathrm{~min}$. Cells were lysed by the addition of TritonX100 to $2 \%$ final concentration and incubation at $4{ }^{\circ} \mathrm{C}$ for $1 \mathrm{~h}$. Cellular debris was removed by two centrifugation steps, first at $3200 \mathrm{~g}$ at $4{ }^{\circ} \mathrm{C}$ for $10 \mathrm{~min}$ and then in an ultracentrifuge at $170000 \mathrm{~g}$ at $4^{\circ} \mathrm{C}$ for $30 \mathrm{~min}$. The supernatant was recovered and TritonX100 concentration was adjusted to $1 \%$ by the addition of an equal volume of the above buffer. $400 \mu 1$ of $50 \%$ slurry of CNBr-activated sepharose beads with immobilized $\alpha$ latrotoxin were equilibrated with the above buffer, containing $1 \%$ Triton, by incubating $3 \times 5$ min, at $4^{\circ} \mathrm{C}$. Beads were collected by centrifugation at $1000 \mathrm{~g}$, at $4{ }^{\circ} \mathrm{C}$ for $1 \mathrm{~min}$ after each incubation and finally resuspended in the same buffer, in a total volume of $600 \mu$. Each of the lysate supernatants was incubated with $150 \mu \mathrm{l}$ of equilibrated beads at $4^{\circ} \mathrm{C} \mathrm{o} / \mathrm{n}$. Beads were collected, washed $3 \times 5 \mathrm{~min}$ at $4^{\circ} \mathrm{C}$ with the same buffer and resuspended in $2 \mathrm{x}$ sample buffer (see section 2.2 . 21). Resuspended beads were heated at $100^{\circ} \mathrm{C}$ for $5 \mathrm{~min}$ and centrifuged at $14000 \mathrm{~g}$ for $1 \mathrm{~min}$. Supernatants, containing eluted proteins, were recovered and analyzed by western blot. 


\section{$\underline{\text { Homogenization buffer }}$}

$20 \mathrm{mM}$ Tris, $\mathrm{pH} 7.5$

$80 \mathrm{mM} \mathrm{NaCl}$

$2.5 \mathrm{mM} \mathrm{CaCl}_{2} \cdot 2 \mathrm{H}_{2} \mathrm{O}$

$100 \mu \mathrm{g} / \mathrm{ml}$ PMSF

\subsubsection{Mouse husbandry}

Mouse husbandry procedures were carried out according to institutional and ethical guidelines for animal treatment, in a facility of the ZTE, Göttingen (Zentrale Tierexperimentelle Einrichtungen, Göttingen, director: Dr. Klaus Nebendahl). Mice were kept in cages with pellet food and water at libidum, in a room with standard temperature and humidity $\left(21 \pm 0.5^{\circ} \mathrm{C}, 55-75 \%\right)$, in a $12 \mathrm{~h}$-light, $12 \mathrm{~h}$-dark cycle. They were weaned at 3-4 weeks of age and a small tail sample was collected for genotyping. An ear-punching numbering identification system was applied. Injections of ES cells into mouse blastocysts, blastocyst transplantations and initial husbandry of the resulted chimaeric mice were carried out at the animal house of the Max Planck Institute for Experimental Medicine, Göttingen, under supervision of Dr. Herman Riedesel. Injected blastocysts derived from the C57B16/J line.

\subsubsection{DNA database search}

DNA databases were searched in order to find new neurexophilin protein sequences in various animals or to complete already known sequences. The searches were performed using the internet site of the National Centre for Biotechnology Information, USA (URL: http://www.ncbi.nlm.nih.gov). Two types of searches were carried out: GenBank search and Basic Local Alignment Search Tool (BLAST) search. In the GenBank database (National Institutes of Health, Bethesda, Maryland, USA), DNA sequences are annotated and if a potential protein sequence shows similarity with an already known protein, this is indicated in the name of the submitted sequence. Therefore, for the current study, a search for "neurexophilin" was performed. BLAST search of a database (Altschul et al., 1990) is carried out using a DNA or protein sequence as a query and results in the identification of sequences with significant homology to that of the query sequence or of a part of it. A DNA database can be searched also with a protein sequence (translated nucleotide database search), thus enabling identification of similar protein sequences (e.g. of different protein isoforms) that are derived from not significantly similar DNA sequences. The following genome databases were 
searched with neurexophilin sequences, using the BLAST set of programmes: Homo sapiens (International Human Genome Sequencing Consortium, 2001), Rattus norvegicus (unpublished), Fugu rubripes (unpublished), Drosophila melanogaster (Adams et al., 2000) and Caenorhabditis elegans (The C. elegans Sequencing Consortium, 1998). The sequences obtained from the searches were analyzed on a Macintosh computer, using Lasergene software (DNASTAR). 


\section{3 .1 Cloning and characterization of the mouse neurexophilin 3 gene}

The basis of all neurogenetic approaches is the detailed knowledge of the gene that is going to be used. If the gene has not already been cloned, its cloning is the first step that needs to be performed. Based on the properties of the genomic DNA and especially the position of its exons and its restriction map, a cloning strategy can be designed for the construction of the required vector that will be used as the tool of the neurogenetic approach. With respect to the current study, the Nph1 mouse gene had already been cloned and characterized (Petrenko et al., 1996). The Nph3 gene, however, was not already cloned. Therefore, the current study initiated with cloning and characterization of the mouse Nph3 gene.

\subsubsection{Screening and restriction enzyme analysis of neurexophilin 3 genomic clones}

A mouse genomic library was screened with a $570 \mathrm{bp}$ NheI-SfiI fragment from rat Nph3 cDNA (see appendix 2). Five positive plaques were identified from the primary library screening. They were re-plated and subjected to secondary screening by picking two individual plaques from each initial plaque and plating them again. One out of the two plaques was further used for elution and DNA isolation.

DNA was digested with NotI, which is an enzyme of the bacteriophage linker flanking the cloned insert and therefore is suitable for excision of the insert for further cloning. Digested DNA was cloned to pBluescript II SK following a "shot-gun" approach, i.e. without separating the individual fragments. One colony from plaque 1 and six colonies from each of the other plaques were collected and used for miniprep DNA isolation. Purified DNA from all minipreps was digested with NotI and used for Southern blot using the same probe that was used for library screening (figure 3).

A $1.6 \mathrm{~kb}$ band was present in some of the clones and is probably the result of the presence of an internal NotI site in the clones that was not digested. Almost half of the clones were positive. The rest corresponded to cloned fragments that were derived either from $\lambda$ bacteriophage DNA or from cloned library sequences that do not contain the probe sequence (if there was an internal NotI site in the original clone). 
A

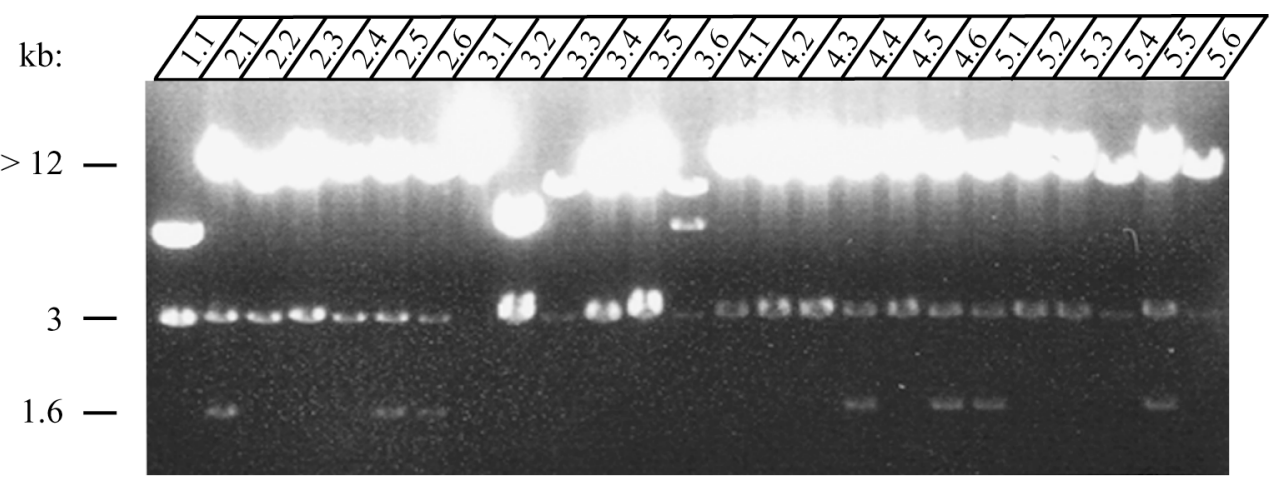

B $\mathrm{kb}$ :

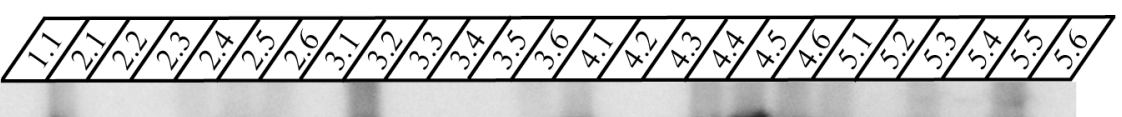

$>12-$

Figure 3 Screening of genomic clones. A Plasmid DNA, representing pieces of genomic DNA, was digested with NotI and electrophoresed in a $0.8 \%$ agarose gel. The number of each clone is given on the top of the picture. The DNA size was estimated by comparison to a DNA standard sample included in the gel, containing DNA fragments of known size. The size of the main DNA bands on the gel are shown on the left of the picture in $\mathrm{kb}$. The $3 \mathrm{~kb}$ band, that is present in almost all samples represents the pBluescript II SK backbone, in which the $\lambda$ bacteriophage genomic clones have been cloned. The $1.6 \mathrm{~kb}$ band in some of the samples is probably the result of an internal NotI site in the genomic clone that was not digested during cloning into pBluescript II SK (partial digestion). B Southern blot analysis of the above gel revealed a positive signal for about half of the clones. 
Clones 2.1, 3.2, 4.1 and 5.1 were amplified by maxiprep and subjected to restriction analysis. Clones 4 and 5 were found to be almost identical to clone 2 and clone 3 to be part of clone 2 . Clones 2 and 3 were subjected to further restriction analysis. All agarose gels used for restriction analysis were also used for Southern blot using the same probe that was used for screening, in order to locate the (probably second) exon of the gene. The Southern blot results provided the means for the location of the exon to which the probe sequence belongs. The $\sim 2$ kb PstI-KpnI DNA sequence (see figure 4), that was found to include the exon was subcloned into pBluescript II SK and used for DNA sequencing. The complete sequence of the exon was obtained with its predicted protein sequence to share $99 \%$ homology with the respective rat Nph3 cDNA sequence.

It was also verified that, as in the case of the Nph1 and Nph2 genes (Petrenko et al., 1996), there are more than one exons in the $\mathrm{Nph} 3$ gene, since the sequence encoding for the $\mathrm{N}$ terminal 18 amino acids of the rat cDNA was not contained in the mouse sequence obtained. Further Southern blot analysis was carried out, using an oligonucleotide probe hybridizing to the missing region, in order to search for the first exon(s) in the cloned sequence. This resulted in the location of the first exon(s) in the 5' region of both clones analyzed (clones 2 and 3). By DNA sequencing the first exon was further located, showing 100\% homology with the respective rat cDNA sequence at the protein level.

The restriction enzyme maps of both clones, including the position of the two exons, are shown in figure 4 . The predicted amino acid sequence of the full length protein is given in figure 5, in alignment with the full length Nph3 rat cDNA sequence. The assembled mouse genomic DNA sequence of the two exons is given annotated in appendix 1. 
Figure 4 Restriction map of neurexophilin 3 genomic clones. Nph3 genomic clones were analyzed by restriction endonuclease digestions. Endonucleases with recognition sequences of 6 or more base pairs were used, since recognition sequences of less than 6 base pairs usually occur very frequently in the genome and therefore the respective endonuclease is of low importance in cloning procedures. The strong dark lines represent the genomic clones and the blue lines part of the pBluescript II SK polylinker sequence. Red boxes indicate the position of the two exons. The restriction sites of most of the endonucleases tested are shown on top of the dark lines in abbreviations. For clarity reasons, not all endonucleases tested are shown. Restriction sites in green represent sites derived from the $\lambda$ bacteriophage linker. Note that the NotI site just upstream of the first exon is shown in black, respresenting an internal (endogenous) NotI site of the genomic clones. A ruler indicating distances in $\mathrm{kb}$ is given below each clone. Grey boxes indicate areas of the genomic clones that were sequenced. $*=$ stop codon, restriction site abbreviations: $\mathrm{KI}=\mathrm{KpnI}, \mathrm{BHI}=$ BamHI, NtI $=$ NotI, $\mathrm{SI}=$ SalI, PI = PstI, NI = NcoI, HIII = HnidIII, BII = BglII, XI = XhoI, MI = MluI, $\mathrm{NhI}=$ NheI, NdI $=$ NdeI, SpI $=$ SpeI, ERI $=$ EcoRI, ScII $=$ SacII. Endunucleases with no restriction sites in both clones: AgeI, BstBI, ClaI, EcoRV, NsiI, PvuI, SfiI. Endonucleases with no restriction sites only in clone Nph3-3: NheI, SpeI, EcoRI, BamHI, MluI, NdeI. Endonucleases with restriction sites in both clones that are not shown: BstEII, SacI. Endonuclease with restriction site only in clone Nph3-2 that is not shown: BamHI. 


\section{Clone Nph3-2}
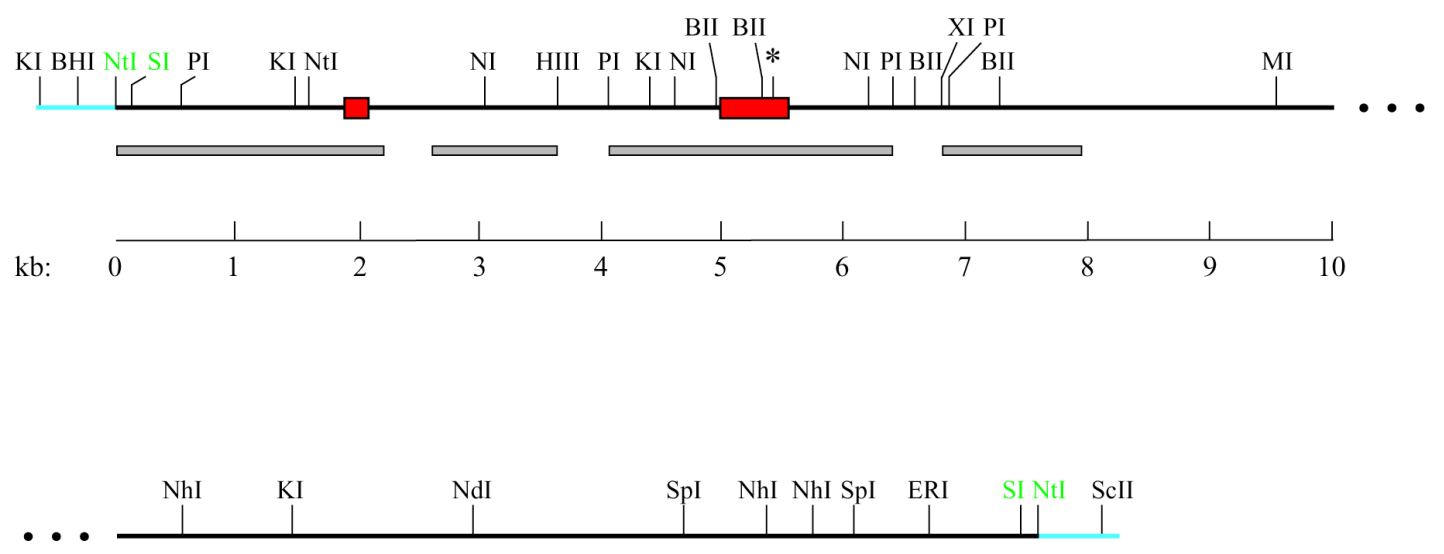

(continued)

$\mathrm{kb}$ :

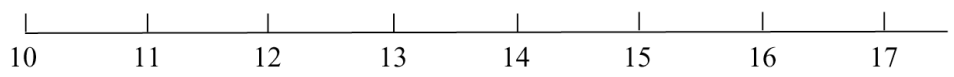

Clone Nph3-3

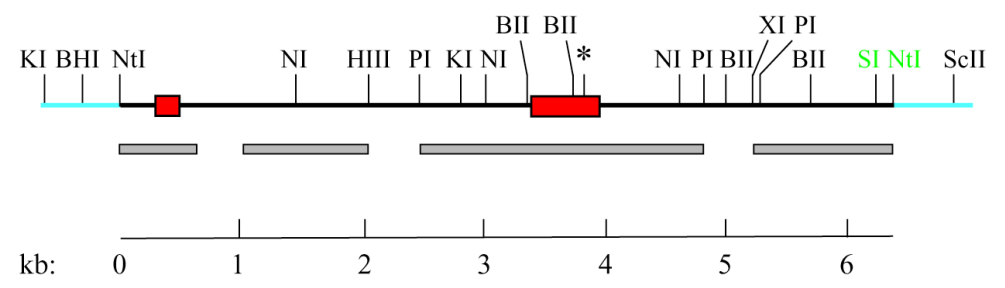


Rat MQLTRCCFVFLVQGSLYLICGQEDGPPGSEDPEHDDHEGQPRPRVPRKRGHISPKSRPLANS 63

Mouse MQLTRCCFVFLVQGSLYLVICGQDDGPPGSEDPEHDDHEGQPRPRVPRKRGHISPKSRPLANS 63

Rat TLLGLLAPPGEVWGILGQPPNRPKQSPLPSTKVKKIFGWGDFYSNIKTVALNLLVTGKIVDHG 126

Mouse TLLGLLAPPGEVWGVLGQPPNRPKQSPLPSTKVKKIFGWGDFYSNIKTVALNLLVTGKIVDHG 126

Rat NGTFSVHFRHNATGQGNISISLVPPSKAVEFHQEQQIFIEAKASKIFNCRMEWEKVERGRRTS 189

Mouse NGTFSVHFRHNATGQGNISISLVPPSKAVEFHQEQQIFIEAKASKIFNCRMEWEKVERGRRTS 189

Rat LCTHDPAKICSRDHAQSSATWSCSQPFKIVCVYIAFYSTDYRLVQKVCPDYNYHSDTPYYPSG 252

Mouse LCTHDPAKICSRDHAQSSATWSCSQPFKVVCVYIAFYSTDYRLVQKVCPDYNYHSDTPYYPSG 252

Figure 5 Comparison of the primary structure of rat and mouse neurexophilin 3. The amino acid sequences of rat and mouse Nph3 were deducted from the rat cDNA and the exons of the mouse genomic DNA sequences respectively. Amino acids are shown in single letter code. Numbers on the right indicate amino acid position. The two proteins are almost identical, with differences in only three amino acids, shown on green background.

\subsubsection{Evolutionary conservation and structure comparison of neurexophilins}

An interesting question, with respect to the putative modulatory signaling function of neurexophilins, is in which species they exist. Addressing this question could shed light upon how neurexophilins have been evolved and possibly provide clues about their role in the central nervous system. Since neurexophilins form a family of four isoforms, evaluation of the existence and the structure of each isoform in various species could also provide useful information regarding the individual properties of each isoform.

The last two years have seen the release of massive sequencing information from various genome projects or from individual laboratories. Based on this information, DNA database searches were performed in order to identify new neurexophilin sequences. Neurexophilins were previously found as genomic, cDNA or expressed sequence tag clones in the human, cattle, rat and mouse (summarized in Missler and Südhof 1998). GenBank search in the current study revealed the existence of neuroxophilins also in the monkey, as well as in the zebrafish, which is a powerful model organism to study vertebrate developmental biology. BLAST search of the pufferfish genome (unpublished) showed that neurexophilins are also present in this organism. Pufferfish is a very interesting organism, since it has the smallest vertebrate genome but with a similar gene content with other vertebrates, which renders it 
very useful in studies of gene validation (Venkatesh et al., 2000). BLAST search of the Drosophila melanogaster genome (Adams et al., 2000) and the Caenorhabditis elegans genome (The C. elegans Sequencing Consortium, 1998) databases failed to identify a neurexophilin homolog (data not shown). The above results indicate that neurexophilins only exist in vertebrate and are absent in invertebrate species. This is in contrast with their binding partners, $\alpha$-neurexins, an isoform of which exists also in Drosophila melanogaster and Caenorhabditis elegans, as revealed by DNA database search (mRNA sequences, accession numbers: NM_079725, NM_073366 respectively). This indicates that neurexophilins were evolved separately from neurexins and possibly appeared in evolution as modulators of the function of neurexins.

The results of the DNA database searches for neurexophilins together with those from BLAST search of the human genome (International Human Genome Sequencing Consortium, 2001) and the rat genome (unpublished) databases, as well as the Nph3 mouse sequence obtained in the current study provided the means for a new alignment map of the primary structure of neurexophilins in various organisms (figure 6, based on Missler and Südhof, 1998).

Figure 6 Primary structure of neurexophilins. The amino acid sequences of neurexophilins from various organisms are aligned for maximal homology, based on the Clustal V method, with hyphens indicating gaps. Amino acids are shown in single letter code. Numbers on the right indicate amino acid position. Residues that are identical in all four isoforms are shown on red background and residues that are identical in at least two isoforms are shown on blue background. The three sequences on the bottom of the figure represent the elongated linker sequence of Nph4. The putative signal peptide sequence is shown in italics. H.sap. = Homo sapiens (human), M.mul. = Macaca mulatta (monkey), R.nor. $=$ Rattus norvegicus (rat), M.mus. $=$ Mus musculus (mouse), D.rer. $=$ Danio rerio (zebrafish), F.rub. $=$ Fugu rubripes (pufferfish), B. tau. $=$ Bos taurus (cattle). $\mathrm{V}=$ predicted cleavage site, $\mathrm{Y}=$ conserved $\mathrm{N}$-glycosylation sites. The six conserved cysteines that characterize the $\mathrm{C}$-terminal domain are indicated with asterisks. 
H.sap. MQAACWYVLFLLQPTVYLVTCANLTNGGKSELLKSGSSKSTLKHIWTESSKDLSISRLLSQTFRGKENDTDLDLRYDTPEPYSEQDLWDWLRNSTDL 97 M.muT.

Nph1 R.nor. MQAACWYVLLLLQPTVYLVTCANLTNGGKSELLKSGNSKSTLKHIWTESSKDLSISRLLSQTFRGKENGTDLDLRYDTPEPYSEQDLWDWLRNSTDL M.mus. VTCANLTNGGKSELLKSGSSKSTLKHIWTESSKDLSISRLLSQTFRGKENDTDLDLRYDTPEPYSEQDLWDWLRNSTD D.rer. F.rub. MRATCWCAVFLLTPALYLVSSAHGSVPGKSELLKGSPKSTLKHIWTESSKDLS I SRLLSQTLHGKENATALDLHYDTPEPYSEQDLWDWLRN
KSDI IKSGSPKATVKHIWTESSKEMS ISRLLSQTLQGKENTTALDLRYDTPEPYSEKELWDWLRNSTEL

MRLRPLPLVVVPGLLQLLFCDKEVVHATEGLDWEDKDAPGTLVGNVVHSRI ISPLRLFVKQSPVPKPG - PMAYADSMENFNDWLANITEI MRLRPLPLVVVPGLLQLLFCDSEKVVHATEGLDWEDKDATGTLVGNVVHSRI I SPLRLFVKQSPVPKPG - - HLAYADSMENF NDWLANITEV

LFCDSEEVIHNTESVDWEDRTVPETLVGNLFHSRITSPLRLFVKQPPDPKPS - . - - YADNTKNFNDWLANITEI ATELI EWSDGITEEKTSPTGASPRI LNPLRLFARGSPGFKSDMREITYLQNMEDF NDWLSNQTDV

H. sap. MRLLPEWLLLLFGPWLLRKAVCGOIVESGRPOYLDLRPAMAGGGARGOQLPAPASSEGLGMARSWSWAWPANHT-

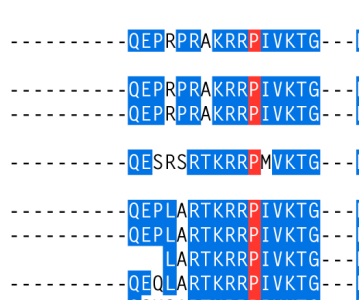

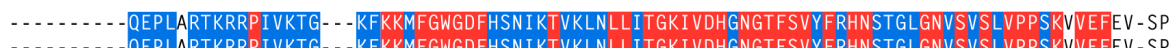
KFKKMFGWGDFHSI KTVKLNLLITGKIVDHGNGTFSVYFRHNSTGLGNVSVSLVPPSKIVEFEV-ST

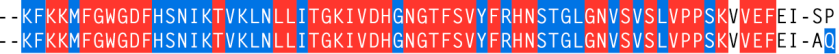

H. sap. GLLAPPGEA-WGI LGQPPNRPNHSPPPSA VVKKIFGWGDFYSNIKTVALNLLVTGKIVDHGNGTFSVHFOHNATGQGNISISLVPPSKAVEFHQ- EO

GLLAPPGEV -WGI IGQPPNRPKQSPLPSTEVKKIFGWGDFYSNI KTVALNLLVTGKIVDHGNGTFSVHFRHNATGOGNISISLVPPSKAVEFHQ-E

Nph3 R.nor.

M.mus. GLLAPPGEV - WGVLGQPPNDPKOSPLPSTKVKKIFGWGDFYSNIKTVALNLLVTGKIVDHGNGTFSVHFRHNATGQGNISISLVPPSKAVEFHQ-E F.rub.

H.sap.

M. mu7.

Nph4 R.nor. GALARPGAAGGPPVPRTKRKPSI RAA - - RAKKIFGWGDFYFRVHTLEKFLLVTGKIVDHVNGTFSVYFRHNSSSLGNLSVSIVPPSKRVEFGG-VW M. mus. GALAKPGTAGGPSVPRTKRKPSI KAA - - RAKKIFGWGDFYFRVHTLKFSLLVTGKI VDHVNGTFSVYFRHNSSSLGNLSVSIVPPSKRVEFGG-VW

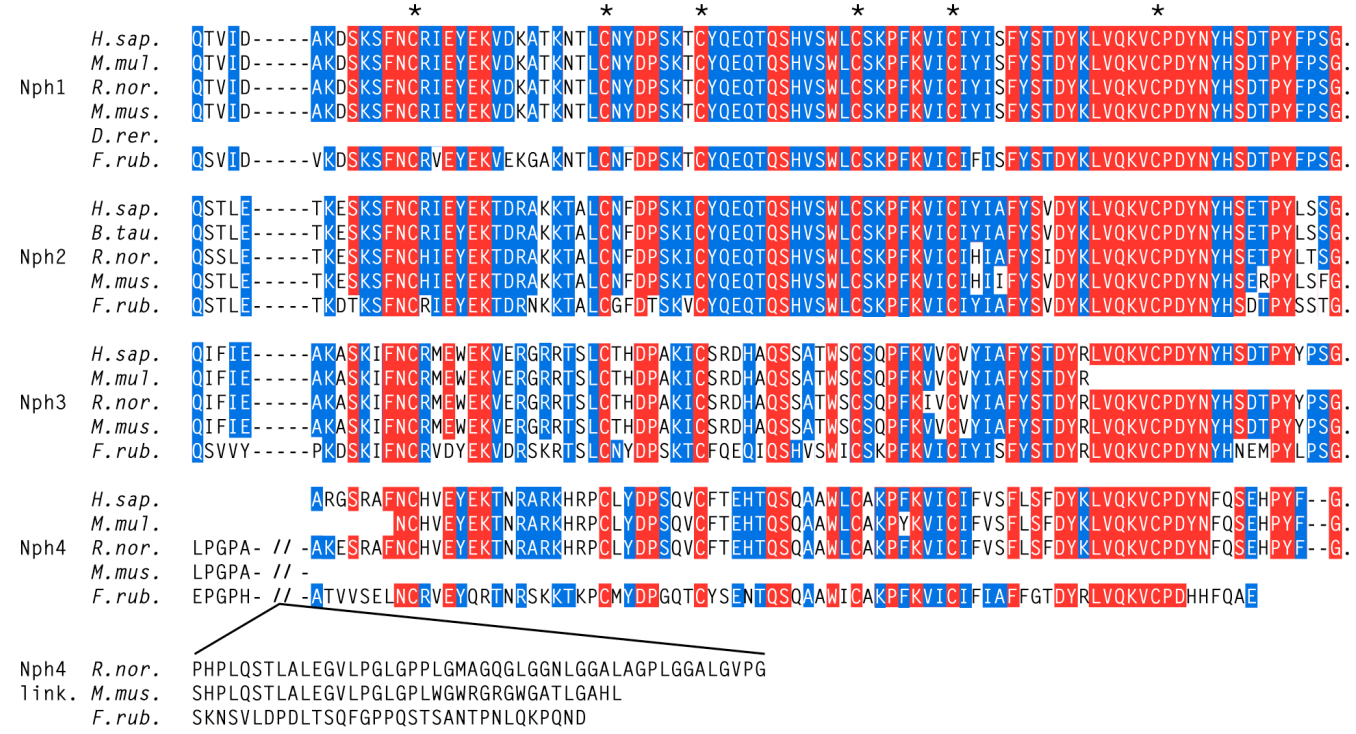


The following table summarizes the database accession numbers of the sequences used in figure 6, or other relative information (in the case of Fugu rubripes sequences, where no accession numbers were available):

\begin{tabular}{|lcccc|}
\hline & Nph1 & Nph2 & $\underline{\text { Nph3 }}$ & Nph4 \\
Homo sapiens & NT_007844 & NT_029250 & NT_010783 & AF043469 \\
Macaca mulatta & AF424833 & not found & AF424823 & AF424820 \\
Bos taurus & not found & L27868 & not found & not found \\
Rattus norvegicus & L27867 & AC094845 & AF042713 & AF042714 \\
Mus musculus & U56651 & U56650 & current study & AK004130 \\
Danio rerio & BM072575 & not found & not found & not found \\
Fugu rubripes & Scaffold_10006 & Scaffold_8040 & Scaffold_6346 & Scaffold_4023 \\
\hline
\end{tabular}

\section{2 Generation of neurexophilin 3 knock-in mice}

Previous studies on neurexophilins revealed their strong binding to $\alpha$-neurexins, in a fashion that implies a modulatory function of neurexophilins similar to that of neuropeptides (Missler and Südhof 1998, Missler et al., 1998). One of the first questions that therefore arises is which neuronal populations express the various isoforms of neurexophilins and in which areas of the brain they act by binding to $\alpha$-neurexins. In order to address this question in the case of Nph3, a transgenic mouse approach was followed, by replacing the endogenous Nph3 gene with a recombinant gene (knock-in technology). The recombinant gene was modified in a way to give rise to a bicistronic mRNA, that would encode for epiotpe-tagged Nph3, as well as for $\beta$ galactosidase fused to a nuclear localization signal. This transgenic approach, apart from providing the tool for the above study, was part of a strategy that led to the generation of Nph3-KO mice. This was based on the use of the Cre-loxP system, by including two loxP sites in the recombinant gene (see next section). The generation of Nph3-KI mouse lines, containing the recombinant Nph3 gene, was accomplished by the following series of procedures: a) a targeting vector containing the recombinant gene was constructed b) the vector was inserted into ES cells in culture and c) homologous recombinant ES cells were injected into mouse blastocysts and the blastocysts were transplanted into uteri of pseudopregnant foster mothers. The function of the targeting vector was tested in vitro by transfecting COS7 cells with expression constructs that contained parts of the targeting vector.

A similar targeting vector was also cloned for $\mathrm{Nph} 1$ and also positively tested in vitro. However, its insertion into ES cells did not result in homologous recombinant ES cell clones. 
The vector was re-cloned and inserted again into ES cells, however, without resulting in positive clones.

Nph4 was not studied by the above approach, since it does not bind to $\alpha$-neurexins (Missler et al., 1998) and, therefore, is probably not functionally correlated to the other neurexophilin isoforms. A knock-in study was not carried out for Nph2 as well, because it is not expressed in the mouse brain (Missler and Südhof, 1998).

\subsubsection{Cloning of targeting vectors}

The Nph3 targeting vector was designed in a way to lead to the generation of a bicistronic mRNA (Mountford and Smith, 1995), consisting of one part encoding for epitope tag-fused Nph3 and one part encoding for $\beta$-galactosidase (based on Mombaerts et al., 1996). As epitope tag the Flag sequence was used, which is an 8-amino acid bacterial epitope (Asp-TyrLys-Asp-Asp-Asp-Asp-Lys) that does not exist in mammalian proteins. It is used in fusion proteins because of its strong staining with antibodies against it. Due to its small size, it is unlikely to alter the structure and therefore the function of the protein on which it is fused. A sequence encoding for 2x Flag was used (for stronger staining), using mammalian-specific codons, and it was cloned into the Nph3 stop codon which had been mutated into a restriction site. The sequence was cloned in frame with the Nph3 sequence and included spacer amino acids (glycine, alanine) between the Nph3 and the first Flag sequence, as well as between the two Flag sequences. A stop codon was included at the end of the second Flag sequence.

An internal ribosomal entry site (IRES) from the encephalomyocarditis virus was cloned between the Nph3-Flag and the $\beta$-galactosidase encoding sequences. The IRES sequence is used in transgenic mouse strategies in order to drive the second part of a bicistronic mRNA to the rivosome (Kim et al., 1992). Directly downstream of the IRES a Kozak sequence (Kozak, 1991) was cloned, which functions by providing to the mRNA with the required signal for the initiation of translation, as well as with the initiation AUG codon. The lacZ sequence, encoding for $\beta$-galactosidase, was cloned downstream of the Kozak sequence and was preceded by a sequence encoding for a nuclear localization signal from the simian virus 40 (Pro-Lys-Lys-Lys-Arg-Lys-Val, Kalderon et al., 1984) with the function of guiding $\beta$ galactosidase to the nucleus of the expressing cells. Therefore, the above array of sequences should enable characterization of the Nph3-expressing cells in the brain of the resulting knock-in mice by assaying for $\beta$-galactosidase activity.

In addition to the sequences described above, a neomycin-resistance gene $\left(n e o^{R}\right)$, flanked by FRT sites was cloned into the intron sequence of the Nph3 gene. This sequence serves the 
purpose of providing recombinant ES cells with resistance for neomycin, an analogue of which is used for selection against non-recombinant clones. The FRT sites serve as recognition sites for Flp recombinase in the Flp-FRT system of Saccharomyces cerevisiae (Broach et al., 1982), which is similar to the Cre-loxP system described below. They were included in the targeting vector for potential future removal of the $n e o^{R}$ gene from the genome of the knock-in mice, in case the presence of the latter would create a transcription stop, resulting in an early knock-out allele.

In order to enable Nph3-KI mice to be later transformed into Nph3-KO, the Cre-loxP system of the bacteriophage P1 was used (Sternberg and Hamilton, 1981). The enzyme Cre recombinase is able to excise DNA sequences that are flanked by loxP sites, leaving behind a single 34 bp long loxP site. In the presence of an additional loxP site, it can transpose the DNA sequence into the loxP site. Cre recombinase can be provided by Cre-expressing transgenic mice. Therefore, when these mice are mated with mice baring two lox $P$ sites in their genome the sequence between the lox $P$ sites is removed. Based on this system, two loxP sites were included in the above targeting vector. One was cloned upstream of the $n e o^{R}$ sequence and the other downstram of the lacZ sequence, thus flanking the whole recombinant part of the Nph3 gene. Excision of this sequence would result in the absence of the second Nph3 exon from the genome and therefore in the generation of a knock-out mouse line, leaving behind only a single loxP site.

The Nph1 targeting vector contained the same elements with the Nph3 one, apart from the sequence encoding for the epitope tag, which in the case of Nph1 was the HA tag (Tyr-ProTyr-Asp-Val-Pro-Asp-Tyr-Ala), which derives from the hemagglutinin protein of the human influenza virus, an epitope also commonly used in fusion proteins.

Both targeting vectors included a double thymidine kinase sequence (provided by vector pTKneo3a) directly downstream of the modified genomic clone, serving as a marker of nonhomologous recombination and functioning by producing a toxic compound during negative selection of ES cell clones (see section 2 .2 .26.4).

A scheme of the composition of the targeting vector, as well as of the recombination strategy is given in figure 7 . 
Wildtype allele

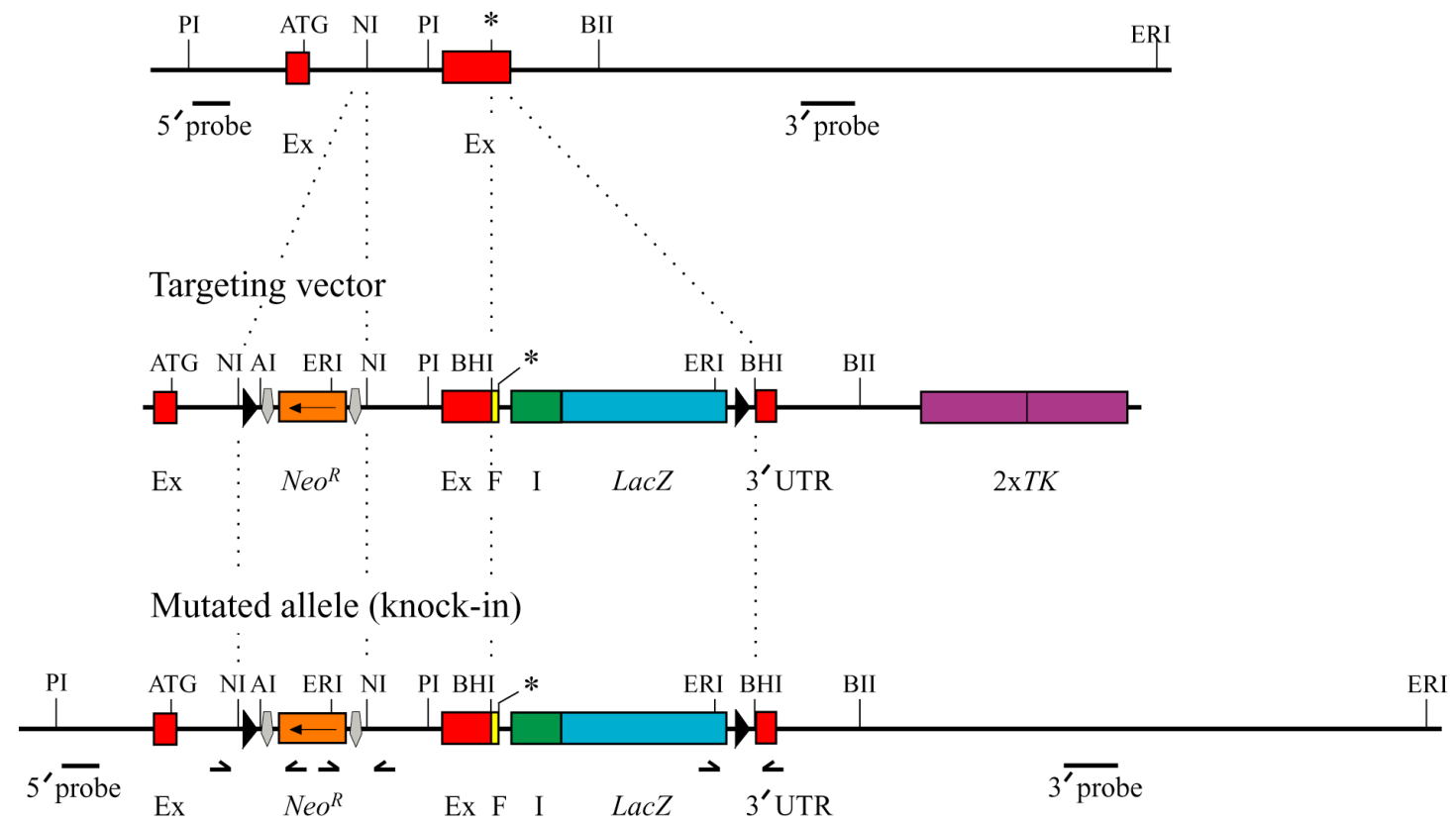

Figure 7 Generation of neurexophilin 3 knock-in mice. The targeting vector was constructed based on the wild type (WT) Nph3 sequence. The various modules used in the construction of the targeting vector are presented, as well as the structure of the resulting knock-in allele. The hybridization positions of the two outside probes used for screening of recombinant ES cells (see section 3.2. 3 . 1) are also shown $\left(5^{\prime}\right.$ probe, $3^{\prime}$ probe), as well as the position of the primers used for PCR genotyping of positive ES cells (shown with arrows, see section 3 . 2.3.1). ${ }^{*}=$ stop codon, $\mathrm{Ex}=$ exon, $\mathrm{ATG}=$ Start codon, $N e o^{R}=$ neomycin resistance gene, $\mathrm{F}=$ Flag epitope $\mathrm{I}=$ internal ribosomal entry site (IRES), lac $Z=$ lactose catabolism gene, $3^{\prime}$ UTR $=3^{\prime}$ untranslated region, $T K=$ thymidine kinase gene, dark triangles $=\operatorname{lox} P$ sites, grey arrows $=F R T$ sites, restriction site abbreviations: $\mathrm{PI}=$ PstI, $\mathrm{NI}=\mathrm{NcoI}, \mathrm{BII}=\mathrm{BgIII}, \mathrm{AI}=$ AgeI, ERI $=$ EcoRI, BHI $=$ BamHI. 


\subsubsection{Neurexophilin 3 targeting vector cloning strategy}

The Nph3 targeting vector was constructed using the genomic clone pmNph3-3, described in section 3 . 1 . 1. The cloning strategy involved four steps: a) mutagenesis of the stop codon, b) construction of $n e o^{R}$ cassette and insertion into a genomic subclone, c) construction of the tagging fusion cassette including the Flag epitope and the lacZ sequence and d) assembly of the final vector.

\section{a) Mutagenesis of the stop codon}

The $2.8 \mathrm{~kb} \mathrm{KpnI} \mathrm{fragment} \mathrm{of} \mathrm{pmNph3-3} \mathrm{was} \mathrm{excised} \mathrm{and} \mathrm{the} \mathrm{backbone} \mathrm{was} \mathrm{re-ligated.} \mathrm{The}$ stop codon of the previous construct was mutated into a BamHI site by PCR-based site directed mutagenesis, using oligonucleotides $00-04 / 00-05$ as PCR primers. The mutation was included in the sequence of the oligonucleotides.

\section{b) Construction of $n e o^{R}$ cassette and insertion into a genomic subclone}

The BamHI site of pBluescript II SK was destroyed by digesting, blunt-ending and religating. The $2.8 \mathrm{~kb} \mathrm{KpnI} \mathrm{fragment} \mathrm{of} \mathrm{Nph3-3} \mathrm{was} \mathrm{cloned} \mathrm{into} \mathrm{the} \mathrm{previous} \mathrm{construct.} \mathrm{The}$ BamHI site of the new construct was destroyed as well, as described above. By DNA adaptor synthesis using oligonucleotides 00-06/00-07 the sequence 5'-NcoI-loxP-AgeI-NcoI-3' was generated and cloned into the NcoI site of the previous construct, in sense orientation. The $F R T-n e o^{R}$-FRT cassette (AgeI fragment) of $\mathrm{pFRT}_{2}$ neo.lacZ was cloned into the AgeI site of the above construct, with the orientation of the $n e o^{R}$ gene being antisense to that of the construct (it has been empirically found to function better when it is cloned in antisense orientation).

c) Construction of the tagging fusion cassette including the Flag epitope and the lac $Z$ sequence

A construct containing the HA-encoding sequence was first cloned and this sequence was then exchanged with the Flag-encoding sequence. The first construct was used in the Nph1 targeting vector cloning strategy (see next section).

The sequence 5'-BamHI-Gly-HA-Gly-HA-stop-SfuI-3' was generated by DNA adaptor synthesis using oligonucleotides 99-34/99-35 and cloned into the BamHI/ClaI sites of pBluescript II SK, thereby destroying its ClaI site (SfuI and ClaI produce compatible cohesive ends). The IRES sequence, excised with XhoI from pblueIRES, was cloned into the XhoI site of the above construct, in sense orientation. By DNA adaptor synthesis using oligonucleotides 99-36/99-37, the sequence 5 '-SfuI-Kozak-NLS-PstI-loxP-BamHI-ApaI-3' was generated and cloned into the ClaI/ApaI sites of the previous construct. The only ClaI site existing was the 
one at the $3^{\prime}$ end of the IRES fragment. The lacZ sequence was excised from pCAG-CATZ by PCR using oligonucleotides 99-38/99-39 and cloned into the PstI site of the previous construct, in sense orientation. The resulting construct was used in the Nph1 targeting vector cloning strategy (see next section). The $70 \mathrm{bp}$ SpeI-SalI fragment of this construct (containing the 2xHA sequence) was exchanged with the sequence 5'-SpeI-BamHI-Gly-Flag-Ala-GlyFlag-stop-XhoI-3', that was generated by DNA adaptor cloning using oligonucleotides 0010/00-11 (SalI and XhoI produce compatible cohesive ends).

\section{d) Assembly of the final vector}

The KpnI fragment of the construct from b) was cloned into the construct from a), in sense orientation. The $4 \mathrm{~kb}$ BamHI cassette of the construct from c) was cloned into the previous construct, in sense orientation. Thus, the genomic clone was reconstituted, containing the $n e o^{R}$ and the tagging fusion cassette. The $12 \mathrm{~kb}$ NotI-SalI fragment of the previous construct was finally cloned into the $7 \mathrm{~kb}$ NotI-SalI fragment of pTKneo3a.

\subsubsection{Neurexophilin 1 targeting vector cloning strategy}

The mouse genomic clone 4 was used for cloning (pmNph1-4, provided by Dr. Markus Missler, Petrenko et al., 1996). The following steps were involved in the cloning strategy: a) construction of $n e o^{R}$ cassette, b) generation of genomic subclones and mutagenesis of the stop codon, c) generation of genomic clone with $n e o^{R}$ and tagging fusion cassettes and d) construction of the final vector.

\section{a) Construction of $n e o^{R}$ cassette}

The sequence 5'-EcoRI-SpeI-loxP-AgeI-SpeI-SalI-3' was generated by DNA adaptor synthesis using oligonucleotides 99-32/99-33 and cloned into pBluescript II SK. The FRT$n e o^{R}-F R T$ cassette (AgeI fragment) of $\mathrm{pFRT}_{2}$ neo.lacZ was cloned into the AgeI site of the previous construct, with the orientation of the $n e o^{R}$ gene being antisense to that of the construct.

\section{b) Generation of genomic subclones and mutagenesis of the stop codon}

The $5 \mathrm{~kb} \mathrm{ClaI}$ fragment of pmNph1-4 was excised and the backbone was re-ligated. The 3.2 $\mathrm{kb}$ HindIII fragment of the previous construct was also excised and the backbone was religated. The $500 \mathrm{bp}$ SpeI-ClaI fragment of the re-ligated backbone was cloned into pBluescript II SK and its stop codon was mutated into a BamHI site using oligonucleotides 99-40/99-41 as PCR primers. The $3.2 \mathrm{~kb}$ HindIII fragment mentioned above was cloned into 
pMal-c2. The $1.3 \mathrm{~kb}$ SpeI fragment of the construct from a) was cloned into the SpeI site of the previous construct. The orientation was kept the same.

\section{c) Generation of genomic clone with $n e o^{R}$ and tagging fusion cassettes}

The $500 \mathrm{bp}$ SpeI-ClaI fragment from b) with its stop codon mutated was cloned back to the plasmid which it was released from. The $4 \mathrm{~kb}$ BamHI tagging fusion cassette containing the HA tag, mentioned in the subsection c) of the previous section, was cloned into the BamHI site (mutated stop codon) of the previous construct, in sense orientation. The $4.5 \mathrm{~kb}$ HindIII fragment of the construct from b) was cloned in sense orientation into the HindIII site of the previous construct.

\section{d) Construction of the final vector}

The $5 \mathrm{~kb}$ ClaI-SalI fragment from pmNph1-4 was cloned into the ClaI/SalI sites of pTKneo3a. The $12 \mathrm{~kb}$ NotI-ClaI partially digested fragment of the construct from c) (the ClaI site of lacZ was not digested) was cloned into the $12 \mathrm{~kb}$ NotI/ClaI fragment of the previous construct.

\subsubsection{In vitro testing of targeting vector function}

In order to ensure that the various elements of the targeting vectors were fully functional, they were tested in a cell culture system before insertion of the targeting vectors into ES cells. This was carried out by transfecting COS7 cells with expression constructs, based on the eukaryotic expression vector pCMV5. In the case of Nph3 two test constructs were cloned, one containing the whole genomic sequence of the targeting vector including the two exons and the various elements and the other containing the Nph1 rat cDNA, fused to the Nph3 tagging fusion cassette, that was cloned into the mutated stop codon of the cDNA. In the case of Nph1, one test construct was cloned, containing the tagging fusion cassette cloned into the mutated stop codon of the Nph1 rat cDNA. The efficacy of the epitope tags and lacZ sequence were tested immunocytochemically by $\beta$-galactosidase staining and by western blot. 


\subsubsection{Transfection with neurexophilin 3 expression vectors}

\section{a) Cloning of test constructs}

Construct I. The BamHI site of pCMVD2, a construct of full length Nph1 rat cDNA in pCMV5, was destroyed by digesting, blunt-ending and re-ligating. The cDNA stop codon of the above construct was mutated into a BamHI site. The $4 \mathrm{~kb}$ BamHI cassette of the construct described in the subsection c) of section 3.2.1 .1, containing the Flag epitope, was cloned into the BamHI site (mutated stop codon) of the above construct, in sense orientation to the Nph1 sequence.

Construct II. The $12 \mathrm{~kb}$ SalI fragment of the reconstituted Nph3 genomic clone, described in the subsection d) of section 3.2.1.1, was cloned into the SalI site of pCMV5, in sense orientation to the pCMV5 promoter. Since the cloned sequence contains the whole Nph3 gene, this construct is able to drive protein expression only when correct splicing of the gene takes place.

\section{b) Control constructs}

pCMVNph3, an expression construct of full length Nph3 rat cDNA in pCMV5 was used as negative control for anti-Flag staining and western blot as well as for $\beta$-galactosidase staining and as positive control for anti-Nph3 western blot.

pCMV $\beta$-gal, an expression construct of $\beta$-galactosidase, was used as positive control for $\beta$ galactosidase staining and as negative control for western blot.

pCMV5Flag, a construct containing the Flag epitope downstream of the pCMV5 promoter but without a Start codon, being therefore unable to drive expression of Flag, was used as negative control for anti-Flag staining and western blot.

\section{c) $\beta$-Galactosidase staining}

Transfections with the control constructs resulted in the expected patterns, i.e. pCMV $\beta$-gal transfected dishes had a high number of $\beta$-galactosidase stained cells and dishes transfected with pCMVNph3 had no stained cells. Dishes transfected with the test constructs had clearly $\beta$-galactosidase stained cells, however in a lower number than the pCMV $\beta$-gal ones. This could be explained by the higher size of the test constructs comparing to that of the $p C M V \beta-$ gal plasmid, a factor that quite often affects negatively the efficiency of transfection.

In cells transfected with the test constructs staining was observed mainly in the nucleus with diffuse staining also in the cytoplasm, in contrast to the pCMV $\beta$-gal transfected cells were staining was spread throughout the cell. This pattern reflects the efficacy of the nuclear 
localization signal that drives the $\beta$-galactosidase molecule to the nucleus of the expressing cells.

\section{d) Immunocytochemistry}

Immunofluorescence staining using the M2 anti-Flag antibody revealed a satisfactory staining of cells at both transfections with test constructs. The number of stained cells was not very high. However, staining was clear and no staining was observed at the negative control transfections. Staining was mainly localized at the Golgi/ER region, in accordance with previous observations (Missler and Südhof, 1998), that COS7 cells do not efficiently process neurexophilins and therefore the latter do not reach the final steps of the secretory pathway.

\section{e) Double ( $\beta$-galactosidase/anti-Flag) staining}

Double $\beta$-galactosidase/anti-Flag staining, using a DAB protocol, compined the results described above in the same cell. Thus, some cells were observed with their nucleus stained blue for $\beta$-galactosidase and the rest of the cell black for anti-Flag, as shown in figure 8 . There were also cells stained only for $\beta$-galactosidase and cells stained only for anti-Flag.

\section{f) Western blot}

Cell lysate samples were loaded on two identical 12\% SDS-PAGE gels. One of them was immunoblotted with the M2 antibody and the other with the anti-Nph1/3 F508 antibody (figure 9).

A band in both test construct samples was recognized by the M2 antibody. No band was present at the negative control samples. Both bands had the predicted size for the prepropeptide forms of $\mathrm{Nph} 1$ and Nph3, i.e. $\sim 45 \mathrm{kDa}$ for construct I and $\sim 42 \mathrm{kDa}$ for construct II (neurexophilins are not processed in non-neuronal cell lines, Missler and Südhof, 1998). The construct I band consisted of 3-4 smaller bands, creating a "fuzzy" appearance, as it has been observed before in COS7 cells (Missler and Südhof, 1998), due to the glycosylation of neurexophilins. On the other hand, the construct II band was a sharp single band. This may reflect better processing of Nph3 with respect to glycosylation, when the whole gene is present. The presence of a Nph3-Flag band at the expected size in the construct II sample indicates that splicing of the mutated gene is not affected by the cloned sequences. Anti-Nph1/3 immunoblotting resulted in a specific band only at the positive control sample, thus failing to detect the tagged Nph3 protein at the test construct samples. A possible explanation is that the addition of the Flag epitope at the C-terminus of the protein probably prevents the antibody-antigen interaction by a conformational change, since the antigen for F508 consists of the C-terminal last 11 amino acids of the protein and the Flag epitope was 
cloned right next to it. The size of the positive control band was as expected ( $\sim 40 \mathrm{kDa})$. The small size difference between that and the construct II band in the M2 western blot ( $\sim 2 \mathrm{kDa})$ is due to the presence of the Flag epitope in the test construct.
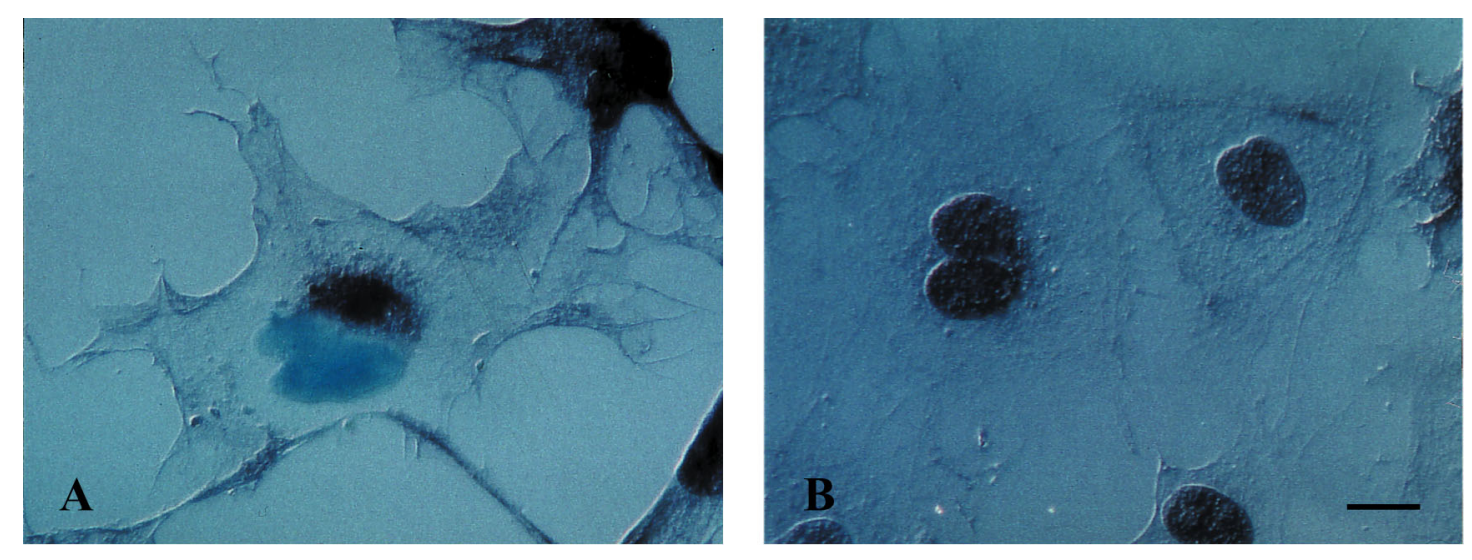

Figure 8 Double staining of COS7 cells, transfected with Nph3-KI vectors. Differential Interference Contrast (DIC) microscope pictures of transfected COS7 cells. A Test construct transfected cells were stained blue for $\beta$-galactosidase activity, as well as strong dark for immunocytochemical staining against the Flag epitope. $\beta$-Galactosidase staining is mainly observed in the nucleus and the area around it, due to the function of the fused nuclear localization signal. Immunocytochemical staining is observed mainly at the Golgi/ER region, showing that Nph3 is not properly processed and targeted in COS cells (a nonneuronal cell line). B Negative control transfected cells exhibited no staining for both of the above assays. The light dark colour of the nuclei reflects the background of the immunocytochemical assay. Scale bar: $50 \mu \mathrm{m}$. 
A

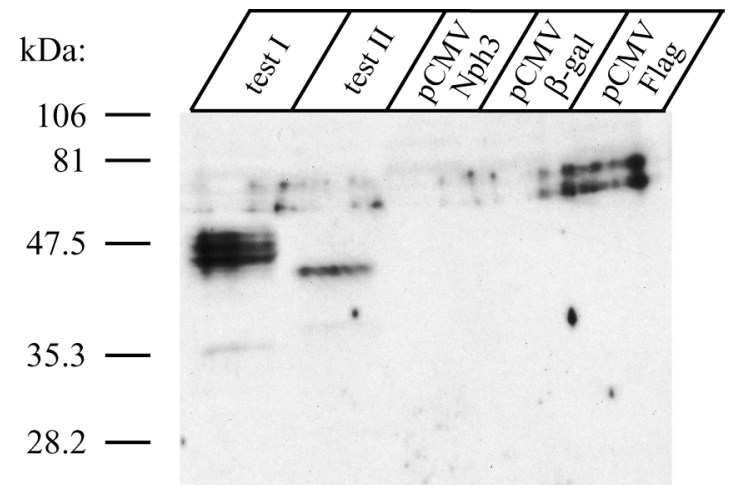

anti-Flag (M2)

B

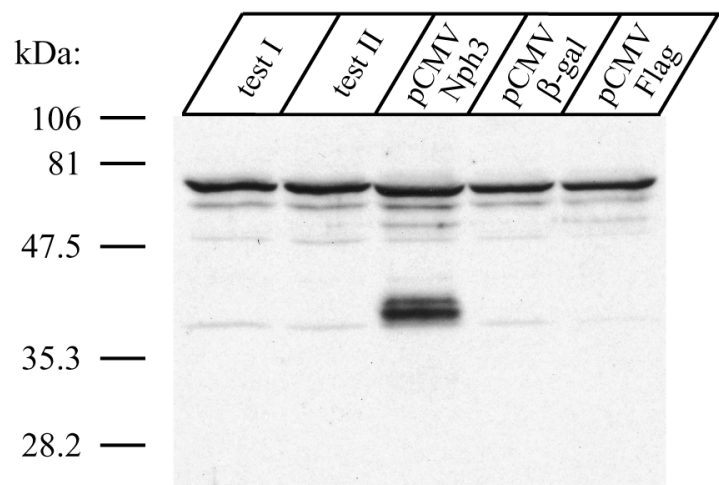

anti-Nph1/3 (F508)

Figure 9 Western blot anaylsis of COS7 cells transfected with Nph3-KI

vectors. A Western blot using the M2 anti-Flag antibody. Cell lysates from transfection with the test constructs were used, together with cell lysates from positive and negative control transfections. The antibody recognized specifically the Flag epitope of the fused proteins expressed from both test constructs. The slight size difference of the bands between the two test constructs reflects the size difference between Nph1 and Nph3. The Nph3-Flag band (test construct II) has also a slightly higher size, comparing to the Nph3 band of the above western blot, due to the presence of the Flag epitope in the former. The duplet of bands at $\sim 60$ $70 \mathrm{kDa}$ in all lanes represents background of the antibody. B Western blot using the anti-Nph1/3 F508 antibody. Cell lysates were loaded as above. The antibody failed to recognize the fusion protein expressed from the test constructs, probably because of a conformational change of the C-terminus of the Nph3, due to the presence of the Flag epitope. Protein sizes are given on the left. A background $70 \mathrm{kDa}$ band is shown in all lanes. test I, II = test constructs I, II . 


\subsubsection{Transfection with neurexophilin 1 expression vector}

\section{a) Cloning of test construct}

The $4 \mathrm{~kb}$ BamHI cassette of the construct described in the subsection c) of section 3.2.1.1, containing the HA epitope, was cloned into the BamHI site (mutated stop codon) of pCMVD2, in sense orientation to the Nph1 sequence.

\section{b) Control constructs}

pCMVD2 was used as negative control for anti-HA and $\beta$-galactosidase staining.

pCMV5-HA-SytI, an expression construct of a fused synaptotagmin I-HA protein, was used as positive control for anti-HA staining.

pCMV $\beta$-gal was used, as in the case of Nph3, as positive control for $\beta$-galactosidase staining.

\section{c) $\beta$-Galactosidase staining}

Similarly to Nph3, transfection with the Nph1 test construct resulted in clearly $\beta$ galactosidase stained cells, also in a lower number than the more efficient positive control transfection. No stained cells were observed at the negative control transfection. The staining localization patterns were also similar to Nph3, with staining being localized mainly in the nucleus at the test contruct transfection and in the whole cell at the positive control transfection.

\section{d) Immunocytochemistry}

Immunofluorescence staining using an anti-HA antibody, revealed a high number of stained cells in the positive control transfection. In cells transfected with the test construct staining was also observed, although in a lower number. This quantitative difference could probably be explained by the different nature of synaptotagmin and Nph1; in other words synaptotagmin is probably expressed better than Nph1 in COS7 cells. However, staining in cells transfected with the test construct was clearly observed and localized mainly at the Golgi/ER region. Cells transfected with the negative control construct showed no staining at all.

Figure 10 summarizes the results of $\beta$-galactosidase and immunofluorescence stainings. 

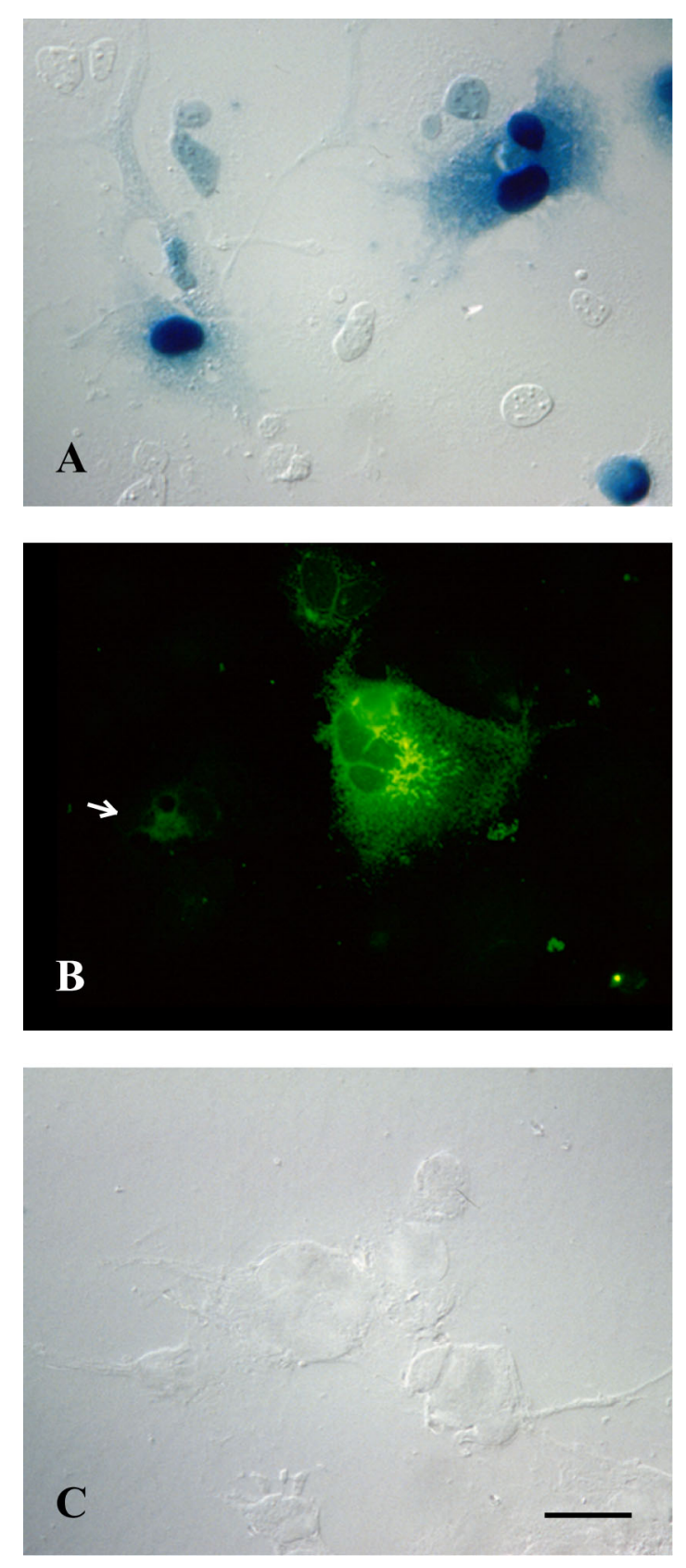

Figure 10 Staining of COS7 cells, tranfected with Nph1-KI vector. DIC (A, C) or fluorescent (B) microscope pictures of transfected COS7 cells. A Cells transfected with the test construct were assayed for $\beta$-galactosidase activity. Although not in a high number, stained cells were observed with staining being stronger in the nucleus than in the cytoplasm. B Immunofluorescence staining of cells transfected with the test construct against the HA epitope revealed staining of the Golgi/ER region, indicating proper function of the epitope. In a nontransfected cell in the same picture (arrow) only background staining is observed (light green colour). C Cells transfected with the negative control construct exhibited no $\beta$-galactosidase staining. Scale bar: $100 \mu \mathrm{m}$. 


\subsubsection{Generation of recombinant embryonic stem cells}

\subsection{3 . 1 Neurexophilin 3 knock in embryonic stem cell culture}

ES cells were electroporated with Nph3 targeting vector DNA and 88 ES cell colonies were collected, split and cultured. Part of each clone's cells were frozen at $-80^{\circ} \mathrm{C}$ and the rest was used for DNA preparation for two Southern blots. The Southern blot strategies (digestion enzymes and probes used) were designed in a way to result in a clearly detectable size difference between the WT and the recombinant band.

For both Southern blots DNA was digested with EcoRI. One of them was probed with an "outside" probe and the other with an "inside" probe. The outside probe (NheI-KpnI) is not part of the sequence that is included in the targeting vector and belongs to the sequence downstream of it. The inside probe (BgIII-BgIII) consists of the sequence of the first half of the Nph3 second exon and is part of the targeting vector sequence. An outside probe is necessary when screening for positive ES cell clones, because it provides the desirable shift in band size only when homologous recombination has taken place. An inside probe on the other hand, hybridizes to the sequence of the targeting vector, also in cases of non-homologous recombination; however it is a helpful way to double-check the correct recombination event. The expected band sizes for the probes used are given below (see also figure 14):

\begin{tabular}{|ccc|}
\hline & WT band & Recombinant band \\
Outside probe & $>16 \mathrm{~kb}$ & $11.3 \mathrm{~kb}$ \\
Inside probe & $>16 \mathrm{~kb}$ & $6.3 \mathrm{~kb}$ \\
\hline
\end{tabular}

Hybridization using the outside probe was carried out for all clones and using the inside probe, due to technical limitations, only for clones 54-88. The result pattern is shown in figure 11.

Around $40 \%$ of the clones that could be clearly analyzed were positive in the outside probeSouthern blot. All of them were also positive in the Southern blot with the inside probe confirming correct recombination.

Six of the above positive clones (clones 59, 62, 68, 69, 73 and 78) were thawed and expanded. Most of the expanded cells were frozen in liquid nitrogen as aliquots and the rest were used for DNA preparation. The outside probe-Southern blot was repeated in order to verify the correct composition of the clones. An additional Southern blot was performed for clone 73, in which DNA was digested with PstI/AgeI and probed with the PstI-KpnI fragment, that belongs to the sequence upstream of that used for the targeting vector $\left(5^{\prime}\right.$ outside probe). The expected band sizes for this Southern blot are given on the following table: 
A

$\mathrm{kb}$ :

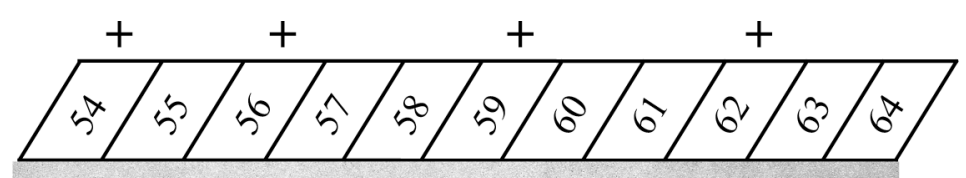

$>16-$

11.3

B

$\mathrm{kb}$ :

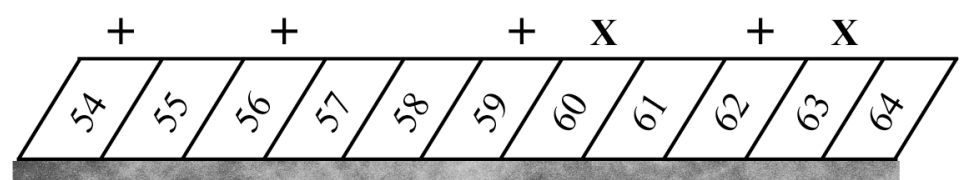

$6.3-$

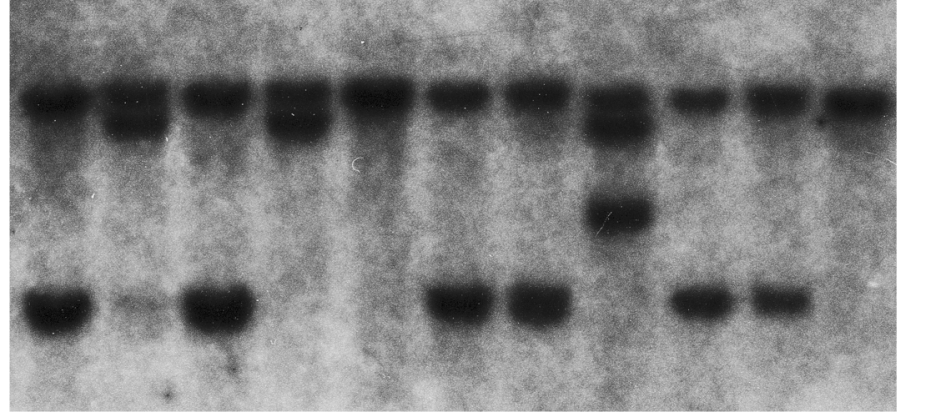

Figure 11 Screening of embryonic stem cell clones. A Southern blot using the outside probe. DNA was digested with EcoRI and probed with the outside probe. The hybridizing WT fragment is longer than $16 \mathrm{~kb}$ (the exact size is unknown since the upstream EcoRI site of the fragment is not included in the genomic clones). Correct homologous recombination with Nph3-KI DNA introduces two additional EcoRI sites in the Nph3 gene (see figure 14). The EcoRI fragment of the Nph3-KI allele that hybridizes to the above probe has a length of $11.3 \mathrm{~kb}$. Numbers of clones are shown on top of the picture. Positive clones are highlighted with a cross on top of their number. The sizes of the two hybridizing bands are shown on the left. B Southern blot using the inside probe. DNA was digested with EcoRI and probed with the inside probe. Both homologous or nonhomologous recombination result in a $6.3 \mathrm{~kb}$ EcoRI fragment that hybridizes to the inside probe. The same clones presented in A are shown. Positive clones that are also positive in A are highlighted with a cross on top of their number. Note that clones 60 and 63 (highlighted with an $\mathrm{X}$ ) are negative for the outside, but positive for the inside probe, indicating non-homologous recombination. 


\begin{tabular}{|cc|}
\hline WT band & Recombinant band \\
$3.5 \mathrm{~kb}$ & $2.7 \mathrm{~kb}$ \\
\hline
\end{tabular}

Both Southern blots resulted in the expected patterns, reconfirming the correct recombination events in the clones tested. The result of the $5^{\prime}$ outside probe-Southern blot is shown in figure 12. A scheme of the Southern blot strategies followed is given in figure 14.

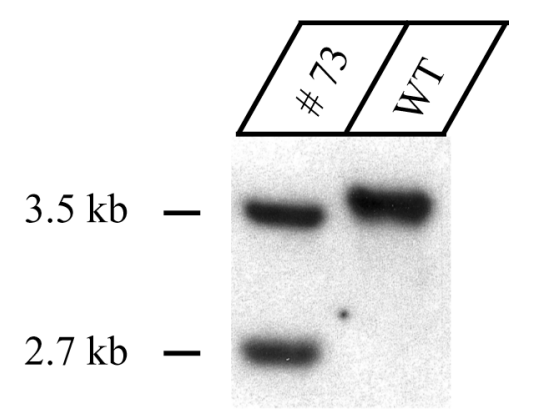

Figure 12 Southern blot of clone 73 using the $\mathbf{5}^{\prime}$ outside probe. Clone 73 was digested with PstI/AgeI and probed with the $5^{\prime}$ outside probe. The hybridizing WT allele is the $3.5 \mathrm{~kb}$ PstI-PstI fragment. Homologous recombination with Nph3-KI DNA results in the insertion of two AgeI sites in the above fragment (see figure 14). The hybridizing Nph3-KI fragment has a length of $2.5 \mathrm{~kb}$. As a control, DNA purified from a tail biopsy of a WT mouse was used. Source of DNA is shown on top and DNA size on the left of the picture.

In addition to Southern blot, PCR analysis was carried out using DNA from the same preparations of the above six clones in order to verify the correct integration of the loxP and FRT sites. Three PCR reactions were set up leading to short fragments. The primers used were designed in a way that the amplified fragment would have a distinct size that would only be correct if the above sites were present. Since the length of the loxP and FRT sites is very short, a long PCR product would not enable a clear recognition of their presence. The positions of the primers in the Nph3-KI genomic DNA are shown in figure 7.

The expected amplified band sizes are given below together with the oligonucleotides that were used as primers:

\begin{tabular}{|c|c|c|}
\hline Reaction & $\underline{\text { Product length }}$ & $\underline{\text { Oligonucleotides }}$ \\
\hline $5^{\prime} l o x P, 5^{\prime} F R T$ sites & $355 \mathrm{bp}$ & $00-19 / 00-20$ \\
\hline $3^{\prime} F R T$ site & $340 \mathrm{bp}$ & $00-21 / 00-22$ \\
\hline 3'loxP site & $388 \mathrm{bp}$ & $00-23 / 00-24$ \\
\hline
\end{tabular}


All reactions showed the expected bands. The PCR patterns are shown for clone 73 in figure 13:

A

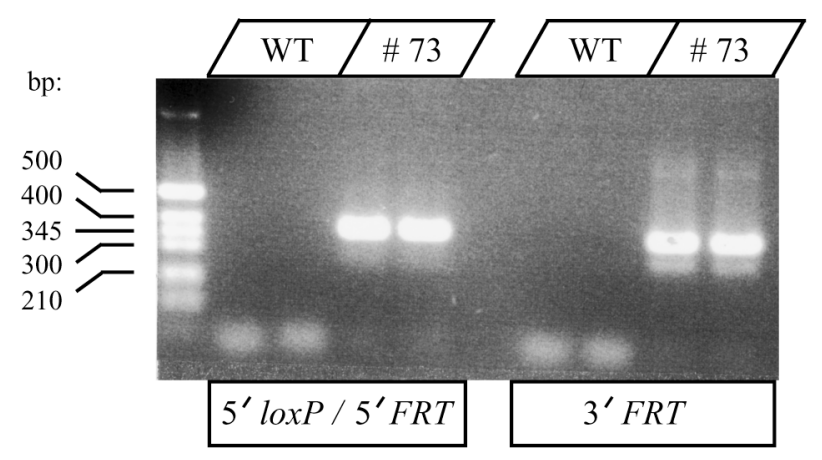

B

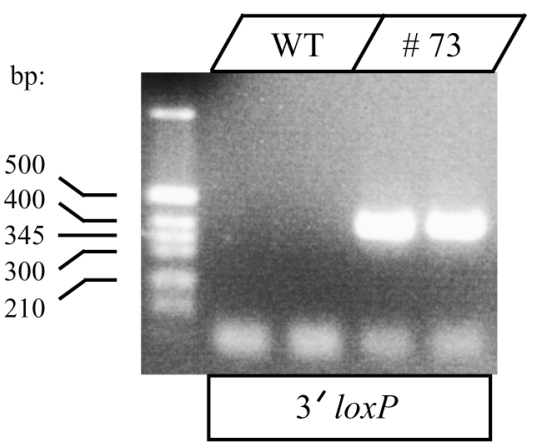

Figure 13 PCR analysis of positive embryonic stem cell clones. A $5^{\prime}$ loxP/5' FRT, 3' FRT reactions. PCR results are shown for clone 73, together with the respective control reactions using DNA from a tail biopsy of a WT mouse. DNA from clone 73 provided PCR products of the expected size and no product was amplified from WT DNA. Source of DNA is shown on top and DNA size on the left of the picture. PCR reactions are shown on the bottom. B 3' loxP reaction. 3' loxP reaction also resulted in a DNA bands of the expected size in clone 73 lanes and in no bands in the WT lanes. 
Figure 14 Embryonic stem cell Southern blot strategy. A Southern blot strategy for screening ES cell clones using the 3' outside probe. DNA was digested with EcoRI. The digestion products are shown below the genomic DNA line. Fragments that hybridize to the probe, as well as the position of the probe are shown in pink. Dashed lines ending on a question mark indicate the continuation of the fragment up to the next EcoRI site which is in not included in the Nph3 genomic clones. WT DNA results in a hybridizing $>16 \mathrm{~kb}$ fragment and Nph3-KI DNA in a hybridizing $11.3 \mathrm{~kb}$ fragment. Red boxes = exons, orange box $=$ neomycin resistance gene $\left(n e o^{R}\right)$, yellow box $=$ Flag epitope, green box $=$ internal ribosomal entry site (IRES), blue box = lactose catabolism gene (lacZ), dark triangles $=\operatorname{lox} P$ sites, grey arrows $=F R T$ sites, ERI $=$ EcoRI. $\quad$ B Southern blot strategy for screening ES cell clones, using the inside probe. DNA was digested with EcoRI. WT DNA results in a hybridizing $>16 \mathrm{~kb}$ fragment and Nph3-KI DNA in a hybridizing $6.3 \mathrm{~kb}$ fragment. C Southern blot strategy for confirmation of positive Nph3-KI ES cell clones, using the $5^{\prime}$ outside probe. DNA was digested with PstI/AgeI. WT DNA results in a hybridizing $3.5 \mathrm{~kb}$ fragment and Nph3-KI DNA in a hybridizing $2.7 \mathrm{~kb}$ fragment. PI $=$ PstI, AI $=$ AgeI. No AgeI site is present in the genomic clone. 
A Southern strategy - $3^{\prime}$ outside probe

Wildtype allele

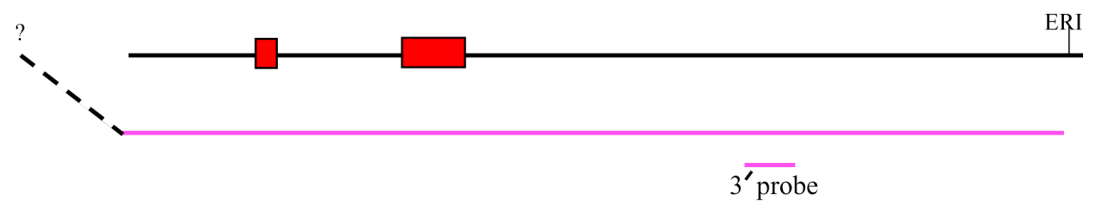

Mutated allele (knock-in)

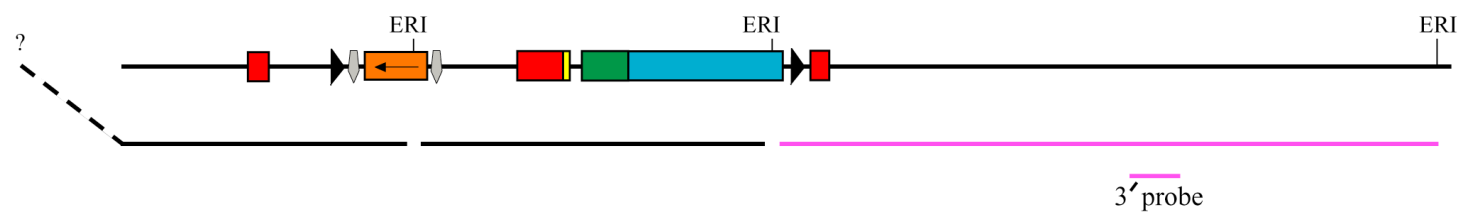

B Southern strategy - inside probe

Wildtype allele

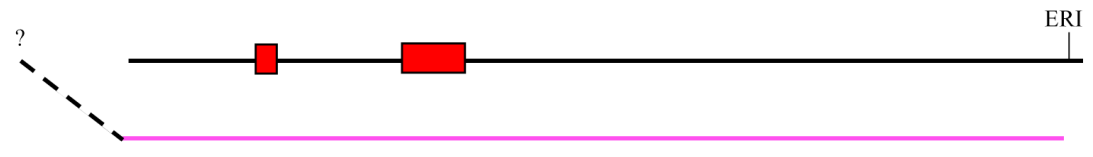

in. $\overline{\text { probe }}$

Mutated allele (knock-in)

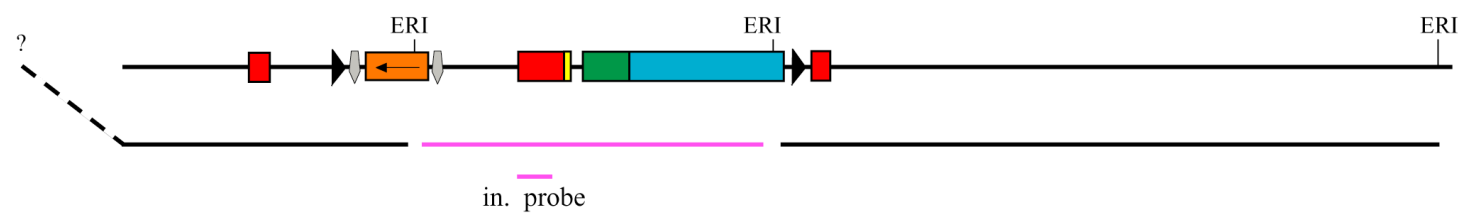

C Southern strategy $-5^{\prime}$ outside probe

Wildtype allele

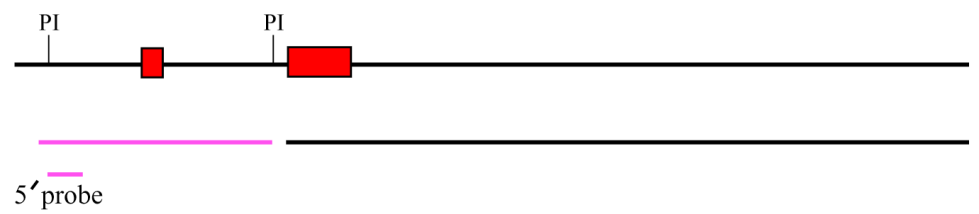

Mutated allele (knock-in)

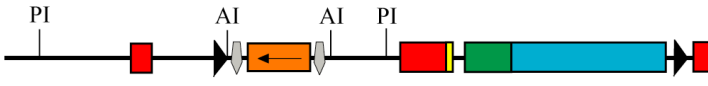

5 'probe 


\subsubsection{Neurexophilin 1 knock in embryonic stem cell culture}

ES cell culture, using the Nph1 targeting vector, was also carried out and clones were analyzed by Southern blot. Although the procedure was repeated several times with increasing number of electroporations and collected colonies, unfortunately none of them led to the generation of a successfully recombined clone. The number of colonies was very low ( 10 colonies per electroporation) in all the above experiments. In an attempt to optimize the recombination conditions, the targeting vector was re-cloned (cloning is not described) and ES cell culture was repeated two times. The number of colonies was substantially increased, but without resulting in a positive clone. An example of the Southern blot analysis is given in figure 15 , together with of a scheme of the two targeting vector constructs.

The following table summarizes the ES cell culture experiments performed with both targeting vectors:

\section{Targeting vector Total number of Total number of Electroporations analyzed colonies}

Targeting vector 1

Targeting vector 2

12

113

8

440 
Targeting vector 1

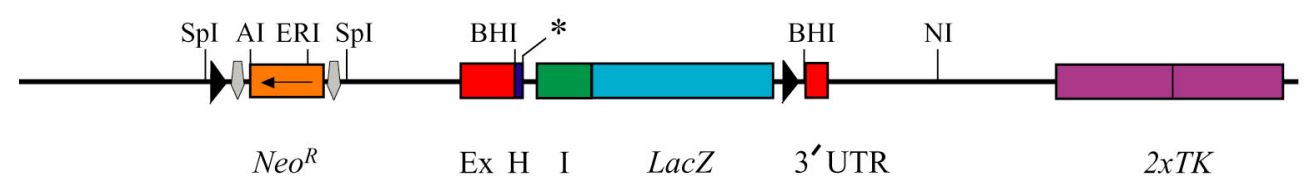

Targeting vector 2

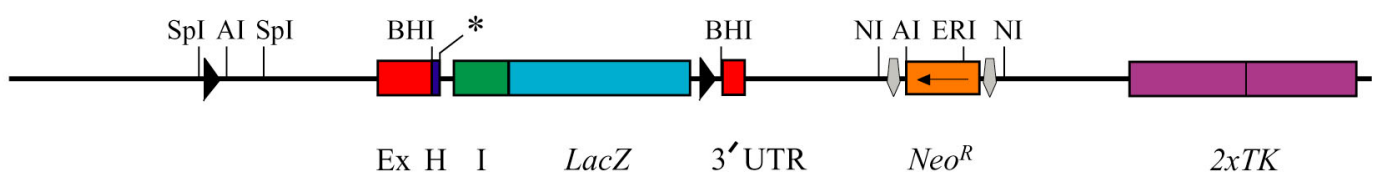

B

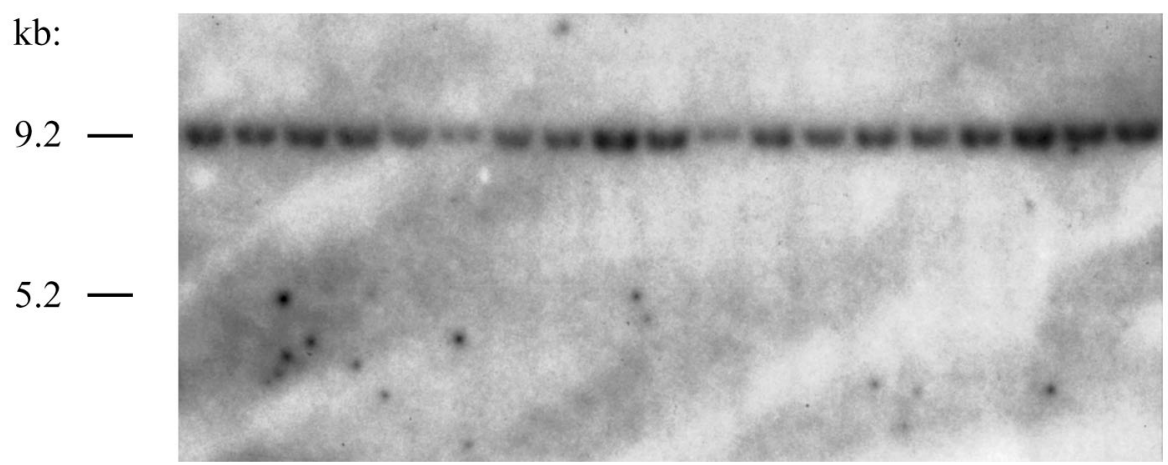

Figure 15 Nph1-KI embryonic stem cell culture. A Composition of targeting vectors. ${ }^{*}=$ stop codon, $\mathrm{Ex}=$ exon, $N e o^{R}=$ neomycin resistance gene, $\mathrm{H}=\mathrm{HA}$ epitope, $\mathrm{I}=$ internal ribosomal entry site (IRES), lac $Z$ = lactose catabolism gene, $3^{\prime} \mathrm{UTR}=3^{\prime}$ untranslated region, $T K=$ thymidine kinase gene, dark triangles $=$ loxP sites, grey arrows $=F R T$ sites, restriction site abbreviations: $\mathrm{SpI}=\mathrm{SpeI}, \mathrm{AI}$ $=$ AgeI, ERI $=$ EcoRI, BHI $=$ BamHI, NI $=$ NcoI. In the second targeting vector, the FRT-Neo ${ }^{R}-F R T$ cassette was transferred downstream of the exon in order to provide the targeting vector with different recombination properties (different length and position of the $5^{\prime}$ and $3^{\prime}$ hybridizing sequences). B Screening of ES cell clones. ES cell DNA was digested with EcoRV/AgeI and probed with a 600 bp SpeI-SpeI fragment upstream of the sequence used in the targeting vectors (outside probe). WT DNA results in a $9.2 \mathrm{~kb}$ band and recombinant DNA in a 5.2 $\mathrm{kb}$ band. DNA sizes are given on the left of the picture. 


\section{2 .4 Establishment of mouse lines}

Following ES cell preparation 5 ES cell injections of clone \#59 and 4 of clone \#73 were carried out successfully into blastocysts that were removed from Black6 (C57B16/J) pregnant mice. Blastocysts were then transplanted into uteri of pseudopregnant foster mothers. Injections and blastocyst transplantations were performed at the animal house of the Max Planck Institute for Experimental Medicine, Göttingen, under supervision of Dr. Herman Riedesel.

Two ES cell clones were used in order to generate and analyze two indepedent knock-in lines. The comparison between the two lines provides a confirmation regarding their analysis. 65$95 \%$ chimaeric mice were obtained for both clones. The precentage of recombinant genome in the mice was roughly estimated by the precentage of the brown colour on their skin (derived from the ES cell strain), in comparison to black (derived from the Black6 strain). This brown skin colour is the result of the function of the agouti allele, which is involved in skin pigmentation. Two \#59 and three \#73 males were bred with Black6 females in order to obtain agouti mice, that is, heterozygous mice with recombinant genome in all of their cells. Generation of agouti mice is the result of germline transmission of recombinant cells. Apart from one \#73 mouse, breeding of all the others resulted in agouti, in addition to Black6 offspring. Agouti mice, judged by their brown skin colour, were genotyped by Southern blot using either the $5^{\prime}$ or the $3^{\prime}$ probe (see section 3.2 . 3 . 1). The Southern blot patterns of two WT and four agouti mice, as well as of four homozygous Nph3-KI mice (see below) are shown in figure 16.

The first litters of agouti mice were additionally genotyped by the three PCR reactions that are described in section 3.2 .3 .1 , providing the expected patterns and therefore confirming the correct composition of the recombinant genome with respect to the loxP and FRT sites. The confirmation of the integrity of the loxP sites was important regarding their future use in the conversion of knock-in to knock-out allele. The PCR patterns of two WT and seven heterozygous agouti mice are shown in figure 17.

$60 \%$ of the agouti mice were found to be heterozygous Nph3-KI and $40 \%$ WT. Not all agoutis have the Nph3-KI allele, since recombinant ES cells were heterozygous. Heterozygous Nph3$\mathrm{KI}$ agouti mice were further bred between them, establishing a homozygous Nph3-KI line.

After the first litters of homozygous mice were obtained and confirmed by Southern blot, PCR reactions were established for genotyping using already genotyped DNA samples and further used for routine genotyping of the line. Oligonucleotides 01-65/01-67 (WT reaction) and 01-64/01-66 (KI reaction) were used as PCR primers. The strategy of this PCR genotyping is shown in figure 18. An example of the resulting pattern is given in figure 30 , together with Nph3-KO DNA samples. 
$\mathrm{kb}$ :

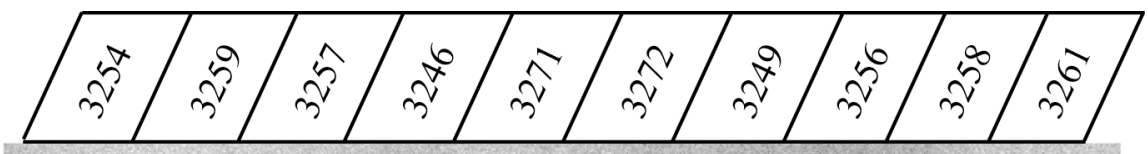

3.5

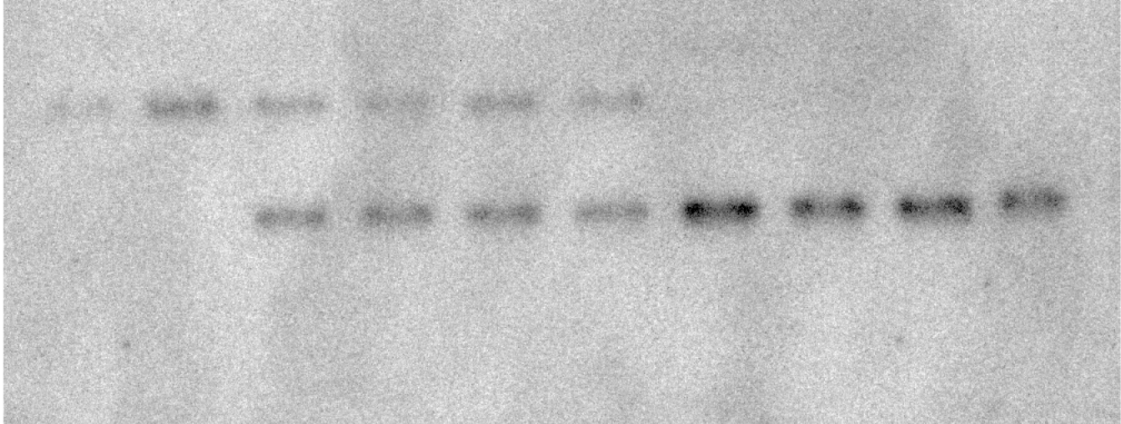

Genotype :

WT / WT

$\mathrm{WT} / \mathrm{KI}$

$\mathrm{KI} / \mathrm{KI}$

Figure 16 Southern blot genotyping of Nph3-KI mice. Genotyping of the first litters of Nph3-KI mice was carried out using either the $5^{\prime}$ prime or the $3^{\prime}$ prime outside probe, used for the analysis of ES cell clones. The genotyping pattern of two WT, four heterozygous and four homozygous mice using the $5^{\prime}$ prime outside probe, is shown. The numbers of the mice, according to the laboratory genotyping numbering system, are given on top of the picture. DNA sizes are given on the left of the picture. 
A

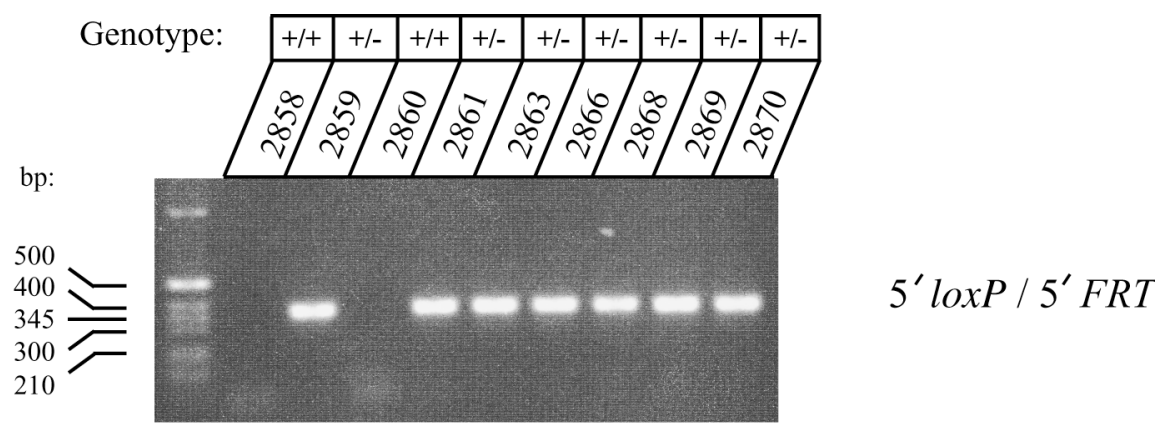

B

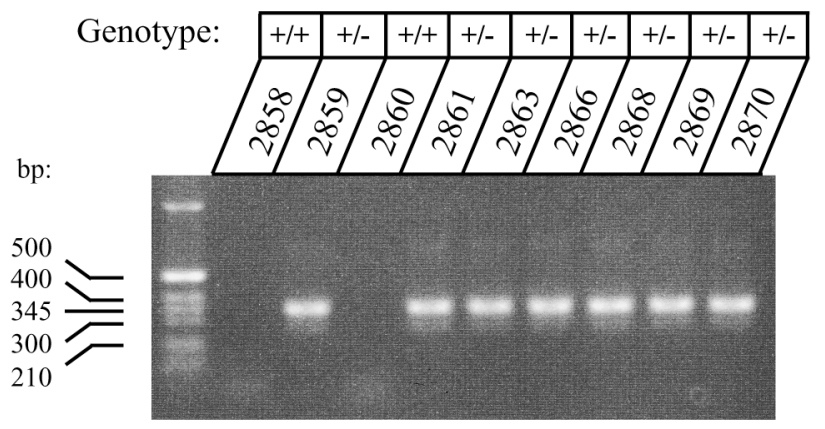

$3^{\prime} F R T$

$\mathrm{C}$

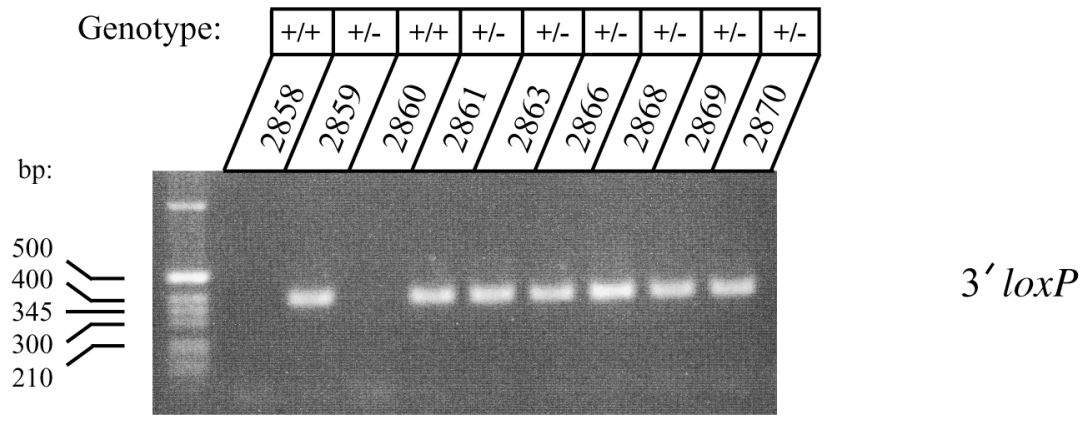

Figure 17 PCR genotyping of Nph3-KI mice. The three PCR reactions, used to reconfirm the correct composition of positive ES cell clones were also used for genotyping of some of the first generations of Nph3-KI heterozygous (+/-) mice in addition to Southern blot. Mouse numbers are given on top and DNA sizes on the left of the picture. Samples 2858 and 2860 represent WT $(+/+)$ mice. Genotype is given on top of the mouse numbers. A $5^{\prime}$ loxP $/ 5^{\prime}$ FRT reaction. B $3^{\prime}$ FRT reaction. C 3' loxP reaction. 
Wildtype allele

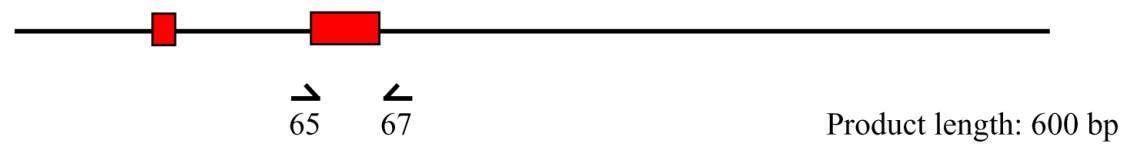

Mutated allele (knock-in)

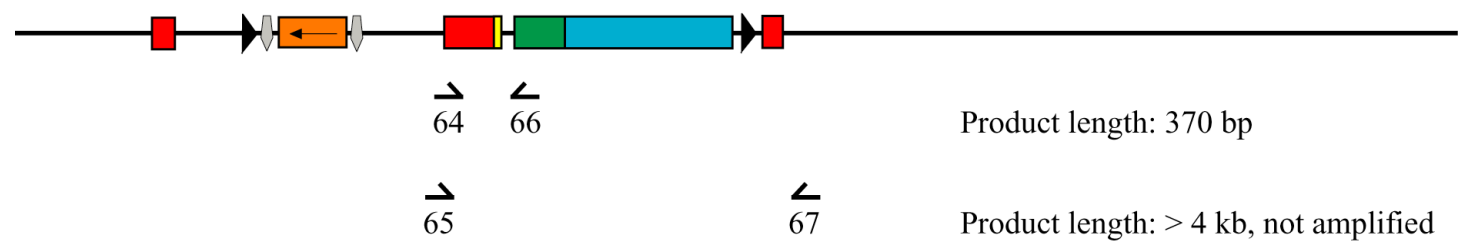

Figure 18 Routine PCR genotyping strategy of Nph3-KI mice. After the Nph3-KI mouse line was established, routine genotyping was performed by two PCR reactions, resulting in amplified fragments with detectable size difference between WT and Nph3-KI alleles. PCR primers are shown with arrows; the end of the arrow represents the position of the primer. Red boxes $=$ exons, orange box $=$ neomycin resistance gene $\left(n e o^{R}\right)$, yellow box $=$ Flag epitope, green box $=$ internal ribosomal entry site (IRES), blue box = lactose catabolism gene (lacZ), dark triangles $=\operatorname{lox} P$ sites, grey arrows $=F R T$ sites. An example of the PCR pattern is shown in figure 30, in connection with Nph3-KO DNA samples.

\subsection{Analysis of neurexophilin 3 knock-in mice}

\subsubsection{Expression of neurexophilin 3 in the brain}

Based on the co-expression of $\beta$-galactosidase by Nph3-expressing cells in Nph3-KI mice, the expression pattern of $\mathrm{Nph} 3$ in the mouse brain was revealed by assaying for $\beta$-galactosidase activity. The Nph3 expression was studied in adult mice, as well as during ontogeny, starting from embryonic day 16 (E16). The high sensitivity and specificity of the $\beta$-galactosidase assay in combination with the localization of $\beta$-galactosidase in the nucleus of the expressing cells (due to the function of the fused nuclear localization signal), led to a clear staining pattern of the expressing cells. The assay was carried out on $60 \mu \mathrm{m}$ sagittal or coronal brain sections from mice of the line \#59. Sections from adult mice of the line \#73 were also assayed 
as a control, confirming the identical Nph3 expression in both lines. In addition, sections from WT adult and postnatal day 11 (P11) mice were assayed as negative controls, showing no staining in any area of the brain. As a control, in situ hybridization using a Nph3 probe was performed by Dr. Astrid Rohlmann (a colleague in our laboratory) on WT adult mouse brain sections, confirming expression in the major areas that were stained with the $\beta$-galactosidase assay (data not shown). In addition, Northern blot analysis of RNA extracts from brains of WT mice at age P1, P6, P10, P40 and adult (carried out by Dr. Astrid Rohlmann) showed constant levels of Nph3 expression in all of the above ages (data not shown), which agrees well with the $\mathrm{Nph} 3$ expression pattern during development, as revealed by the $\beta$-galactosidase assay.

\subsubsection{Expression in adult mice}

Expression of Nph3 in the central nervous system of adult knock-in mice was studied on sagittal sections and was observed mainly in the neocortex. In addition, a weaker expression was found on parts of the cerebellum.

\section{a) Expression in neocortex}

In the neocortex most stained cells were found along the entire layer VIc, right above the border between cortex and white matter. This is one of the earliest cell populations generated in the neocortex and, among other functions, serves as a source of corticothalamic axons (De Carlos and O'Leary 1992). Some scattered neurons also extend into higher sublayers of layer VI and beyond into the lower half of layer V. This pattern of expression in layers VI and V extends on most cortical areas (e.g. Oc1, Par1) with similar density. The principal staining pattern is shown in figure 19.

\section{b) Expression in cerebellum}

In the cerebellum Nph3 expression was observed in granule cells of lobules 9 (uvula) and 10 (nodule) of the vermis, as shown in figure 20. These are small cells and constitute the internal granule cell layer, a densely packed layer that is formed relatively late in development. Lobule 10 constitutes the vestibulocerebellum, which is the earliest part of the cerebellum in vertebrate evolution and controls eye movements and body equilibrium (Kandel et al., 2000). Lobule 9 is part of the spinocerebellum, an area involved in the control of limb movement (Kandel et al., 2000). 

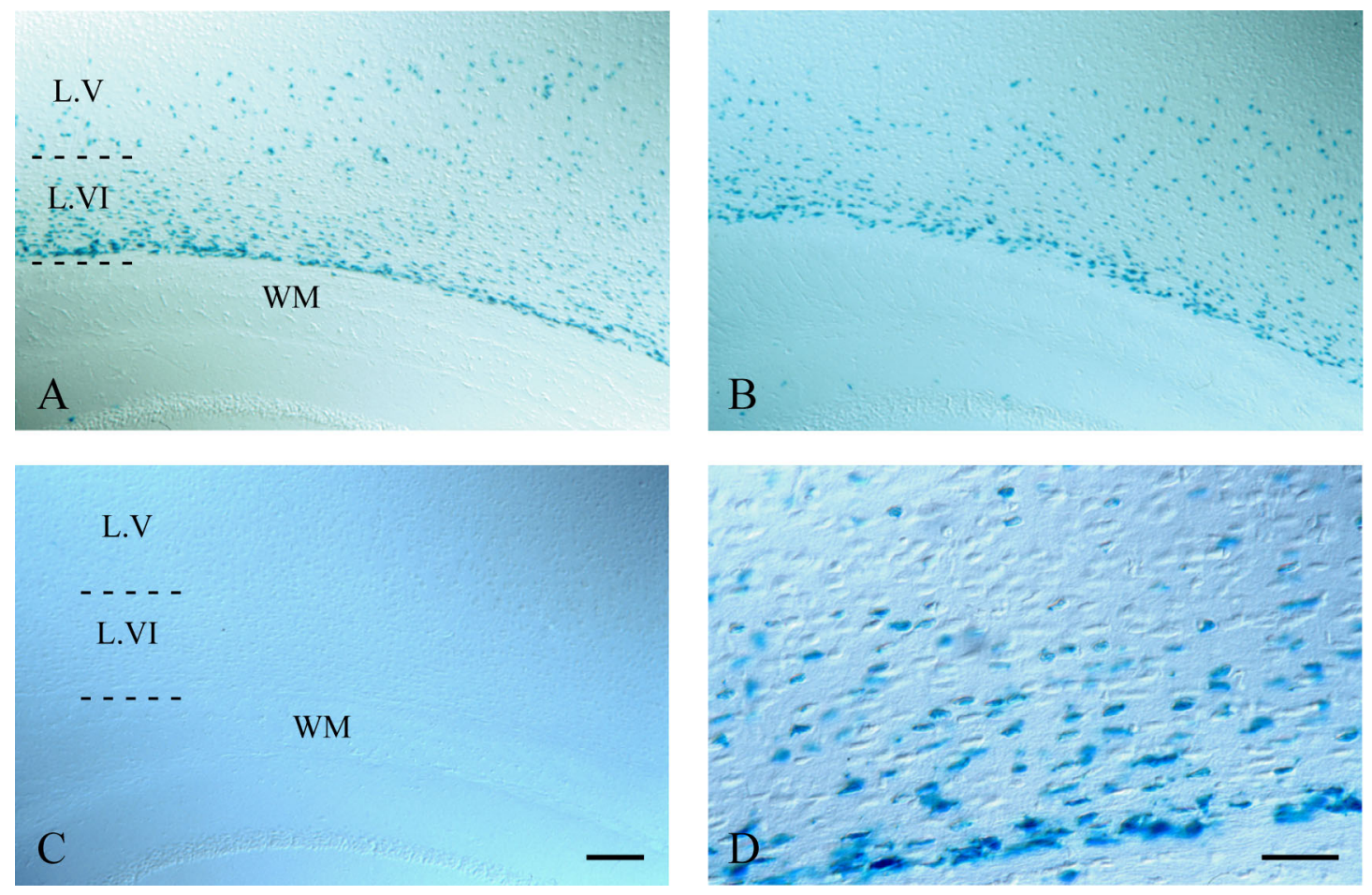

Figure 19 Expression of neurexophilin 3 in neocortex of adult mice. DIC microscope pictures of adult sagittal brain sections. A Nph3-KI \#59 line, B Nph3-KI \#73 line (heterozygous animal), C WT, D Nph3-KI \#59 line, high magnification. On picture $\mathrm{D}$ the horizontal shape of most of the expressing cells can be visualized. L.V. = layer V, L.VI = layer VI, WM = white matter. Scale bars: A, B, C: $300 \mu \mathrm{m}, \mathrm{D}: 100 \mu \mathrm{m}$.
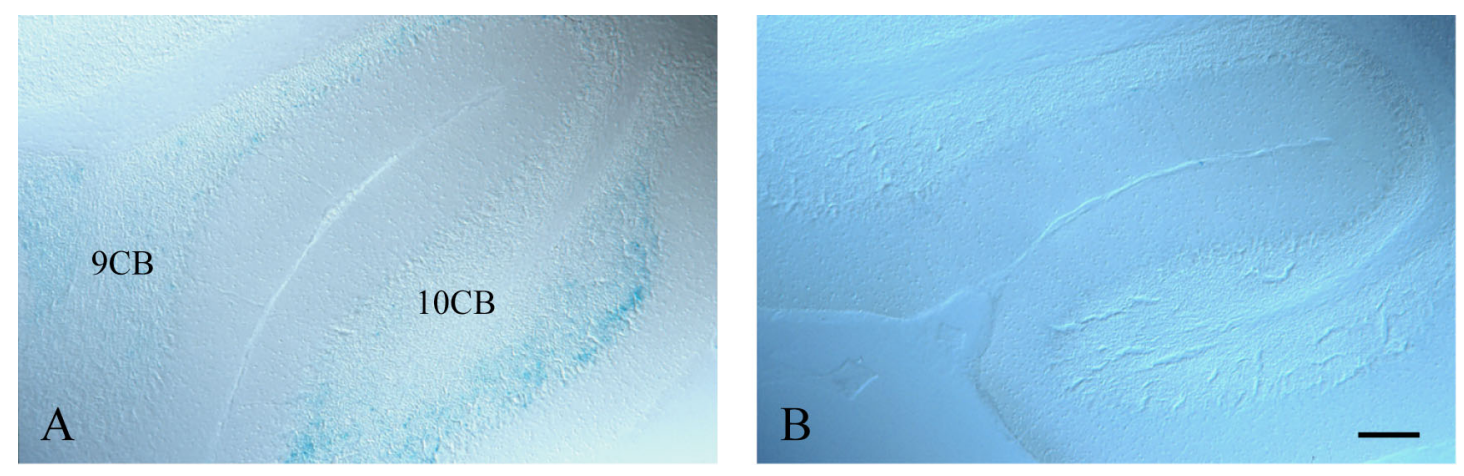

Figure 20 Expression of neurexophilin 3 in cerebellum of adult mice. DIC pictures of adult sagittal sections, showing Nph3 expression in the granule cells of lobule 9 (9CB, uvula) and 10 (10CB, nodule). A Nph3-KI \#59 line, B WT. Scale bar: $300 \mu \mathrm{m}$. 
In addition to the neocortex and cerebellum, expression of Nph3 in solitary cells was observed also in other regions of the brain, although at much lower levels. The following table summarizes all areas of Nph3 expression in the adult brain and compares the results of the $\beta$-galactosidase assay with those from in situ hybridization (Dr. Astrid Rohlmann, unpublished results), which was performed as a control experiment in order to confirm that epitope-tagged Nph3 is expressed naturally in the brain of Nph3-KI mice. To allow comparison of the expression patterns of the neurexin-binding isoforms in mice (Nph1 and Nph3), in situ hybridization was also performed using a Nph1 probe (by Dr. Astrid Rohlmann, unpublished results). These results are also summarized on the following table:

\begin{tabular}{|c|c|c|c|}
\hline & $\beta$-galactosidase & \multicolumn{2}{|c|}{ In situ hybridization } \\
\hline Brain region & Nph3 & Nph3 & Nph1 \\
\hline Cerebral cortex & $\begin{array}{l}\text { Strong band of } \\
\text { labeled neurons in } \\
\text { layer VIc, spotted } \\
\text { staining in upper } \\
\text { layer VI, layer V }\end{array}$ & $\begin{array}{l}\text { Band of labeled } \\
\text { neurons in layer VIc, } \\
\text { spotted staining of } \\
\text { large layer V neurons }\end{array}$ & $\begin{array}{l}\text { Numerous scattered } \\
\text { neurons throughout } \\
\text { cortical layers } \\
\text { (highest in } 1 . \mathrm{VI}, \mathrm{V}, \\
\text { lowest in } 1 . \mathrm{I} \text { ), spotted } \\
\text { staining in piriform } \\
\text { cortex and cortex- } \\
\text { amygdala transition } \\
\text { zone }\end{array}$ \\
\hline $\begin{array}{l}\text { Hippocampal } \\
\text { formation }\end{array}$ & $\begin{array}{l}\text { Small number of } \\
\text { stained cells in the } \\
\text { hilar region }\end{array}$ & $\begin{array}{l}\text { Uniform staining of } \\
\text { CA region, staining } \\
\text { in dentate gyrus, } \\
\text { staining of subiculum }\end{array}$ & $\begin{array}{l}\text { Scattered neurons in } \\
\text { dentate gyrus and } \\
\text { especially in hilar } \\
\text { region }\end{array}$ \\
\hline Cerebellum & $\begin{array}{c}\text { Granule cell layer of } \\
\text { lobules } 9,10\end{array}$ & $\begin{array}{l}\text { Weak staining of } \\
\text { Purkinje cells }\end{array}$ & No staining \\
\hline Olfactory bulb & No staining & No staining & Periglomerular cells \\
\hline Brainstem & Single cells & Possibly single cells & $\begin{array}{l}\text { Spotted staining of } \\
\text { single neurons }\end{array}$ \\
\hline Other regions & $\begin{array}{l}\text { Spotted staining in } \\
\text { superior culliculi }\end{array}$ & $\begin{array}{c}\text { Amygdaloid } \\
\text { complex: } \\
\text { cortical amygdaloid } \\
\text { nucleus, basolateral } \\
\text { amygdaloid nucleus }\end{array}$ & $\begin{array}{l}\text { Staining of thalamic } \\
\text { nuclei: } \\
\text { Reticular thal. nuclei } \\
\text { Anderod. thal. nuclei } \\
\text { Mediod. thal. nuclei } \\
\text { Reuniens thal. nuclei } \\
\text { Interant. dors. thal. } \\
\text { nuclei }\end{array}$ \\
\hline
\end{tabular}


As shown on the table, the main area of Nph3 expression as revealed by the $\beta$-galactosidase assay, i.e. the deep layers of the neocortex, is also an area of major staining by in situ hybridization. Some staining differences between the two methods are observed in other regions, which reflects the different nature of the two methods and perhaps the strain difference between the assayed mice or the contribution of background labeling in in situ hybridization staining. The $\beta$-galactosidase assay produced a high signal-to-noise ratio resulting in distinct staining even of single cells, e.g. in the hippocampal formation or the brainstem, where staining with in situ hybridization was not very clear. In conclusion, the Nph3 expression pattern was similar between the two methods, especially in the major area of expression, the layers VI and V of the neocortex, although minor differences were observed in other areas. Nph1 expression is observed mostly in interneuron populations, as previously hypothesized (Petrenko et al., 1996). Its expression pattern is clearly different from that of Nph3, especially in the neocortex where Nph3 exhibits a strong band of expressing cells in layer VIc, while Nph1 expression is scattered. However the two isoforms are not expressed in a complementary fashion, which suggests that they perform clearly different functions.

\subsubsection{Expression during ontogeny}

The neurons of layer VIc of the neocortex, where expression of Nph3 was mainly observed in adult mice, are among the earliest formed neurons of the cortical plate. This led to the hypothesis that $\mathrm{Nph} 3$ is probably expressed also in other developmentally early neuronal populations. The simplicity and high sensitivity of the $\beta$-galactosidase assay allowed to screen various developmental stages for $\mathrm{Nph} 3$ expression.

Interestingly, Nph3 expression appeared to rely on a developmentally regulated fashion. In general, Nph3 was highly expressed in some developmentally early neuronal populations, with expression levels decreasing as the animal approaches maturity. The major band of expressing cells in the layer VIc of the adult neocortex was also present during ontogeny, as well as the granule cell population of the cerebellum. In addition, expressing cells were observed in a number of transient cell populations in the marginal zone of the neocortex and the hippocampal formation. Expression of Nph3 was also observed in the nasal epithelium, a structure that was only visualized in embryonic sections, since these samples were cut using the whole head, in contrast to sections from postnatal mice where only the brain was used in most experiments. 


\section{a) Expression in neocortex}

The majority of stained neurons during the first postnatal week appeared in the subplate of the cortical anlage. During the following weeks, stained cells are progressingly found also in the upper layers, reaching the adult pattern at P20. Additionally, transient Nph3 expressing cells were observed perinatally in the marginal zone. Most of these cells had an bipolar, horizontally oriented appearance, leading to the assumption that they probably represent Cajal-Retzius cells. At P3 a few of these cells were still present. These two populations of cells, the cells of the subplate and the Cajal-Retzius cells, are connected early in development, since they both derive from the preplate, which is the most early formed cortical area (Allendoerfer and Shatz, 1994). Expression of Nph3 in these two cell populations implies a possible function in the development of early primordial circuits, formed between the marginal zone and the subplate. Figure 21 shows the staining pattern in the neocortex from E16 to P20.

Figure 21 Expression of neurexophilin 3 in neocortex during ontogeny. DIC microscope pictures of sections from E16 to P20 mice. Coronal sections from E16 and E18 and sagittal sections from P1 to P20 mice were used. Mouse age is shown on the pictures. $\mathrm{P} 1$ (magn) = high magnification picture of $\mathrm{P} 1$. As shown in the $\mathrm{P} 1$ pictures, Nph3 is expressed at this age only in cells of the subplate and the marginal zone, which are the earliest layers formed in the neocortex after differentiation of the preplate. $\mathrm{MZ}=$ marginal zone, $\mathrm{CP}=$ cortical plate, $\mathrm{SP}=$ subplate, $\mathrm{RSC}=$ retrosplenial cortex, $\mathrm{CRC}=$ possible Cajal-Retzius cells. Scale bars: $300 \mu \mathrm{m}$, apart from P1(magn): $100 \mu \mathrm{m}$. 

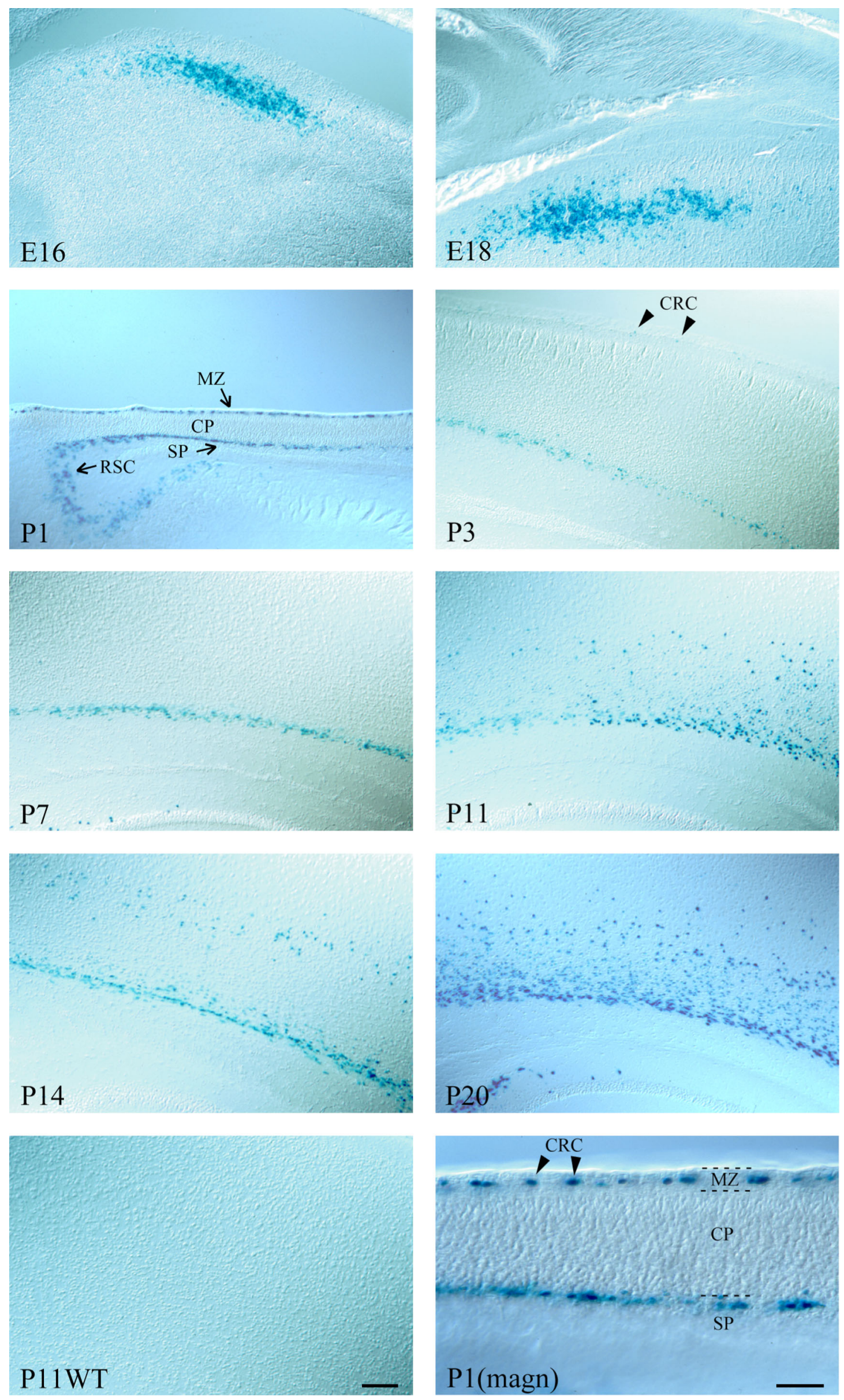


\section{b) Expression in cerebellum}

Reflecting the relatively late development of the cerebellum, Nph3 expression occurs only after the first postnatal week. As in adult mice, staining was located in the granule cells of lobules 9 and 10 of the vermis, but in a higher number of cells. Representative sections from $\mathrm{P} 1$ to $\mathrm{P} 20$ are shown in figure 22 :
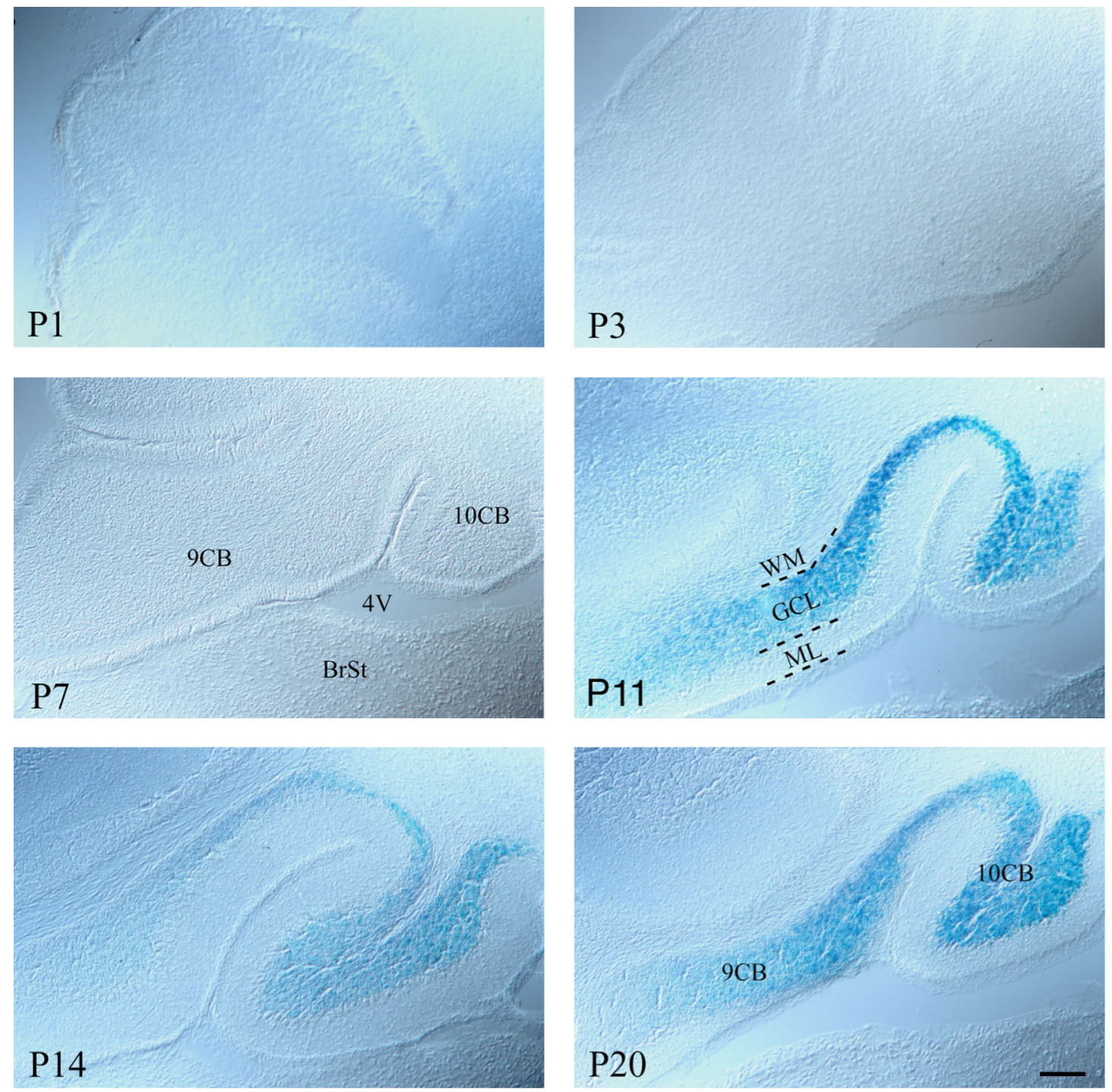

Figure 22 Expression of neurexophilin 3 in cerebellum during ontogeny.

DIC microscope pictures of sagittal sections from P1 to P20 mice, showing a sudden increase in Nph3 expression in the granule cell layer of lobules 9 and 10 of the cerebellum after the first postnatal week, which is still observed at P20. $9 \mathrm{CB}=$ lobule $9,10 \mathrm{CB}=$ lobule $10,4 \mathrm{~V}=$ fourth ventricle, $\mathrm{BrSt}=$ brain stem, $\mathrm{WM}$ $=$ white matter, $\mathrm{GCL}=$ granule cell layer, $\mathrm{ML}=$ molecular layer. Scale bar: 300 $\mu \mathrm{m}$. 


\section{d) Expression in hippocampal formation}

The hippocampal formation shows peak expression of Nph3 during the first postnatal week, that becomes more and more inapparent during the following weeks. Highest expression levels are seen in cells located in the molecular layer of the dentate gyrus, presumambly being Cajal-Retzius cells. After the second postnatal week, some scattered neurons in the hilar region become Nph3 positive and are the only ones that are still present in adult mice. Figure 23 demonstrates the staining pattern in the hippocampal formation from E18 to P20.

\section{e) Expression in nasal cavity}

In embryonic stages E16 and E18, Nph3 is also expressed in populations of sensory neurons outside the central nervous system. These include olfactory neurons of the nasal epithelium and neurons of the vomeronasal organ, as shown in figure 24. Neurons of the nasal epithelium are the mediators of the sense of smell, stimulated mainly by volatile odors, and project into glomeruli of the main olfactory bulb (Paxinos, 1995). On the other hand, neurons of the vomeronasal organ are exposed to non-volatile odor molecules and project into the accessory olfactory bulb, a structure that does not exist in humans (Paxinos, 1995). These neurons are involved in pheromone recognition.

\section{Figure 23 Expression of neurexophilin 3 in hippocampal formation during ontogeny.}

DIC microscope pictures of a coronal section from E18 and sagittal sections from P1 to P20 mice. High Nph3 expression is observed in the first postnatal days in the molecular layer of the dentate gyrus, decreasing during the second and third weeks. $\mathrm{SO}=$ stratum oriens, $\mathrm{SP}=$ stratum pyramidale, $\mathrm{SR}=$ stratum radiatum, $\mathrm{CA} 1, \mathrm{CA} 3=$ subregions of the hippocampus proper, $\mathrm{DG}=$ dentate gyrus, $\mathrm{H}=$ hilar region, $\mathrm{ML}=$ molecular layer, $\mathrm{GCL}=$ granule cell layer. Arrowheads point to possible Cajal-Retzius cells (CRC). Scale bar: $300 \mu \mathrm{m}$. 

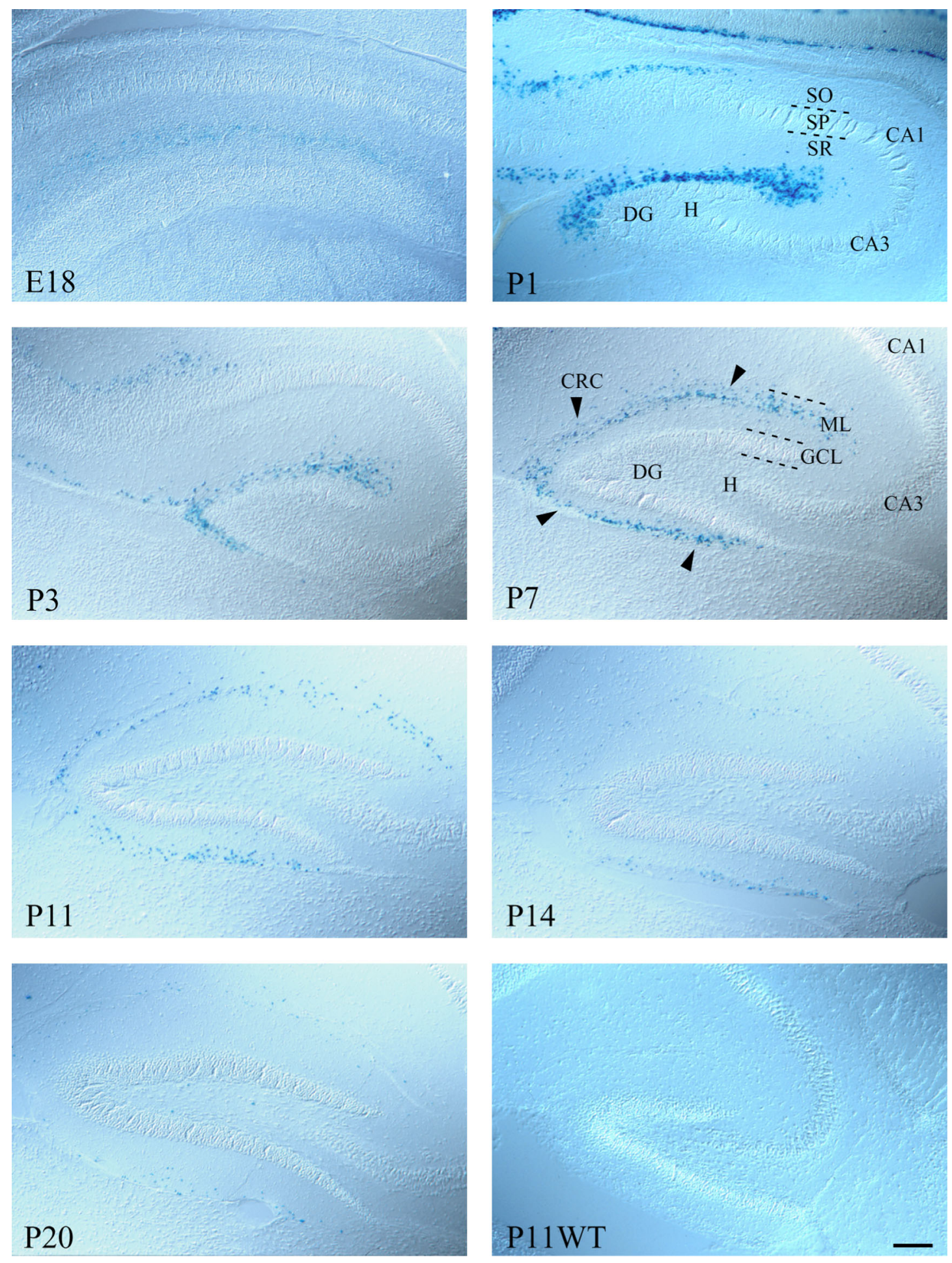

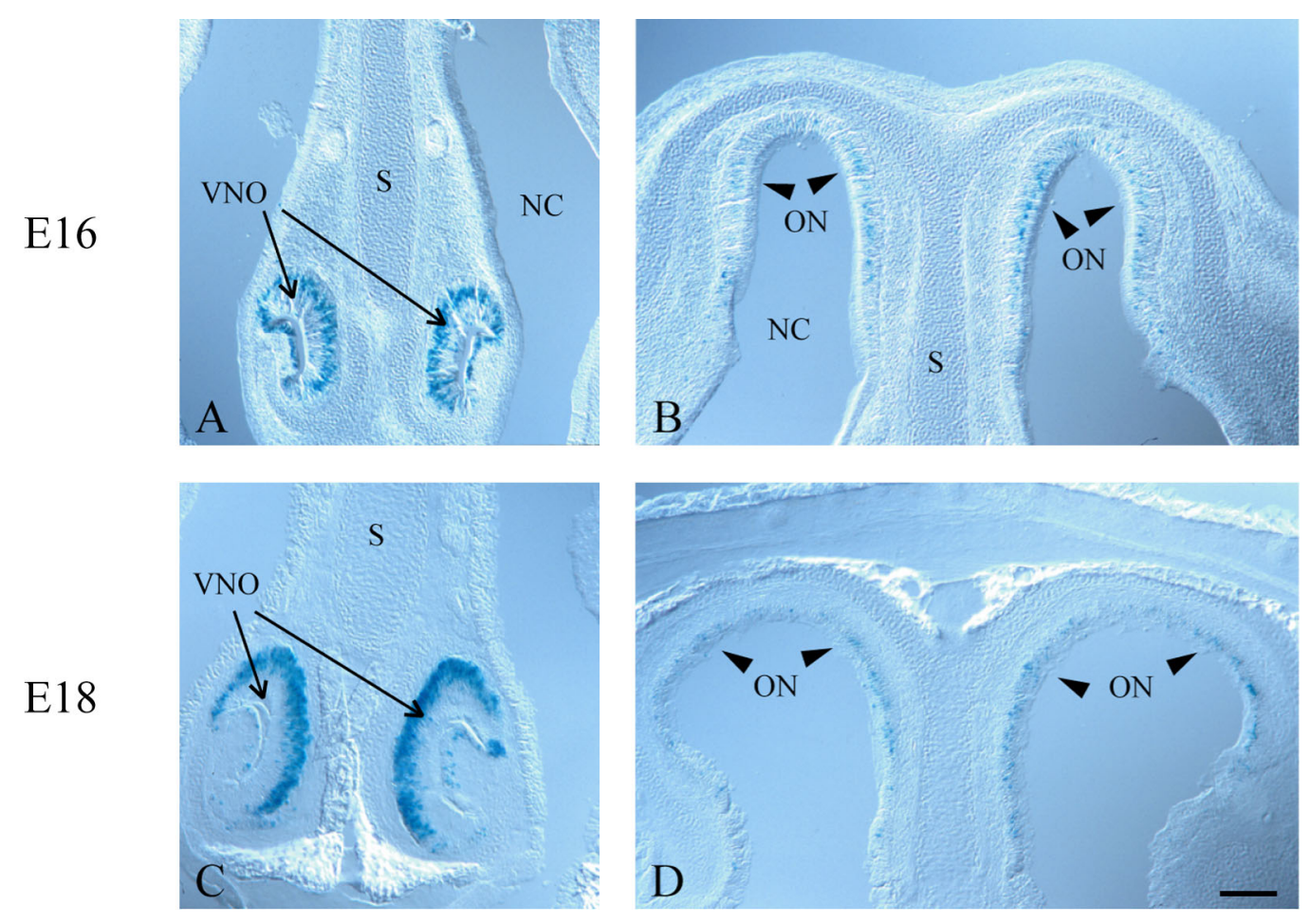

Figure 24 Expression of neurexophilin 3 in embryonic nasal cavity. DIC microscope pictures of the nasal cavity of coronal sections from E16 (A, B) and E18 (C, D) mouse embryos. $\mathrm{VNO}=$ vomeronasal organ, $\mathrm{S}=$ nasal septum, $\mathrm{NC}=$ nasal cavity, $\mathrm{ON}=$ olfactory neurons. Scale bar: $300 \mu \mathrm{m}$.

\subsubsection{Expression of neurexophilin 3-Flag fusion protein}

Expression of the Nph3-Flag fusion protein in Nph3-KI mice was tested by reverse transcriptase PCR, RT-PCR (Dr. Astrid Rohlmann), resulting in the detection of the correct fusion protein mRNA, as shown in figure 25 .

Detection of the localization of the fusion protein in the brain was attempted in the current study by means of immunohistochemistry using anti-Flag antibodies. However, no clear localization pattern was observed (data not shown). This was probably due to the very low abundance of neurexophilins in the brain, which makes them difficult to be distinguished from background staining. Western blot analysis of total brain extracts using anti-Flag antibodies also showed no specific signal (data not shown), probably due to the same reason. 
A

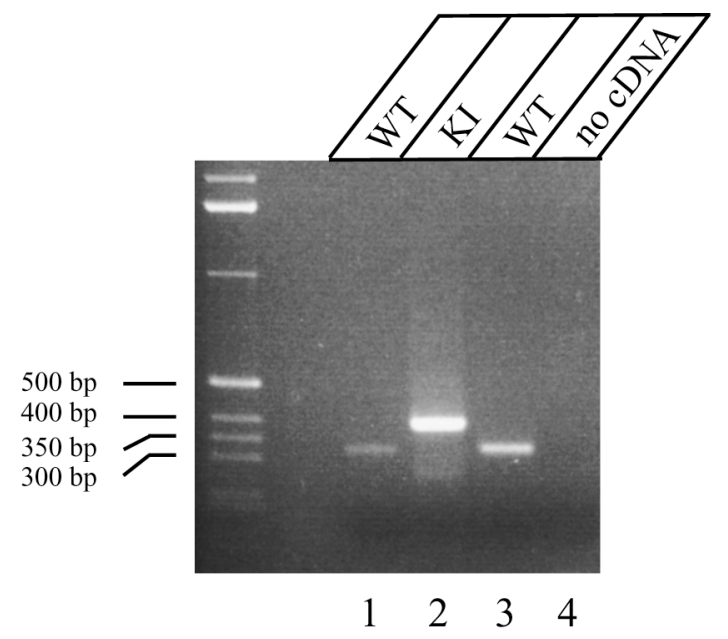

B

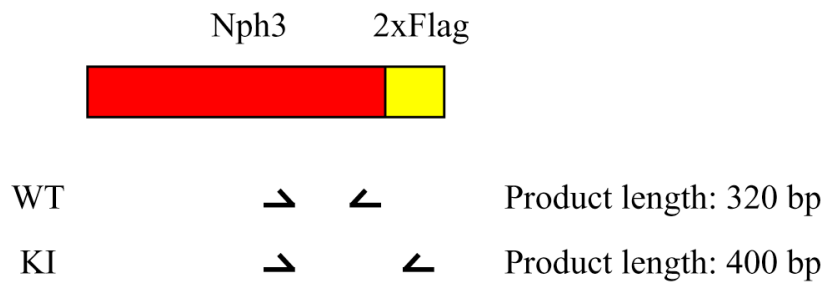

Figure 25 Reverse transcriptase PCR analysis of neurexophilin 3-Flag expression (experiment performed by Dr. Astrid Rohlmann). A RT-PCR result. cDNA was synthesized using oligodT primer (annealing on the polyA sequence of mRNAs) using as template RNA purified from a heterozygous Nph3-KI mouse brain extract. cDNA was then used in two PCR reactions with a WT specific and a Nph3-KI specific primer pair. Oligonucleotides 01-63/01-57 (WT reaction) and 01-63/01-62 (Nph3-KI reaction) were used as PCR primers. Fragments of the expected sizes were amplified from both reactions. The WT primer pair can amplify the respective fragment from both the WT and Nph3-KI alleles. Lanes 1, 3: WT reaction with different buffers, lane $2:$ Nph3-KI reaction, lane $4:$ control reaction with no cDNA, including both primer pairs. DNA sizes are given on the left of the picture. B RT-PCR strategy. The WT primer pair was designed to amplify a $320 \mathrm{bp}$ fragment at the C-terminus of Nph3. The same 5' primer was also used for the Nph3-KI reaction, together with a $3^{\prime}$ primer, that belongs to the $2 x$ Flag sequence, amplifying a $400 \mathrm{bp}$ fragment. 


\subsubsection{Double histochemical staining of brain sections for $\beta$-galactosidase and reelin/calretinin}

In order to characterize further the cell populations that express Nph3 in the neocortex and hippocampus, brain sections from P6 Nph3-KI mice were double stained for $\beta$-galactosidase and reelin or calretinin. This double staining method had already been applied successfully on transfected COS7 cells, although with a different antibody and a slightly different protocol (anti-Flag/DAB staining, see section 3.2.2.1). Reelin is an extracellular matrix protein, that is quite often used in histochemical procedures as a marker of Cajal-Retzius cells (D’Arcangelo et al., 1995, Ogawa et al., 1995). Calretinin is a calcium-binding protein expressed in Cajal-Retzius cells (Del Rio et al., 1995), in addition to other cell populations in the mouse brain.

As shown in figures 26, 27 the transient Nph3-expressing cell population in the dentate gyrus of the hippocampus, exhibit co-localization with reelin and calretinin, demonstrating that it most likely consists of Cajal-Retzius cells. Characterization of the above Nph3-expressing cells as Cajal-Retzius suggests that the Nph3-expressing cell population in the marginal zone around birth also comprises Cajal-Retzius cells.

In contrast, the major Nph3-expressing cell population, persisting in layer VIc of the cerebral cortex was calretinin-positive (figure 27), but reelin-negative (figure 26), providing further evidence that calretinin is not a representative molecule of a single cell type. The fact that this cell population was not stained for reelin indicates that it does not consist of Cajal-Retzius cells. A few calretinin-positive cells were observed also in other areas of the neocortex (not shown). Further characterization of them needs to be carried out.

Figure 26 Double staining for $\beta$-galactosidase and reelin. Staining pattern of P6 sagittal sections. Pictures on the left present the staining pattern, visualized under fluorescent microscopy, showing reelin staining. The same area is shown on the right, under DIC microscopy, demonstrating $\beta$-galactosidase staining. Note that $\beta$-galactosidase-positive cells appear black in the fluorescent microscopy pictures. A and $\mathbf{B}$ show pictures of the dentate gyrus of the hippocampus and $\mathbf{C}$ and $\mathbf{D}$ higher magnification pictures of the same area. In $\mathbf{E}$ and $\mathbf{F}$ high magnification pictures of layer VIc of the neocortex show no reelin staining in this area. $\mathrm{H}=$ hilar region, $\mathrm{GCL}=$ granule cell layer, $\mathrm{ML}=$ molecular layer, L.VIc $=$ layer VIc. Scale bars: A, B: $50 \mu \mathrm{m}, \mathrm{C}, \mathrm{D}, \mathrm{E}, \mathrm{F}: 30 \mu \mathrm{m}$. 

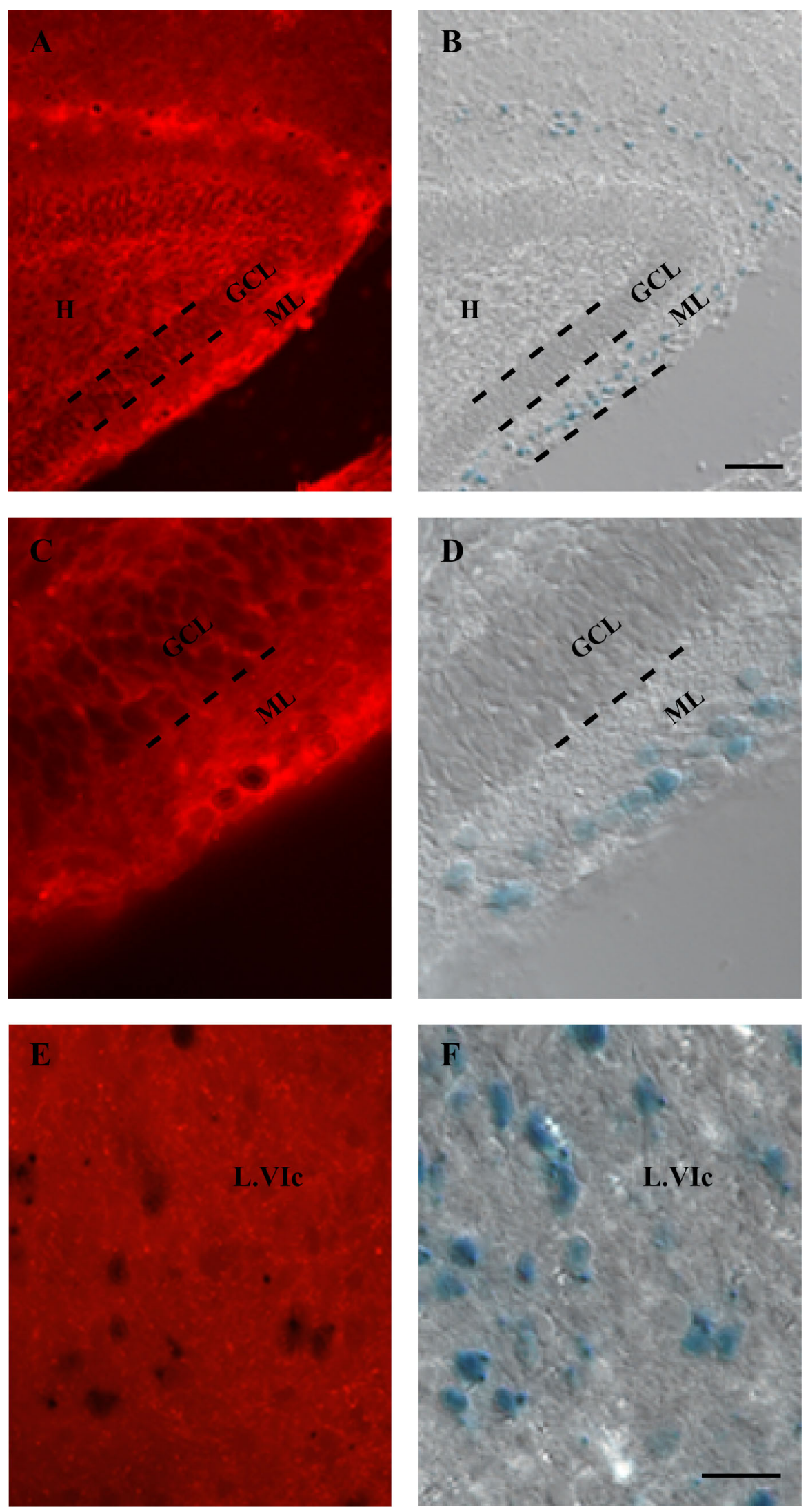

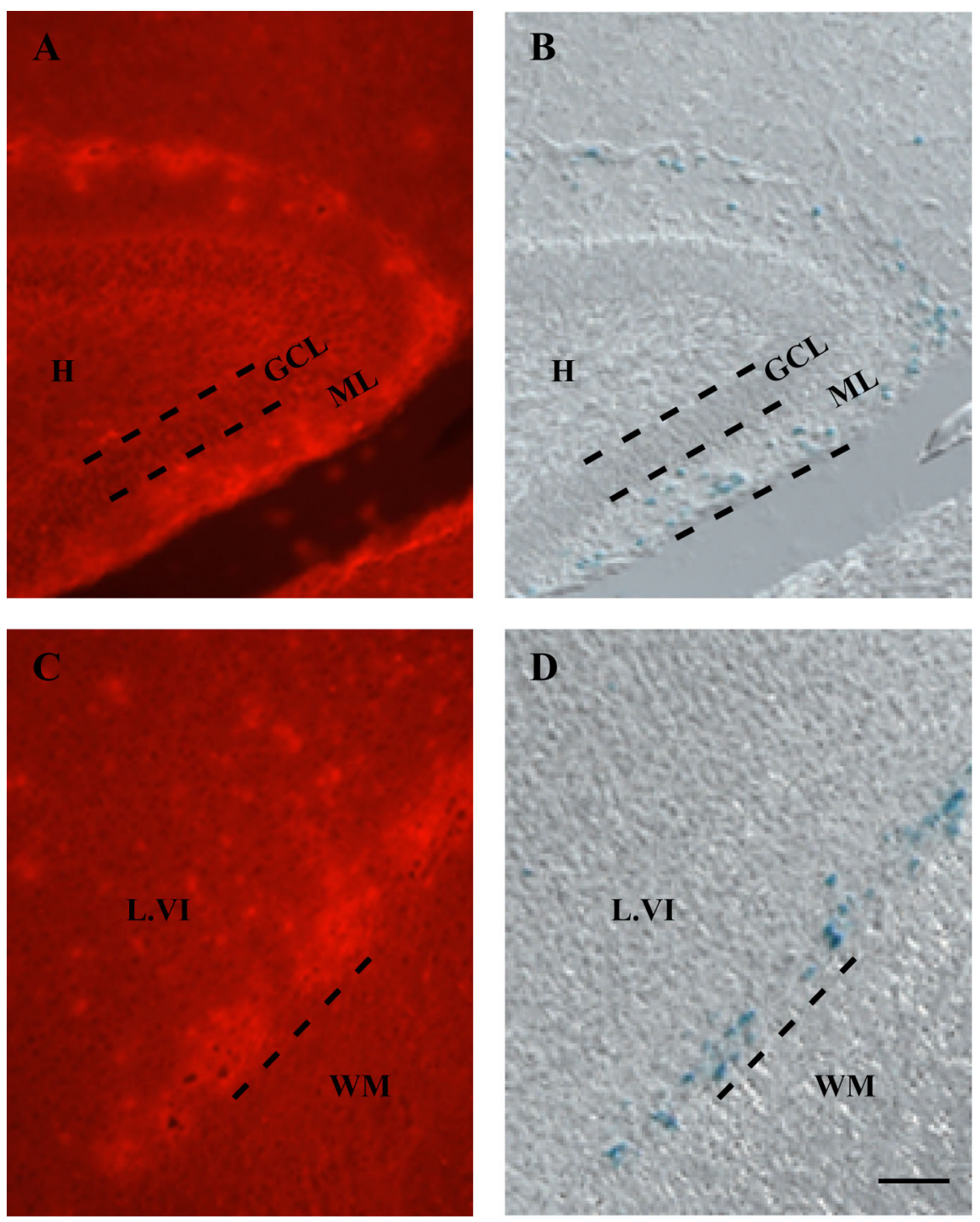

Figure 27 Double staining for $\beta$-galactosidase and calretinin. Staining pattern of P6 sagittal sections. As in figure 26, pictures on the left were visualized under fluorescent microscopy and pictures on the right under DIC microscopy. A and $\mathbf{B}$ show pictures of the dentate gyrus of the hippocampus and $\mathbf{C}$ and $\mathbf{D}$ pictures of layer VI of the neocortex. $\mathrm{H}=$ hilar region, $\mathrm{GCL}=$ granule cell layer, $\mathrm{ML}=$ molecular layer, $\mathrm{L} . \mathrm{VI}=$ layer VI, $\mathrm{WM}=$ white matter. Scale bar: $50 \mu \mathrm{m}$. 


\section{4 Generation of neurexophilin knock-out mouse lines}

\subsubsection{Generation of neurexophilin 3 knock-out mice}

Nph3-KO mice were generated by the use of the Cre-loxP system, based on the presence of loxP sites in the Nph3-KI mouse genome (see section 3.2 . 1). The Cre recombinase was provided by Cre-expressing transgenic mice, kindly provided by Dr. Nils Brose, Max Planck Institute for Experimental Medicine, Göttingen. In this mouse line the Cre recombinase is expressed under the control of the adenovirus EIIa promoter, which drives expression of the recombinase in the early mouse embryo (Lakso et al., 1996). Since the Cre transgene had been inserted in the mouse genome in a random, unknown position, heterozygous mice were used in order to avoid a potential dysfunction of a gene, if it was disrupted by the insertion of the transgene. A scheme demonstrating the recombination event and the composition of the resulting knock-out allele is given in figure 28 . 
Knock-in allele

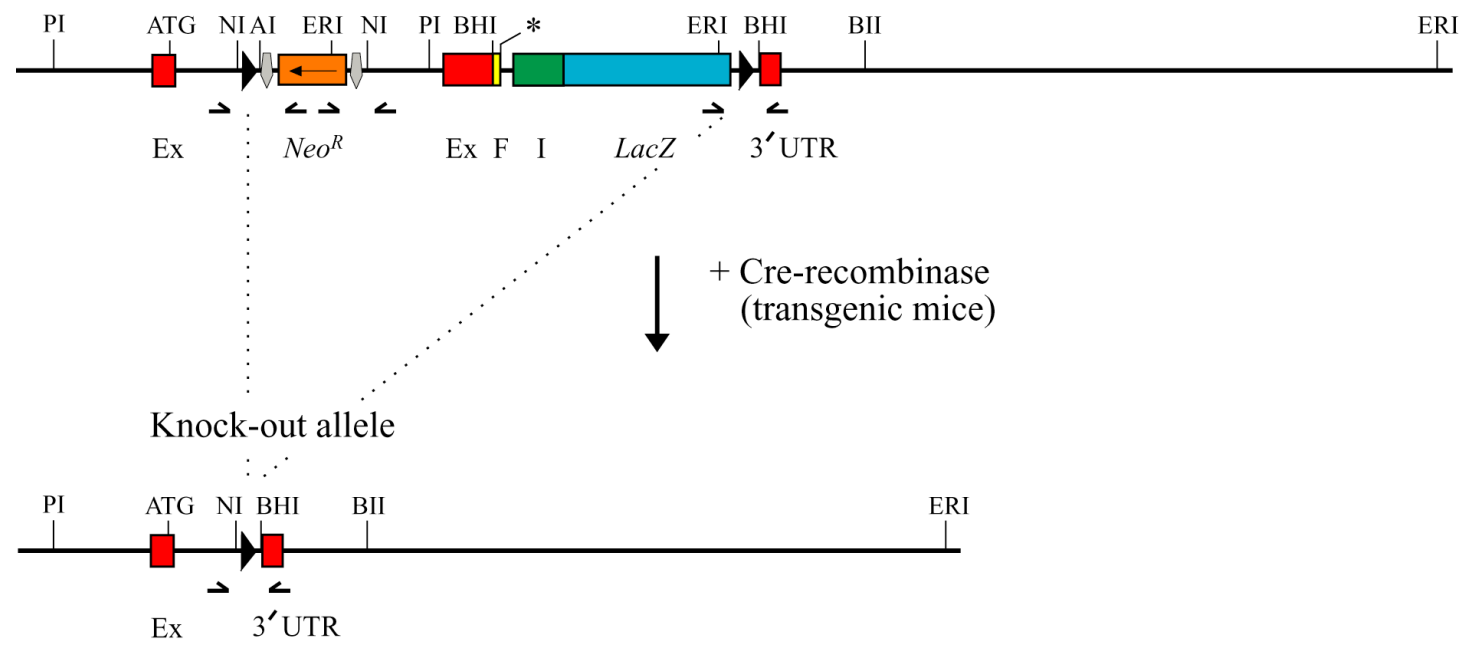

Figure 28 Generation of neurexophilin 3 knock-out mice. Nph3-KO mice were generated by mating Nph3-KI mice with Cre-expressing transgenic mice. Cre recombinase excised the area between the two loxP sites (shown as dark triangles) including the second Nph3 exon, resulting in a null mutant allele with a single loxP site at the position of the excised sequences. The position of the PCR primers that were used before for checking the integrity of the loxP and FRT sites in the Nph3-KI allele are shown with arrows. Note that the two outmost primers are in a very short distance from each other in the knock-out allele. This was taken into account in the initial design of the primers and enabled them to be used for genotyping of the knock-out mice. $*=$ stop codon, $\mathrm{Ex}=$ exon, ATG $=$ Start codon, $N e o^{R}=$ neomycin resistance gene, $\mathrm{F}=$ Flag epitope, $\mathrm{I}=$ internal ribosomal entry site (IRES), lac $Z=$ lactose catabolism gene, $3^{\prime}$ UTR $=3^{\prime}$ untranslated region, grey arrows $=F R T$ sites, restriction site abbreviations: $\mathrm{PI}=$ PstI, $\mathrm{NI}=$ NcoI, AI = AgeI, ERI = EcoRI, BHI = BamHI, BII = BgIII . 
The breeding strategy followed is shown in figure 29:

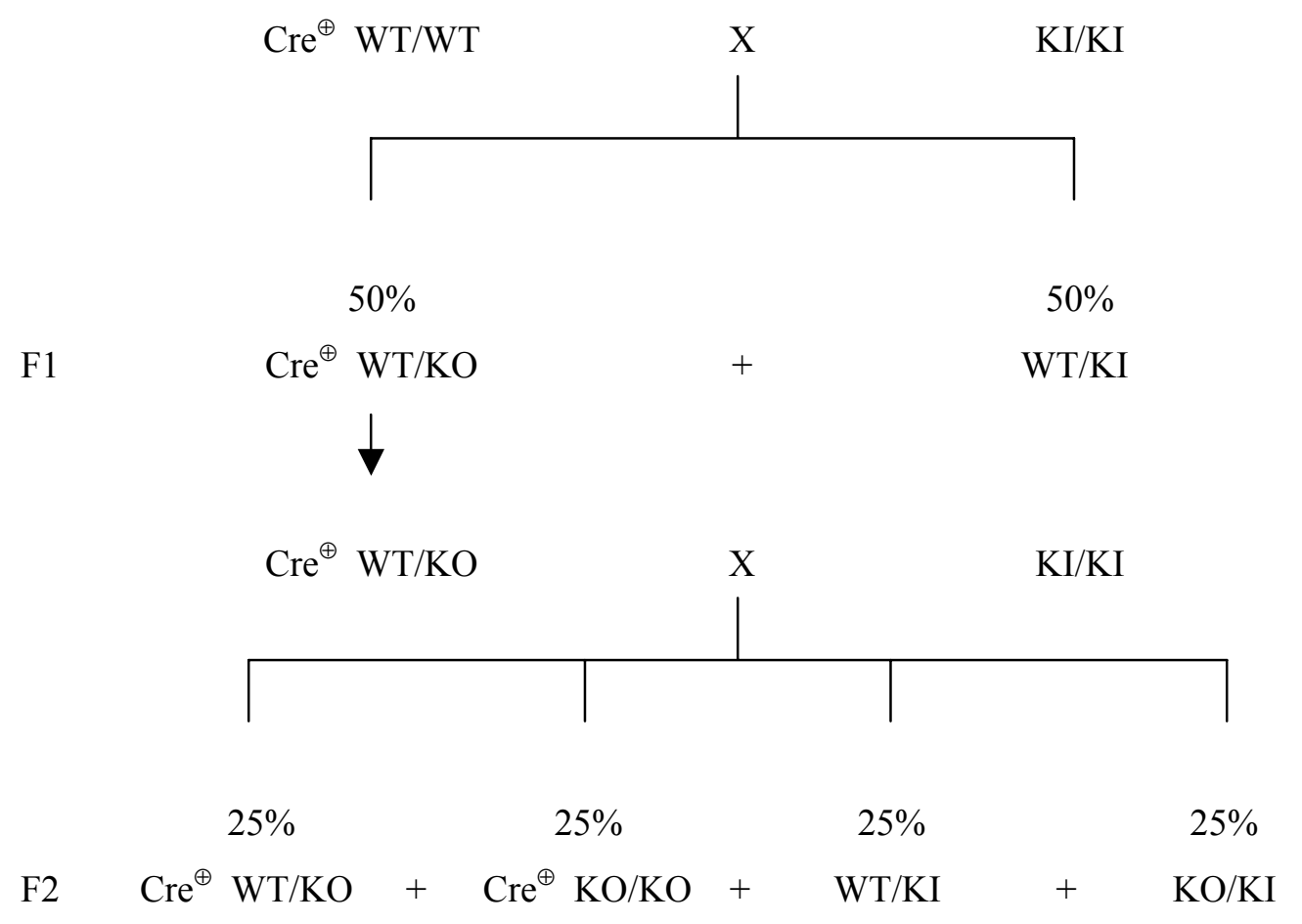

Figure 29 Neurexophilin 3 knock-out breeding strategy. The figure shows the breeding steps involved in the generation of Nph3-KO mice. The presence of the Cre allele is indicated as $\mathrm{Cre}^{\oplus}$. Nph3 allele genotype is shown as WT, KI or KO. The precentages above offspring genotypes indicate mendelian distribution. $\mathrm{X}=$ crossing, $\mathrm{F} 1, \mathrm{~F} 2$ = first, second generation. The resulting homozygous genotype is shown underlined.

\subsubsection{Establishment of the mouse line}

Mice were genotyped by PCR using the following reactions:

a) WT reaction, as described in section 3 .2 . 4. Product length: $600 \mathrm{bp}$

b) KI reaction, as described in section 3 . 2 . 4. Product length: $370 \mathrm{bp}$

c) KO reaction, using oligonucleotides 00-19/00-24 (oligonucleotides were also used for genotyping of KI mice, but in different combinations). Product length: $400 \mathrm{bp}$

d) Cre reaction, using an oligonucleotide pair. Product length: $500 \mathrm{bp}$ 
In the first generation offspring (20 mice), 17 mice were $\mathrm{Cre}^{\oplus} \mathrm{WT} / \mathrm{KO}(85 \%)$ and 3 mice WT/KI (15\%). However, 5 of the $\mathrm{Cre}^{\oplus} \mathrm{WT} / \mathrm{KO}$ mice also showed a faint band at the KI reaction, resulting from incomplete Cre-mediated $\mathrm{KI} \rightarrow \mathrm{KO}$ transformation. These mice were not used further. Genotyping of the second generation offspring (96 mice) provided the following result:

\begin{tabular}{|c|c|c|}
\hline Genotype & Number of mice & Precentage $(\%)$ \\
\hline $\mathrm{Cre}^{\oplus} \mathrm{KO} / \mathrm{KO}$ & 16 & 16.7 \\
\hline $\mathrm{Cre}^{\oplus} \mathrm{KO} / \mathrm{KI}$ (incomplete) & 12 & 12.5 \\
\hline other genotypes & 68 & 70.8 \\
\hline
\end{tabular}

$\mathrm{Cre}^{\oplus} \mathrm{KO} / \mathrm{KO}$ mice were further bred between them, establishing a homozygous KO line. These mice were viable, without any obvious morbidity, premature mortality or any other abnormality.

The PCR patterns of two DNA samples from different first generation offspring $\left(\mathrm{Cre}^{\oplus}\right.$ $\mathrm{WT} / \mathrm{KO}$ and $\mathrm{WT} / \mathrm{KI}$ ) are shown in figure 30. In addition, the patterns of DNA samples representing the genotype of the parental mice $\left(\mathrm{Cre}^{\oplus} \mathrm{WT} / \mathrm{WT}\right.$ and $\left.\mathrm{KI} / \mathrm{KI}\right)$ are also shown. In order to confirm that Nph3-KO mice do not express Nph3, i.e. that they are null mutant, 60 $\mu \mathrm{m}$ sagittal sections from adult $\mathrm{KO}$ mice were assayed for $\beta$-galactosidase activity. No staining was observed, as shown in figure 31, verifying the absence of Nph3 expression. 


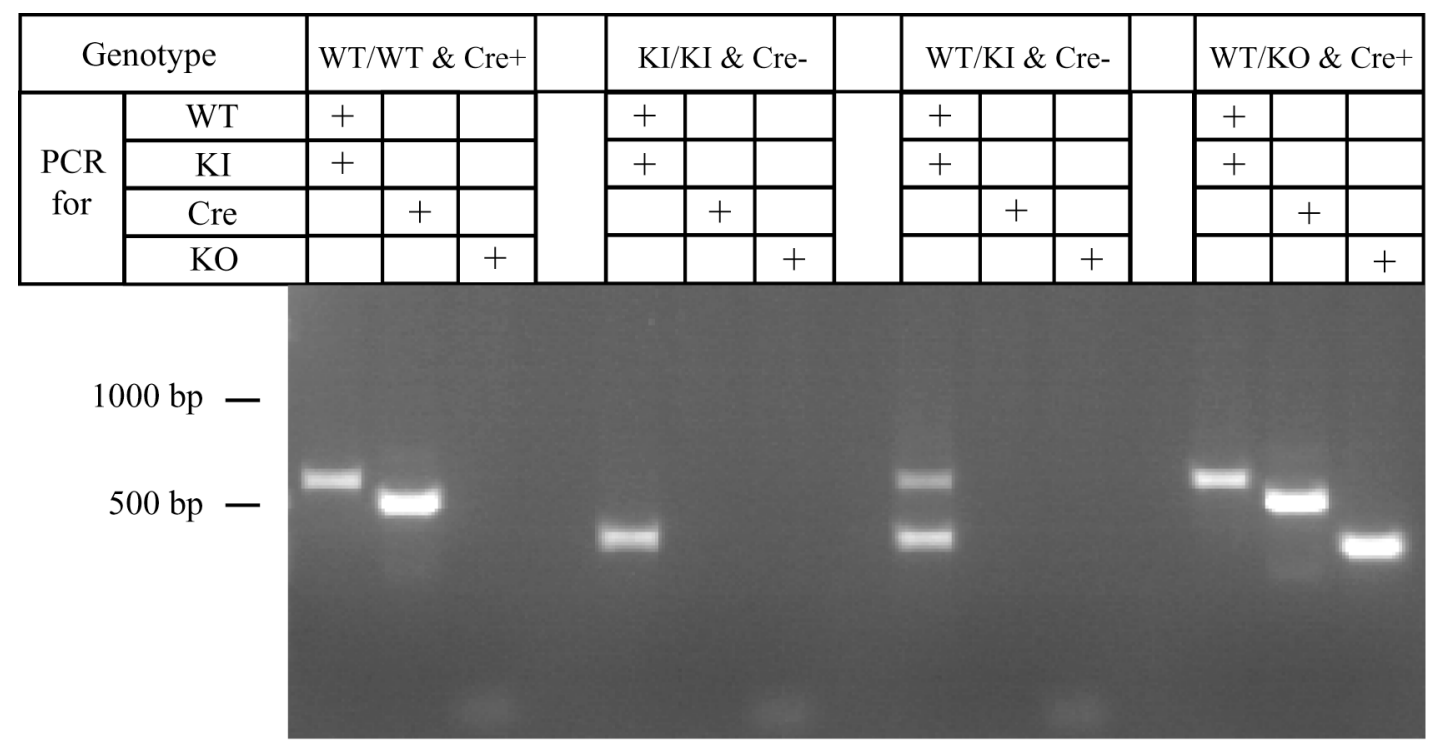

Figure 30 Routine genotyping of neurexophilin 3 knock-in and knock-out mice. The PCR genotyping patterns of a Cre-expressing transgenic mouse (WT/WT \& Cre+), a homozygous Nph3-KI mouse (KI/KI \& Cre-), a heterozygous Nph3-KI mouse (WT/KI \& Cre-) and a Cre-expressing, heterozygous Nph3-KO mouse (WT/KO \& $\mathrm{Cre}+$ ) are shown. The PCR reaction applied for each lane is indicated by a cross on top of the lane. WT and KI primer pairs were included in the same reaction mixture. DNA sizes are given on the left of the picture. 


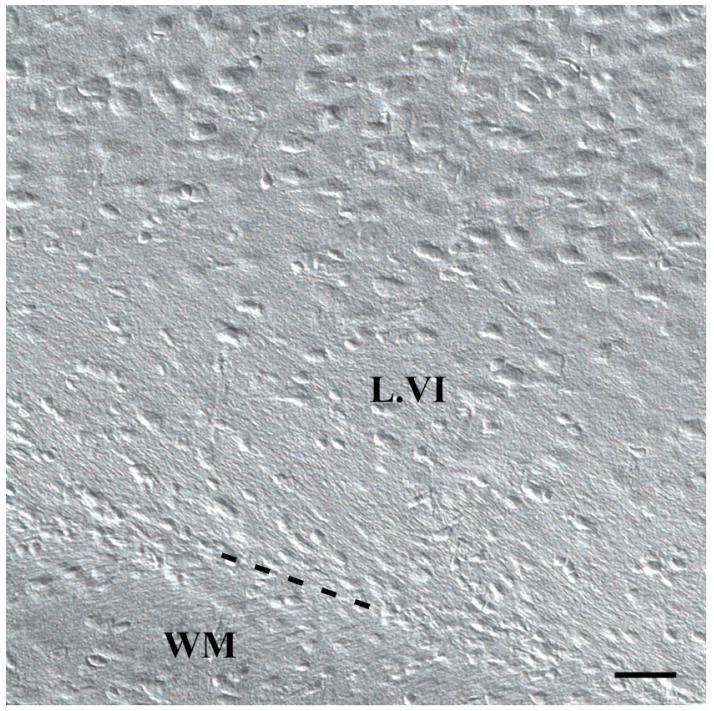

Figure $31 \quad \beta$-Galactosidase staining of Nph3-KO brain sections. DIC microscope picture, showing the layer VI of the neocortex of a sagittal section from an adult Nph3-KO mouse. No staining is observed, confirming the absence of $\mathrm{Nph} 3$ expression. $\mathrm{WM}=$ white matter, $\mathrm{L} . \mathrm{VI}=$ layer VI. Scale bar: $30 \mu \mathrm{m}$.

\subsection{2 Nissl staining of neurexophilin 3 knock-out mouse brain sections}

Nissl staining was performed on $30 \mu \mathrm{m}$ sagittal sections from adult Nph3-KO mouse brains, together with WT controls, in order to look for any defficiencies in the gross anatomy of the brain of Nph3-KO mice. As shown in the figure 32 no specific difference was observed. 

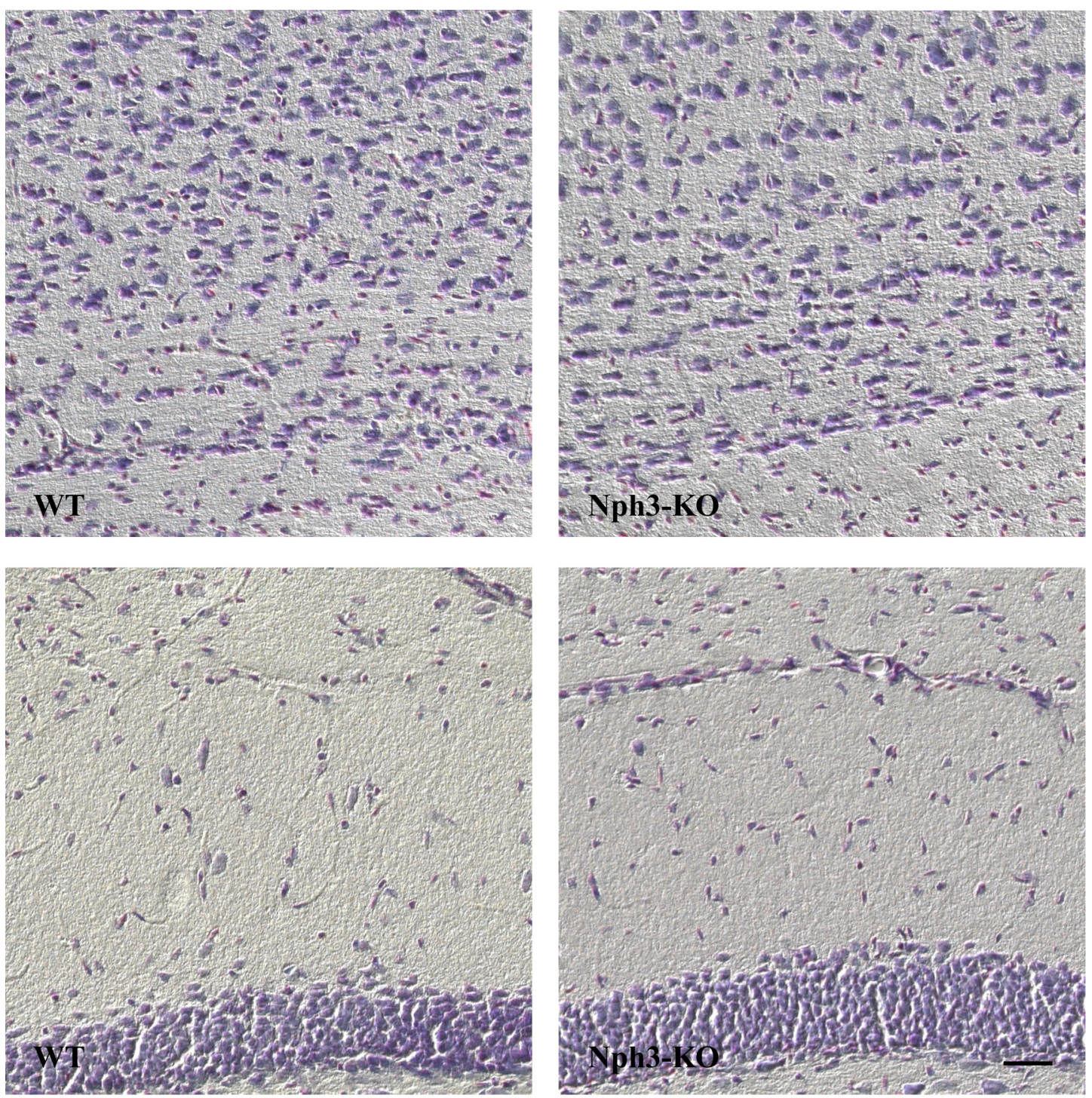

Figure 32 Nissl staining of Nph3-KO brain sections. DIC pictures showing Nissl staining of sagittal sections from WT (left panel) and Nph3-KO (right panel) adult mice. Pictures of the neocortex (layer VI) are shown on top and of the hippocampus (granule cell and molecular layers of the dentate gyrus) on the bottom. No apparent morphological difference was observed between WT and Nph3-KO sections. Scale bar: $30 \mu \mathrm{m}$. 


\subsubsection{Generation of neurexophilin 1/neurexophilin 3 double knock-out mice}

As described in the previous two sections, Nph3-KO mice exhibit no obvious morphological abnormality, compared to WT mice. This was the case also for Nph1-KO mice (Missler et al., 1998). In order to investigate the effect of the lack of both neurexophilin isoforms that are expressed in mice and are able to bind to $\alpha$-neurexins, a double Nph1/Nph3-KO mouse line was generated by breeding Nph3-KO with Nph1-KO mice.

\subsubsection{Establishment of the mouse line}

Homozygous knock-out mice from each line were used for breeding. The generation of double homozygous knock-out mice involved a series of multiple steps, due to the high variety of possible offspring genotypes. Double homozygous knock-out mice have already been obtained and are viable and fertile. A detailed analysis of them with respect to structural and functional properties will follow. Although the first double homozygous mice have been generated, a statistical analysis of the offspring genotypes is not currently possible, since the number of animals is not sufficiently high yet.

Five PCR reactions were used in genotyping. Three of them are identical to the WT (Nph3 allele), Nph3-KO and Cre reactions, described in section 3.4.1.1. The other two, used to characterize the Nph1 allele are the following:

a) WT (Nph1 allele) reaction, using oligonucleotides 01-73/01-75. Product length: $700 \mathrm{bp}$

b) Nph1-KO reaction, using oligonucleotides 01-70/99-18. Product length: $250 \mathrm{bp}$

An example of the genotyping pattern is given in figure 33, showing one Nph1 +/-, Nph3 -/sample, one Nph1 +/-, Nph3 +/+ sample, two Nph1 +/-, Nph3 +/- samples and one Nph1 +/+, Nph3 +/- sample. 
$\mathbf{A}$

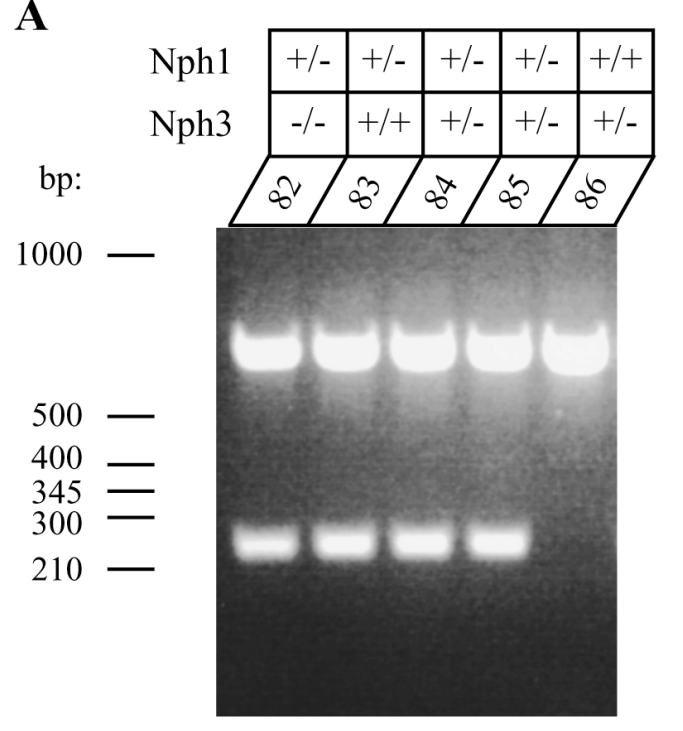

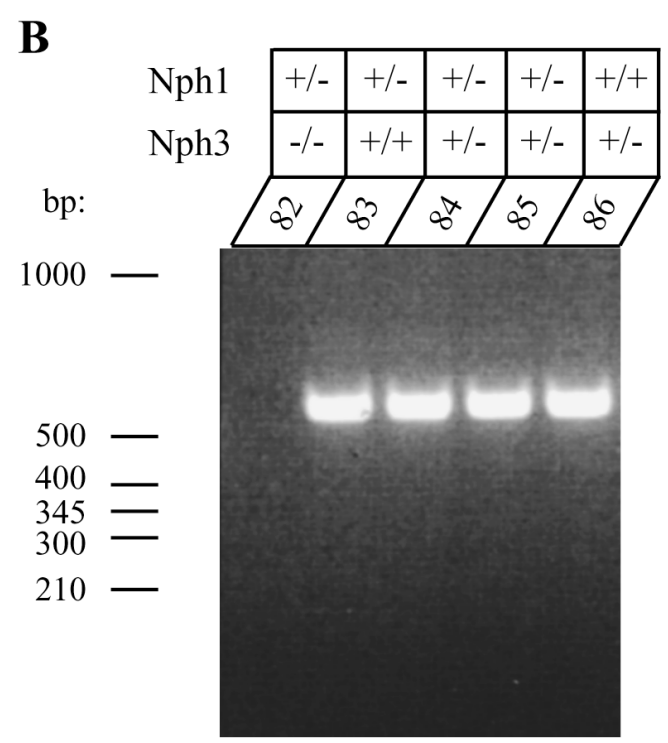

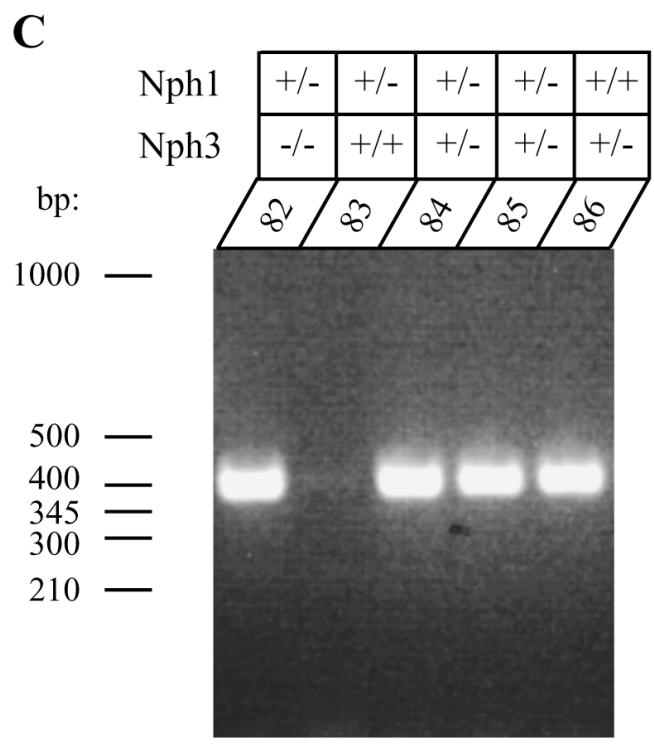

Figure 33 Genotyping of neurexophilin 1/neurexophilin 3 double knock-out mice. PCR genotyping patterns of five mice. A Nph1 WT/Nph1-KO reaction. Both primer pairs were included in the reaction mixture. Nph1 WT band: $700 \mathrm{bp}$, Nph1-KO band: 250 bp. B Nph3 WT reaction. Nph3-WT band: 600 bp. C Nph3 KO reaction. Nph3-KO band: 400 bp. Mouse numbers are given on top (82-86 : 5782-5786) and DNA sizes on the left of the pictures. Genotypes are shown on top of the mouse numbers. $+/+=$ homozygous $\mathrm{WT},+/-=$ hetrozygous $\mathrm{WT} / \mathrm{KO}$, -/- = homozygous KO. 


\subsubsection{Western blot analysis}

The absence of Nph1 and Nph3 in the brain of double KO mice was confirmed by western blot analysis of brain extracts, using the anti-Nph1/3 F508 antibody. An $\alpha$-latrotoxin binding assay was applied, since this is the only so far method to detect endogenous neurexophilins at the protein level (Missler et al., 1998). The principle behind this assay relies on the binding of Nph1 and Nph3 to $\alpha$-neurexins, which are enriched by their binding to immobilized $\alpha$ latrotoxin. Binding of neurexophilins to $\alpha$-neurexins can then be demonstrated.

Total brain extract was prepared from a double KO mouse as well as from a WT, a Nph3-KI and a Nph3-KO mouse as controls. It has to be noted that, since the F508 antibody recognizes both Nph1 and Nph3, this method, as in the case of Nph1-KO mice (Missler et al., 1998), is not able to confirm the absence of Nph3 in the brain of Nph3-KO mice. Brain extracts were incubated with $\alpha$-latrotoxin coupled on sepharose beads and bound proteins were analyzed by western blot (figure 34). A clear band at the size of Nph1/Nph3 was observed in the three control samples lanes but not in the double KO lane. Samples from the same assay were also used for a western blot using the anti-neurexin A473 antibody, in order to verify purification of neurexins from all extracts tested. The expected set of bands at the size of 160-220 kDa was present in all four lanes.

Figure 34 Wetsern blot analysis of neurexophilin 1/neurexophilin 3 double knock-out mice. A Western blot with anti-Nph1/3 antibody. Mouse brain protein extracts were analyzed by an $\alpha$-latrotoxin binding assay (pull-down), followed by western blot using the anti-Nph1/3 F508 antibody. Genotypes are given on top and protein sizes on the left of the picture. N3KO $=$ Nph3-KO, D$\mathrm{KO}=$ double KO. Nph1 and Nph3 are detected at the expected size in the WT, Nph3-KI and Nph3-KO samples, but not in the Nph1/Nph3 double KO sample. B Western blot with anti-neurexin antibody. In order to verify that the absence of a neurexophilin band in the double $\mathrm{KO}$ lane of the above western blot is not an artifact, samples from the same binding assay were analyzed by western blot using the anti-neurexin A473 antibody. Binding of $\alpha$-neurexins to $\alpha$-latrotoxin is a prerequisite for the presence of neurexophilins in the products of the above assay. As shown in the picture, $\alpha$-neurexins are detected in all lanes, confirming that Nph1 and Nph3 are indeed absent in the brain of double KO mice. 

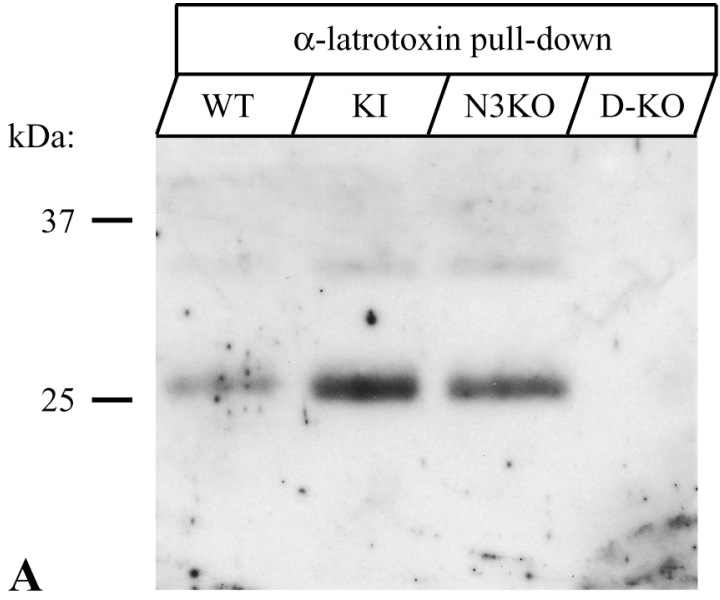

anti-Nph1/3 (F508)
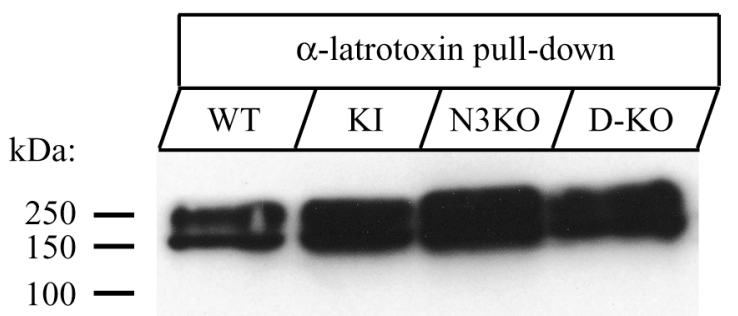

anti-neurexin (A473)

B ᄂ

\lrcorner 


\section{3 . 5 Expression of recombinant neurexophilins}

In parallel to the in vivo approach for the study of the role of neurexophilins, a recombinant protein expression system was established to enable production of sufficient amounts of protein for use in in vitro experiments (e.g. extracellular effect on neurons, binding studies). This was attempted using a bacterial system expressing either the full length mature protein (starting from the double lysine motif) or single domains of neurexophilins, fused to glutathione-S-transferase (GST). Expression constructs were cloned for Nph1, Nph3 and Nph4. Nph2 was not included in this study, since there is not enough information about it, due to its lack of expression in the mouse brain. Nph4 was also expressed, although it is not a typical neurexophilin, since it does not bind to neurexins, in order to be used as a negative control with regard to the function of neurexophilins via their binding to $\alpha$-neurexins. Four expression constructs were cloned for each isoform, containing the following domains: a) full length (FL), b) N-glycosylated domain (NG), c) N-glycosylated domain with linker (NGL) and d) cysteine-rich domain (CR). All expression sequences were cloned downstream and in frame of the GST sequence, which provides expressed proteins with the ability to bind to glutathione agarose beads and by this means, to be purified from the bacterial cytosol.

\subsubsection{Cloning of expression constructs}

pET-42b(+) was used as expression vector, containing a GST sequence upstream of its multicloning site. Expression with this vector is under control of the strong bacteriophage T7 promoter. A recognition sequence for factor $\mathrm{Xa}$ (an endoprotease) is also included in the above vector, between the GST sequence and the multicloning site enabling future removal of GST from the fused protein. Neurexophilin sequences were amplified by PCR from cDNA clones. The PCR products were cloned into the multicloning site of pET-42b(+) using restriction endonucleases, the sites of which were included in the 5' end of the PCR primers. The oligonucleotides that were used as PCR primers, as well as the respective restriction sites are given on the following table: 


\begin{tabular}{|c|c|c|}
\hline Expressed protein & $\underline{\text { PCR primers }}$ & $\underline{\text { Restriction sites }}$ \\
\hline Nph1-FL & $00-35 / 00-45$ & NcoI/BamHI \\
\hline Nph1-NG & $00-35 / 00-46$ & NcoI/BamHI \\
\hline Nph1-NGL & $00-35 / 00-47$ & NcoI/BamHI \\
\hline Nph1-CR & $00-39 / 00-45$ & NcoI/BamHI \\
\hline Nph3-FL & $00-30 / 00-31$ & NcoI/EcoRI \\
\hline Nph3-NG & $00-30 / 00-32$ & NcoI/EcoRI \\
\hline Nph3-NGL & $00-30 / 00-33$ & NcoI/EcoRI \\
\hline Nph3-CR & $00-34 / 00-31$ & NcoI/EcoRI \\
\hline Nph4-FL & $00-40 / 00-41$ & NcoI/EcoRI \\
\hline Nph4-NG & $00-40 / 00-42$ & NcoI/EcoRI \\
\hline Nph4-NGL & $00-40 / 00-43$ & NcoI/EcoRI \\
\hline Nph4-CR & $00-44 / 00-41$ & NcoI/EcoRI \\
\hline
\end{tabular}

\subsubsection{Determination of optimal expression conditions}

Expression and purification of recombinant proteins was performed using $50 \mathrm{ml}$ bacterial culture volume. Large scale expression $(500 \mathrm{ml})$ was also tested, without however resulting in satisfactory protein production. Therefore, expression and purification conditions were established using multiple $50 \mathrm{ml}$ bacterial cultures.

The T7 RNA polymerase that is required for transcription is provided by the host cell ( $E$. coli, BL21(DE3)) and is under the control of the lacUV5 promoter, activation of which is induced by the addition of IPTG to the bacterial culture. A range of IPTG concentrations from 0.01 $\mathrm{mM}$ to $1 \mathrm{mM}$ was applied. Concentrations $0.1-1 \mathrm{mM}$ were found to be optimal with no improvement of expression with concentrations higher than $0.1 \mathrm{mM}$. Therefore, $0.1 \mathrm{mM}$ was further used. A wide range of induction incubation times and temperatures were applied, summarized in the following tables:

\begin{tabular}{|c|}
\hline Incubation times $(\mathrm{h})$ \\
1 \\
1.5 \\
2 \\
4 \\
6 \\
7 \\
\hline
\end{tabular}

\begin{tabular}{|c|}
\hline Temperatures $\left({ }^{\circ} \mathrm{C}\right)$ \\
37 \\
30 \\
22 \\
20 \\
18 \\
\end{tabular}

The rationale behind applying an induction temperature lower than $37^{\circ} \mathrm{C}$ is that, at a low temperature production of recombinant protein may be favoured, instead of bacterial growth. In this case, longer induction time is usually necessary in order to compensate for the slower bacterial metabolism. The following table shows the optimal induction conditions found for the recombinant proteins of the current study and subsequently applied: 


\begin{tabular}{|c|c|}
\hline $\begin{array}{c}\text { N-glycosylated domains } \\
\text { N-glycosylated domains with linker } \\
\text { GST (control) }\end{array}$ & $37^{\circ} \mathrm{C}, 2 \mathrm{~h}$ \\
\hline $\begin{array}{l}\text { Full length mature proteins } \\
\text { Cysteine-rich domains }\end{array}$ & $18^{\circ} \mathrm{C}, 6-7 \mathrm{~h}$ \\
\hline
\end{tabular}

\subsubsection{Purification of expressed proteins}

Expressed proteins were purified from the cytosol fraction of sonication-lysed bacteria, based on the binding of GST to glutathione agarose beads. Various purification conditions were tested in order to establish an optimal protocol. Lysozyme incubation before sonication did not improve extraction of the purified protein and therefore was not further applied. The optimal glutathione agarose bead volume was found to be $50 \mu \mathrm{l}$ bed volume (100 $\mu 1$ of $50 \%$ slurry) for each $50 \mathrm{ml}$ culture. In addition, incubation of the bacterial lysate with $1 \%$ TritonX100 increased the yield of purified protein. The various fractions of the purification procedure were analyzed by SDS-PAGE, followed by Coomassie-blue staining. Figure 35 shows the SDS-PAGE analysis of a purification step during optimization of the general protocol, demonstrating the effect of TritonX100 incubation on the purification of Nph3-FL:

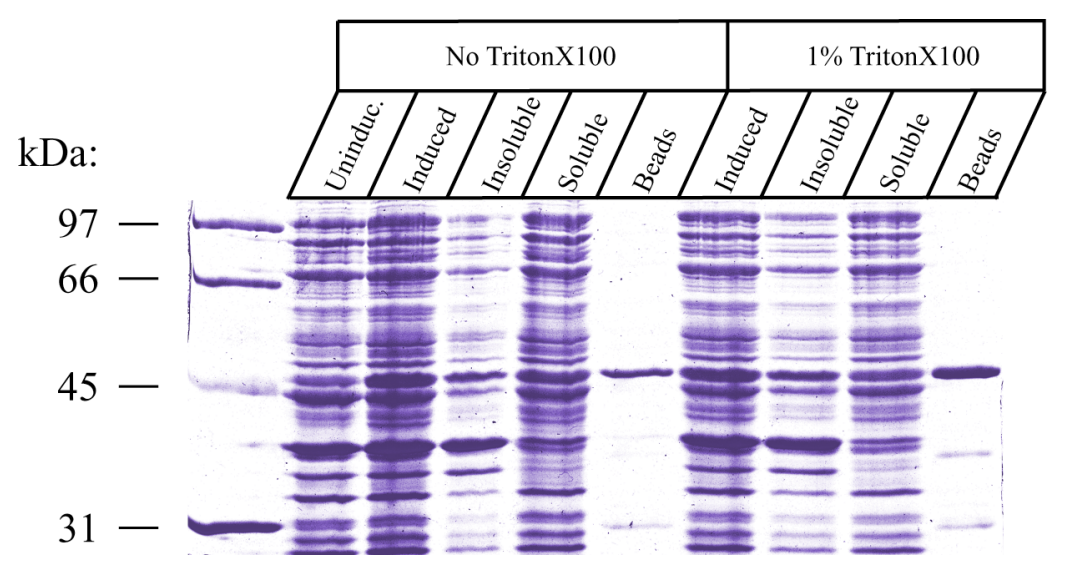

Figure 35 Effect of TritonX100 in the purification of recombinant Nph3-FL.

Samples taken from the various steps of Nph3-FL purification were loaded on an $10 \%$ SDS-PAGE gel, followed by Coomassie-blue staining. Uninduc. $=$ before induction, Induced $=$ after induction, Insoluble $=$ inclusion body fraction, Soluble $=$ soluble (cytosolic) fraction, beads $=$ bead-bound sample. Application of a TritonX100 incubation step is shown on top of the sample names. Protein sizes are given on the left. 
The N-glycosylated and N-glycosylated with linker domains of all three neurexophilins were found to be expressed and purified in higher amounts in comparison to the full length and cysteine-rich, although purification of Nph1-FL and Nph3-FL was quite satisfactory too. Figure 36 shows the SDS-PAGE analysis of the purification of all four domains of recombinant Nph3:
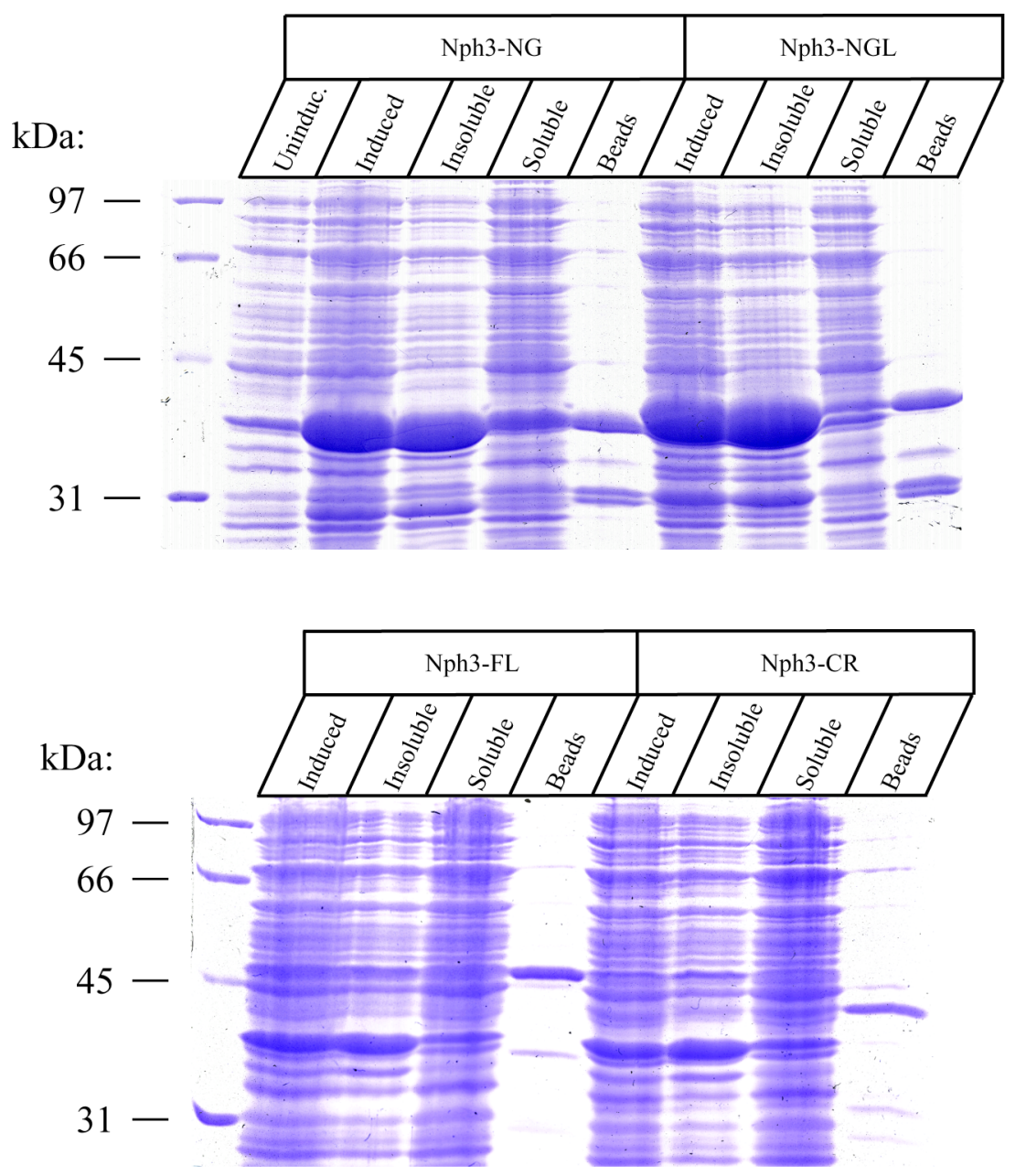

Figure 36 Purification of the different domains of Nph3-FL. Samples from the same fractions as in figure 35 of the purification of all four domains of $\mathrm{Nph} 3$ were loaded on a $10 \%$ SDS-PAGE gel, followed by Coomassie-blue staining. A TritonX100 incubation step was included in all purifications. N-glycosylated and $\mathrm{N}$-glycosylated with linker domains are produced in higher amounts than full length and cysteine-rich domains. Most of the expressed protein in all purifications was included in the inclusion body fraction. However, a significant amount was soluble and could be purified by binding to glutathione agarose beads. 
The better purification properties of the N-glycosylated domains, compared to the cysteinerich ones, led to the hypothesis that the presence of the six cysteines at the C-terminus of neurexophilins affects negatively the solubility of the recombinant proteins in the bacterial cytosol. In an attempt to overcome this problem, expression of the Nph1-FL, Nph3-FL and Nph4-FL was tested in the E. coli strain Origami(DE3), in combination with the vector pET$32 \mathrm{~b}(+)$. This system enhances the formation of disulfide bonds in the cytosol. Cloning was performed by releasing the NcoI-BamHI fragment (for Nph1-FL) or the NcoI-EcoRI fragments (for Nph3-FL and Nph4-FL) from the respective pET-42b(+) constructs and inserting them into the same sites of pET-32b(+). However, expression conditions were not improved and therefore this system was not further used.

In order to confirm that the purified proteins are indeed the respective neurexophilins, western blot analysis of purified samples was carried out using antibodies F508 (anti-Nph1/3) and U347 (anti-Nph4), resulting in the expected positive bands (data not shown).

\subsubsection{Elution and concentration of expressed proteins}

Purified full length Nph1 and Nph3 (fused to GST), as well as GST, were eluted from the glutathione agarose beads and concentrated by centrifugation using centriprep30 concentration columns. In an attempt to use the purified proteins in order to test electrophysiologically the extracellular effect of Nph1 and Nph3 on hippocampal neurons, concentrated proteins and GST, as a negative control, were dialyzed against a physiological Na-HEPES buffer. Unfortunately, Nph1 and Nph3 fusion proteins were not soluble in the above buffer and, therefore, they were not able to be used for the above experiment. However, concentrated proteins can be used in biochemical experiments like e.g. binding studies, where the specific dialysis step would not be required. Improvement of the solubility of the above proteins in the above Na-HEPES buffer could also possibly be improved by cleaving the GST molecule from the fused protein utilizing the factor Xa recognition site, thereby reducing the size of the protein. Other buffer systems could also be tested in the future.

Figure 37 shows the SDS-PAGE analysis of the purification-concentration-dialysis procedure, described above. 
A

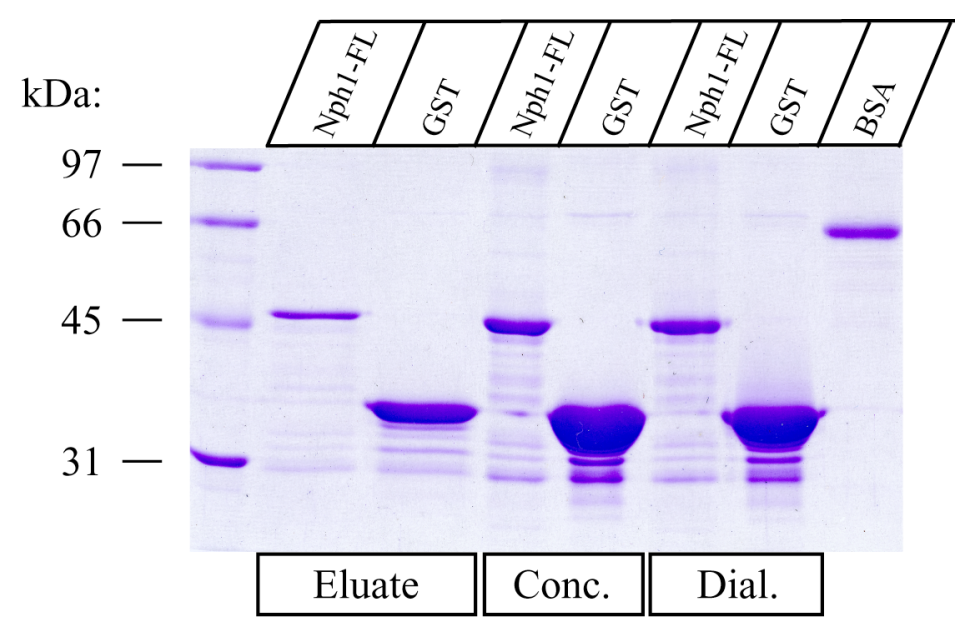

B

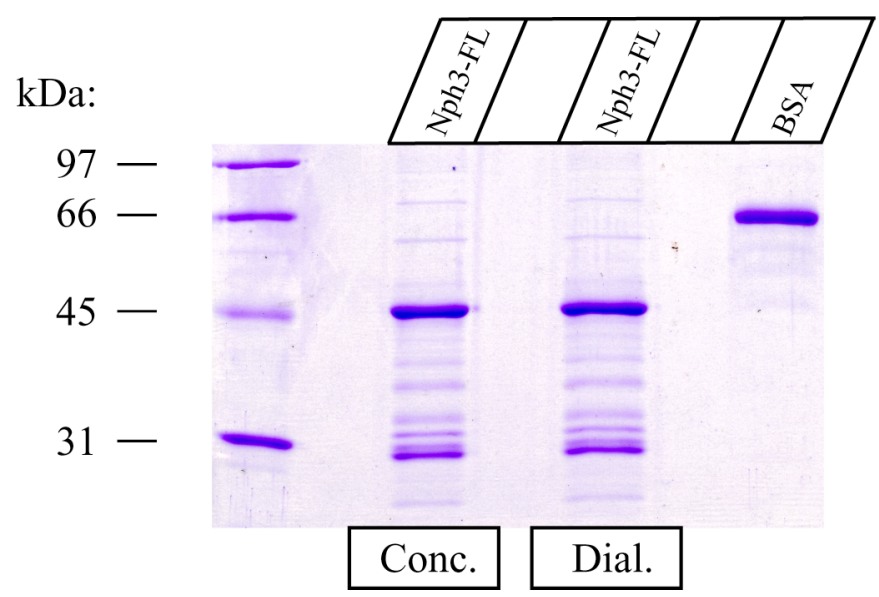

Figure 37 Elution/concentration of recombinant neurexophilins 1 and 3. A Purification of GST-Nph1 and GST. Protein samples taken after elution, concentration and dialysis were analyzed by SDS-PAGE electrophoresis, followed by Coomassie-blue staining. In the last lane a control sample of $1 \mu \mathrm{g}$ bovine serum albumin (BSA) was loaded, enabling a rough estimation of the amount of the purified proteins. Relative amounts loaded from each fraction: Eluate: $0.6 \%$, Concentrate (Conc.): 3\%, Dialysate (Dial.): $3 \%$. Around $30 \mu \mathrm{g}$ of GST-Nph1 and $150 \mu \mathrm{g}$ of GST were purified in total in the concentrated and dialyzed forms, in $\sim 170 \mu \mathrm{l}$ volume. Protein sizes are given on the left of the picture. Note that neurexophilins have a smaller size comparing to their size when they are produced in vivo, due to the absence of glycosylation. B Purification of GST-Nph3. Concentrate and dialysate samples (3\% of each fraction) were analyzed by SDS-PAGE electrophoresis and Coomassie-blue staining, together with a control sample of $1 \mu \mathrm{g}$ bovine serum albumin. As in the case of Nph1, around $30 \mu \mathrm{g}$ of recombinant protein were purified in total in the concentrated and dialyzed forms, in $\sim 180 \mu$ l volume. 
Neurexophilins are secreted proteins that bind to the synaptic membrane proteins $\alpha$ neurexins. Although studies on them have already provided information about their structure and biochemical properties, their role at the synapse is still unclear. Two potential roles could be be hypothesized: Based on their strong binding to $\alpha$-neurexins, a possible function could be that neurexophilins act as co-factors of $\alpha$-neurexins by stabilizing their structure. On the other hand, taking into account the structural and biochemical properties of neurexophilins, it is likely that they comprise a family of signaling molecules that modulate the function of $\alpha$ neurexins.

An important question that arises in order to shed light upon the putative signaling function of neurexophilins is in which cell populations neurexophilins are expressed and on which synapses they act. In situ hybridization for Nph1 in rat brain sections has shown a very localized expression pattern (Petrenko et al., 1996). On the other hand, the three $\alpha$-neurexins together are expressed essentially in all regions of the brain (Ullrich et al., 1995). Given that Nph1 and Nph3 bind to all three $\alpha$-neurexins (Missler et al., 1998), the localized expression pattern of Nph1 mainly in interneurons led to the hypothesis that neurexophilins play a spatially-related regulatory function by binding to $\alpha$-neurexins at specific areas of the brain. Since Nph1 and Nph3 are the only members of the family that are expressed in rodents and bind to $\alpha$-neurexins (Petrenko et al., 1996, Missler et al., 1998), identification of the cell populations that express Nph3 is essential for investigation of the above hypothesis. Given the secreted nature of neurexophilins, another important question is, as mentioned above, which are the synapses where neurexophilins act as extracellular signaling molecules. Addressing this question has been difficult using conventional immunohistochemistry (Dr. Markus Missler, personal communication), since neurexophilins are expressed in very low levels, as indicated for example by the long film exposure time that is required in Northern blot analysis of them (Missler and Südhof, 1998). An additional approach towards unraveling the function of Neurexophilins is to analyze the in vivo effect of their absence. A knock-out mouse line has already been generated for Nph1, without exhibiting any obvious abnormality (Missler et al., 1998). The generation of a Nph3 and a double Nph1/Nph3-KO mouse lines would provide the means for a complete knock-out analysis of neurexophilins, with respect to their binding to $\alpha$ neurexins.

In order to address the above aspects, a neurogenetic approach was followed in the current study. A knock-in mouse strategy was designed in a way to facilitate generation of a Nph3 allele, bearing the following features: a) $\beta$-galactosidase would be co-expressed along with 
Nph3 by a bicistronic mRNA and would be driven to the nucleus of the expressing cell; therefore it would be possible to identify the nuclei of Nph3-expressing cells by assaying for $\beta$-galactosidase activity, b) a Flag epitope tag would be fused to Nph3, improving its immunohistochemical properties and c) the Nph3 second exon as well as all the cloned sequences would be flanked by two loxP sites, enabling the generation of a knock-out mouse line by mating the knock-in with Cre-expressing transgenic mice. The same approach was followed also for Nph1, although some of the above goals had already been met, because the $\beta$-galactosidase assay is more powerful comparing to in situ hybridization, as well as in order to localize Nph1 at the potein level.

\section{4 . 1 Study of neurexophilin 3 with reference to the knock-in approach}

The knock-in approach for the study of Nph3 provided a means of identifying with high sensitivity the Nph3 expressing cells in the brain. This was the result of the combination of various DNA elements, having been used before in other systems, that were cloned in the targeting vector. The main concept behind using the specific combination was the generation of a Nph3 allele that would give rise to a bicistronic mRNA, which would also encode for $\beta$ galactosidase, in addition to Nph3. This was based on the presence of an internal ribosomal entry site between the two coding sequences. This site consists of a set of sequences from the encephalomyocarditis virus and has been widely used in in vitro and in vivo systems. The most prominent application of the above approach in an in vivo system is a series of studies on the projection of mouse olfactory sensory neurons to the olfactory bulb, first performed by Mombaerts et al., 1996. In this study the internal ribosomal entry site allowed co-expression of $\beta$-galactosidase along with the $\mathrm{P} 2$ olfactory receptor, with $\beta$-galactosidase bearing the bovine microtubule-associated protein tau, fused to its $\mathrm{N}$-terminus. The tau protein provides a means of even distribution of $\beta$-galactosidase into axons by being driven to microtubules (Callahan and Thomas, 1994). In the current study however, the generation of a bicistronic mRNA aimed to the visualization of the cell bodies of the Nph3 expressing neurons. Therefore, instead of the tau protein, a nuclear localization signal from the simian virus 40 (Kalderon et al., 1984) was used, targeting $\beta$-galactosidase to the nucleus of the expressing cells. This is the first time that this signal has been used in an in vivo system, following a bicistronic mRNA approach. The high efficacy of this method, as revealed by $\beta$-galactosidase assay of Nph3-KI brain sections, suggests a novel approach for the very sensitive identification of cell populations that express a particular protein in vivo. 
The generation of the Nph3-KO mouse line was accomplished by the use of the Cre-loxP system, based on the presence of two loxP sites in the Nph3-KI allele. This system makes use of the ability of the Cre protein of bacteriophage P1 to delete a DNA sequence between two loxP sites (Sternberg and Hamilton, 1981). The Cre protein was provided by mating Nph3-KI with Cre-expressing transgenic mice. In the Cre-expressing mouse line used in the current study the Cre transgene is under the control of the adenovirus EIIa promoter that drives expression of the recombinase in the early mouse embryo (Lakso et al., 1996). This mouse line is considered to be quite efficient in delivering Cre expression in all tissues including, most importantly, the germ cells. Cre expression and deletion of the area between the two loxP sites took place also in the case of Nph3-KI mice, although not always completely, since in some of the offspring the KI allele was still present in low amounts (see section 3 .4 .1. 1). These mice were not further used and, therefore, incomplete recombination was not a drawback for the establishment of the knock-out line.

The conventional way for the generation of a knock-out mouse line is to replace in the targeting vector one or more exons of the targeted allele with the neomycin resistance gene, therefore removing part of the coding sequence and providing recombinant ES cells with the ability to be selected against non-recombinant ones in the presence of a neomycin analog. Although this strategy has been proven very efficient and led to the generation of a high number of knock-out lines, it has the disadvantage that the resulting knock-out allele contains a foreign gene which may cause an undesirable effect and therefore affect the phenotype of the line. By generating a knock-out mouse line using the Cre-lox $P$ system, the resulting allele contains as a foreign element only a single 34 bp long loxP sequence, which is highly unlikely to affect the phenotype of the line by disturbing neighboring genes. This is the case in the generation of the Nph3-KO mouse line and verifies that the result of the absence of Nph3 in this line is not affected by the presence of a foreign gene.

The Cre-lox $P$ approach has been proven very useful in conditional knock-out mouse studies of developmentally essential proteins, where the absence of the protein is lethal in early development (Copp, 1995). In this case two loxP sites are introduced into the gene that encodes for the given protein at "silent" sites and mutation of the gene is facilitated by expression of Cre recombinase at a specific developmental stage (mice are mated with transgenic mice that express Cre under the control of a developmentally-regulated promoter). Another application of the conditional knock-out technology, based on the Cre-loxP system, is the generation of mouse lines where the gene of interest is mutated only in specific cell types or tissues (depending on the promoter that controls Cre expression), in order to overcome a lethal phenotype caused by its mutation in the whole body (Gu et al., 1994), or to study its effect in specific cells or tissues (Tsien et al., 1996). Cre recombinase can also be transferred into mice by injection with recombinant adenovirus (Rohlmann et al., 1996). 
Although the absence of Nph3 is not lethal in mice, the generation of the Nph3-KI mouse line provides the means for future studies of $\mathrm{Nph} 3$ in certain cell populations or developmental stages by generating conditional Nph3-KO mouse lines.

An approach similar to the Cre-loxP system is the Flp-FRT system of Saccharomyces cerevisiae, functioning by excision of the DNA sequence between two FRT sites by Flp recombinase (Broach et al., 1982). Two FRT sites were included in the Nph3-KI targeting vector flanking the neomycin resistance gene, as a safety measure in case that the presence of the last created a transcriptional dysfunction. These sites were present intact in the Nph3-KI mice, as shown by PCR analysis, but their use was not required since transcription and function of the bicistronic mRNA were normal, as revelaed by RT-PCR analysis of Nph3Flag expression and by $\beta$-galactosidase activity.

During cloning of the Nph3 targeting vector, a series of intermediate constructs were generated involving a combination of various cloning methods, as described in section 3.2 . 1. 1. These constructs contain sequences that can be excised and used directly in the generation of similar targeting vectors for other genes or in other tagging applications in in vivo or in vitro systems. The most important of them is a construct containing the cassette BamHI-Flag-stop-IRES-Kozak-NLS-lacZ-loxP-BamHI cloned in pBluescript II SK (described in section $3.2 .1 .1, \mathrm{c}$ ). This cassette can either be excised directly and cloned into another construct or can be used after being modified by exchanging some of its modules. Finally, although ES cell culture in the case of Nph1 did not result in the generation of Nph1KI ES cells, the Nph1-KI targeting vectors can be used again in future applications either in a new attempt to generate a knock-in mouse line, or in in vitro studies of Nph1.

\subsection{Neurexophilins in evolution}

By DNA database search the presence of neurexophilins in a variety of organisms was revealed as discussed in section 3.1.2. Neurexophilin genes exist in various vertebrate species but they do not seem to exist in invertebrates. This is in accordance with the fact that the most prominent area of Nph3 expression in the brain, and also an area of Nph1 expression, is the neocortex, which is a structure that was formed late in evolution and exists only in vertebrates. In contrast, an isoform of $\alpha$-neurexins exists in Drosophila melanogaster and Caenorhabditis elegans, as discussed in section 3.1 .2 , indicating that neurexophilins were not co-evolved with neurexins. These findings argue against a possible function of neurexophilins as structural co-factors of neurexins, since the former do not seem to be necessarily required for the function of the latter. This is reinforced by the fact that 
recombinant neurexin Ia binds to $\alpha$-latrotoxin with high affinity and also to $\alpha$-dystroglycan (Sugita et al., 2001), without requiring neurexophilins (Davletov et al., 1995). The above lead to the hypothesis that neurexophilins appeared in evolution as regulators of neurexins (among possible other functions), in a way specific to the vertebrate nervous system.

All new neurexophilin isoforms that were identified by DNA database search share the same domain structure with the already known ones and show conservation of all amino acids that seem to characterize the various domains, i.e. the predicted cleavage site KxKK between the second and the third domain, the four potential N-glycosylation sites in the middle of the protein sequence and the six cysteines at the C-terminal domain. All of them contain also a hydrophobic sequence at their $\mathrm{N}$-terminus, representing the putative signal peptide.

Comparing to known neuropeptide families, neurexophilins exhibit both similarities and differences. The main similarity is the fact that they are synthesized in a prepropeptide form typical for secreted proterins, containing a hydrophobic N-terminal sequence that probably acts as signal peptide, as well as a cleavage site in the beginning of their first highly conserved domain. On the other hand, neurexophilins are distinguished from most neuropeptide families, with respect to the way that the different members of the family are formed. Most neuropeptides are synthesized as parts of a polyprotein, that contains all members of a given family. The individual peptides are then formed by proteolytic processing of the polyprotein at specific cleavage sites (Kandel et al., 2000). Although proteolytic cleavage takes place also in the case of neurexophilins, the above procedure does not apply for them, since the different isoforms of the family are expressed from different genes.

\subsection{Expression of neurexophilin 3 in the brain}

Expression of $\mathrm{Nph} 3$ is highly localized and is observed in subpopulations of cells in various regions of the brain. The most typical area of expression are the deep layers of the neocortex, where a prominent band of expressing cells is observed both in adult mice and throughout ontogeny. This area is important in cortical development and is represented by the subplate in early development and the layer VI in late development and adulthood. Early in development, postmitotic neurons generated in the ventricular zone migrate into the preplate, which is the most early formed corical area, and split it into two components, the subplate (the inner component) and the marginal zone (the outer component) (Allendoerfer and Shatz, 1994). The migrating neurons form the cortical plate which grows in an inside-out fashion, from layer VI to layer II. Nph3 expression in the neocortex is therefore specific only to developmentally early structures, implying a role in neocortex development. 
Subplate cells as well as cells of the later layer VI express in rats the calcium-binding protein calretinin, and by double immunohistochemistry at P0-P3 these cells have been found to be $\gamma$ amminobutyric acid (GABA) negative (Fonseca et al., 1995). By performing a co-localization experiment on brain sections from Nph3-KI mice, Nph3 expressing cells in layer VI at P6 were shown to be calretinin positive. The above lead to the indirect suggestion that Nph3 expressing neurons are not GABAergic.

Recent studies on the role of Tbr1, a transcription factor that is expressed in high levels in the preplate and layer VI, have revealed that it regulates differentiation of these areas (Hevner et al., 2001). In particular, mice with a loss-of-function mutation in the Tbrl gene exhibit developmental abnormalities in the laminar organization of neurons and the guidance of cortical axons. This phenotype is similar to that of the mouse mutant reeler (Falconer, 1951), which is the result of the absence of reelin (D'Arcangelo et al., 1995, Hirotsune et al., 1995). The above finding is of special interest with regard to Nph3, due its localized expression in the above areas. Since Nph3-KO mice do not show a similar phenotype, Nph3 is excluded from a synergistic role to the Tbr1 function. A potential regulatory effect needs to be further studied.

In addition to the persisting cell population described above, Nph3 is also expressed in a number of transient populations throughout ontogeny. One of them is located perinatally in the marginal zone, probably representing Cajal-Retzius cells. The marginal zone is important for the guidance of cortical neurons and the formation of the neocortex architecture (reviewed in Marin-Padilla, 1998). Expression of Nph3 in this sttucture reinforces the hypothesis of a potential function in the development of the neocortex.

Expression of Nph3 is also observed in the cerebellum, in a strikingly developmentallyregulated fashion. In particular, Nph3 seems to be expressed in a maturation-dependent way, since it is not expressed at all in the cerebellum till P7 and exhibits its highest expression levels between P11 and P20. In adult mice expression is still observed, although in lower levels. As in the neocortex, Nph3 shows a localized expression pattern also in the cerebellum, where it is expressed in the granule cell layer of lobules 9 and 10. These areas are involved in limb movement and vestibular orientation respectively (Kandel et al., 2000). The granule cells of the cerebellum are very small, densely packed cells that comprise the most abundant cell population in the central nervous system (Shepherd, 1998). The mature granule cells, that constitute the internal granule layer are derived from migrating cells of the external germinal layer that are located in the periphery of the cerebellar cortex (Altman and Bayer, 1997). In the mouse, proliferation of cells of the external germinal layer takes place up to P15 and their migration to the internal granule layer begins at birth and continues till P20, when maturation of the cerebellum is complete (Altman and Bayer, 1997). The peak of Nph3 expression during the second and third postnatal weeks seems to be concurrent with the latest phase of granule 
cell differentiation. This points to a possible function of $\mathrm{Nph} 3$ in arresting granule cell development.

Another area of transient $\mathrm{Nph} 3$ expression is the developing hippocampal formation. Expression of Nph3 is observed in the molecular layer of the dentate gyrus during the first postnatal week, gradually fainting during the following weeks. By means of double histochemical staining for $\beta$-galactosidase and reelin or calretinin, the Nph3-expressing cells were characterized as Cajal-Retzius cells. These cells are essential in the development of layer-specific hippocampal connections (Del Rio et al., 1997). Therefore, similarly to the Nph3-expressing cells in the neocortex, Nph3-expressing cells in the hippocampal formation have an important function in the formation of this structure. The role of Nph3 in this function remains to be determined. Expression of $\mathrm{Nph} 3$ in the above area is interesting for future electrophysiological studies, since the hippocampal formation is the best studied structure of the brain in that respect.

During development, Nph3 is also expressed in populations of sensory neurons of the nasal cavity. These are olfactory neurons of the nasal epithelium and neurons of the vomeronasal organ. Both types of neurons are odorant receptors that project into the olfactory bulb. Taken into account the possible neuropeptide function of neurexophilins, it is likely that $\mathrm{Nph} 3$ is secreted at synapses of the olfactory bulb, probably in the glomeruli.

Comparing to already known neuropeptide families, neurexophilins exhibit an interesting feature. Most neuropeptide families perform their function in specific brain structures, like corticotropin- and gonadotropin-releasing hormones that act in the hypothalamus or $\beta$ endorphin and prolactin, acting in the pituitary gland (Kandel et al., 2000). In these cases all members of the neuropeptide family function in the same area. On the contrary, neurexophilins are expressed in various areas of the brain and, in addition, Nph1 and Nph3 have different expression patterns, providing the family with a plethora of expression areas and possible functions. This attributes a specialized function to neurexophilins, which resembles that of neuropeptides but is not typical of this category of signaling molecules.

\section{4. $4 \quad$ Putative function of neurexophilins as signaling molecules}

$\alpha$-Neurexins have been shown to be essential in the control of a transsynaptic signaling pathway, involving pre- and postsynaptic $\mathrm{Ca}^{2+}$ channels (Missler et al., submitted for publication). In the same study $\alpha$-neurexin knock-out mice were shown to have a dramatic deffect in postnatal survival. Triple knock-out mice die on the first postnatal day, most of the double knock-out in the following weeks and even single knock-out mice exhibit premature 
mortality and behavioral abnormalities. As mentioned above, two possible functions have been speculated for neurexophilins, concerning their binding to $\alpha$-neurexins: either they act as structural co-factors of $\alpha$-neurexins, thereby stabilizing their structure, or they perform a signaling function that regulates $\alpha$-neurexins. If the first hypothesis was valid, Nph1-KO, Nph3-KO and double Nph1/Nph3-KO mice would show at least a mild form of premature mortality due to impairment of the structure of a proportion of $\alpha$-neurexins. However, this was not observed, indicating that the role of binding of neurexophilins to $\alpha$-neurexins does not have a stabilization effect. This is reinforced by the comparison of the expression patterns of $\alpha$-neurexins with those of Nph1 and Nph3. $\alpha$-Neurexins are expressed essentially in all structures of the brain (Ullrich et al., 1995), whereas the expression patterns of Nph1 and Nph3 are highly localized and not uniform as it would be expected for a stabilizing co-factor molecule. This had already been hypothesized from the results about Nph1 expression and was confirmed by the expression pattern of Nph3. Together the above observations support the second hypothesis posed above, suggesting a function of neurexophilins as signaling molecules that exert a modulatory effect on $\alpha$-neurexins.

Insights into the proposed signaling function of neurexophilins are expected to arise following two approaches: a) electrophysiological analysis of the double Nph1/Nph3-KO mouse line will investigate the potential effect of $\mathrm{Nph} 1$ and $\mathrm{Nph} 3$ in synaptic function, especially regarding the role of $\alpha$-neurexins in controling the coordinated activity of $\mathrm{Ca}^{2+}$-channels and b) in vitro experiments using recombinant neurexophilins should provide the means for further analysis of their properties and the nature of the signal elicited. An interesting experiment would be to perform binding studies in order to investigate a potential ineraction of neurexophilins with other $\alpha$-neurexin associated proteins. If the solubility of recombinant neurexophilins in physiological buffers is improved (e.g. by cleacage of GST), electrophysiological analysis of their extracellular effect on synapses would also provide valuable information about their function.

\subsection{Conclusion and outlook}

Neurexophilin binding to $\alpha$-neurexins has proposed that they either act as co-factors of $\alpha$ neurexins, stabilizing their structure, or that they have a signaling function, modulating the role of $\alpha$-neurexins in synaptic terminals. The neurogenetic approach that was followed in the case of Nph3 towards studying of a potential signaling role, led to the generation of a knockin mouse line featuring some interesting properties. A novel approach for the sensitive in vivo identification of cells expressing a given protein was established. At the same time the Nph3- 
KI mouse line enabled generation of a Nph3-KO line with no foreign elements in the Nph3 allele (apart from a short $\operatorname{lox} P$ sequence) and provided the potential for the generation of conditional knock-out mouse lines in the future. Analysis of Nph3 expression in the brain of knock-in mice revealed a higly localized pattern, consisting mainly of developmentally important cell populations, suggesting a role of Nph3 in brain development. These results, together with addressing evolutionary apsects of neurexophilins, excluded a role of them as structural co-factors and supported the concept of a signaling function that regulates spatially and/or developmentally the role of $\alpha$-neurexins at the synapse.

The main question for future studies on neurexophilins is what is their exact role at the synapse. Clues about this role are expected to be provided by functional analysis of the Nph3$\mathrm{KO}$ and the double Nph1/Nph3-KO mice. In addition, in vitro experiments using recombinant neurexophilins can potentially identify additional molecular interactions of them at the synapse. By improving the solubility of recombinant neurexophilins using alternative buffers or other expression systems (e.g. baculovirus), further insights about their function can be gained. 
Neurexophilins form a family of proteins that were discovered as components of the $\alpha$ latrotoxin receptor, based on their strong binding to the synaptic membrane proteins $\alpha$ neurexins (Petrenko et al., 1993). Previous studies have shown that neurexophilins are secreted proteins of small molecular weight with structural features that resemble those of neuropeptides, suggesting a possible signaling function mediated by $\alpha$-neurexins (Petrenko et al., 1996, Missler and Südhof, 1998, Missler et al., 1998). In addition, Nph1 was studied by in situ hybridization on rat brains showing that its expression is restricted in specific areas of the brain, in a nonuniform pattern (Petrenko et al., 1996), as well as by generating a knock-out mouse line that did not exhibit any obvious phenotypic abnormality (Missler et al., 1998).

The current study aimed to investigate further the hypothesis of a signaling function of neurexophilins in the central nervous system and to provide the tools for uncovering this potential function. Taken into account the studies on Nph1 mentioned above, a neurogenetic approach was followed by the use of the knock-in technology in order to characterize in vivo the role of $\mathrm{Nph} 3$ in the mouse brain. This involved the generation of three transgenic mouse lines, namely a Nph3-KI, a Nph3-KO and a double Nph1/Nph3-KO mouse line. As a first step, the Nph3 gene was cloned and its exon-intron structure was mapped. A Nph3-KI targeting vector was designed in a way to result in the generation of a bicistronic mRNA, encoding for a fusion Nph3-Flag protein, as well as for $\beta$-galactosidase fused to a nuclear localization signal. The targeting vector was cloned and its function was tested successfully in COS7 cells by Flag immunocytochemistry and $\beta$-galactosidase staining. The targeting vector was inserted into ES cells in culture and a Nph3-KI mouse line was generated by injecting positive cells into blastocysts and transplanting the blastocysts into pseudopregnant foster mothers (injections and blastocyst transplantations were performed at the animal house of the Max Planck Institute for Experimental Medicine, Göttingen, under supervision of Dr. Herman Riedesel). By the use of the Cre-loxP systrem, based on two loxP sites in the Nph3-KI allele, a Nph3-KO mouse line was established by mating Nph3-KI with Cre-expressing transgenic mice. Finally, a double Nph1/Nph3-KO mouse line was generated by mating Nph3-KO with Nph1-KO mice, already existing in the laboratory (Missler et al., 1998). In parallel to the in vivo approach, a bacterial protein expression system was established, leading to the production of recombinant $\mathrm{Nph} 1$ and $\mathrm{Nph} 3$ for use in future in vitro experiments.

Analysis of Nph3 expression in Nph3-KI mice was performed by assaying brain sections for $\beta$-galactosidase activity, based on the co-expression of $\beta$-galactosidase from $\mathrm{Nph} 3$-expressing cells. This method revealed the Nph3 expression pattern with high accuracy and sensitivity, 
suggesting a novel approach for the detailed in vivo identification of cells that express a particular protein. A highly localized Nph3 expression pattern was observed with the most characteristic area of expression being the deep layers of the neocortex, where a band of expressing cells persisted throughout ontogeny and adulthood. In addition, expression of Nph3 was observed in a number of transient cell populations in the marginal zone of the developing neocortex, the dentate gyrus of the hippocampal formation and the granule cell layer of lobules 9 and 10 of the cerebellum, where low expression levels were also observed in adulthood. Neurons of the nasal epithelium and the vomeronasal organ were also shown to express Nph3 in embryonic stages. Most of the above cell populations are among the earliest in the brain and are important for the formation of the respective structures, implying a role of $\mathrm{Nph} 3$ in brain development.

The above results, together with findings about the existence of neurexophilins in other organisms, as revealed by DNA database search, excluded a possible function of neurexophilins as structural co-factors of $\alpha$-neurexins and supported the concept that neurexophilins perform a signaling function, regulating the role of $\alpha$-neurexins at the synapse. The question that now arises is what is the exact function of neurexophilins in the brain. This can be adressed by electrophysiological analysis of the double Nph1/Nph3-KO mouse line, as well as by in vitro experiments using recombinant neurexophilins. 
Adams MD et al. (2000). The genome sequence of Drosophila melanogaster. Science 287, 2185-95.

Allendoerfer KL, Shatz CJ (1994). The subplate, a transient neocortical structure: its role in the development of connections between thalamus and cortex. Annu Rev Neurosci 17, $185-218$.

Altman J, Bayer SA (1997). Development of the cerebellar system: in relation to its evolution, structure, and functions. CRC Press.

Altschul SF, Gish W, Miller W, Myers EW, Lipman DJ (1990). Basic local alignment search tool. J Mol Biol 215, 403-10.

Arvan P, Castle D (1998). Sorting and storage during secretory granule biogenesis: looking backward and looking forward. Biochem J 332, 593-610.

Bennett MV (1997). Gap junctions as electrical synapses. $J$ Neurocytol 26, 349-66.

Broach JR, Guarascio VR, Jayaram M. Recombination within the yeast plasmid $2 \mu$ circle is site-specific (1982). Cell 29, 227-34.

Butz S, Okamoto M, Südhof TC (1998). A tripartite protein complex with the potential to couple synaptic vesicle exocytosis to cell adhesion in brain. Cell 94, 773-82.

Callahan CA, Thomas JB (1994). Tau-beta-galactosidase, an axon-targeted fusion protein. Proc Natl Acad Sci U S A 91, 5972-6.

Copp AJ (1995). Death before birth: clues from gene knockouts and mutations. Trends Genet $11,87-93$.

Cowan WM, Südhof TC, Charles FS (2001). Synapses. Johns Hopkins Univ Press. 
D'Arcangelo G, Miao GG, Chen SC, Soares HD, Morgan JI, Curran T (1995). A protein related to extracellular matrix proteins deleted in the mouse mutant reeler. Nature 374, $719-23$.

Davletov BA, Krasnoperov V, Hata Y, Petrenko AG, Sudhof TC (1995). High affinity binding of alpha-latrotoxin to recombinant neurexin I alpha. J Biol Chem 270, 23903-5.

de Bergeyck V, Naerhuyzen B, Goffinet AM, Lambert de Rouvroit C (1998) A panel of monoclonal antibodies against reelin, the extracellular matrix protein defective in reeler mutant mice. J Neurosci Methods 82, 17-24.

De Carlos JA, O'Leary DD (1992). Growth and targeting of subplate axons and establishment of major cortical pathways. J Neurosci 12, 1194-211.

Del Río JA, Martinez A, Fonseca M, Auladell C, Soriano E (1995). Glutamate-like immunoreactivity and fate of Cajal-Retzius cells in the murine cortex as identified with calretinin antibody. Cereb Cortex 5, 13-21.

Del Río JA, Heimrich B, Borrell V, Förster E, Drakew A, Alcántara S, Nakajima K, Miyata T, Ogawa M, Mikoshiba K, Derer P, Frotscher M, Soriano E (1997). A role for CajalRetzius cells and reelin in the development of hippocampal connections. Nature 385, $70-4$.

Dymecki SM (1996). A modular set of Flp, FRT and lacZ fusion vectors for manipulating genes by site-specific recombination. Gene 171, 197-201.

Falconer DS (1951). Two new mutants, "trembler" and "reeler", with neurological actions in the mouse house (Mus musculus L). J Genet 50, 192-201.

Feinberg AP, Vogelstein B (1983). A technique for radiolabeling DNA restriction endonuclease fragments to high specific activity. Anal Biochem 132, 6-13.

Fonseca M, del Rio JA, Martinez A, Gomez S, Soriano E (1995). Development of calretinin immunoreactivity in the neocortex of the rat. J Comp Neurol 361, 177-92. 
Frontali N, Ceccarelli B, Gorio A, Mauro A, Siekevitz P, Tzeng MC, Hurlbut WP (1976). Purification from black widow spider venom of a protein factor causing the depletion of synaptic vesicles at neuromuscular junctions. $J$ Cell Biol 68, 462-79.

Garner CC, Zhai RG, Gundelfinger ED, Ziv NE (2002). Molecular mechanisms of CNS synaptogenesis. Trends Neurosci 25, 243-250.

Gu H, Marth JD, Orban PC, Mossmann H, Rajewsky K (1994). Deletion of a DNA polymerase beta gene segment in $\mathrm{T}$ cells using cell type-specific gene targeting. Science 265, 103-6.

Hata Y, Butz S, Südhof TC (1996). CASK: a novel dlg/PSD95 homolog with an N-terminal calmodulin-dependent protein kinase domain identified by interaction with neurexins. $J$ Neurosci 16, 2488-94.

Hevner RF, Shi L, Justice N, Hsueh Y, Sheng M, Smiga S, Bulfone A, Goffinet AM, Campagnoni AT, Rubenstein JL (2001). Tbr1 regulates differentiation of the preplate and layer 6. Neuron 29, 353-66.

Hille B (2001). Ion Channels of Excitable Membranes, 3rd edition. Sinauer Associates.

Hirotsune S, Takahara T, Sasaki N, Hirose K, Yoshiki A, Ohashi T, Kusakabe M, Murakami Y, Muramatsu M, Watanabe S, et al (1995). The reeler gene encodes a protein with an EGF-like motif expressed by pioneer neurons. Nat Genet 1995 10, 77-83.

Ichtchenko K, Hata Y, Nguyen T, Ullrich B, Missler M, Moomaw C, Südhof TC (1995). Neuroligin 1: a splice site-specific ligand for $\beta$-neurexins. Cell 81, 435-43.

International Human Genome Sequencing Consortium (2001). Initial sequencing and analysis of the human genome. Nature 409, 860-921.

Kalderon D, Roberts BL, Richardson WD, Smith AE (1984). A short amino acid sequence able to specify nuclear location. Cell 39, 499-509.

Kandel ER, Schwartz JH, Jessell, TM (2000). Principles of neural science, 4th edition. McGraw-Hill. 
Kim DG, Kang HM, Jang SK, Shin HS (1992). Construction of a bifunctional mRNA in the mouse by using the internal ribosomal entry site of the encephalomyocarditis virus. Mol Cell Biol 12, 3636-43.

Kozak M (1991), An analysis of vertebrate mRNA sequences: intimations of translational control. J Cell Biol 115, 887-903.

Laemmli UK (1970). Cleavage of structural proteins during the assembly of the head of bacteriophage T4. Nature 227, 680-5.

Lakso M, Pichel JG, Gorman JR, Sauer B, Okamoto Y, Lee E, Alt FW, Westphal H (1996). Efficient in vivo manipulation of mouse genomic sequences at the zygote stage. Proc Natl Acad Sci U S A 93, 5860-5.

Marín-Padilla M (1998). Cajal-Retzius cells and the development of the neocortex. Trends Neurosci 21, 64-71.

Missler M, Hammer RE, Südhof TC (1998). Neurexophilin binding to $\alpha$-neurexins. $J$ Biol Chem 273, 34716-23.

Missler M, Südhof TC (1998). Neurexophilins form a conserved family of neuropeptide-like glycoproteins. J Neurosci 18, 3630-8.

Missler M, Zhang W, Rohlmann A, Hammer RE, Südhof TC (2002). A transsynaptic signalling pathway involving $\alpha$-neurexins required for assembly of pre- and postsynaptic $\mathrm{Ca}^{2+}$-channels. Submitted for publication.

Mombaerts P, Wang F, Dulac C, Chao SK, Nemes A, Mendelsohn M, Edmondson J, Axel R (1996). Visualizing an olfactory sensory map. Cell 87, 675-86.

Mountford PS, Smith AG (1995). Internal ribosome entry sites and dicistronic RNAs in mammalian transgenesis. Trends Genet 11, 179-84.

Ogawa M, Miyata T, Nakajima K, Yagyu K, Seike M, Ikenaka K, Yamamoto H, Mikoshiba $\mathrm{K}$ (1995). The reeler gene-associated antigen on Cajal-Retzius neurons is a crucial molecule for laminar organization of cortical neurons. Neuron 14, 899-912. 
Paxinos G (1995). The rat nervous system, 2nd edition. Academic Press.

Petrenko AG, Kovalenko VA, Shamotienko OG, Surkova IN, Tarasyuk TA, Ushkaryov YA, Grishin EV (1990). Isolation and properties of the $\alpha$-latrotoxin receptor. EMBO J 9, 2023-7.

Petrenko AG, Lazaryeva VD, Geppert M, Tarasyuk TA, Moomaw C, Khokhlatchev AV, Ushkaryov YA, Slaughter C, Nasimov IV, Südhof TC (1993). J Biol Chem 268, 18607.

Petrenko AG, Ullrich B, Missler M, Krasnoperov V, Rosahl TW, Südhof TC (1996). Structure and evolution of neurexophilin. J Neurosci 16, 4360-9.

Rohlmann A, Gotthardt M, Willnow TE, Hammer RE, Herz J (1996). Sustained somatic gene inactivation by viral transfer of Cre recombinase. Nat Biotechnol 14, 1562-5.

Rohlmann A, Zhang W, Hammer RE, Südhof TC, Missler M (2002). $\mathrm{Ca}^{2+}$-channel rescue in $\alpha$-neurexin deficient mice by presynaptic expression of transgenic neurexin $1 \alpha$. Submitted for publication.

Rosahl TW, Geppert M, Spillane D, Herz J, Hammer RE, Malenka RC, Sudhof TC (1993). Short-term synaptic plasticity is altered in mice lacking synapsin I. Cell 75, 661-70.

Saiki RK, Gelfand DH, Stoffel S, Scharf SJ, Higuchi R, Horn GT, Mullis KB, Erlich HA (1988). Primer-directed enzymatic amplification of DNA with a thermostable DNA polymerase. Science 239 , 487-91.

Sanger F, Nicklen S, Coulson AR (1977). DNA sequencing with chain-terminating inhibitors. Proc Natl Acad Sci U S A 74, 5463-7.

Seidah NG, Chrétien M (1997). Eukaryotic protein processing: endoproteolysis of precursor proteins. Curr Opin Biotechnol 8, 602-7.

Shepherd GM, (1998). The synaptic organization of the brain, 4th edition. Oxford University Press. 
Southern EM (1975). Detection of specific sequences among DNA fragments separated by gel electrophoresis. J Mol Biol 98, 503-17.

Sternberg N, Hamilton D (1981). Bacteriophage P1 site-specific recombination. I. Recombination between loxP sites. J Mol Biol 150, 467-86.

Südhof TC (1990). The structure of the human synapsin I gene and protein. J Biol Chem 265, 7849-52.

Südhof TC (1995). The synaptic vesicle cycle: a cascade of protein-protein interactions. Nature 375, 645-53.

Sugita S, Saito F, Tang J, Satz J, Campbell K, Südhof TC (2001). A stoichiometric complex of neurexins and dystroglycan in brain. J Cell Biol 154, 435-45.

The $C$. elegans Sequencing Consortium (1998). Genome sequence of the nematode $C$. elegans: A platform for investigating biology. Science 282, 2012-8.

Towbin H, Staehelin T, Gordon J (1979). Electrophoretic transfer of proteins from polyacrylamide gels to nitrocellulose sheets: procedure and some applications. Proc Natl Acad Sci U S A 76, 4350-4.

Tsien JZ, Chen DF, Gerber D, Tom C, Mercer EH, Anderson DJ, Mayford M, Kandel ER, Tonegawa S (1996). Subregion- and cell type-restricted gene knockout in mouse brain. Cell 87, 1317-26.

Ullrich B, Ushkaryov YA, Südhof TC (1995). Cartography of neurexins: More than 1000 isoforms generated by alternative splicing and expressed in distinct subsets of neurons. Neuron 14, 497-507.

Ushkaryov YA, Petrenko AG, Geppert M, Südhof TC (1992). Neurexins: Synaptic cell surface proteins related to the $\alpha$-latrotoxin receptor and laminin. Science 257, 50-6.

Ushkaryov YA, Hata Y, Ichtchenko K, Moomaw C, Afendis S, Slaughter CA, Südhof TC (1994). Conserved domain structure of $\beta$-neurexins. J Biol Chem 269, 11987-92. 
Venkatesh B, Gilligan P, Brenner S (2000). Fugu: a compact vertebrate reference genome. FEBS Lett 476, 3-7.

Weisskopf MG, Zalutsky RA, Nicoll RA (1993). The opioid peptide dynorphin mediates heterosynaptic depression of hippocampal mossy fibre synapses and modulates longterm potentiation. Nature $362,423-7$.

Whitehead TP, Kricka LJ, Carter TJ, Thorpe GH (1979). Analytical luminescence: its potential in the clinical laboratory. Clin Chem 25, 1531-46.

Willnow TE, Herz J (1994). Homologous recombination for gene replacement in mouse cell lines. Methods Cell Biol 43 Pt A, 305-34. 


\section{ACKNOWLEDGEMENTS}

I am deeply grateful to Dr. Markus Missler, group leader of the SFB406 Junior Research Group, who supported me exceptionally throughout this study and who was always ready to answer my questions.

I am especially thankful to Professor Friedrich-Wilhelm Schürmann who supervised my $\mathrm{PhD}$ in the Biological Faculty of the University of Göttingen and to Professor Diethelm W. Richter for providing support to the Junior Research Group.

I wish to express my gratitude to Dr. Astrid Rohlmann, who has been a great colleague in the laboratory and has introduced me to numerous experimental procedures.

My special thanks to Sandra Gerke for her excellent technical assistance and for taking care of the routine genotyping of the mouse lines.

I am very grateful to Dr. Nils Brose for providing the Cre-expressing transgenic mice and the $\lambda$-bacteriophage mouse genomic library.

I would like to thank Fritz Benseler and Ivonne Thanhäuser for carrying out DNA sequencing and synthesis of oligonucleotides.

I feel very thankful to Christian Bertram for his valuable advice on the use of computer graphics.

I would like to thank Dr. Herman Riedesel and his colleagues for performing the blastocyst injections and transplantations.

Finally, I would like to thank Michael Bleßmann for carrying out part of the routine mouse husbandry. 


\section{APPENDIX}

Appendix $1 \quad$ Mouse neurexophilin 3 genomic sequence (annotated)

Appendix 2 Rat neurexophilin 3 cDNA sequence (annotated) 


\section{Appendix $1 \quad$ Mouse neurexophilin 3 genomic sequence (annotated)}

The mouse Nph3 exon genomic sequence was obtained by DNA sequencing, using the genomic clone pmNph3-3 or subclones of it. The sequence of the first exon including the $5^{\prime}$ untranslated region and the first $54 \mathrm{bp}$ of the coding region (encoding for 18 amino acids) was obtained by sequencing clone pmNph3-3 from its $5^{\prime}$ end. The sequence of the first $435 \mathrm{bp}$ of the second exon (145 amino acids) was obtained by sequencing a subclone containing the 500 bp BglII fragment from clone pmNph3-3. The rest of the assembled sequence was obtained by sequencing a pmNph3-3 subclone containinng the $2 \mathrm{~kb}$ NcoI fragment using oligonucleotide 99-46, that was designed based on the sequence from the BglII subclone, mentioned above. It contains the rest of the coding sequence up to the stop codon and part of the $3^{\prime}$ untranslated region. The complete coding region is indicated by a boxed arrow, ending at the stop codon. The $5^{\prime}$ and $3^{\prime}$ untranslated regions (5' and $3^{\prime}$ UTR respectively) are underlined with a dark line. Red arrows represent the two exons. Encoded amino acids are shown below the DNA sequence in single letter code. Numbers on the right indicate base pair position. Restriction sites ares shown on top of the DNA sequence. 


\section{SanDI BsmBI}

CGGAGGGGGCCTGGGACCCCGAAAGGAAAGAGAGACGGGTGAGAGCAAAGGAGGAAGAT $1+1,1,1,1,1,1,1,1,1,1,1,1,1,1,1,1,1,1,1,1,1,60$ GCCTCCCCCGGACCCTGGGGCTTTCCTTTTCTCTCTGCCCACTCTCGTTTCCTCCTTCTA

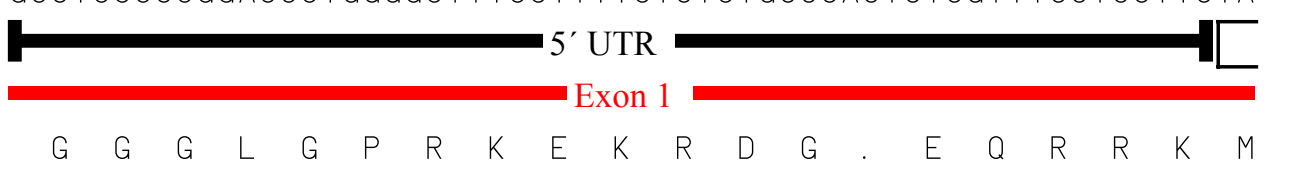

\section{EcoNI}

Bsgl

GCAACTGACCCGTTGCTGCTTCGTGTTCCTAGTGCAGGGCAGCCTCTATCTGGTCATCTG

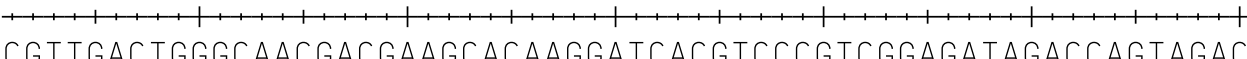
CGTTGACTGGGCAACGACGAAGCACAAGGATCACGTCCCGTCGGAGATAGACCAGTAGAC

\begin{tabular}{clllllllllllllllllll}
\hline Coding region & Exon 1 \\
\hline & $L$ & $T$ & $R$ & $C$ & $C$ & $F$ & $V$ & $F$ & $L$ & $V$ & $Q$ & $G$ & $S$ & $L$ & $Y$ & $L$ & $V$ & $I$ & $C$
\end{tabular}

\section{BstXI Bgll}

CGGCCAAGACGATGGCCCGCCTGGCTCAGAGGACCCTGAACACGATGACCATGAGGGCCA

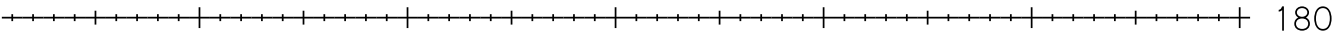
GCCGGTTCTGCTACCGGGCGGACCGAGTCTCCTGGGACTTGTGCTACTGGTACTCCCGGT

\begin{tabular}{ccccccccccccccccccccc}
\hline 11 & Coding region \\
\hline & $G$ & $Q$ & $D$ & $D$ & $G$ & $P$ & $P$ & $G$ & $S$ & $E$ & $D$ & $P$ & $E$ & $H$ & $D$ & $D$ & $H$ & $E$ & $G$ & 0
\end{tabular}

Avrll

$\mathrm{Mscl}$

GCCTCGGCCTAGGGTGCCTCGCAAGCGAGGTCATATCTCACCTAAGTCCCGCCCCTTGGC

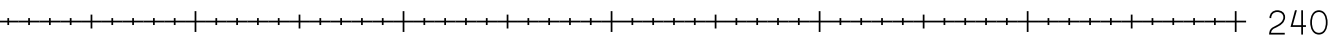
CGGAGCCGGATCCCACGGAGCGTTCGCTCCAGTATAGAGTGGATTCAGGGCGGGGAACCG

\begin{tabular}{llllllllllllllllllllll}
\hline 11 & Coding region \\
\hline & $P$ & $P$ & $R$ & $V$ & $P$ & $R$ & $K$ & $R$ & $G$ & $H$ & $I$ & $S$ & $P$ & $K$ & $S$ & $R$ & $P$ & $L$ & $A$
\end{tabular}

\section{Avrll}

Xmal

Smal

CAACTCCACCCTCCTAGGGCTGTTAGCCCCACCCGGGGAGGTTTGGGGTGTCCTTGGGCA

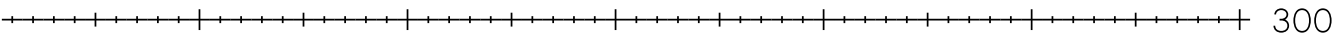
GTTGAGGTGGGAGGATCCCGACAATCGGGGTGGGCCCCTCCAAACCCCACAGGAACCCGT

\begin{tabular}{llllllllllllllllllllll}
\hline \multicolumn{11}{c}{ Coding region } \\
\hline
\end{tabular}

\section{Sspl}

GCCCCCCAACCGCCCCAAACAAAGTCCCTTACCCTCGACCAAGGTGAAAAAAATATTTGG

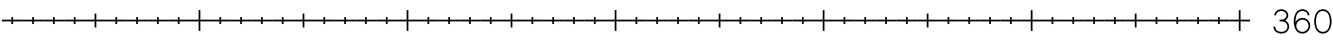
CGGGGGGTTGGCGGGGTTTGTTTCAGGGAATGGGAGCTGGTTCCACTTTTTTTATAAACC

\begin{tabular}{llllllllllllllllllllllll}
\hline 1 & Coding region \\
\hline & $P$ & $P$ & $N$ & $R$ & $P$ & $K$ & $Q$ & $S$ & $P$ & $L$ & $P$ & $S$ & $T$ & $K$ & $V$ & $K$ & $K$ & $I$ & $F$ & $G$
\end{tabular}


CTATATTGCCTTCTATAGCACGGACTATCGACTGGTGCAGAAGGTGTGCCCAGATTACAA

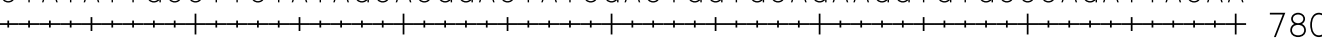
GATATAACGGAAGATATCGTGCCTGATAGCTGACCACGTCTTCCACACGGGTCTAATGT T

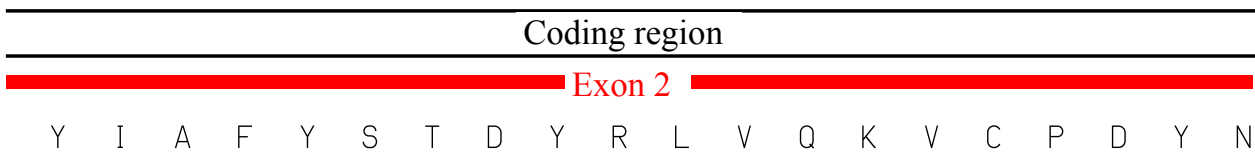

\section{BstEll}

CTACCACAGTGATACCCCCTACTACCCATCTGGGTGACCTAGATGGGCGGCAGAGGCCGG W GATGGTGTCACTATGGGGGATGATGGGTAGACCCACTGGATCTACCCGCCGTCTCCGGCC

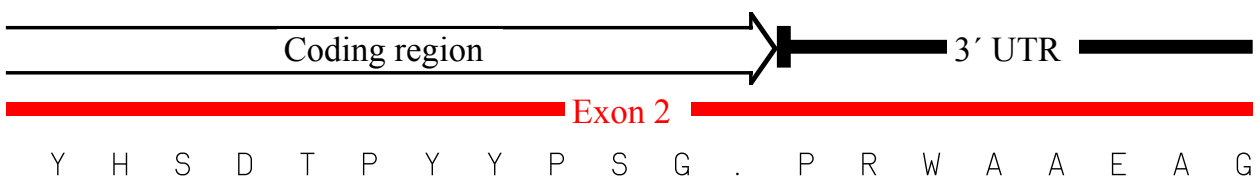

Bsgl

Bmrl

Bsu36I

TGCAGGAGGCTGGC TGGC TGGACACTGGGCAGGGAAAGGGATGGACCTCAGGTAGGGAGG 900 ACGTCCTCCGACCGACCGACCTGTGACCCGTCCCTTTCCCTACCTGGAGTCCATCCCTCC

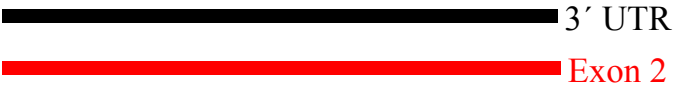

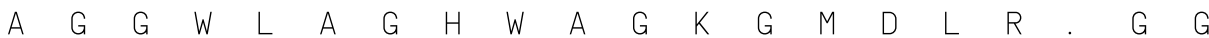

Earl Stul

Bmrl

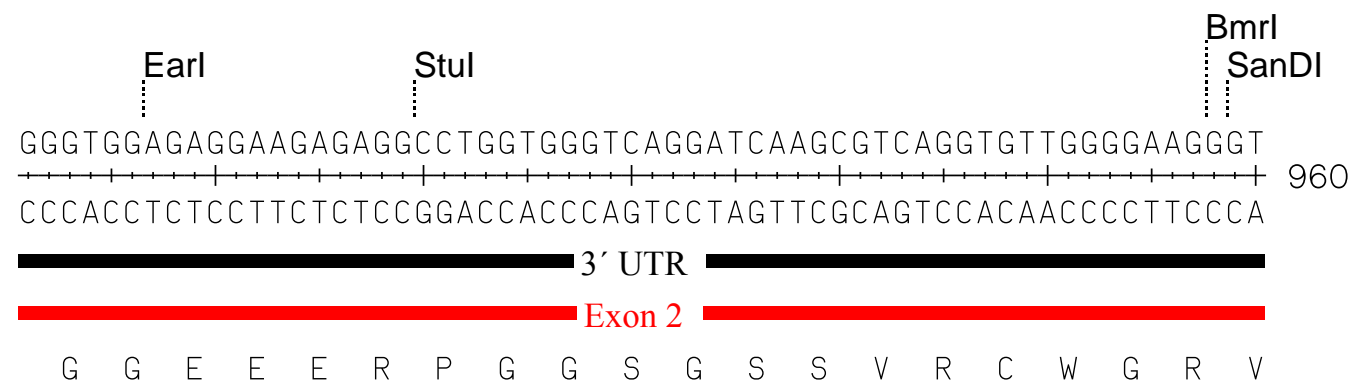

Bsu36

Earl

CCCCAGTGCTGTGCCCAACCTGAGGTTAGAAGATACTTGTTATGGAAGAGAAATATGCCC

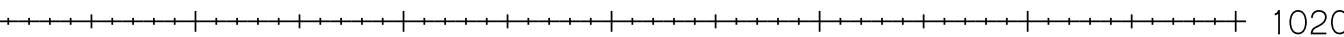
GGGGTCACGACACGGGT TGGACTCCAATCTTCTATGAACAATACC TTCTCTTTATACGGG

3' UTR

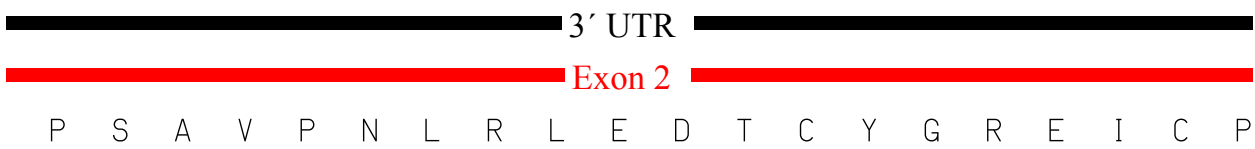

TGGGCAGCCTTACAGGGCTTTCCCTNCTATC $\ldots 1051$

ACCCGTCGGAATGTCCCGAAAGGGANGATAG

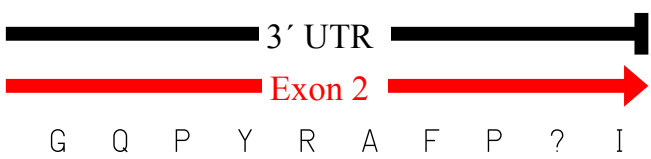




\section{Appendix 2 Rat neurexophilin 3 cDNA sequence (annotated)}

Tha rat Nph3 cDNA sequence (Missler and Südhof, 1998, GenBank accession number: AF042713), based on which a $\lambda$-bacteriophage mouse genomic library was screened, is presented. The complete coding region is indicated by a boxed arrow, ending at the stop codon. The $5^{\prime}$ and $3^{\prime}$ untranslated regions (5' and 3' UTR respectively) are underlined with a dark line. Encoded amino acids are shown below the DNA sequence in single letter code. Numbers on the right indicate base pair position. Restriction sites ares shown on top of the DNA sequence. The $570 \mathrm{bp}$ NheI-Sfil fragment that was used as probe for screening is underlined with a blue line. 
Pvull Bsgl

CGCAGC TGGACGCGGGGAGGGGGCGGCGGC TGCACACC TGGACCGAAGGGGGCGGGGTCG

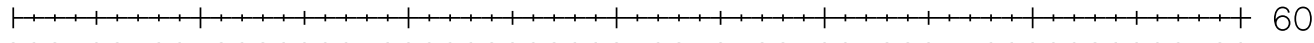
GCGTCGACCTGCGCCCCTCCCCCGCCGCCGACGTGTGGACCTGGCTTCCCCCGCCCCAGC

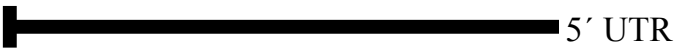

$\begin{array}{lllllllllllllllllllllllllll}R & S & W & T & R & G & G & G & G & G & C & T & P & G & P & K & G & A & G & S\end{array}$

AlwNI BbvCl

PfIMI Bpu10I

BssHII

GTCCCAGCAACTGGCTGAGGGGAGGGCCGCAAGCCACCAGGGACCGAAGCATGGAACAGC GH, 120 CAGGGTCGTTGACCGACTCCCCTCCCGGCGTTCGGTGGTCCCTGGCTTCGTACCTTGTCG

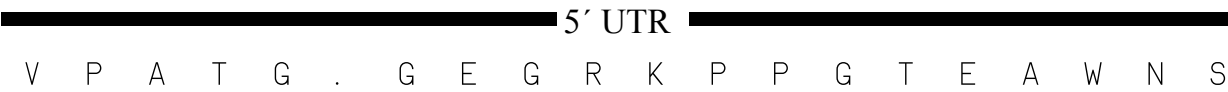

Eco57I

SanDI

Ecil BsmBI

GCGCCTGAAGGAGCAGTCCGGGGCGGAGGGGGCCTGGGACCCCGAAAGGAAAAGAGAGAC CGCGGACTTCCTCGTCAGGCCCCGCCTCCCCCGGACCCTGGGGCTTTCCTTTTCTCTCTG

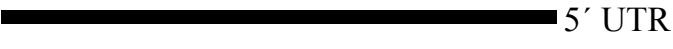

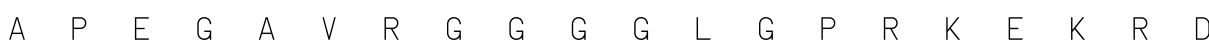

BseRl

EcoNI

GGGTGAGAGCAGAGGAGGAAGATGCAACTGACCCGCTGCTGCTTCGTGTTCCTAGTGCAG

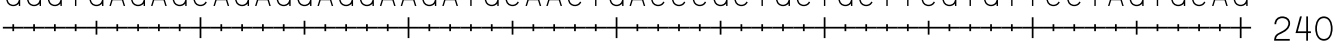
CCCACTCTCGTCTCCTCCTTCTACGTTGACTGGGCGACGACGAAGCACAAGGATCACGTC

\begin{tabular}{llllllllllllllllllll}
\hline & 5' & Coding region \\
\hline & $E$ & $Q$ & $R$ & $R$ & $K$ & $M$ & $Q$ & $L$ & $T$ & $R$ & $C$ & $C$ & $F$ & $\vee$ & $F$ & $L$ & $\vee$ & $Q$
\end{tabular}
Bsgl $\quad \begin{gathered}\text { BstXI } \\ \text { PspOMl } \\ \text { Apal Bpu10l }\end{gathered}$ GGCAGCCTCTATCTGGTCATCTGCGGCCAAGAGGATGGGCCCCCTGGCTCAGAGGACCCT G, 300 CCGTCGGAGATAGACCAGTAGACGCCGGTTCTCCTACCCGGGGGACCGAGTCTCCTGGGA

\begin{tabular}{lllllllllllllllllllll}
\hline \multicolumn{11}{c}{ Coding region } \\
\hline$G$ & $S$ & $L$ & $Y$ & $L$ & $V$ & $I$ & $C$ & $G$ & $Q$ & $E$ & $D$ & $G$ & $P$ & $P$ & $G$ & $S$ & $E$ & $D$ & $P$
\end{tabular}

Avrll

GAGCATGATGACCATGAGGGTCAGCCTCGGCCTAGGGTGCCTCGCAAGAGAGGTCACATT

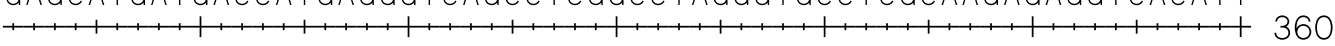
CTCGTACTACTGGTACTCCCAGTCGGAGCCGGATCCCACGGAGCGTTCTCTCCAGTGTAA

\begin{tabular}{llllllllllllllllllllll}
\hline \multicolumn{11}{c}{ Coding region } \\
\hline$E$ & $H$ & $D$ & $D$ & $H$ & $E$ & $G$ & $Q$ & $P$ & $R$ & $P$ & $R$ & $V$ & $P$ & $R$ & $K$ & $R$ & $G$ & $H$ & I
\end{tabular}




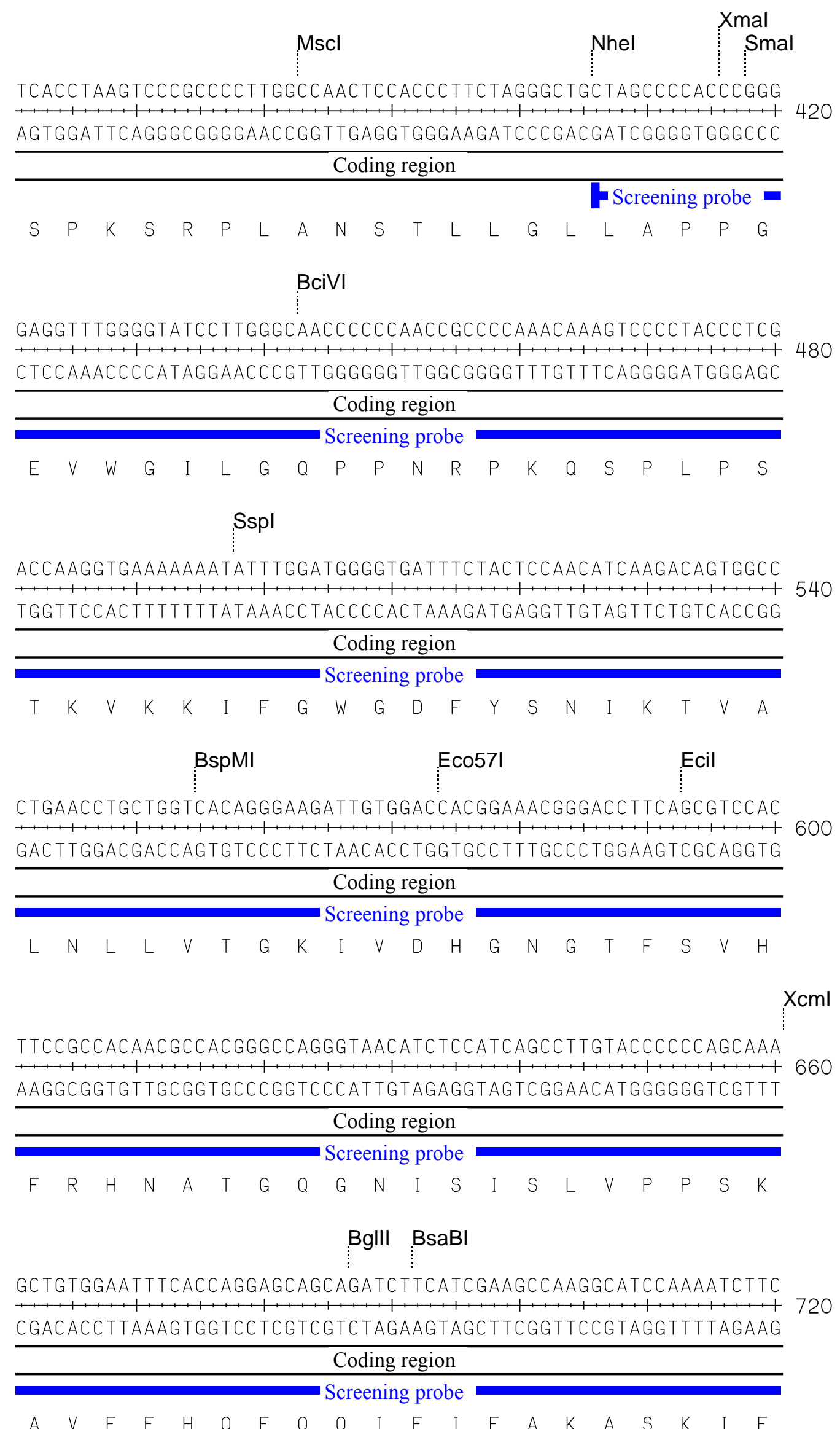




\section{Coding region}

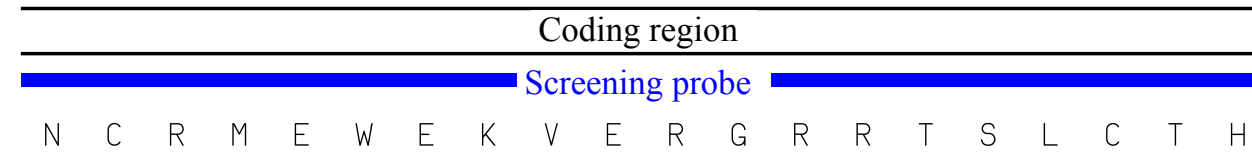

\section{Bglll}

\section{EcolCRI}

Sacl

GACCCAGCCAAGATCTGTTCCCGAGATCACGCTCAGAGCTCCGCTACCTGGAGCTGCTCC W $1 \ldots$ CTGGGTCGGTTCTAGACAAGGGCTCTAGTGCGAGTCTCGAGGCGATGGACCTCGACGAGG

\begin{tabular}{lllllllllllllllllllll}
\hline \multicolumn{11}{c}{ Coding region } \\
\hline
\end{tabular}

\section{Bpml}

CAGCCCTTCAAAATCGTCTGCGTCTATATTGCCTTCTATAGCACGGACTATCGACTGGTG $\cdots, 1,1,1, \cdots 1,1,1,1,1, \cdots, 1,1, \cdots+900$ GTCGGGAAGTTTTAGCAGACGCAGATATAACGGAAGATATCGTGCCTGATAGCTGACCAC

\begin{tabular}{llllllllllllllllllllllll}
\hline \multicolumn{11}{c}{ Coding region } \\
\hline
\end{tabular}

\section{Bsgl}

BstEll

CAGAAGGTGTGCCCAGATTACAACTACCACAGTGATACCCCCTACTACCCATCTGGGTGA C, $, 1,1,1,1,1,1,1,1,1,1,1,1,1,+1,960$ GTCTTCCACACGGGTCTAATGTTGATGGTGTCACTATGGGGGATGATGGGTAGACCCACT

\begin{tabular}{lllllllllllllllllllllll}
\hline \multicolumn{11}{c}{ Coding region } & \\
\hline & Screening probe & & \\
\hline & $K$ & $V$ & $C$ & $P$ & $D$ & $Y$ & $N$ & $Y$ & $H$ & $S$ & $D$ & $T$ & $P$ & $Y$ & $Y$ & $P$ & $S$ & $G$
\end{tabular}

\section{Bgll}

Sfil Stul EcoNI

Bmrl

CCTAGATGGGCCACAGAGGCCTGTTCAAGGAGGCTGGCTGTCTGGACACTGGGCAGGGAA GGATCTACCCGGTGTCTCCGGACAAGTTCCTCCGACCGACAGACCTGTGACCCGTCCCT

3' UTR

- Screening probe

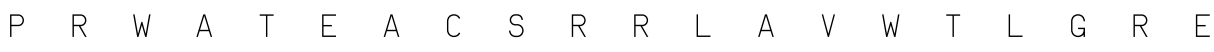

\section{Bsu36l}

$\mathrm{EcoNI}$

Earl

AGGGATGGGCC TCAGGAAGGGAGGGGTGGAGAGGAAGAGAGGCCAAGTGGGTCCGGGTC TCCCTACCCGGAG TCC T TCCCTCCCCCACC TC TCC T TC TC TCCGG T TCACCCAGGCCCAG

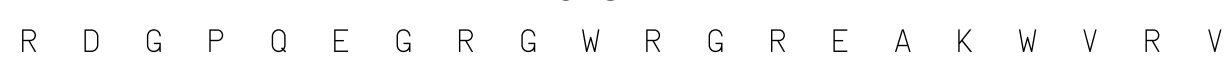


$A G G$

1083

TCC

R 


\section{Curriculum Vitae}

\section{Personal data}

Name:

Date and place of birth:

Marital status:

Nationality:

\section{School education}

$1980-1986$

$1986-1989$

$1989-1992$

\section{University education}

09.1992 - 09.1997

$10.1996-01.1997$

$09.1997-09.1998$

$07.1999-06.2002$

\section{Work experience}

09.1998 - 04.1999
Vasileios Benglopoulos

27.12.1974 in Thessaloniki, Greece

Single, no children

Greek

25th Primary School of Thessaloniki, Greece

2nd Gymnasium of Triandria, Thessaloniki, Greece

Lyceum of Triandria, Thessaloniki, Greece

Aristotle University of Thessaloniki, Department of Chemistry, Greece Ptichio (Degree) in Chemistry

University of Strathclyde, Department of Pure and Applied Chemistry, Glasgow, UK

Diploma work (under the Erasmus Exchange Programme) in the laboratory of Profesor Colin J. Suckling

Subject: "Synthesis of 7-substituted-7-deazaguanines"

University of Hull, Department of Biological Sciences, UK

MSc in Biotechnology and Molecular Biology

Diploma work in the Medical Research Laboratory, University of Hull, under the supervision of Dr. Christopher J. Newton

Subject: "Glucocorticoids as modulators of oxidant-induced apoptosis in endothelial cells"

Georg-August-Universität Göttingen, Zentrum Physiologie und Pathophysiologie

$\mathrm{PhD}$ in the laboratory of Dr. Markus Missler

Subject: "Functional characterization of neurexophilins in the central nervous system"

University College London, Department of Anatomy and Developmental Biology, UK

Research assistant in the laboratory of Dr. Martin Rosendaal

Subject: Role of gap junctions in the blood forming system 